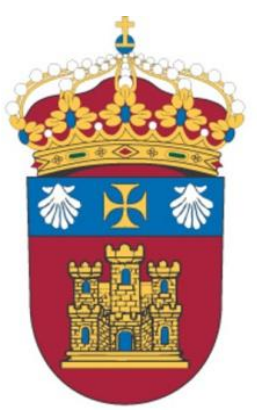

Tesis Doctoral

\title{
Multipurpose Spectroelectrochemistry: \\ Paving the Way for In Vivo Measurements
}
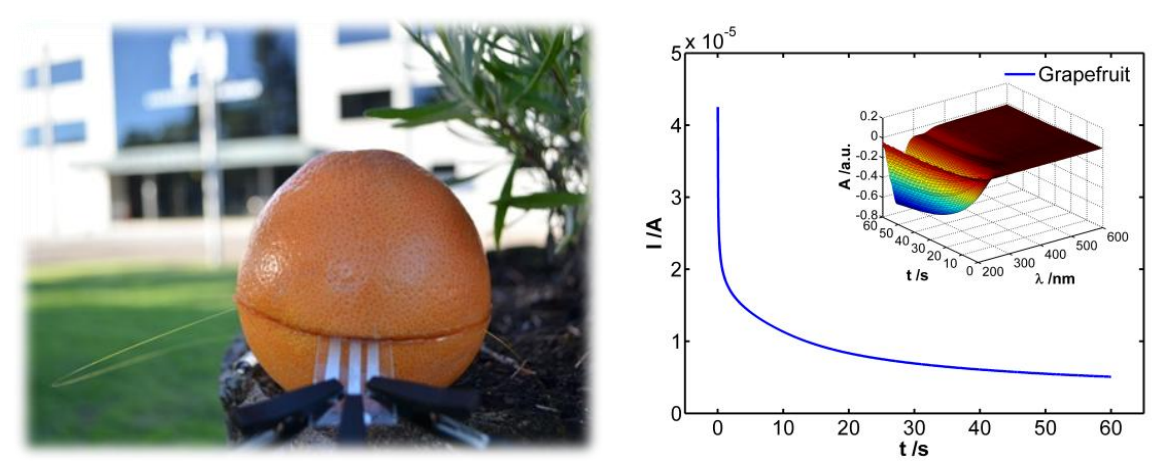

Jesús Garoz Ruiz

\section{Directores}

Dra. Aránzazu Heras Vidaurre

Dr. Álvaro Colina Santamaría

Burgos, 2017 



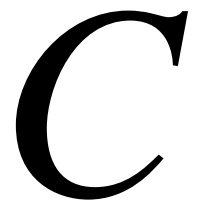

omienza el doctorado. Llevo esperando este momento prácticamente desde que crucé por primera vez las puertas de la Facultad de Ciencias de la Universidad de Burgos. Investigación, esfuerzo, logros, avances o amistad son algunas de las palabras que ocupan mi mente cuando entro por primera vez a los laboratorios del Grupo Análisis Instrumental del Área de Química Analítica. El sueño comienza. El sueño ya está aquí. Porque el sueño, a pesar de lo que pueda parecer, no es ser doctor. El sueño es estudiar el doctorado. Disfrutar de tu trabajo. Compartir buenos momentos. Llegar al laboratorio cada día con las ganas de conseguir soluciones a algunas de las cuestiones importantes del mundo actual. Este objetivo se logrará algunas jornadas, sin embargo, tal vez otras salga un poco apenado por no conseguir los resultados esperados. Por supuesto, siempre se volverá a la mañana siguiente con la felicidad y satisfacción de que con tu trabajo contribuyes al bienestar general y al avance de la sociedad. Con esfuerzo e ilusión se consigue saber tanto el camino a seguir como los senderos a descartar. Y si todo esto lo puedes hacer dedicándote a la investigación que te interesa, en el lugar que quieres y con el grupo que deseas, eso es ya un auténtico placer. Me siento, por qué no decirlo, afortunado. Bienvenidos a mis siguientes cinco años de trabajo. Sentiros partícipes de los mismos. Sed conscientes de que, únicamente por estar leyendo estas líneas, ya sois parte fundamental de esta inolvidable etapa. Mis más sinceras gracias. 



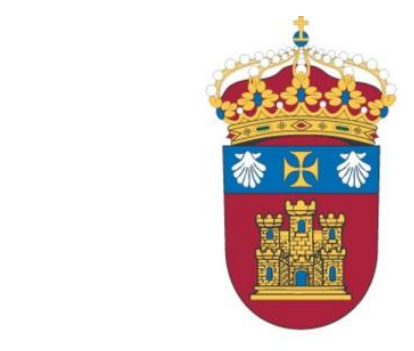

\section{Departamento de Química}

Facultad de Ciencias

\section{Universidad de Burgos}

Dña. $M^{\mathrm{a}}$ Aránzazu Heras Vidaurre y D. Álvaro Colina Santamaría, Profesores Titulares del Área de Química Analítica de la Universidad de Burgos,

\section{HACEN CONSTAR:}

Que la presente memoria resume el trabajo titulado "Multipurpose Spectroelectrochemistry: Paving the Way for In Vivo Measurements" realizado por D. Jesús Garoz Ruiz en el Área de Química Analítica y bajo nuestra dirección para optar al Grado de Doctor por la Universidad de Burgos.

Manifestamos nuestra conformidad con el contenido de la memoria y autorizamos su presentación para ser defendida como Tesis Doctoral.

Burgos, 24 de enero de 2017

Ma Aránzazu Heras Vidaurre

D. Álvaro Colina Santamaría 

A mis padres, Trini y José

A mi esposa, Inés

A mi familia palentina, Ulloa Varona 

Las personas que aparecen mencionadas a continuación han puesto todo su esfuerzo para que este viaje haya podido suceder y para que mi vida posea unas experiencias, unos conocimientos y unas vivencias que a día de hoy considero imprescindibles. Gracias de corazón.

Gracias a mis directores de tesis, Aránzazu Heras Vidaurre y Álvaro Colina Santamaría. Habéis sido, verdaderamente, unos excelentes profesores de doctorado. Gracias por todo lo que dicha definición significa, por vuestra confianza, paciencia, sabiduría y total dedicación. Gracias por haberme hecho disfrutar y aprender cada segundo a vuestro lado.

Gracias a Susana Palmero Díaz y a Jesús López Palacios. Gracias porque vuestra presencia, tanto dentro como fuera de los laboratorios, ha sido fuente de inspiración y sinónimo de acogida e ilusión.

Gracias a todos mis compañeros del Grupo Análisis Instrumental, tanto a los actuales como a los que realizaron sus trabajos a lo largo de estos años. Gracias, en especial, a David Ibáñez Martínez y Daniel Izquierdo Bote, por ser unos estupendos amigos, acompañándome día a día desde el comienzo de esta aventura con vuestra ayuda, vuestras conversaciones y vuestra fabulosa forma de ser.

Gracias a las personas que forman el área de Química Analítica por poder formar parte de la misma. Gracias a los profesores y al personal técnico de laboratorio por haberme transmitido vuestra pasión por esta rama de la química. Gracias, en particular, a María Ángeles García García y a Silvia Sanllorente Méndez, por vuestras atenciones y por los buenos ratos. Gracias a todos los doctorandos, por lo vivido durante estos años. 
Gracias a todas las amistades de la Universidad de Burgos en general y de la Facultad de Ciencias en particular. A todos los compañeros del café, a profesores, alumnos y personal de administración y servicios. Es imposible nombraros aquí a todos, por suerte sois muchos los que, con vuestra dedicación y vuestro trato, hacéis que llegar cada día a este trabajo sea un placer.

Gracias a los investigadores que he podido conocer en los numerosos congresos a los que he tenido la oportunidad de asistir, por el intercambio de opiniones y conocimientos. Gracias a los compañeros del Warwick Electrochemistry \& Interfaces Group (University of Warwick, United Kingdom), especialmente a Barak D. B. Aaronson y Joshua C. Byers, con quienes tuve la oportunidad de trabajar más intensamente. Gracias a Barak y familia por vuestra calurosa acogida, a María Adobes Vidal y a Aleix G. Güell por tantos buenos ratos y a Patrick R. Unwin por haberme dado la oportunidad de trabajar en un grupo de investigación tan prestigioso como ejemplar.

Gracias a las instituciones que con su financiación han hecho posible la investigación recogida en esta tesis doctoral. La ciencia necesita recursos y la sociedad necesita ciencia.

Gracias a las personas que he podido conocer a través de la música. Cabe destacar en este párrafo a los profesores y alumnos de la Academia Luber y a los compañeros de la Coral Canticorum: escuchar o tocar una melodía es fundamental tras los experimentos de cada jornada.

Gracias a la Congregación y al personal del Colegio Jesús María, por los valores y conocimientos enseñados a lo largo de importantes años. 
Gracias a Miguel Ángel Queiruga Dios, por involucrarme en tantos proyectos novedosos, por tantas ideas compartidas y llevadas a cabo.

Gracias a Sonia, Álvar y Dafne, por vuestra simpatía, por vuestra enorme amistad y por las buenas experiencias que compartimos. Gracias a los amigos de Villarcayo y Puente Arenas, por todos esos veranos inolvidables.

Gracias a mi tía Celi. Porque sacar una sonrisa, en la más difícil de las situaciones, indica que repetir un experimento hasta obtener los resultados necesarios puede ser más fácil de lo que parece. Gracias a Javi y Carlos, algo me dice que estaríais orgullosos. Gracias a mi tío Ricardo, por tus atenciones y detalles.

Gracias a mi querida familia palentina. Gracias José, Nieves, Yuri, Zoé, Miriam y Diego, por vuestras valoraciones tan positivas, por los buenos momentos a vuestro lado y por haberme acompañado con muchas ganas, de la mejor manera posible, en este viaje del doctorado.

Gracias especialmente a mis padres, Trini y José, por todo lo que me habéis enseñado. Gracias por vuestra energía, por poder ser un niño feliz y un científico apasionado, por las oportunidades que me habéis ofrecido para la vida y por ser un maravilloso estímulo y ejemplo para mí.

Gracias a mi mujer, Inés, por ser un rayito de luz en cada instante. Por toda la ayuda demostrada a lo largo de estos años, por compartir cada experiencia y por hacer que juntos emprendamos un proyecto común lleno de química, ilusiones y metas. Gracias a nuestro hijo por estar ya en camino, porque verte por primera vez y tenerte en nuestros brazos será una señal de que lo mejor está por llegar... 



\section{Index}

1. UV-Vis Molecular Absorption Spectroelectrochemistry ...................19

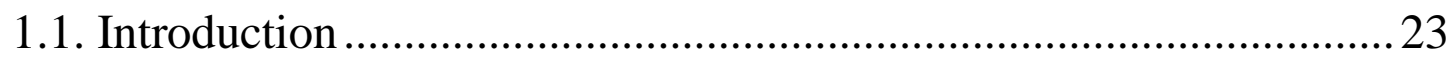

1.2. Monodimensional UV-Vis Molecular Absorption

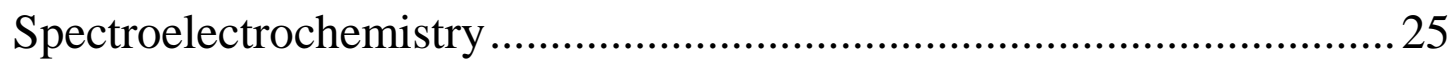

1.2.1. Normal Configuration Spectroelectrochemistry ..........................2 27

1.2.1.1. Optically Transparent Electrodes ..........................................229

1.2.2. Parallel Configuration Spectroelectrochemistry ......................... 32

1.3. Bidimensional Spectroelectrochemistry ............................................33

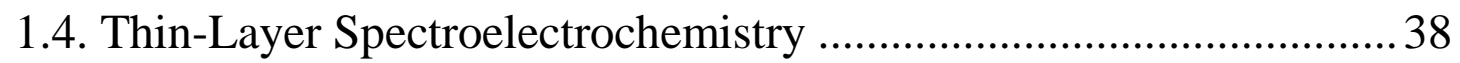

2. Carbon Nanomaterials.............................................................................43

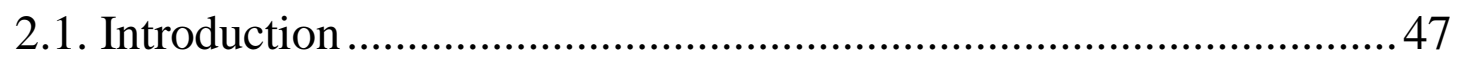

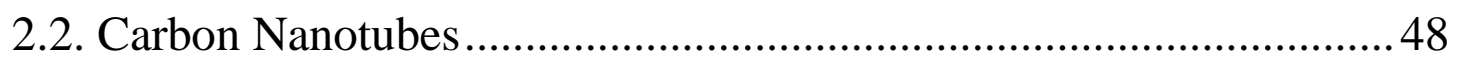

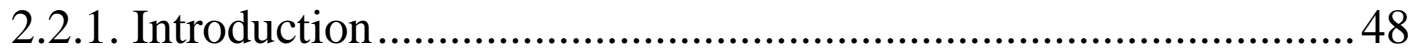

2.2.2. Synthesis and Transference .................................................... 51

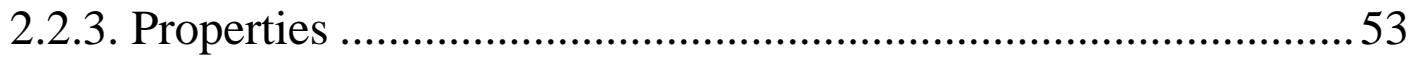

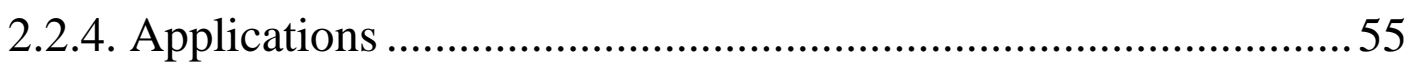

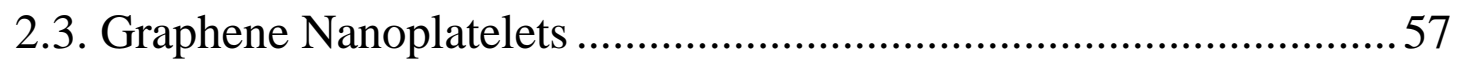

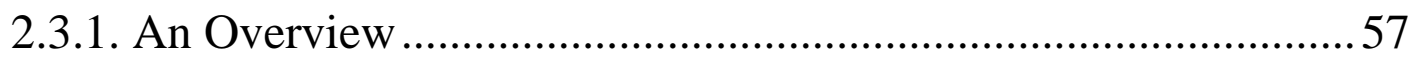

3. Conducting Polymers.............................................................................................559

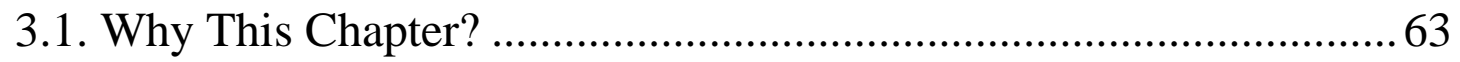

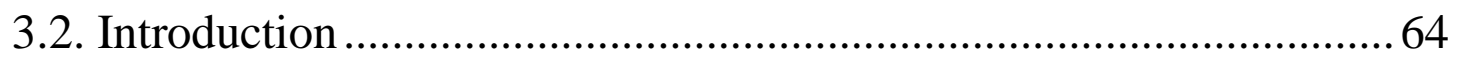

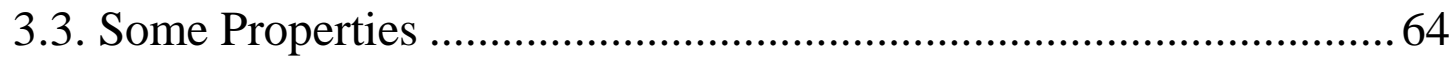

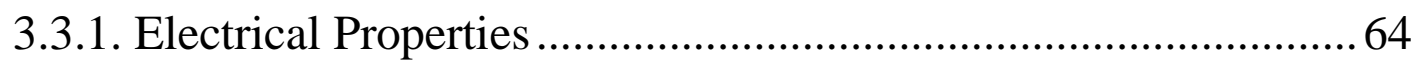




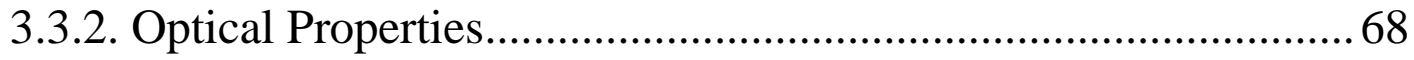

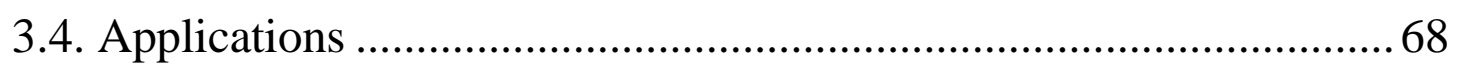

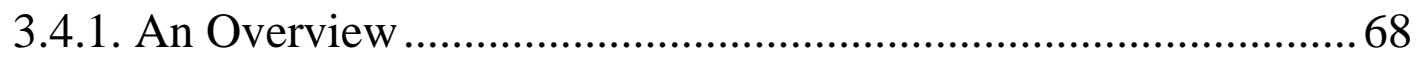

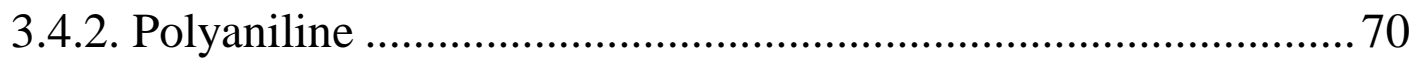

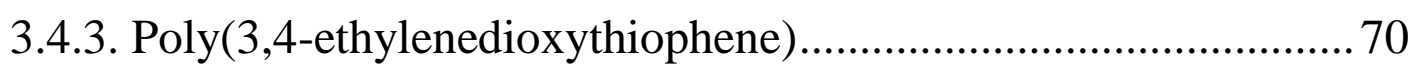

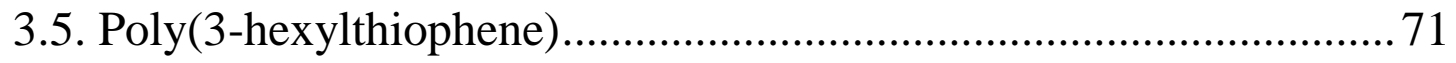

4. Molecules of Biological Interest .....................................................75

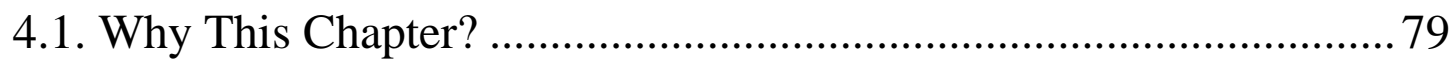

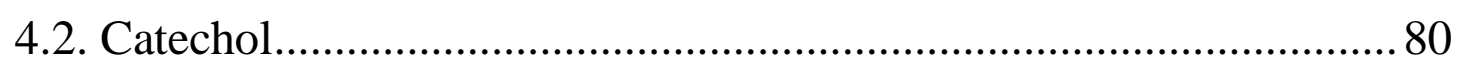

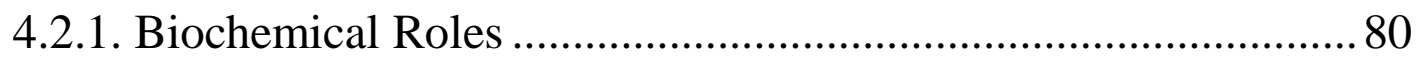

4.2.2. Previous Electrochemical and UV-Vis Spectroelectrochemical

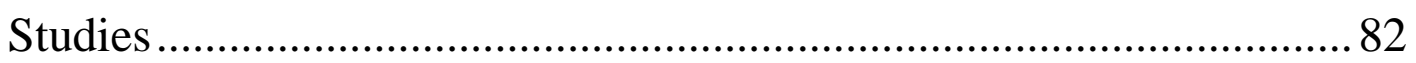

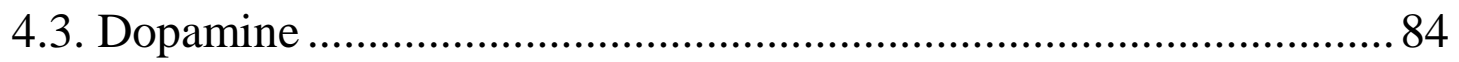

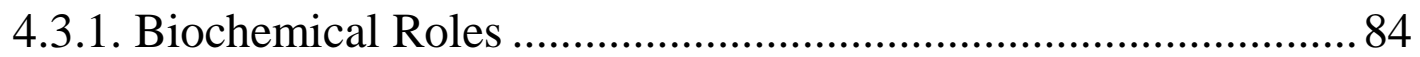

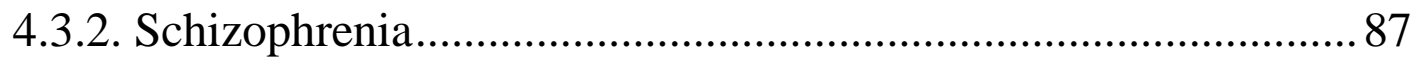

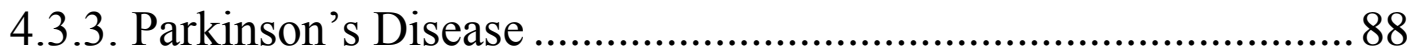

4.3.4. Previous Electrochemical and UV-Vis Spectroelectrochemical

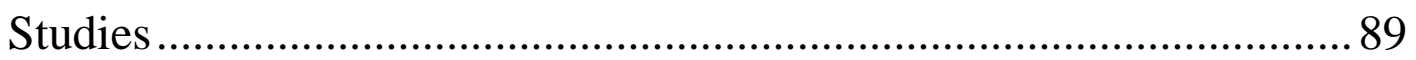

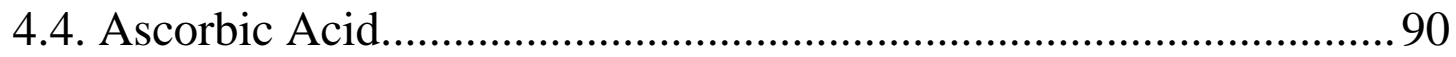

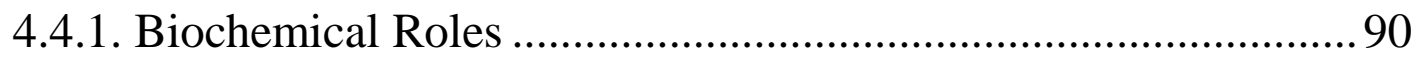

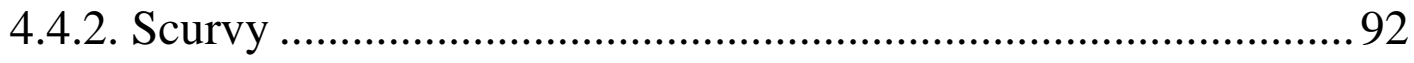

4.4.3. Previous Electrochemical and UV-Vis Spectroelectrochemical

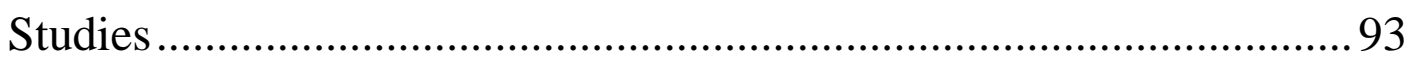

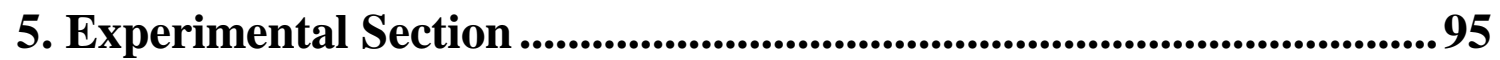

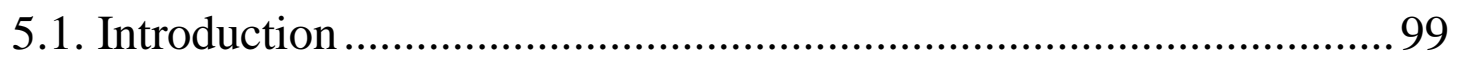

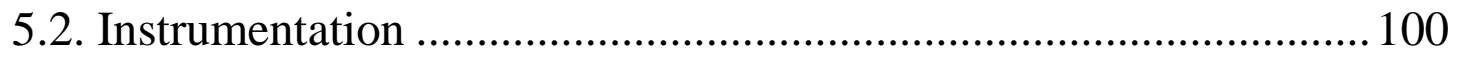

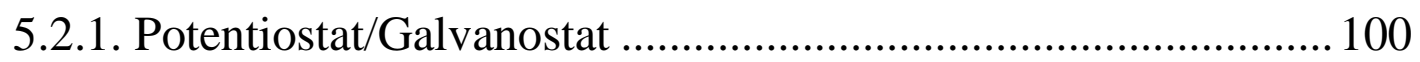

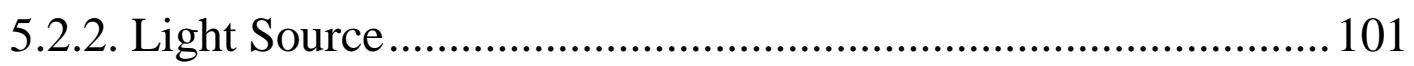

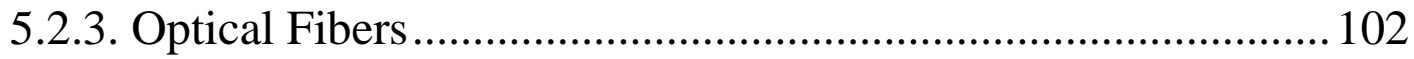

5.2.4. Spectroelectrochemistry Cell .................................................... 104 


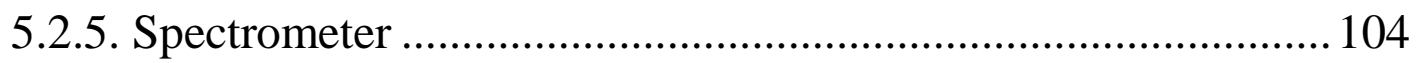

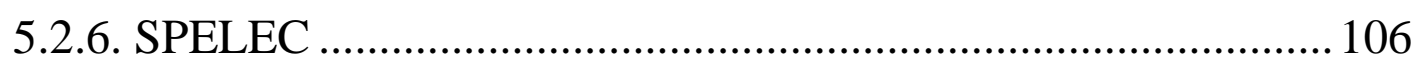

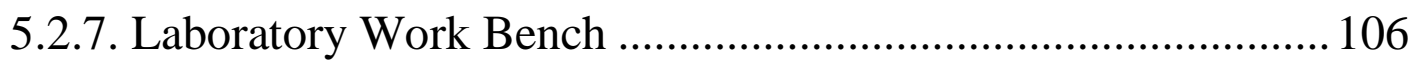

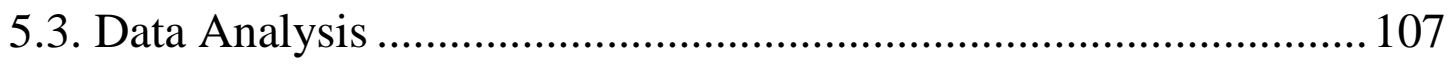

6. Research Results.............................................................................................. 111

6.1. Press-Transfer Optically Transparent Electrodes Fabricated from Commercial Single-Walled Carbon Nanotubes.......................115

6.1.1. Some Important Points to Keep in Mind ................................. 117

6.1.2. Experimental Section ............................................................. 118

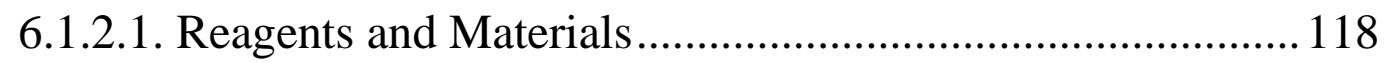

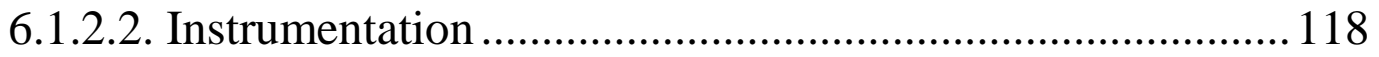

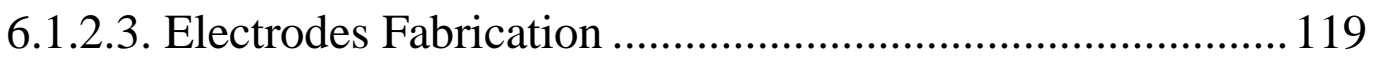

6.1.3. Results and Discussion ........................................................ 120

6.1.4. Conclusions and Future Work ................................................ 127

6.2. Optically Transparent Electrodes for Spectroelectrochemistry Fabricated with Graphene Nanoplatelets and Single-Walled Carbon

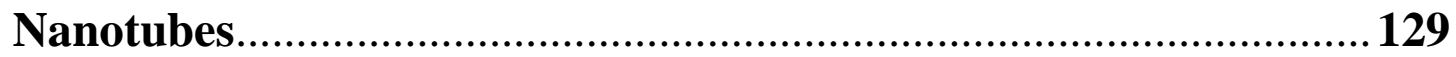

6.2.1. Some Important Points to Keep in Mind ................................. 131

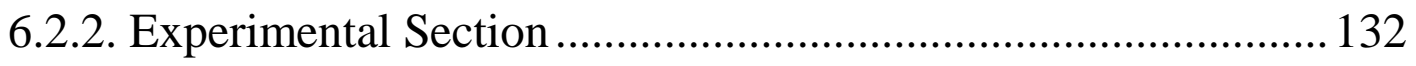

6.2.2.1. Reagents and Materials ....................................................... 132

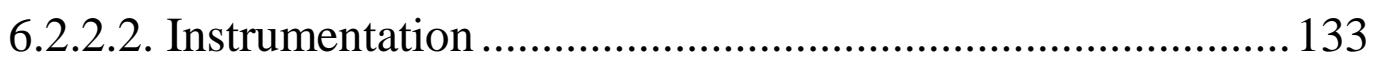

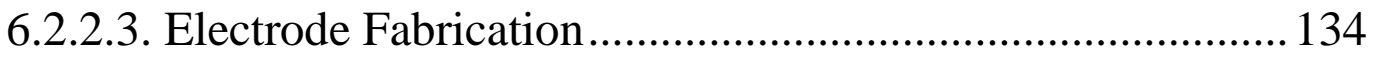

6.2.2.4. Electrode Characterization .................................................. 137

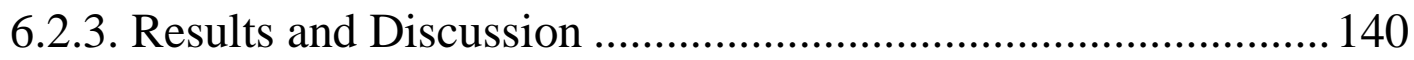

6.2.4. Conclusions and Future Work .................................................. 154

6.3. Development of a Novel Bidimensional Spectroelectrochemistry

Cell Using Transfer Single-Walled Carbon Nanotubes Films as

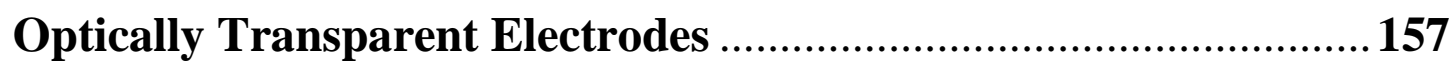

6.3.1. Some Important Points to Keep in Mind ................................... 159

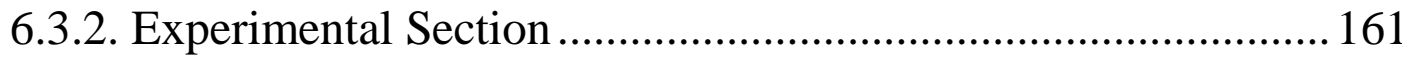




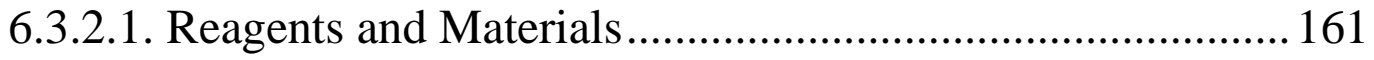

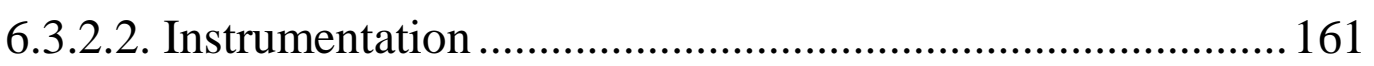

6.3.2.3. Single-Walled Carbon Nanotubes Film Preparation and

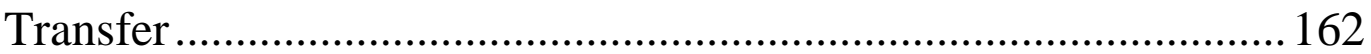

6.3.2.4. Electrode Fabrication........................................................ 165

6.3.2.5. Design and Fabrication of the Optical Fiber Bidimensional Spectroelectrochemistry Cell ......................................................... 165

6.3.2.6. Experimental Setup for Bidimensional Spectroelectrochemistry Measurements .......................................... 168

6.3.3. Results and Discussion ........................................................... 169

6.3.4. Conclusions and Future Work ................................................ 181

6.4. Simultaneous UV-Vis Absorption and Raman

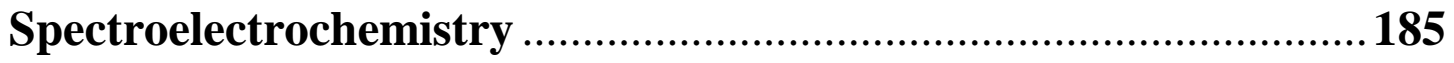

6.4.1. Some Important Points to Keep in Mind ................................... 187

6.4.2. Experimental Section ................................................................ 189

6.4.2.1. Reagents and Materials..................................................... 189

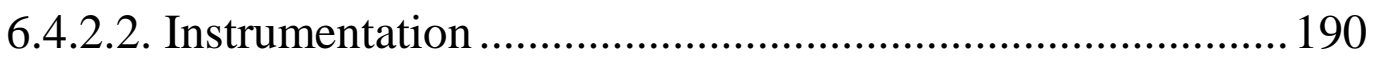

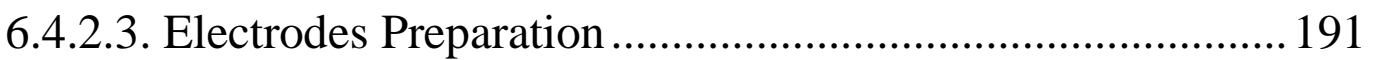

6.4.2.4. Fabrication of the Device for UV-Vis/Raman Spectroelectrochemistry Measurements ........................................ 192

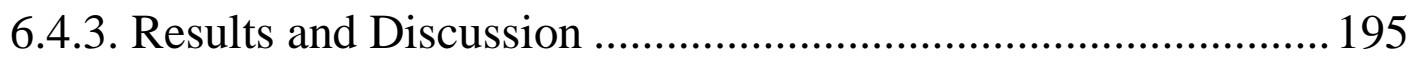

6.4.3.1. Ferricyanide/Ferrocyanide Redox Couple.......................... 195

6.4.3.2. Oxidation of Dopamine on a Single-Walled Carbon

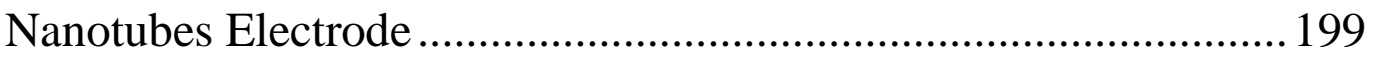

6.4.3.3. Electropolymerization of 3,4-Ethylenedioxythiophene in

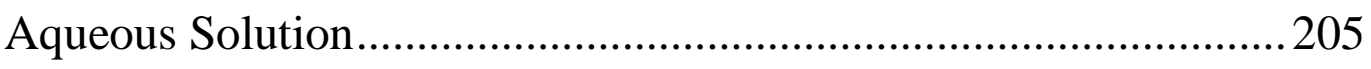

6.4.4. Conclusions and Future Work ..................................................210

\subsection{Development of a New Multipurpose Spectroelectrochemistry}

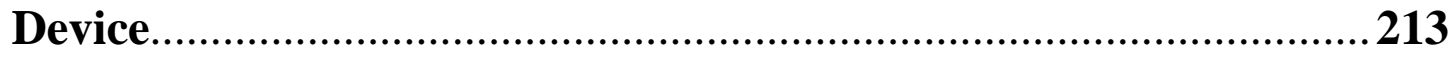

6.5.1. Some Important Points to Keep in Mind ................................. 215

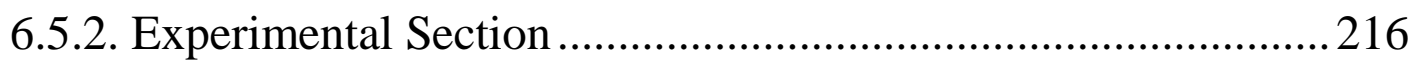


6.5.2.1. Reagents and Materials .......................................................2216

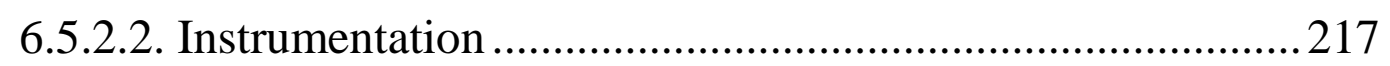

6.5.2.3. Transference of Single-Walled Carbon Nanotubes Using a

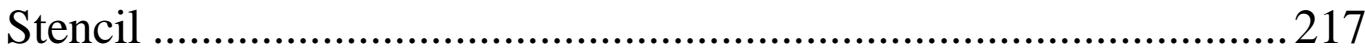

6.5.2.4. Fabrication of the Electrochemical Device ........................ 219

6.5.2.5. Fabrication of the Spectroelectrochemistry Device ........... 220

6.5.2.6. Experimental Setup for UV-Vis Absorption

Spectroelectrochemistry Measurements ..........................................222

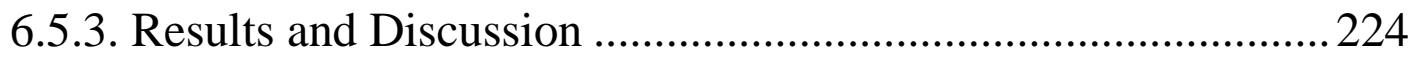

6.5.3.1. Validation of the Spectroelectrochemistry Device............. 224

6.5.4. Conclusions and Future Work ................................................... 228

6.6. Quantitative Resolution of Complex Mixtures by

Spectroelectrochemistry: The Case of Catechol and Dopamine .....231

6.6.1. Some Important Points to Keep in Mind ................................... 233

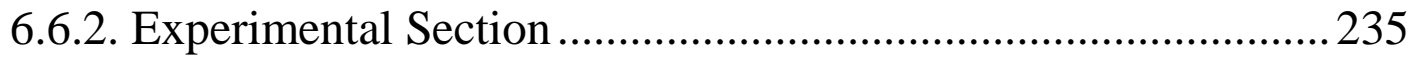

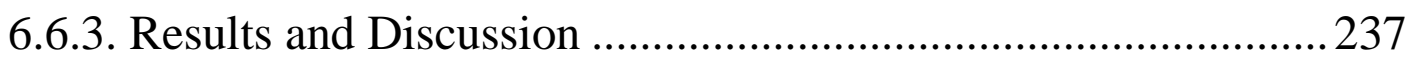

6.6.3.1. Determination of Dopamine by Potentiodynamic UV-Vis Absorption Spectroelectrochemistry .............................................237

6.6.3.2. Determination of Dopamine by Potentiostatic UV-Vis Absorption Spectroelectrochemistry ............................................. 241

6.6.3.3. Quantitative Resolution of Mixtures of Catechol and

Dopamine by Spectroelectrochemistry .......................................... 245

6.6.4. Conclusions and Future Work ................................................. 255

6.7. Monitoring the Evolution of $\mathrm{pH}$ at the Electrode-Solution Interface by Spectroelectrochemistry ..............................................257

6.7.1. Some Important Points to Keep in Mind ...................................259

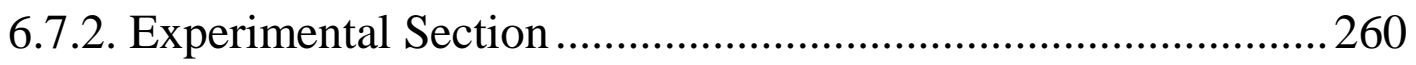

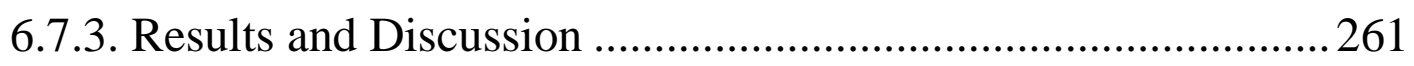

6.7.3.1. Spectroscopic Properties of Species Related to Ascorbic Acid 
6.7.3.2. Following the Evolution of $\mathrm{pH}$ at the Electrode-Solution Interface by Spectroelectrochemistry …………..............................2264

6.7.4. Conclusions and Future Work ...............................................2 271

6.8. Direct Determination of Ascorbic Acid in a Grapefruit: Paving the Way for In Vivo Spectroelectrochemistry .................................273

6.8.1. Some Important Points to Keep in Mind .................................. 275

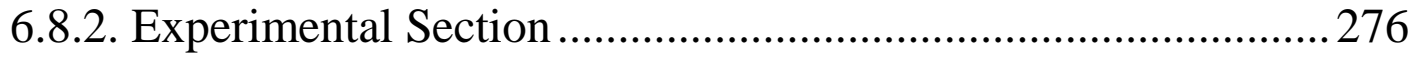

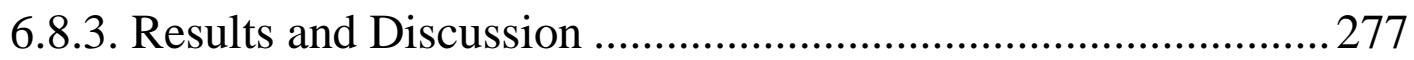

6.8.3.1. Determination of Ascorbic Acid in a Complex Matrix ......277

6.8.4. Conclusions and Future Work ................................................28

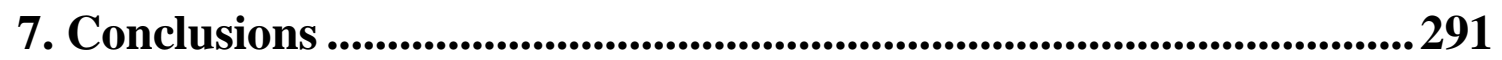

8. Future Perspectives ........................................................................................ 297

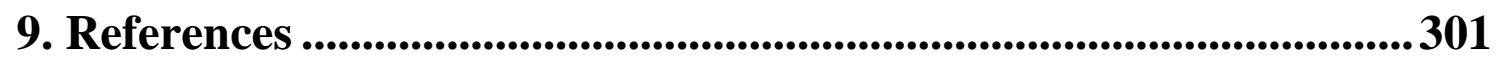

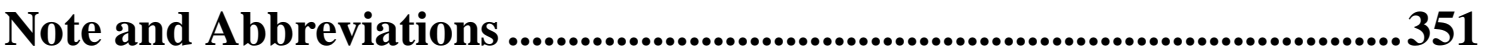




\section{UV-Vis Molecular Absorption Spectroelectrochemistry}





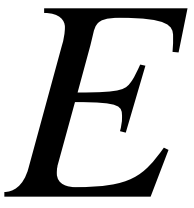

spectroelectroquímica. Una palabra de jerga científica con las cinco vocales presentes en el alfabeto español. Esta sutil observación acerca de esta poderosa técnica no hace sino corroborar un aspecto esencial, un aspecto sustancial. Las ciencias y las letras, tal y como debe ser, están feliz e indisolublemente unidas.

Y es que ser investigador, además de la experimentación en el laboratorio y la obtención de resultados que prueben la consecución de las metas planteadas, consiste en saber trasladar a la sociedad en general, y a la comunidad científica en particular, los objetivos propuestos, las metodologías llevadas a cabo y las conclusiones alcanzadas. Los artículos en revistas científicas, los eventos y congresos de investigación, la elaboración de tesis doctorales y la redacción de escritos de divulgación son algunos de los múltiples ejemplos de que las ciencias necesitan de las letras para ser contadas. De la misma forma, curiosamente, las letras tienen sentido al estar acompañadas por las correspondientes imágenes, figuras y tablas que indiquen y reflejen fielmente los resultados científicos obtenidos. Por cierto, en este punto debe destacarse la importancia de la lectura. Leer para aprender, aprender para experimentar, experimentar para escribir, escribir para que otros lean, aprendan, experimenten, escriban, y así sucesivamente.

Precisamente justo antes del capítulo que nos acompaña, que versa sobre la espectroelectroquímica de absorción molecular UV-Vis, esta sinergia entre ciencias y letras recuerda gratamente a la sinergia entre electroquímica y espectroscopía. Uniones potentes y consolidadas que nos permiten obtener lo mejor y mucho más de lo que representa cada uno de estos términos por separado. Emocionante, realmente apasionante. 



\subsection{Introduction}

Teamwork is a decisive factor in the current world to solve important problems in all working environments. Increasingly, companies require to their employees broad powers in terms of dialogue and teamwork skills. In parallel, the development of analytical techniques based on the successful marriage between techniques of different nature allows researchers to obtain fascinating results.

Sometimes, a picture, Figure 1.1, is worth a thousand words:
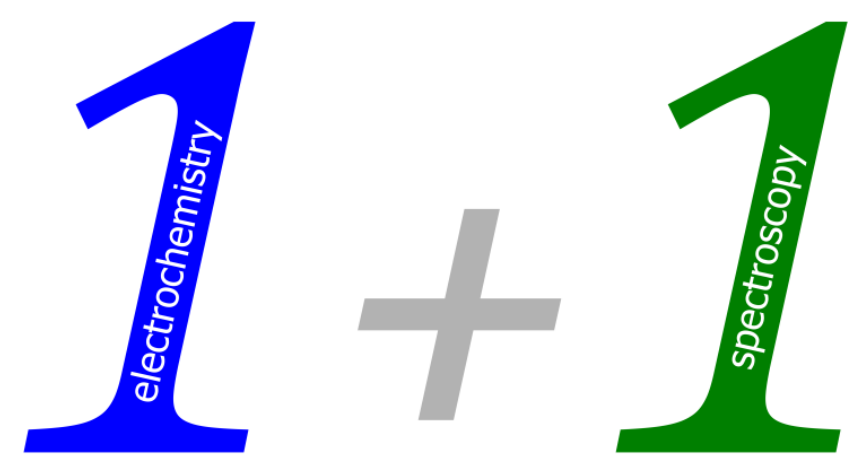

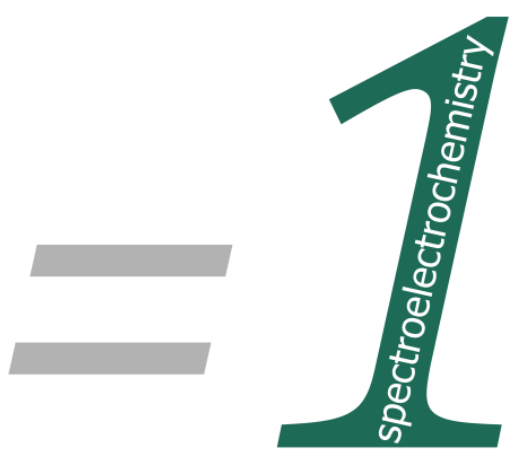

just one but incredibly powerful!

Figure 1.1. The concept of spectroelectrochemistry.

A single spectroelectrochemistry experiment contains electrochemical and spectroscopic information about a chemical system, allowing the study of a wide range of processes from, at least, two different points of view. ${ }^{1,2}$ As can be inferred, versatility is truly huge because multiple electrochemical techniques can be used as well as different spectral regions can be analyzed depending on the system under study and the desired information to be obtained. ${ }^{3,4}$ 
Therefore, spectroelectrochemistry ${ }^{1,5}$ is a "teamwork technique" that joins the best of electrochemistry and spectroscopy together. This hybrid technique studies simultaneously not only the electrochemical but also the spectroscopic evolution of an electron-transfer process. Thus, spectroelectrochemistry, by definition, allows us to obtain information with at least two signals of different nature at the same time, an uncommon but very powerful feature. As can be deduced, this multiresponse technique has been applied to a large number of fields, including, for example:

- Electron transfer processes. ${ }^{6}$

- Reaction mechanisms. ${ }^{7}$

- Electrocatalysis. ${ }^{8}$

- Conducting polymers. ${ }^{9}$

- Solar cells. ${ }^{10}$

- Memory devices. ${ }^{11}$

- Supercapacitors. ${ }^{12}$

- Synthesis of nanoparticles. ${ }^{13}$

- Carbon nanomaterials. ${ }^{14}$

- Characterization of metal complexes. ${ }^{15}$

- Liquid/liquid interfaces. ${ }^{16,17}$

- Electrochromic materials. ${ }^{18}$

- Study and determination of compounds of biological interest. ${ }^{19-21}$ 
It is noteworthy that, at present, the technical developments allow us to perform spectroelectrochemistry measurements with much chemical information for the quantification of analytes and for the comprehension of their reaction mechanisms. ${ }^{19,22-24}$

There are many different spectroelectrochemistry techniques. Electronic (UV-Vis, NIR), luminescence (fluorescence, phosphorescence), or vibrational (IR, Raman) spectroelectrochemistry are some of them. Nevertheless, according to the importance of UV-Vis molecular absorption spectroelectrochemistry in this doctoral thesis, we are going to be particularly focused on this technique.

\subsection{Monodimensional UV-Vis Molecular}

\section{Absorption Spectroelectrochemistry}

As can be deduced from the introduction section, UV-Vis absorption spectroelectrochemistry can be defined as a multiresponse technique that enables us to obtain simultaneously the electrochemical and the UV-Vis absorption spectroscopic evolution of an electron-transfer process, all in a single experiment. ${ }^{2,25}$ Therefore, signals of different nature are obtained at the same time, giving an overview about the changes that take place in solution, in the electrode surface, or in both of them, during the course of an electrochemical reaction.

According to the numerous advantages of UV-Vis absorption spectroelectrochemistry, the use of this technique, which has been established in multiple and diverse research fields, raises interest in the study of compounds of biological interest. ${ }^{26}$ 
Besides, UV-Vis absorption spectroelectrochemistry has been used throughout history to study a great variety of chemical systems in different research fields such as, for example, reaction mechanisms, diffusive and adsorptive processes, substances of biological interest, characterization of compounds, optical and electrical properties of materials, and evaluation of significant parameters of electron-transfer reactions. ${ }^{3}$

Curiously, separately, electrochemistry and UV-Vis spectroscopy are not particularly selective techniques to identify the different organic compounds present in a complex mixture. Both electrochemical and spectroscopic signals commonly show broad peaks and bands, which often include information about more than a single process or compound. Nevertheless, it should be noted that finding two compounds that exhibit, for example, the same electrochemical behavior and identical spectroscopic properties, is practically impossible. For this reason, the result of coupling electrochemistry and UV-Vis absorption spectroscopy, ${ }^{1}$ known as UV-Vis absorption spectroelectrochemistry, should be a truly powerful hybrid technique for analysis. Actually, we should be happy because the use of this technique in the field of quantitative analysis is becoming increasingly important. ${ }^{19,22,24,26-29}$

Undoubtedly, the potential of this technique on this topic could be much higher. The main reason for this statement is the large amount of data obtained in a single UV-Vis absorption spectroelectrochemistry experiment which is not always exploited. It is noteworthy that, nowadays, the electrochemical signal can be recorded almost continuously and that a full spectrum is often registered every tens or hundreds of milliseconds. As the system evolves during the experiment, the high amount of electrochemical and spectroscopic data contains essential information not 
only to explain the electron-transfer processes but also to determine the amount of the compounds present in a complex mixture. Thus, the recording of both electrochemical and spectroscopic responses during an experiment and the use of univariate and multivariate analysis can provide us valuable information for quantitative purposes.

For these reasons, this doctoral thesis provides valuable information in order to contribute with this topic, quantitatively resolving complex mixtures of compounds of biological interest (section 6.6) $)^{30}$ and determining the ascorbic acid concentration directly in a grapefruit (section $6.8){ }^{31}$

Normal and parallel configurations with respect to the WE surface are the main monodimensional spectroelectrochemistry arrangements, which are explained below (sections 1.2.1 and 1.2.2, respectively), while the simultaneous combination of both is called BSEC (section 1.3).

\subsubsection{Normal Configuration Spectroelectrochemistry}

Normal configuration includes information related to the spectral changes occurring in the solution and at the electrode since the light beam samples the system perpendicularly to the electrode surface. UV-Vis spectroelectrochemistry in normal arrangement can be performed in two modes: normal reflection and normal transmission.

On the one hand, the scheme for normal reflection spectroelectrochemistry is displayed in Figure 1.2. As can be observed, the light beam travels in normal direction with respect to the WE surface and, after sampling the 
system (both the solution and the electrode), is collected to the spectrometer.

This configuration is widely used when the optical characteristics of the electrode material do not allow passing the light beam through the WE.

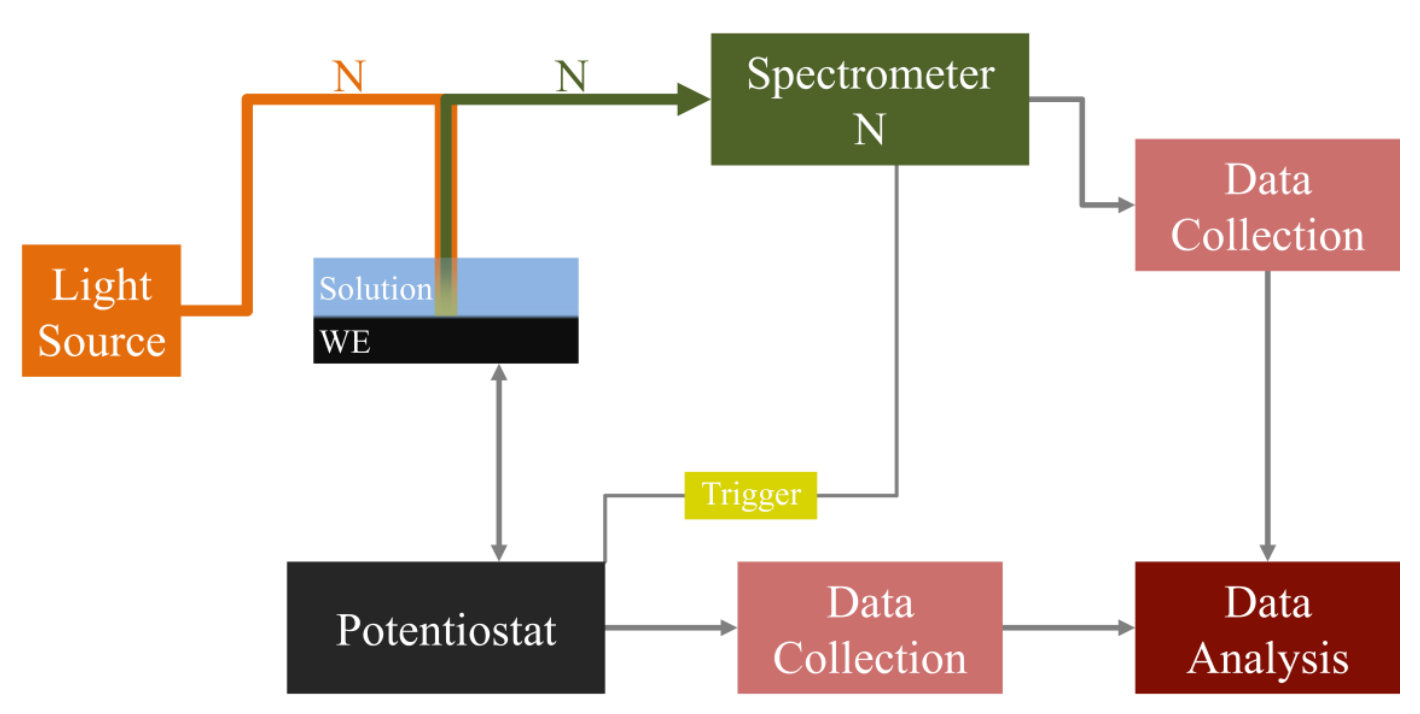

Figure 1.2. General scheme for spectroelectrochemistry in normal reflection configuration.

On the other hand, the scheme for normal transmission spectroelectrochemistry can be observed in Figure 1.3. As can be seen, the light beam passes through the WE, sampling both the electrode and the solution, and it is finally collected in the spectrometer.

Therefore, normal spectroelectrochemistry in transmission configuration requires the use of OTEs, materials with a good electrical conductivity and optical transparency, to allow the light beam to pass directly through the WE surface. 


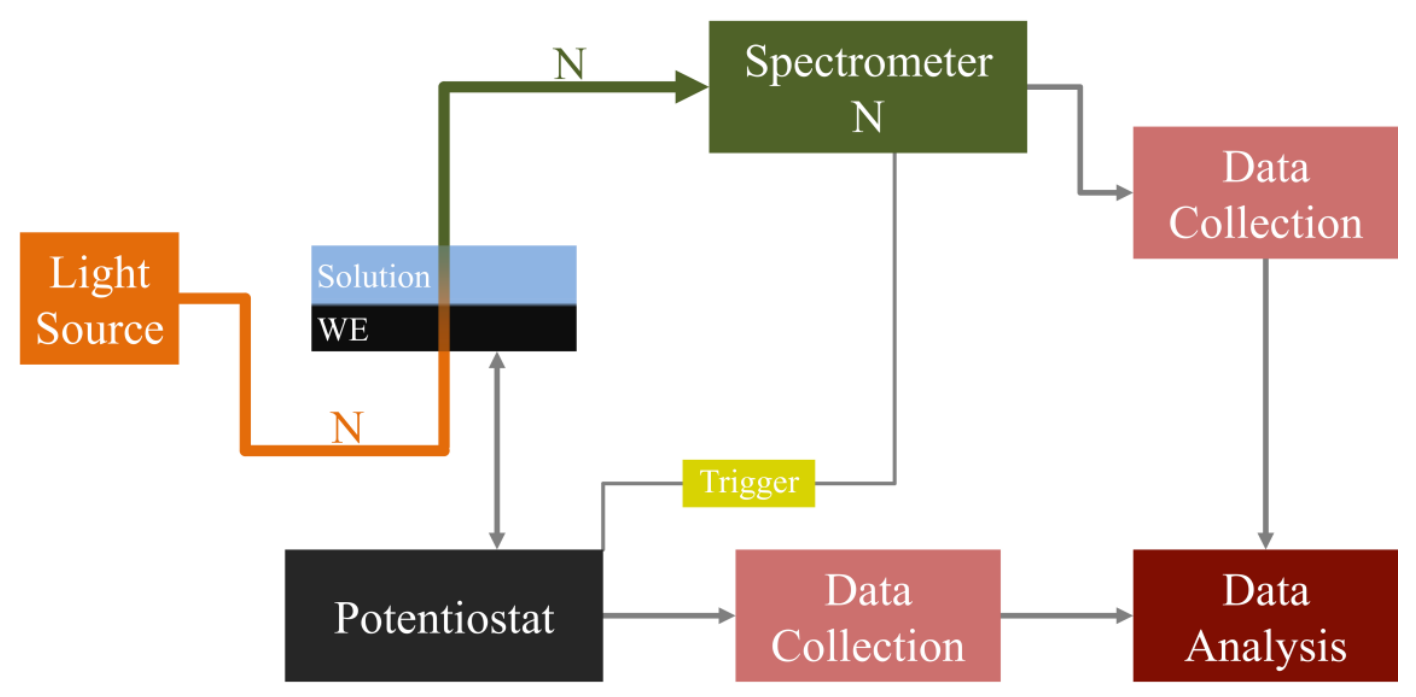

Figure 1.3. General scheme for spectroelectrochemistry in normal transmission configuration.

\subsubsection{Optically Transparent Electrodes}

Apart from being necessary for normal transmission spectroelectrochemistry to obtain simultaneously electrochemical and spectroscopic responses, OTEs are required for a wide range of applications such as electronics or light emitting diodes, playing important roles in information and energy technologies. Their importance today is unquestionable.

Doped metal oxide films such as ITO and fluorine-doped tin oxide have dominated this field due to the ability to deposit these materials with controlled thickness and controlled doping concentration. However, the next generation of optoelectronic devices requires transparent conductive electrodes to be lightweight, flexible, cheap, and compatible with largescale manufacturing methods. These requirements limit the use of ITO as transparent conductors because: ${ }^{32}$ 
- ITO films fail under bending.

- There is a limited availability of indium sources resulting in everincreasing prices of indium.

In addition, ITO films are irreversible reduced leading on to a worsening of their conductive and transparent properties.

Therefore, the search for new materials with a good transparency and conductivity to be used as OTEs is outstanding, with carbon nanomaterials being potential candidates. In fact, benefits associated with carbon based OTEs, such as the wide working potential window, the good electrochemical activity, the chemical stability under different $\mathrm{pH}$ conditions and the simplicity of surface modification, are already known for spectroelectrochemistry. ${ }^{33}$

Carbon nanomaterials (section 2) are becoming more and more important in different fields such as electronic devices, ${ }^{34}$ catalysis, ${ }^{35}$ reinforcing materials $^{36}$ and energy conversion ${ }^{37}$ and storage. ${ }^{38}$ Presumably, these new materials will conquer areas associated with OTEs due to their prospective advantages, ${ }^{39}$ leading to replace the ITO. ${ }^{40}$ In fact, carbon nanomaterials are being included in the development of OTEs devices, ${ }^{41}$ for example, SWCNTs in screens that detect touch force and location ${ }^{42}$ and GNPs in solar cells. ${ }^{43}$ Furthermore, the applications of carbon nanomaterials in analytical chemistry, ${ }^{44}$ specifically in electrochemistry, ${ }^{45,46}$ are growing significantly in recent years. ${ }^{47}$

SWCNTs electrodes show important advantages with respect to other classical electrode materials. ${ }^{48-51}$ For example, electrochromic properties of both PEDOT and tungsten oxide films improve considerably when SWCNTs films are used instead of ITO as the transparent conductive 
layer. ${ }^{49}$ Networks of carbon nanotubes are considered as a new transparent and flexible electrode that can be seen as an alternative to ITO electrodes. ${ }^{52}$ Our group has previously demonstrated the good behavior of SWCNTsOTEs. ${ }^{53,54}$

The fabrication of optically transparent films of carbon nanotubes in general, and SWCNTs in particular, has been achieved using different approaches. ${ }^{53,55-63}$ In some cases, a transparent conductor can be used as support, in other cases, non-conductor supports are used. SWCNTs dispersions are sometimes prepared with a surfactant that typically needs to be removed. When the SWCNTs film is transferred from a filter, this membrane is usually dissolved and the film should be carefully washed to remove any degradation product. Our group developed a press-transfer method using SWCNTs collected directly on filters from the CVD reactor. $^{53}$

In summary, OTEs are needed for normal transmission spectroelectrochemistry, a good transparency being necessary to ensure that the normal light beam passes across the electrode, and a good electrical conductivity to obtain information about the electron transfer. In this sense, carbon nanotubes are one of the most promising carbon nanomaterials. ${ }^{56}$ Their optical and electrical properties have made them potential targets for nanotechnology, and their use in analytical chemistry ${ }^{64-67}$ is outstanding.

As homogeneous thin films of carbon nanotubes are required for several applications, ${ }^{68}$ highlighting sensors ${ }^{69}$ and OTEs, ${ }^{41,55,70-72}$ in this doctoral thesis we have developed several methodologies to fabricate OTEs made of carbon nanotubes and other carbon nanomaterials (sections 6.1, 6.2, and 6.3). ${ }^{73-75} \mathrm{We}$ have used commercial nanomaterials because they can be 
obtained easily by any researcher, offer a great versatility, and the need to have a CVD reactor in the laboratory is avoided, among other reasons.

\subsubsection{Parallel Configuration Spectroelectrochemistry}

Unlike what happens in normal arrangement, where the spectroscopic response includes information about the solution and the electrode, parallel configuration, also known as long optical path length arrangement, is related to the spectral changes that occur only in the solution closest to the WE. The scheme for parallel spectroelectrochemistry is represented in Figure 1.4. As can be seen, the light beam travels in parallel direction with respect to the WE surface, samples just the first micrometers of the solution adjacent to the WE surface, and it is finally collected in the spectrometer.

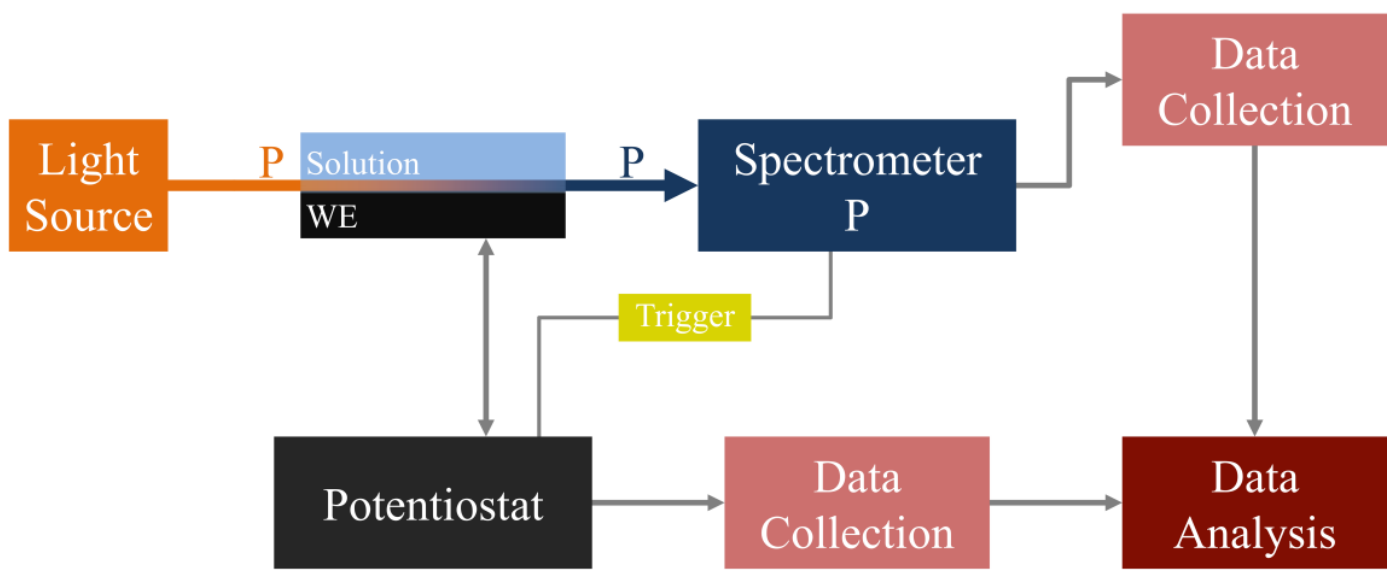

Figure 1.4. General scheme for spectroelectrochemistry in parallel configuration.

Although the alignment of the light beams is a little bit difficult in this case, parallel configuration presents several advantages compared to normal 
arrangement: (i) a higher sensitivity; (ii) lower limits of detection; (iii) the use of OTEs is not required; and (iv) the light beam only samples the first micrometers of the solution adjacent to the electrode surface, so the spectral changes recorded during the electrochemical reaction are related to the electrode-solution interface.

Taking into account these advantages, in this doctoral thesis we have managed to measure simultaneously the Raman dispersion and the UV-Vis absorption spectra during electrochemical reactions (section 6.4) ${ }^{76}$ and to perform quantitative analysis using a novel and singular UV-Vis absorption spectroelectrochemistry device in long optical path length arrangement (section 6.5) ) $^{31}$ that can even be used to monitor the evolution of $\mathrm{pH}$ at the electrode-solution interface (section 6.7). ${ }^{77}$

\subsection{Bidimensional Spectroelectrochemistry}

$\mathrm{BSEC}^{78,79}$ is a powerful multiresponse technique that offers the possibility of obtaining simultaneously one electrochemical and two spectroscopic signals providing independent but complementary information. In this case, a normal UV-Vis light beam samples the system in perpendicular direction (reflection or transmission) to the electrode surface while, at the same time, a parallel UV-Vis light beam passes only through the solution layer adjacent to the electrode surface. Therefore, BSEC can be defined as the simultaneous performance of normal and parallel spectroelectrochemistry.

By combining the two main monodimensional spectroelectrochemistry arrangements in a single setup, it is possible to spectroscopically distinguish which processes take place in solution and which ones on the 
electrode surface during an electrochemical experiment. The scheme for BSEC is illustrated in Figure 1.5:

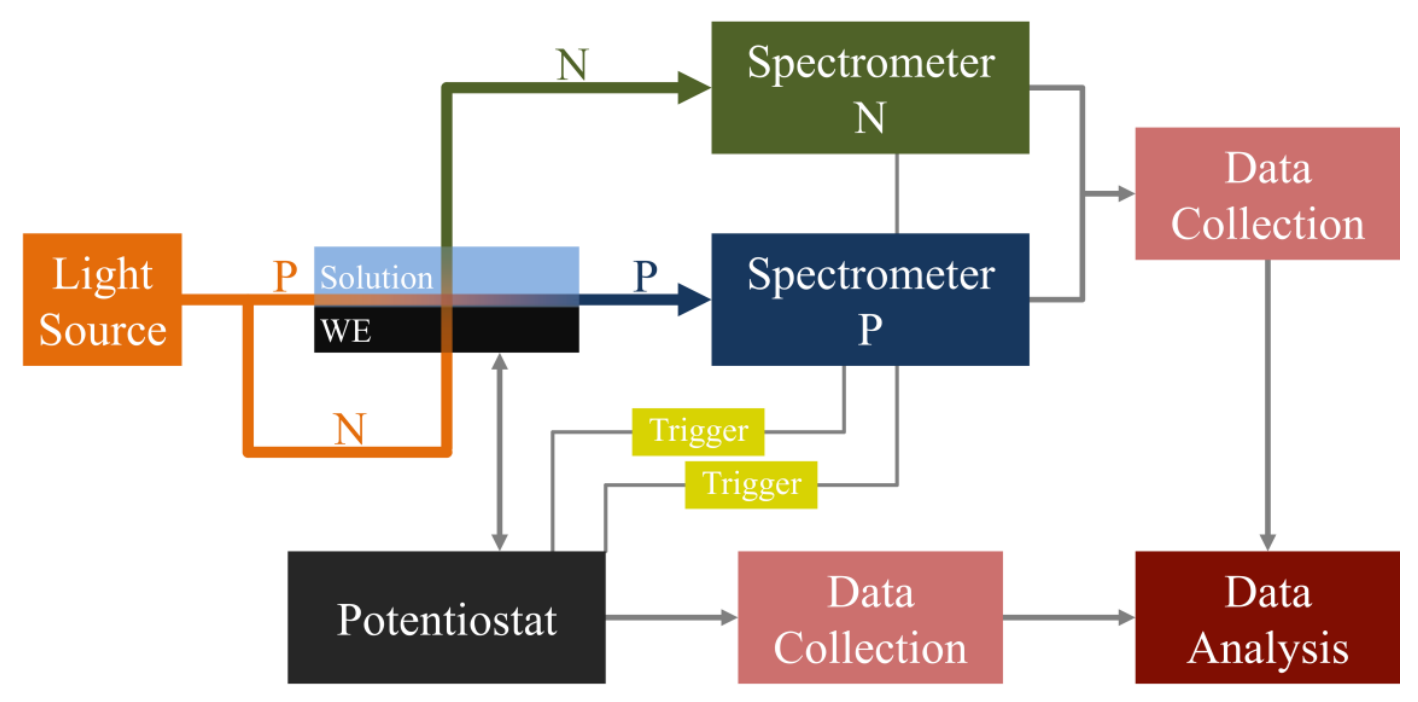

Figure 1.5. General scheme for BSEC in normal transmission configuration.

This technique was developed by our research group in $2001^{78}$ and, since then, its advantages have allowed us to obtain very valuable information in different research fields. Moreover, a digital simulation model for BSEC experiments, ${ }^{79}$ based on an explicit finite difference method, was developed and experimentally validated, being valid for any potential controlled experiment. It reproduces not only chronoabsorptometric but also voltabsorptometric experiments under different diffusion conditions, either in the equilibrium state (thin-layer cells) or under finite/semi-infinite diffusion regime (bulk cells), and both with reversible and non-reversible electron-transfer reactions. In addition, this work demonstrated that the analysis of the absorbance in parallel direction with respect to the electrode surface, which is the most informative magnitude, is crucial to classify properly a diffusion regime during an electrode reaction, because the 
electrochemical data or the absorbance data in normal direction with respect to the electrode surface, both related to the global process, are not enough to achieve this objective.

Figure 1.6 shows the first device fabricated to carry out BSEC. The cell consisted of a planar optically transparent gold-sputtered WE and allowed the light beams to cross the solution simultaneously in both normal and parallel directions with respect to the electrode surface. The device was able to fit into a standard spectrophotometric cuvette and combined simplicity of assembly and cleaning with versatility of use and low cost. It could be used both in semi-infinite and thin-layer diffusion measurements, with both OTEs and long optical pathway configuration. ${ }^{78}$

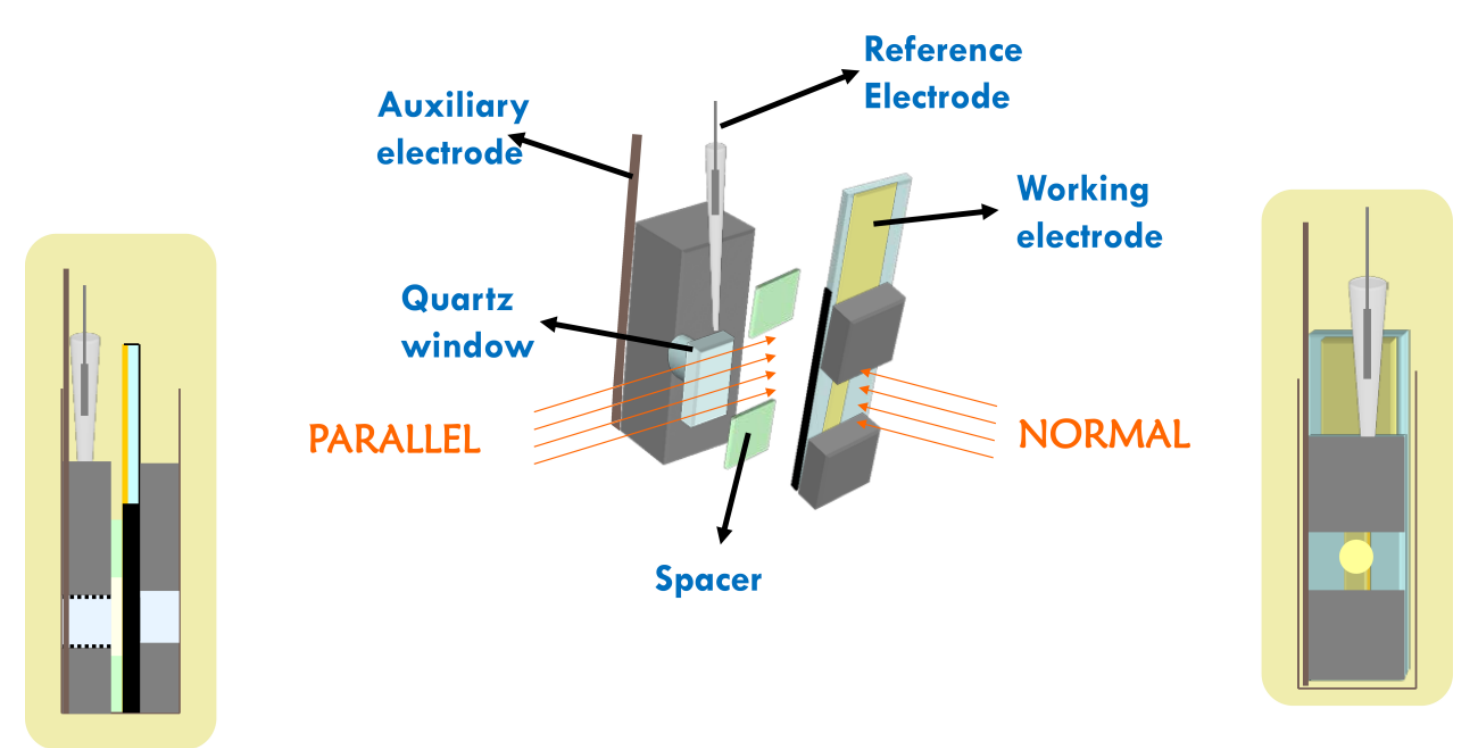

Figure 1.6. Schematic diagrams (3D, side and front views) of the spectroelectrochemistry device.

Several differences between normal and parallel arrangement were noted, for example, in the electropolymerization study of 4-4'-bis(methylthio)2,2'-bithiophene in acetonitrile (Figure 1.7). The electrogeneration of the 
corresponding conducting polymer enabled researchers to observe the polymer growth and its oxidation and reduction on the electrode surface by normal arrangement concomitantly with the observation of soluble oligomers with shorter chain lengths in parallel configuration. As was expected, parallel configuration did not show the polymer growth because it was adsorbed on the electrode surface and did not diffuse to the solution, being only detected in normal arrangement. However, normal configuration also included information about the presence of the oligomers, fact that should be taken into account depending on the required information to be obtained. All these results demonstrate the need to perform BSEC experiments because neither solely electrochemical nor monodimensional spectroelectrochemistry measurements alone allow us to obtain this information. On the one hand, if only the parallel signal is taken into account, the chemist is not able to know that an adsorption process occurs. On the other hand, if only normal light beam is observed, differentiation between adsorbed and soluble species is not possible.
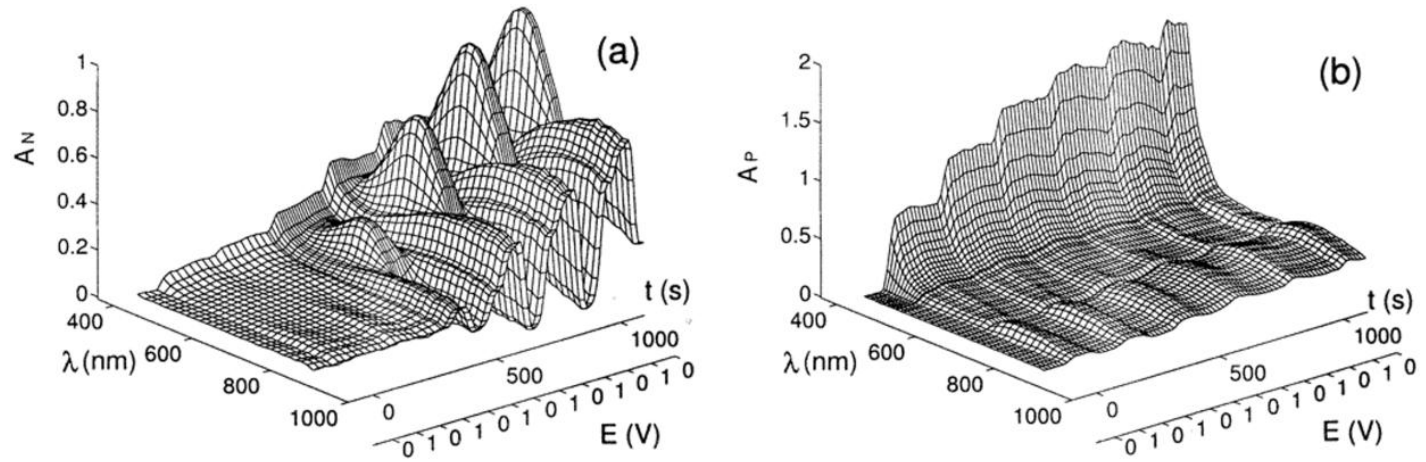

Figure 1.7. 3D plot absorbance/potential (time)/wavelength during electropolymerization of $0.005 \mathrm{M}$ 4-4'-bis(methylthio)-2,2'-bithiophene in acetonitrile with $\mathrm{TBAPF}_{6} 0.1 \mathrm{M}$ as the supporting electrolyte. Display of six scans performed between 0.0 and $1.1 \mathrm{~V}$ versus $\mathrm{Ag} / \mathrm{AgCl}$ at $v=0.01 \mathrm{~V} \cdot \mathrm{s}^{-1} ; \omega=$ $220 \mu \mathrm{m} ; l=3 \mathrm{~mm}$. (a) Normal beam and (b) parallel beam signals. ${ }^{78}$ 
This is the first and, quite possibly, one of the best examples to understand the importance of carrying out BSEC experiments when unknown systems must be studied and the maximum amount of information should be obtained. As might be expected, this is only the beginning. Many other BSEC studies with organic conducting polymers, such as for example poly[4,4'-bis(butylthio)-2,2'-bithiophene $],{ }^{80,81}$ poly[4,4'-bis $(2-$ methylbutylthio)-2,2'-bithiophene $],{ }^{82,83} \quad$ PANI $^{84}{ }^{84}$ polypyrrole, ${ }^{85}$ and PEDOT, ${ }^{86}$ have been performed. All these works have enabled researchers to extract significant conclusions about, for example, the complex reaction mechanisms of these electropolymerizations ${ }^{78,80,82,83}$ and the stability or degradation of polymer films. ${ }^{81,84}$ Moreover, BSEC experiments also show the electrically controlled release of chemicals from a conducting polymer as well as the release of oligomers trapped in electrochemically synthesized polymer films, ${ }^{85,86}$ simultaneously with information about the corresponding polymers. According to these results, BSEC is a potential suitable technique to shed more light on this type of chemical systems to be used in controlled delivery of drugs and the detection of interfering compounds during the potential controlled release of chemicals to make further progress in the field of conducting polymers. In addition, BSEC has also been applied in the study of the electrogeneration of soluble Prussian Blue from hexacyanoferrate(II) aqueous solutions, showing, as some new findings about this complicated mechanism, that the hexacyanoferrate(II)/supporting electrolyte concentration ratio and the potential scan rate influence significantly in the generation of this compound. $^{87}$

As was expected from the advantages of monodimensional spectroelectrochemistry techniques mentioned in previous sections, BSEC provides more inherent and competitive advantages that have allowed us to 
obtain valuable information related to several processes. Particularly, normal configuration contains information about the global process while parallel arrangement provides information only about diffusive species. Therefore, the comparison of both signals is crucial for the elucidation of complex reaction mechanisms.

In summary, BSEC has emerged as a very useful technique to understand complex electrochemical reactions, providing time-resolved electrochemical and spectroscopic information in normal and parallel configuration with respect to the electrode surface about the different products generated during the electrode processes. As has been shown, this multiresponse technique has been applied in the study of diffusive processes and adsorptive electrode reactions.

However, although a few UV-Vis monodimensional spectroelectrochemistry cells ${ }^{88-92}$ and instruments ${ }^{93-95}$ are commercially available, to the best of our knowledge there are neither BSEC cells nor BSEC instruments, probably due to the technical complexity of this technique. For this reason, an easy-to-use homemade BSEC cell is presented in this doctoral thesis (section 6.3), ${ }^{75}$ aiming to increase the number of applications for BSEC to exploit its multiple advantages.

\subsection{Thin-Layer Spectroelectrochemistry}

One of the main aims of chemistry is the development of new compounds with outstanding properties. Evidently, a thorough characterization of these substances is necessary before their use. As far as electrochemical properties are concerned, spectroelectrochemistry techniques, particularly 
thin-layer spectroelectrochemistry, can significantly help to assess several parameters of compounds that undergo electron-transfer reactions. ${ }^{96}$

$\mathrm{UV}-\mathrm{Vis}$ absorption thin-layer spectroelectrochemistry is a powerful hybrid technique that allows researchers to obtain electrochemical and spectroscopic responses of the same system at the same time in the first micrometers of solution confined closest to the surface of the WE. ${ }^{3,5,97}$ As can be inferred from the previous sections, the light beam travels in perpendicular direction with respect to the electrode surface in normal configuration, ${ }^{98,99}$ while the light beam is parallel to the electrode in the long optical path length arrangement. ${ }^{100}$ As can be expected, BSEC combines the best features of both arrangements. ${ }^{78}$

Combining the Nernst equation with the Beer-Lambert law, Equation (1.1), the formal potential $E^{0^{\prime}}$ and the number of electrons transferred $n$ of an electrochemical process can be obtained using UV-Vis absorption thinlayer spectroelectrochemistry:

$$
E=E^{0^{\prime}}-2.3 \frac{R T}{n F} \log \frac{A_{R e d}-A}{A-A_{O x}}
$$

The advantages provided by UV-Vis absorption thin-layer spectroelectrochemistry have been exploited in multiple research fields, including:

- Side-reactions. ${ }^{87,96}$

- Self-assembled monolayers. ${ }^{101}$

- Compounds of biological interest. ${ }^{102-106}$ 
- Photovoltaic cells. ${ }^{107}$

- Optoelectronics. ${ }^{108}$

- Conducting polymers. ${ }^{82,84}$

- Corrosion phenomena. ${ }^{109}$

- Porphyrins. ${ }^{110}$

- Metal complexes. ${ }^{111-115}$

Several devices have been widely used and have laid the groundwork for numerous $\mathrm{UV}-\mathrm{V}$ is absorption thin-layer spectroelectrochemistry research studies. Nevertheless, it should be noted that the complexity of the existing $\mathrm{UV}-\mathrm{Vis}$ absorption thin-layer spectroelectrochemistry cells is one of their most important drawbacks so far. On the one hand, normal transmission arrangement needs OTEs, drastically reducing the number of electrodes that can be used. On the other hand, a perfect but difficult alignment of the light beams is required in parallel configuration. In practice, this means that many different parts must be duly assembled to carry out a single experiment.

To overcome these problems, and although it is not part of the research results section, a novel and easy-to-use UV-Vis absorption thin-layer spectroelectrochemistry cell was developed. ${ }^{116,117}$ The cell consisted of placing a quartz plate on top of the spectroelectrochemistry device that is explained in section $6.5,{ }^{31}$ allowing to create a thin-layer whose thickness, which is the diameter of the optical fibers, is reproducibly controlled in a friendly and inexpensive way, reducing the complexity associated with this type of devices and thus eliminating one of the major disadvantages of this technique. Therefore, the assessment of electrochemical parameters of 
electron-transfer reactions is simpler and more accessible to all researchers. As an example, Figure 1.8 shows a UV-Vis absorption thin-layer spectroelectrochemistry measurement of $o$-tolidine, demonstrating the great performance of the cell. The redox behavior of $o$-tolidine at very acidic $\mathrm{pH}$ involves a two-electron transfer reaction to the corresponding quinonediimine, with a well-defined absorption band at $437 \mathrm{~nm} .{ }^{118,119}$ As can be observed, a maximum absorbance value is reached at the highest potential, indicating the exhaustive consumption of $o$-tolidine (total electrolysis).

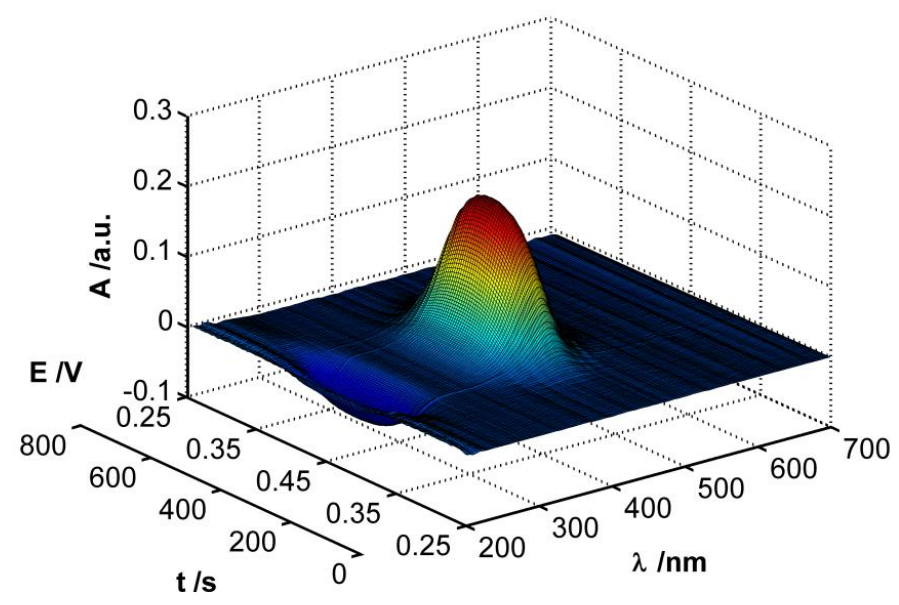

Figure 1.8. Spectra evolution with time/potential recorded during a cyclic voltammetry of $4 \times 10^{-5} \mathrm{M}$ o-tolidine in $0.5 \mathrm{M} \mathrm{CH}_{3} \mathrm{COOH}$ and $1 \mathrm{M} \mathrm{HClO}_{4}$ between $+0.25 \mathrm{~V}$ and $+0.45 \mathrm{~V}$ at $0.0005 \mathrm{~V} \cdot \mathrm{s}^{-1}$, using a solution drop of only 20 $\mu \mathrm{L}$. 

2. Carbon Nanomaterials 



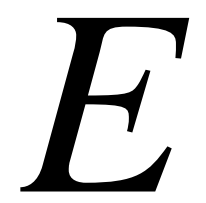
l noventa y siete por ciento de nuestro cuerpo es "C $\mathrm{H} O \mathrm{~N}$ ”. Las infinitas combinaciones de átomos de carbono, hidrógeno, oxígeno y nitrógeno nos permiten desplazarnos, pensar, estudiar, querer, amar... Nuestro cuerpo es materia orgánica porque en nuestro organismo hay átomos de carbono. Y hoy os quiero hablar brevemente de este átomo, $C$, y de la trascendencia que lo rodea. De algunas de las diferentes formas en las que de momento, porque nunca está todo descubierto, se puede encontrar.

Estará presente en tu anillo de compromiso. Eso sí, que no te den gato por liebre, o mejor dicho, grafito por diamante. Sólo en el segundo de los casos llegarás a la boda. Deja por tanto el grafito para la mina de tus lápices y escribe con él una bella poesía a tu pareja. Una vez la hayas entregado, coge una fina lámina del grafito de un único átomo de espesor y sepárala completamente del resto. Tendremos entonces un material que está siendo muy estudiado en la actualidad, principalmente por su dureza, ligereza, transparencia y conductividad: el grafeno. Si enrollas la lámina que habíamos creado de grafeno sobre sí misma, formando un pequeño conducto, tendrás en tu poder un nanotubo de carbono. Es un material muy largo y a la vez muy estrecho, que está siendo utilizado en celdas solares, transistores y memorias de la industria electrónica, piezas de automóviles, como agente de refuerzo de plásticos o en electroquímica. Pero el carbono da tanto para estudiar y trabajar como para divertirse. Existe una estructura altamente simétrica de átomos de carbono idéntica a la de un balón de fútbol: el C60 o Buckminsterfullereno, veinte hexágonos y doce pentágonos distribuidos directamente para disfrutar. ;Si es que es como un juego de niños!

Diamante, grafito, grafeno, nanotubos, fullerenos... Diferentes estructuras pero todas formadas únicamente por el mismo tipo de átomos: átomos de carbono. Diferentes formas de obtenerlos, diferentes precios y diferentes utilidades. Como nosotros mismos. Todos somos “C H O N", pero cada uno somos de nuestro padre y nuestra madre. Yo, por ejemplo, prefiero una preciosa carta de amor escrita a grafito antes que el más caro de los diamantes.

Basado en el artículo publicado el 7 de mayo de 2013 durante mi etapa como colaborador en "El Correo de Burgos" (El Mundo). 



\subsection{Introduction}

Carbon atom is one of the best examples of the huge versatility of chemistry and of the importance of research. With six protons and six electrons, this element, the first member of group 14 of the periodic table, is part of almost all compounds in the human body and plays a key role in the world around us. In fact, carbon is found in all living things. Writing with a pencil, filling the car tank with fuel, or simply breathing are some of the possible actions we do without being aware of the importance of carbon in our daily life. But many more specific and perhaps complex examples are related to this atom, for instance, the steel and electronics industries, nanotechnology, the development of new drugs, and the climate change. ${ }^{120}$

A great effort has been devoted to research about the different carbon allotropes during the last years, especially in the nanoscale dimension. Some of them are plotted in Figure 2.1, which constitutes a proper starting point for this chapter.

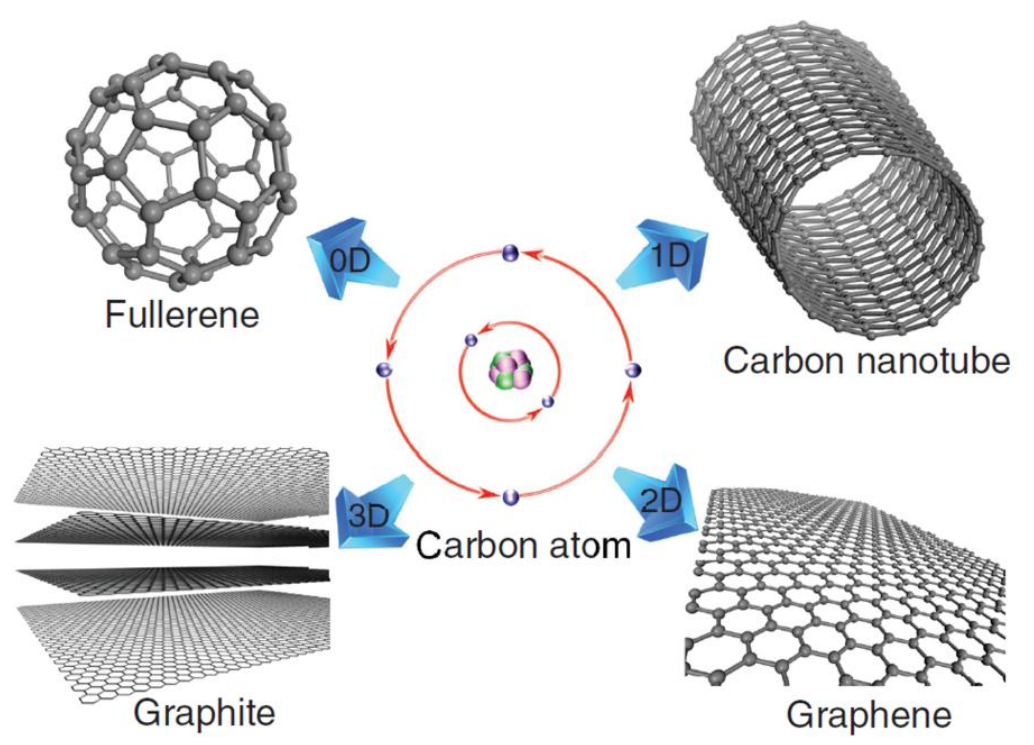

Figure 2.1. Crystal structures of different carbon allotropes. ${ }^{34}$ 
As is known, nanotechnology is playing a crucial role during these last years, improving the quality of life in many different fields. According to the importance of the novel carbon nanomaterials, not only in the current world but also in the research carried out along this doctoral thesis, this chapter is dedicated to some of them, particularly SWCNTs and GNPs.

\subsection{Carbon Nanotubes}

\subsubsection{Introduction}

A thick mat of fine fibres and crystallites was found on the surfaces of graphite and carbon anodes after low current arc operation in nitrogen by Wiles and Abrahamson in 1978. ${ }^{121}$ These fibres were ranged in diameter from about 4 to about $100 \mathrm{~nm}$, with lengths up to $15 \mu \mathrm{m}$. According to the literature, ${ }^{122}$ these fibres are commonly known today as carbon nanotubes. In fact, the term "carbon nanotube" was coined when this carbon allotrope was rediscovered by Iijima in $1991 .{ }^{123}$ In this work, finite carbon structures consisting of needle-like tubes were produced at the negative end of the electrode used in an arc-discharge evaporation method similar to that used for fullerene synthesis. Each needle comprised coaxial tubes of graphitic sheets ranging in number from 2 up to about 50 (see Figure 2.2a). Each tube consisted of hexagons of carbon atoms arranged in a helical way about the needle axis. Two years later, in 1993, Iijima and Ichihashi reported the synthesis of single-shell carbon nanotubes, curiously at the same time as Bethune et al., ${ }^{124,125}$ with diameters of about $1 \mathrm{~nm}$ (Figure 2.2b), grown in 
the gas phase in contrast to multi-shell carbon nanotubes which were formed on the carbon cathode. ${ }^{126}$
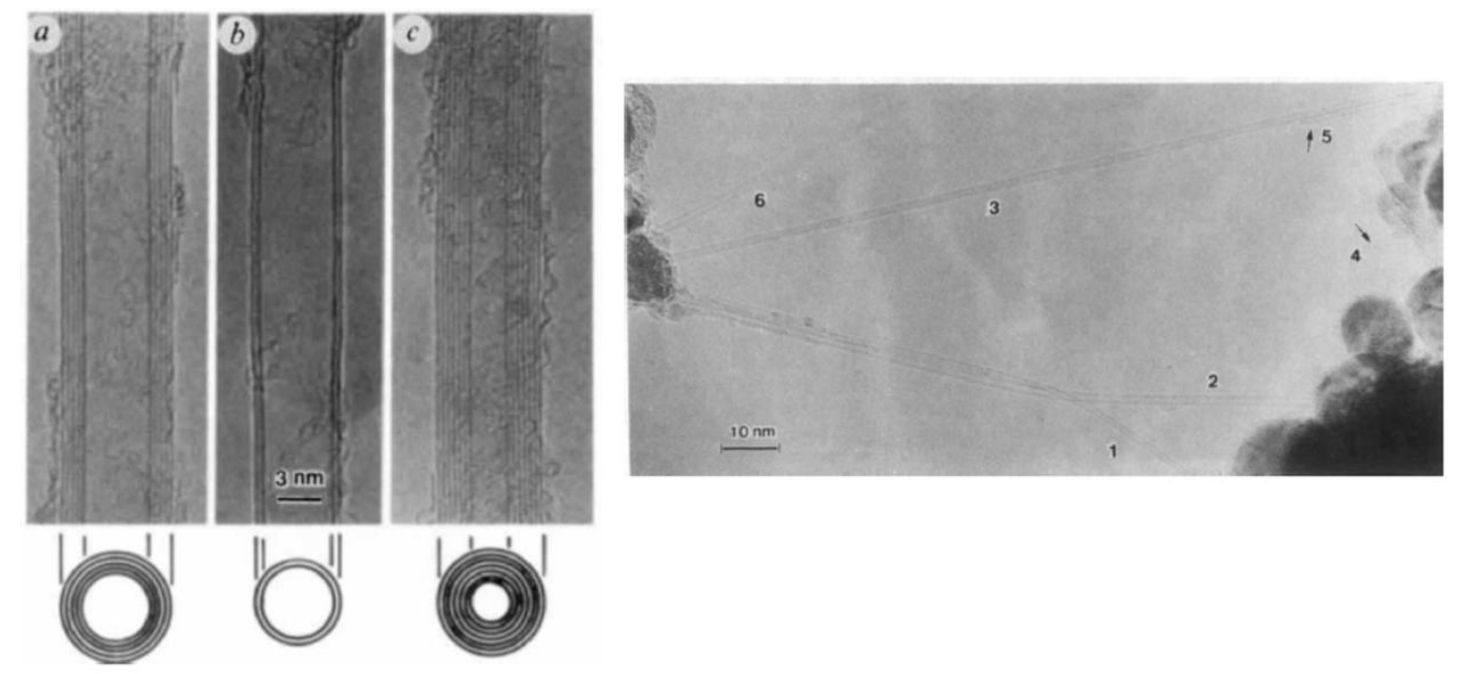

Figure 2.2. (a) Electron micrographs of microtubules of graphitic carbon consisting of five, two, and seven graphitic sheets, respectively. ${ }^{123}$ (b) Electron micrograph showing individual single-shell nanotubes. The tubule labeled 1 is $0.75 \mathrm{~nm}$ in diameter and tubule 2 is $1.37 \mathrm{~nm}$ in diameter. ${ }^{126,127}$

Therefore, as can be seen in Figure 2.3, carbon nanotubes are usually divided into two types taking into account the number of concentric cylinders present:

- SWCNTs.

- MWCNTs.

It should be noted that it is also very common to distinguish double- and triple-walled carbon nanotubes as intermediate types from the previous classification. 

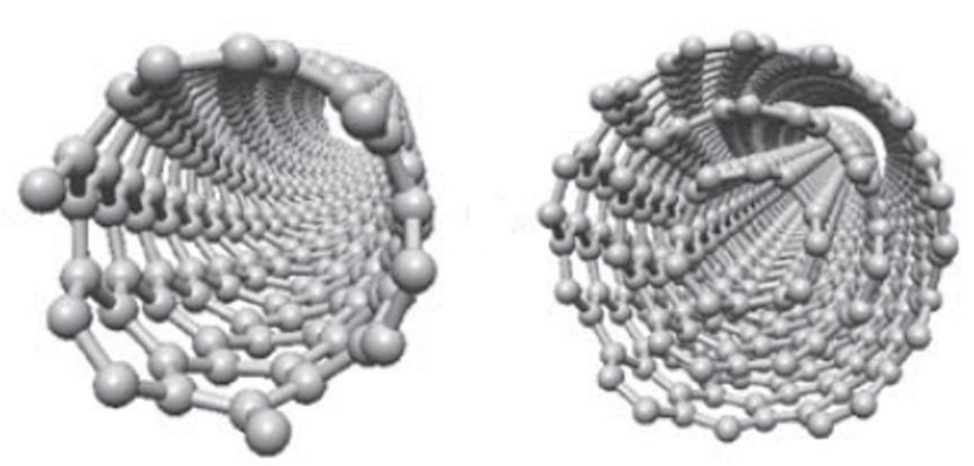

Figure 2.3. Ball and stick illustrations of a SWCNT and a MWCNT. ${ }^{128}$

A SWCNT can be described as a single layer of a graphite crystal rolled up into a seamless cylinder, one atom thick, usually with a small number (perhaps 10-40) of carbon atoms along the circumference and a long length (microns) along the cylinder axis. ${ }^{129}$ Therefore, rolling-up a narrow strip of a single $2 \mathrm{D}$ carbon sheet of graphite in a seamless way into a cylinder forms a SWCNT. Double- and triple-walled carbon nanotubes are obtained by adding one and two-layer concentric cylinders to a SWCNT. A MWCNT is thus obtained by adding many rolled-up concentric cylinders. $^{130}$

This chapter is focused more on SWCNTs because this is the type of carbon nanotubes used along this doctoral thesis, aiming to guarantee the similarity between the experimental conditions and to improve the reproducibility of the results. It should be mentioned that SWCNTs have unique properties, particularly interesting for electrochemistry and spectroelectrochemistry, ${ }^{131-133}$ and a wide range of applications, especially for biosensors. ${ }^{134-136}$ However, information about other carbon nanotubes is also present taking into account that the different methodologies carried out can be applied to other carbon nanomaterials. 


\subsubsection{Synthesis and Transference}

Different methods for the synthesis of carbon nanotubes have been reported, being arc discharge, laser ablation, and CVD the most prominent examples. $^{137}$

This last in particular, CVD, can be performed in different ways, highlighting hot-filament, water assisted, oxygen assisted, microwave plasma, radiofrequency, and catalytic CVD. Catalytic CVD, either thermal or plasma enhanced, can be considered as the standard method for the production of carbon nanotubes and economically viable for large scale. ${ }^{137}$ In a simplified manner, SWCNTs are produced by catalytic CVD when a carbon precursor (normally in gaseous phase) is catalytically converted into solid SWCNTs upon interacting with the catalysts. ${ }^{138}$ As can be seen in Figure 2.4, the process of CVD is a catalytic conversion of a gaseous precursor at high temperatures into a solid material at the surface of catalyst particles. During this process, the factors influencing the structures of SWCNTs could be analyzed through the interaction of gas, catalyst, substrate, and the SWCNTs: ${ }^{139}$

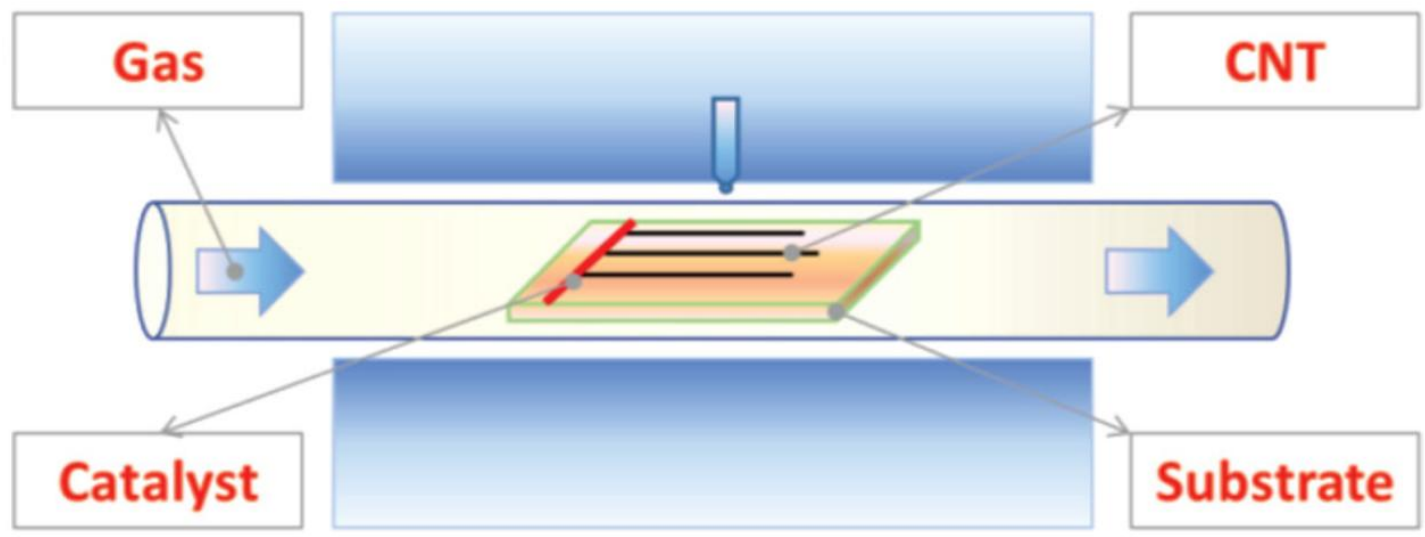

Figure 2.4. Illustration for the general growth process of SWCNTs in CVD. ${ }^{139}$ 
The transference of carbon nanotubes films to a variety of supports is of great importance. This transference step is commonly carried out with CVD films ${ }^{140,141}$ using different methods, including dry-transfer, ${ }^{142}$ imprinted conductive adhesive, ${ }^{143}$ functionalization of carbon nanotubes, ${ }^{144}$ transfer printing, ${ }^{145}$ contact printing, ${ }^{146}$ stacked multiple transfer, ${ }^{147}$ spin coating of a PMMA film, ${ }^{148}$ using the growth substrate as a stamp, ${ }^{149}$ onestep direct transfer, ${ }^{150}$ laser assisted, ${ }^{151}$ or using polydimethylsiloxane. ${ }^{152}$ Growing carbon nanotubes onto a catalyst and subsequent sputtering ${ }^{153}$ and spray deposition ${ }^{154}$ are other ways that yield good results. However, some of these techniques are not available for all laboratories.

Filtering carbon nanotubes dispersions is another methodology that also gets good results. ${ }^{60,155-158}$ Nevertheless, the use of strong etching agents such as nitric acid, the need to dissolve the filter or the use of surfactants to obtain good carbon nanotubes dispersions introduce unnecessary impurities that can affect the optical and electrical behavior of carbon nanotubes. There are also some supports that cannot resist the pressure, the vacuum, or the curing processes required by some methods cited above. Besides, a large number of intermediate steps are associated with difficult and tedious transferences.

In accordance with the importance of transferring carbon nanotubes and other carbon nanomaterials on different supports, in this doctoral thesis we have developed several methodologies in this direction (sections 6.1, 6.2, 6.3 , and 6.5), ${ }^{31,73-75}$ trying to overcome the drawbacks associated with other methods. As can be observed in these works, the resulting films show an excellent performance as electrodes for electrochemical and spectroelectrochemical purposes. 


\subsubsection{Properties}

The importance of carbon nanomaterials, in particular carbon nanotubes, is undoubtedly prominent. This fact is due to the unique and exceptional features of this carbon allotrope. The following properties of carbon nanotubes should be highlighted:

- Mechanical properties. ${ }^{129}$

- Thermal properties. ${ }^{129}$

- Optical properties. ${ }^{129,159}$

- Electronic properties. ${ }^{45,50,66,128,129,160-163}$

- Electrical properties. ${ }^{45,66,128,164}$

- Catalytic properties. ${ }^{45,50,66,122,128,160,161}$

- Electrochemical properties. ${ }^{45,50,66,122,128,160-162}$

In addition, carbon nanotubes are relatively easy to modify or functionalize, ${ }^{165,166}$ to improve their properties, and expand their scope of applications.

It should be noted that several properties of SWCNTs are highly dependent on their chirality. ${ }^{138}$

As shown in Figure 2.5, each carbon atom in a single sheet of graphite can be identified with a pair of integers $(n, m)$ and a pair of basis vectors $\left(\mathbf{a}_{\mathbf{1}}\right.$, $\mathbf{a}_{2}$ ), together with the initial and final carbon atoms, lead to the definition of a "chiral vector", $C_{h}=n \mathbf{a}_{1}+m \mathbf{a}_{2}$. When the single sheet of graphite is 
rolled up, whether the resulting SWCNTs are metallic or semiconducting depends on the starting and end points of the chiral vector in the $\mathrm{sp}^{2}$ bonded carbon atom lattice. SWCNTs with the chiral vector $C_{h}=n \mathbf{a}_{1}+m \mathbf{a}_{2}$ are metallic (they can work as conductive wires) when $|n-m|=3 j$, where $j$ is an integer, and the remaining SWCNTs are semiconducting with geometry-dependent band gaps (they can be applied as gate materials). Pure metallic SWCNTs and pure semiconducting SWCNTs are ideal metals and semiconductors, respectively. ${ }^{129,138,167}$ Therefore, there are mainly three different crystallographic types of carbon nanotubes depending on the way the one-atom-thick sheet of graphite is distorted, namely, armchair $(n, n)$, zigzag $(n, 0)$, and chiral $(n, m)$ carbon nanotubes. ${ }^{37,64,137}$

$\mathbf{a}$

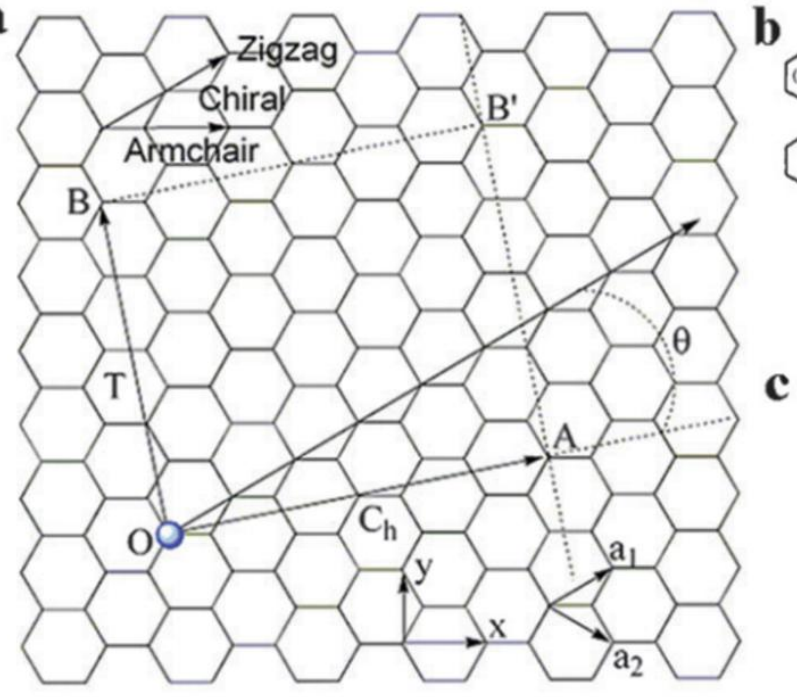

1 (n) $(10.0)(1.0)(12.0)(3.0)(4.0)(15.0)(6.0))(17.0)(8.0)(10.0)(10.0)$

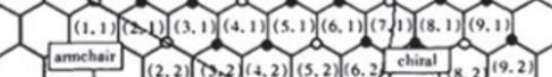

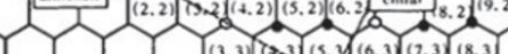
110 $0101(15.5)(0.05)(17.5)$ ○ Metals - Semiconductors

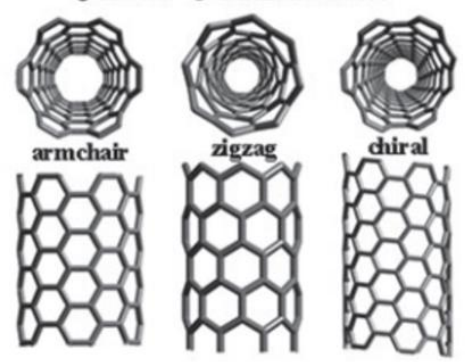

Figure 2.5. (a) Schematic plot of the chiral vector $\left(C_{h}\right)$ in a graphene 2D lattice. (b) The relationship between integers $(n, m)$ and the metallic or semiconducting nature of nanotubes. (c) The structure of "armchair", "zigzag" and "chiral" nanotubes. ${ }^{167}$ 


\subsubsection{Applications}

Many references of the previous sections already gave an idea about the applications of carbon nanotubes.

In general, the use of carbon materials in electrochemistry has numerous advantages. ${ }^{168}$ As can be inferred, the fascinating properties of carbon nanotubes make them an outstanding material for electrochemical purposes, among others. ${ }^{169-177}$

Carbon nanotubes, due to their unique and exceptional properties, are a highly promising carbon allotrope with a wide range of applications, ${ }^{178,179}$ including batteries, solar cells, electronic devices, field-effect transistors, diodes, supercapacitors, fuel cells, OTEs, energy storage, and polymer composites, among many others.

Particularly, the use of carbon nanotubes in different branches of medicine, such as neuroscience, ${ }^{180}$ multifunctional cellular endoscopes, ${ }^{181}$ regenerative medicine, ${ }^{182}$ molecular imaging, ${ }^{183}$ and especially sensors ${ }^{184-}$ 186 is increasing steadily in recent years, with particular emphasis on biocompatibility. ${ }^{187}$

Taking into account the research field of this doctoral thesis, it should be noticed the importance of carbon nanotubes for electrochemical measurements, highlighting their advantages such as the large active surface at electrodes of small dimensions, the enhanced electron transfer or the often indicated electrocatalytic properties. ${ }^{51}$ In fact, SWCNTs networks are very effective for trace level measurements, offering a simple and useful route to concentration levels which have proved inaccessible to other electrode materials. ${ }^{188}$ Besides, carbon nanotubes can also be employed as 
modifying agent to improve the electrochemical properties of other electrodes. ${ }^{67}$ Furthermore, carbon nanotubes have also been employed in conjunction with nanoparticles for electroanalysis. ${ }^{189,190}$ Carbon nanotubes have a great importance in the field of electroanalytical chemistry ${ }^{65}$ and have been used extensively in electrochemical biosensing studies because biomolecules have been successfully integrated with them. ${ }^{191}$

In particular, our research group has demonstrated the usefulness of SWCNTs networks to detect very similar molecules by spectroelectrochemistry, showing the potential of this technique for the quantification of analytes (results not shown in this doctoral thesis). ${ }^{192}$ In addition, in collaboration with the research group "Miniaturización y Nanotecnología Analíticas" of the Universidad de Alcalá (Alcalá de Henares, Madrid), ${ }^{193}$ led by Dr. Alberto Escarpa, SWCNTs have been employed successfully for electrochemical microfluidic sensing. ${ }^{194,195}$

In summary, carbon nanotubes play an important role in electrochemistry because of their remarkable properties, and are one of the most promising carbon nanomaterials in a wide variety of fields. ${ }^{56}$ According to all the advantages of this carbon nanomaterial, electrodes based on carbon nanotubes are extensively used for electroanalytical applications, and, definitively, in the electrochemical detection of several biomolecules. ${ }^{46,47,128,196,197}$

One of the main objectives achieved in this doctoral thesis is to demonstrate that well interconnected networks of SWCNTs act as fantastic electrodes for studying redox reactions by electrochemistry and spectroelectrochemistry (section 6). ${ }^{30,31,73-77}$ 


\subsection{Graphene Nanoplatelets}

\subsubsection{An Overview}

The Nobel Prize in Physics 2010 was awarded jointly to Andre Geim and Konstantin Novoselov for groundbreaking experiments regarding the twodimensional material graphene, a single atomic layer of carbon. ${ }^{198,199}$ Graphene, a hexagonal bidimensional network of carbon atoms, is another carbon allotrope with remarkable hardness, strength, flexibility, thermal behavior, electrical conductivity and transparency. ${ }^{200}$ These properties allow graphene to be used as one of the best transparent electrodes, ${ }^{201}$ for example in organic electronics, improving the behavior under bending of ITO electrodes that show irreversible failures. ${ }^{202}$ Graphene has also been widely employed for electrochemical sensing, ${ }^{203}$ among many other applications. ${ }^{204}$ It should be noted that carbon nanotubes and graphene are being increasingly used together for different applications, ${ }^{205}$ being filtration a methodology that is achieving promising results even for transparent electrodes. ${ }^{206,207}$

GNPs are layers of stacked graphene sheets with high surface area that are easier to obtain and handle than graphene. Their electrochemical properties have been deeply studied, for example, in order to determine endocrinedisrupting chemicals. ${ }^{208}$ GNPs have been used as a solid phase extraction sorbent for the quantitative analysis of phthalate esters in aqueous solutions. ${ }^{209}$ They have also been used for other applications such as electrochemical detection of biomarkers and DNA bases, ${ }^{210}$ adsorption and removal of pharmaceutical pollutants in order to solve environmental 
problems $^{211}$ and development of biosensors ${ }^{212}$ and temperature sensors. ${ }^{213}$ In addition, GNPs can be used as optically transparent cathode for solar cells. ${ }^{43}$ It must be highlighted that polymer composites filled with GNPs and carbon nanotubes show an improved electrical performance. ${ }^{214,215}$ In addition, several methodologies including microwave irradiation ${ }^{216}$ or filtration ${ }^{217}$ have allowed GNPs and carbon nanotubes to be jointly used. Screen-printed pressure sensors, ${ }^{218}$ free-standing papers prepared by filtration for lithium ion batteries, ${ }^{219}$ filtered sheets with piezoresistive behavior for multi-directional strain sensing, ${ }^{220}$ temperature stable supercapacitors $^{221}$ and hydrogen gas sensors, ${ }^{222}$ are some applications in which carbon nanotubes and GNPs are currently being used together.

In section $6.2^{74}$ of this doctoral thesis, GNPs are used to modify SWCNTs electrodes, allowing us to obtain homogeneous bilayer films of both carbon nanomaterials to be used as OTEs. 


\section{Conducting Polymers}





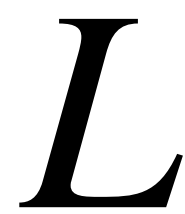

os polímeros conductores son un claro y fiel reflejo de que, sin duda alguna, la unión hace la fuerza. Como bien es sabido, los monómeros son, generalmente, pequeñas unidades orgánicas que presentan ciertas características de diferente naturaleza. Sin embargo, en determinadas circunstancias, estos compuestos presentan la capacidad de aproximar entre sí algunas regiones de su estructura, como si se tratase de una cariñosa unión de manos de unos con otros, para dar así lugar a la formación inicial de dímeros y, en sucesivas etapas, ser capaces de constituir trímeros y tetrámeros. Cuando estos grupos adquieren un mayor número de miembros pasan a formarse los oligómeros, y, en una etapa final, tiene lugar la formación de los denominados polímeros conductores.

Como es esperable, las propiedades de los polímeros conductores son muy diferentes a las de los monómeros iniciales. Esas distintas propiedades, por lo general mejores que las de los monómeros individuales, han hecho que se haya desarrollado un amplio abanico de aplicaciones empleando polímeros conductores y que, incluso, se otorgase el Premio Nobel de Química en el año 2000 a Alan J. Heeger, Alan G. MacDiarmid y Hideki Shirakawa por el descubrimiento y desarrollo de dichos materiales.

Eso sí, no todos los polímeros conductores son iguales. Como ocurre en la vida, las diferencias radican en distintos aspectos. En primer lugar, en el tipo de monómero empleado, es decir, en cada uno de los individuos que forman parte de un grupo. En segundo lugar, en el estilo de la unión establecida entre cada uno de ellos. Y en tercer y último lugar, en lo que ha propiciado esa unión. En los sentimientos, porqués y motivos que mueven a cada agrupación. Esos sentimientos, porqués y motivos que, como en este caso, pueden llegar a hacer que lo que todo el mundo daba por eléctricamente aislante, llegue a ser conductor. 



\subsection{Why This Chapter?}

Two types of conducting polymers have been employed throughout this doctoral thesis, specifically PANI (section 6.1) ${ }^{73}$ and PEDOT (sections 6.2 and 6.4) ${ }^{74,76}$ For this reason, this chapter is intended to introduce these new materials in a concise way.

PANI and PEDOT have been used to demonstrate the suitable performance of the electrodes based on carbon nanomaterials that have been developed in these works. As will be seen below, these results allow us to obtain carbon-based electrodes modified with conducting polymers that could be used not only for spectroelectrochemistry but also for other important applications in the current world.

It is noteworthy that conducting polymers have been widely studied by our Instrumental Analysis group since 2001. ${ }^{9,78,80-86,223-230}$ Taking into account (i) this previous extensive experience of the research group and (ii) the reason why these materials have been used in the works presented in this doctoral thesis, this chapter is focused on the electrical and optical properties of these materials, as well as on the main applications of conducting polymers in general and of PANI and PEDOT in particular.

Finally, I had the opportunity to work three months of 2014 in the Warwick Electrochemistry \& Interfaces Group (University of Warwick, United Kingdom) under the supervision of Patrick R. Unwin. ${ }^{231}$ A fascinating project about the electrodeposition of $\mathrm{P} 3 \mathrm{HT}$ and the measurement of the corresponding photoelectrochemical activity using SECCM was carried out. ${ }^{232}$ Although this quite interesting work is not part of the research results section, a brief summary is given in this chapter. 


\subsection{Introduction}

Conducting polymers are not really a novel material. In fact, PANI was probably discovered by Letheby in $1862 .{ }^{233,234}$ However, it is necessary to mention that polyacetylene is the conducting polymer that actually launched this new field of research in the 1970 s. ${ }^{233,235-239}$ In 2000, the Nobel Prize in Chemistry was awarded jointly to Alan J. Heeger, Alan G. MacDiarmid and Hideki Shirakawa for the discovery and development of conductive polymers. ${ }^{233,240}$ Conducting polymers can be roughly defined as a class of materials which combine the electrical and optical properties of traditional semiconductors with the mechanical and processing advantages of polymers. ${ }^{241}$

\subsection{Some Properties}

\subsubsection{Electrical Properties}

One of the main properties of a conducting polymer is the presence of conjugated double bonds along the backbone of the polymer, which means that the bonds between the carbon atoms are alternately single and double. In addition, charge carriers, which can be extra electrons or holes (positions where an electron is missing), have to be injected into the material. Charge migrates a long distance when a hole is filled by an electron jumping in from a neighboring position, creating a new hole again. ${ }^{233}$ Figure 3.1 shows a graphic about the conductivities of different materials to give an idea about the place occupied by conducting polymers. 


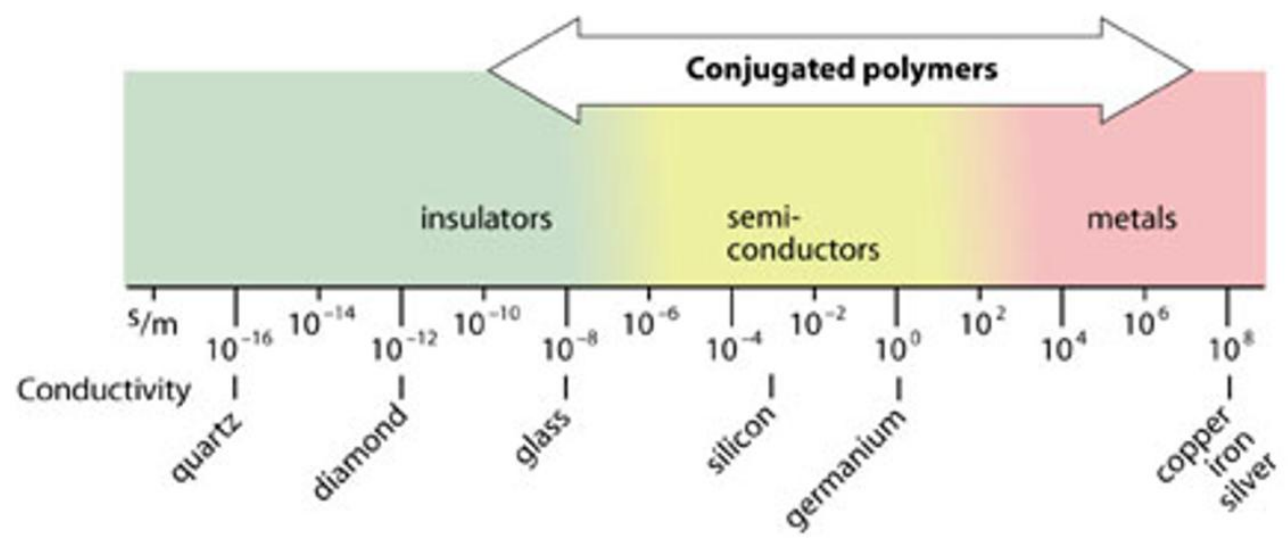

Figure 3.1. Conducting polymers conductivity compared to those of other materials, from quartz (insulator) to copper (conductor). ${ }^{233}$

Figure 3.2 illustrates the energy levels for an insulator, a semi-conductor and a metal material. As can be seen, the electronic structure of a material determines its electrical properties. The lowest unoccupied band is called the conduction band and the highest occupied one the valence band, being the energy spacing between them called band gap. ${ }^{233,238}$ Therefore, the band gap (minimum energy difference between ground state and excited state) corresponds to the energy needed to create a charge pair with one electron in the upper and empty manifold of orbitals and one positive charge or hole in the lower and filled manifold. ${ }^{233}$ The electrical properties of conventional materials depend on how the bands are filled. No conduction occurs when the bands are filled or empty. In fact, the high conductivity of metals is due to partially occupied bands (partially filled conduction band, partially empty valence band, or a zero band gap). If the band gap is narrow, at room temperature thermal excitation of electrons from the valence band to the conduction band gives rise to conductivity (classical semiconductors). When the band gap is too wide, thermal excitation at room temperature is not enough to excite electrons across the gap (insulating materials). ${ }^{238}$ 


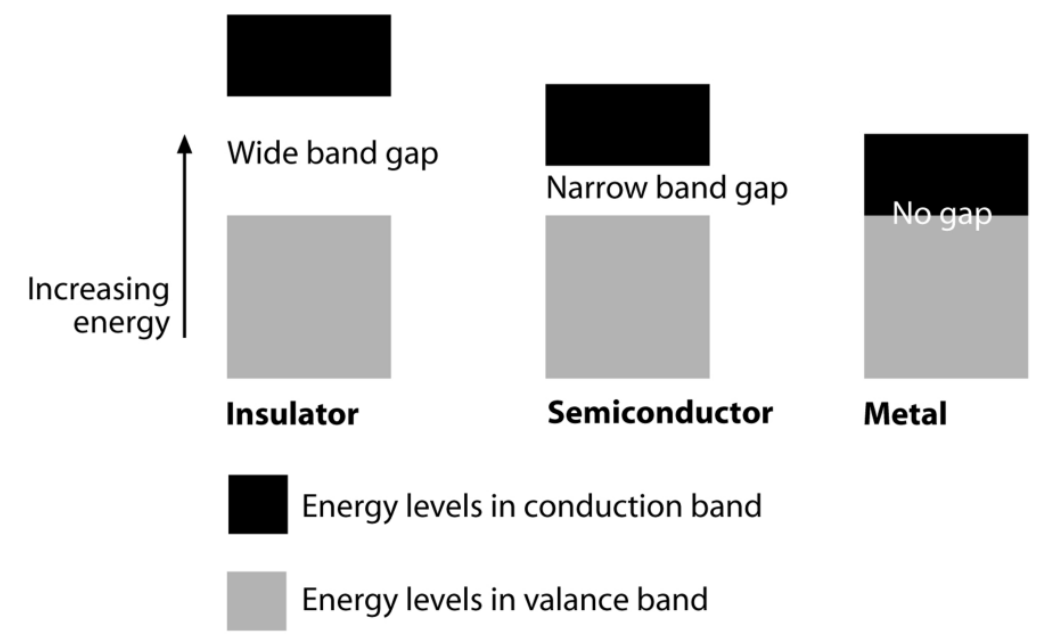

Figure 3.2. Diagram that shows the valence and the conduction band for an insulator, a semiconductor and a metal material. ${ }^{233}$

However, conducting polymers are peculiar because they conduct current without having a partially empty or partially filled band. Their electrical conductivity cannot be explained well by simple band theory. If an electron is removed from the top of the valence band of a conjugated polymer, a vacancy (hole or radical cation) is created and is not delocalized completely, as would be expected from classical band theory. Therefore, simple band theory fails to explain conductivity in polymers. Only partial delocalization occurs, extending over several monomeric units and causing them to deform structurally. The energy level associated with this radical cation represents a destabilized bonding orbital and, thus, has a higher energy than the energies in the valence band. In other words, its energy is in the band gap (see Figure 3.3). A radical cation that is partially delocalized over some polymer segment is called a polaron and it stabilizes itself by polarizing the medium around it, hence the name. If another electron is removed from the already oxidized polymer containing the polaron, two things can happen: this electron could come (a) from either a 
different segment of the polymer chain, thus creating another independent polaron, or (b) from the first polaron level to create a special dication (bipolaron). Low doping levels give rise to polarons, whereas higher doping levels produce bipolarons (Figure 3.3). The two positive charges of the bipolaron are not independent, but act as a pair. Both polarons and bipolarons are mobile and can move along the polymer chain by the rearrangement of double and single bonds in the conjugated system that occurs in an electric field. If many bipolarons are formed, their energies can start overlapping at the edges, which creates narrow bipolaron bands in the band gap (see Figure 3.3). Conduction by polarons and bipolarons is thought to be the dominant mechanism of charge transport in polymers with nondegenerate ground states. These concepts also explain very well the optical absorption changes seen in these polymers with doping. ${ }^{238}$ It is noteworthy that bulk conductivity in the polymer material is limited by the need for the electrons to jump from one chain to the next, that is to say, in molecular terms an intermolecular charge transfer reaction. ${ }^{233}$

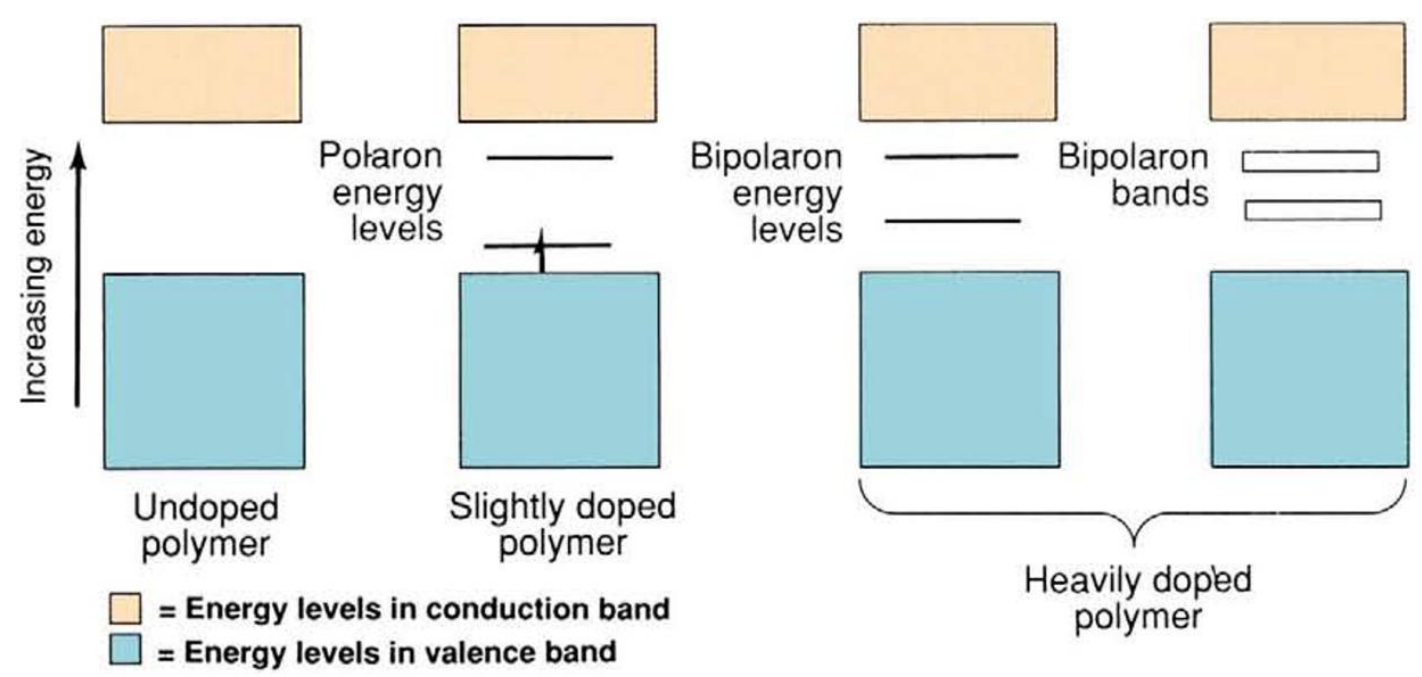

Figure 3.3. Diagram that shows the valence and the conduction band, and the presence of levels and bands in the band gap for different types of polymers. ${ }^{238}$ 


\subsubsection{Optical Properties}

The optical properties of conducting polymers are very important to understand their basic electronic structures. The $\pi$ conjugation in the polymers is implied by their color and their electronic spectra. Thus, spectroscopy is a powerful technique for characterizing the electronic processes that occur in the polymer in the undoped and doped states, as well as during doping. The changes of the optical spectra accompanying doping are significant, playing a key role in elucidating the mechanism of doping and the nature of the charge-storage species in the polymer chain. ${ }^{242}$

Undoped conjugated polymers have a band structure of a highly anisotropic semiconductor. However, a rigid band approach is not valid here, but the quasi-one-dimensional structure and the electron-phonon coupling lead to self-localized soliton, polaron and bipolaron excitations and give the conjugated polymers interesting optical properties. ${ }^{243}$

As can be inferred, spectroelectrochemistry, which allows us to obtain not only the electrochemical but also the spectroscopic evolution of an electrochemical process, has much to say in this research field.

\subsection{Applications}

\subsubsection{An Overview}

As is well known, conducting polymers are employed for several applications, some of which are mentioned below: 
- Conducting polymers are compatible with biological molecules, act as a suitable matrix for the entrapment of biological materials, and have the ability to transfer the electric charge produced by a biochemical reaction to the electronic circuit. Therefore, conducting polymers have been widely used for sensors and biosensors. ${ }^{24-247}$

- The use of conducting polymers and their composites for biomedical purposes is widely reported. ${ }^{248,249}$ For instance, the modification of metal electrode materials used in active implantable devices with conducting polymer coatings has been suggested as an approach for improving the neural tissue-electrode interface and increasing the effective lifetime of these implants. ${ }^{250}$

- Conducting polymers are flexible, highly conductive, easily processable and can be made into films, features that, along with their high specific capacities and capacitances and the ability to deliver energy at a relatively rapid rate, make them good materials for supercapacitor electrodes. ${ }^{251,252}$

- A broad range of uses including artificial muscles, ${ }^{253}$ photocatalysts for environmental protection, ${ }^{254}$ flexible light-emitting diodes, ${ }^{255}$ or touch panels ${ }^{256}$ can also be cited, along with the applications derived from the combination of conducting polymers and nanoparticles to form nanocomposites. ${ }^{257}$

- In addition, different applications concerning the joint use of carbon nanotubes and conducting polymers can be found in literature, such as transparent and flexible supercapacitors ${ }^{258}$ and batteries, ${ }^{259}$ among others. 


\subsubsection{Polyaniline}

Several applications of PANI (chemical structure displayed in Figure 3.4), are described in literature. Counter electrodes for solar cells, ${ }^{260,261}$ ultrafiltration membranes with antifouling properties, ${ }^{262}$ asymmetric hybrid capacitors, ${ }^{263}$ electrochromic devices, ${ }^{264,265}$ cardiac tissue engineering, ${ }^{266}$ corrosion inhibition and adhesion promotion, ${ }^{267}$ adsorbent agent, ${ }^{268}$ batteries $^{269,270}$ and fuel cells ${ }^{271}$ are some of them. The use of PANI for the development of sensors and biosensors is unquestionable. ${ }^{272-276}$

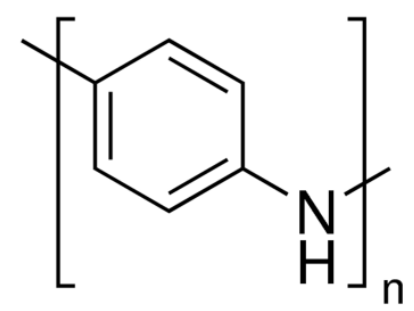

Figure 3.4. Chemical structure of PANI. ${ }^{277}$

The use of PANI and carbon nanotubes together has been applied to achieve different objectives, as for example, the development of supercapacitors with long cyclic stability and better capacitive characteristics than pure PANI and carbon nanotubes ${ }^{278}$ and the study of the electrochemical behavior and determination of medications. ${ }^{279}$

\subsubsection{Poly(3,4-ethylenedioxythiophene)}

PEDOT is one of the most used conducting polymers due to its exceptional properties, alone, or forming composites. ${ }^{227,280-282}$ As can be observed in 
literature, PEDOT (chemical structure shown in Figure 3.5) has been widely used for several applications such as thermoelectric materials to generate electricity by the touch of fingertips, ${ }^{283}$ supercapacitors, ${ }^{284}$ solar cells, ${ }^{285}$ light-emitting diodes, ${ }^{286}$ and, of course, for sensor applications, ${ }^{287,288}$ among many others. ${ }^{289,290}$

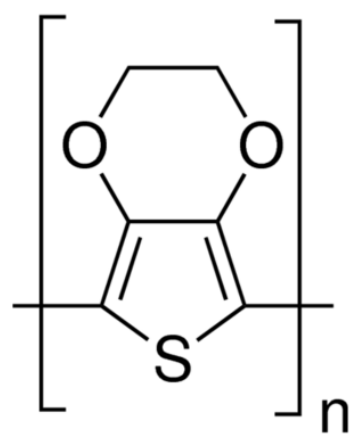

Figure 3.5. Chemical structure of PEDOT. ${ }^{291}$

In addition, the use of PEDOT together with carbon nanotubes is successful, as has been previously demonstrated for the development of sensing devices ${ }^{292}$ and for the improvement of the stability of microelectrodes in neural prostheses. ${ }^{293}$

\subsection{Poly(3-hexylthiophene)}

SECCM is a novel high-resolution imaging technique that allows researchers to obtain simultaneously electrochemical, conductance and topographical visualization of surfaces and interfaces using a thin meniscus or droplet at the end of a double-barreled pipette. ${ }^{294}$ This meniscus droplet constitutes a mobile, nanoscopic electrochemical cell that can be brought 
into contact with a surface for electrochemical (ion-transfer and electrontransfer) imaging with positional feedback. SECCM, introduced in 2010, ${ }^{295}$ has contributed to solve many problems and its potential to be a major technique in electrochemistry and interfacial science is clearly demonstrated, as can be inferred from the high-quality results obtained in several research fields, as for example, carbon materials and nanomaterials. ${ }^{131,161,169}$ Selecting and visualizing the behavior of different components and relating this activity to structure at the nanoscale is one of the many attractions of this creative technique.

The work, performed at the end of 2014, demonstrates the correlation between the morphology of electrochemical deposited P3HT films (see its chemical structure in Figure 3.6) and the corresponding photoelectrochemical activity. ${ }^{232}$

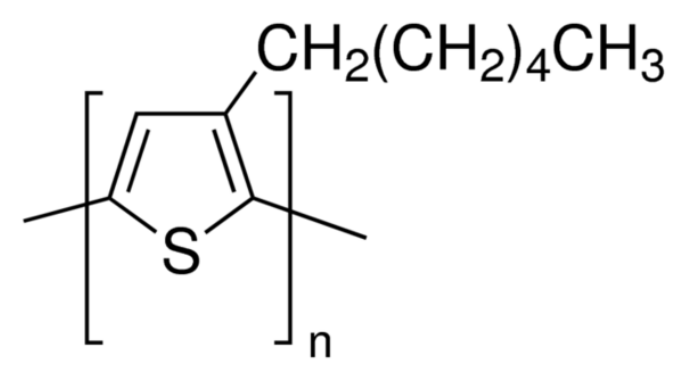

Figure 3.6. Chemical structure of $\mathrm{P} 3 \mathrm{HT}{ }^{296}$

With this objective, optically transparent gold electrodes were used and SECCM, Raman spectroscopy and AFM techniques were used to obtain as much information as possible, as can be observed in Figure 3.7. On the one hand, order and thickness were revealed by Raman spectroscopy and AFM, respectively. On the other hand, photocurrents were measured by switching a light-emitting diode off and on. 


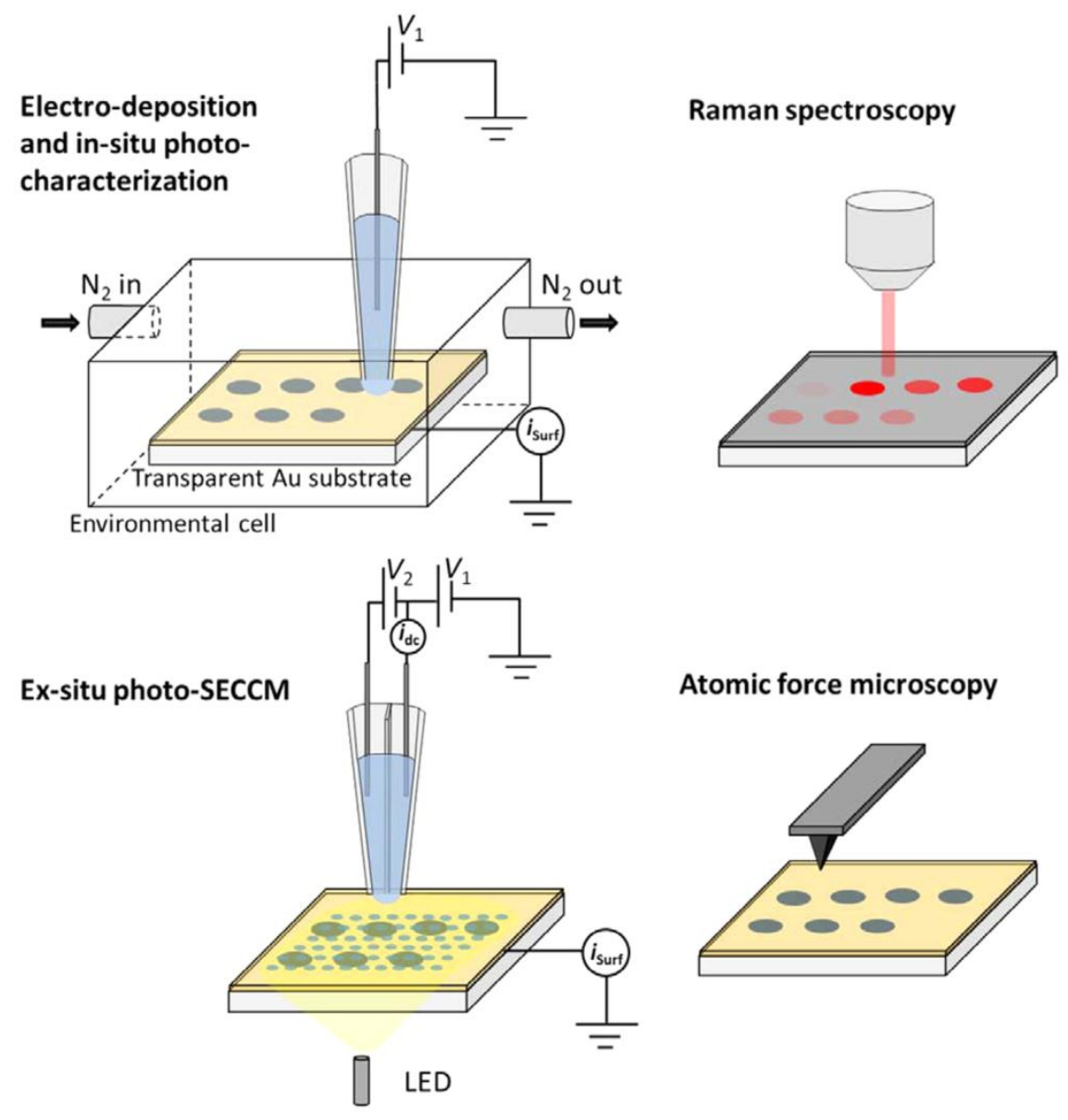

Figure 3.7. Schematic of the combinatorial multimicroscopy approach to the study of electrodeposited P3HT thin films. ${ }^{232}$

The potentiodynamic P3HT growth begins with a thin and ordered film after which a second disordered film is deposited. Firstly, photoelectrochemical activity was measured in situ immediately after the electrodeposition, being the thin and ordered films the most photoactive and showing a decrease or plateauing in the photoactivity for the thicker films which is attributed to an increase in bulk film disorder. Secondly, higher-resolution photoelectrochemical activities were obtained using ex situ SECCM, allowing us to distinguish local photoactivity variations for each P3HT film. Thin and ordered regions of a P3HT deposit exhibit higher 
photocurrents than thicker and more disordered regions for the same P3HT deposit.

This work, performed in close collaboration with Barak D. B. Aaronson and Joshua C. Byers, under the supervision of Patrick R. Unwin and the support from the Instrumental Analysis group, allowed me to know the way of working of another research group in a foreign country, something personally and scientifically remarkable. 
4. Molecules of Biological

Interest 



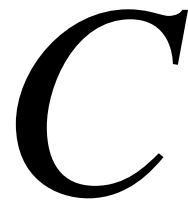

omo grandes protagonistas de la investigación desde tiempos inmemoriales pueden ser encontradas a nuestro alrededor y también en nuestro interior. Están presentes en la flora y la fauna. En el aire que nos rodea y en los alimentos que saboreamos. En la más simple bacteria y en los seres más evolucionados. En el fondo del mar, en la superficie terrestre y en la cúspide más elevada. En la naturaleza y en los laboratorios, valga la "redundancia”.

Forman parte de nuestro cuerpo físico llegando a habitar en lo más profundo de nosotros mismos. Tal vez sean incluso capaces de lograr un delicado esculpido del espíritu, un sonoro cincelado del alma. ¿Dónde está el origen, el verdadero comienzo de cada emoción que experimentamos? ¿Serán los sentimientos un simple alboroto de moléculas de interés biológico?

Estos compuestos químicos, minúsculos y descomunales, escurridizos y estructurales, son los responsables de muchos de los procesos que tienen lugar en los ecosistemas, así como de la evolución de los mismos. Sin ir más lejos, las reacciones químicas que tienen lugar entre ellos posibilitan, nada más y nada menos, que podamos vivir lo que vivimos.

Debemos dar nuestras más sinceras gracias a todas las sustancias responsables de la vida. Sin embargo, no nos queda opción alguna más que luchar intensamente contra las que ejercen efectos adversos sobre nuestro organismo y perjudican la salud del hábitat que nos rodea. De un modo u otro, teniendo en cuenta todos sus poderes, capacidades, obligaciones y responsabilidades, bien se merecen que las estudiemos. Que las analicemos. Que las cuantifiquemos por diferentes medios. Que las determinemos en ambientes dispares. Que las utilicemos para sacar lo mejor de cada una de ellas. Que se sientan útiles, orgullosas de todas sus funciones. Que las mimemos. Que las manejemos éticamente para aportar un bienestar común a todos los seres vivos de nuestro cercano y lejano entorno. 



\subsection{Why This Chapter?}

Several molecules of biological interest have been studied by spectroelectrochemistry techniques in these last years, namely hydroquinone, glutamic acid, levodopa, adrenaline, noradrenaline, among others, and especially the results obtained with catechol, dopamine and ascorbic acid are shown in this doctoral thesis (sections 6.4, 6.6, 6.7 and 6.8). ${ }^{30,31,76,77}$ As can be inferred, this chapter is devoted to these compounds, particularly catechol, dopamine, and ascorbic acid, because the results obtained with them by experimental studies are widely explained in the research results section of this doctoral thesis.

Once the proper performance of the spectroelectrochemistry devices fabricated with carbon-based electrodes and optical fibers was demonstrated using conducting polymers and/or redox probes, they are ready to be used for the study and determination of compounds of biological interest both in aqueous solutions and complex samples. As can be observed in the corresponding chapters, SWCNTs electrodes and bare optical fibers make a good team for the study of the reaction mechanisms of these molecules and for their quantification by univariate and multivariate analysis using the electrochemical and the spectroscopic signals obtained by spectroelectrochemistry along with statistical tools.

It should be noted that this chapter provides information about the different key roles of catechol, dopamine, and ascorbic acid, trying to give an overview about why these compounds are part of the family of molecules of biological interest. In addition, information about their possible determination methods, emphasizing previous electrochemical and, if possible, spectroelectrochemistry studies are shown below. 


\subsection{Catechol}

\subsubsection{Biochemical Roles}

Although this section is dedicated to catechol, also called pyrocatechol (see Figure 4.1), it is more interesting to make this brief introduction about the biochemical roles of catechols in general.

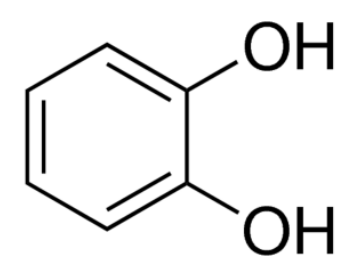

Figure 4.1. Chemical structure of catechol. ${ }^{297}$

Catechols are benzene derivatives with two neighboring hydroxyl groups that are widely present in nature. Clear examples are catecholamine neurotransmitters, such as dopamine, adrenaline and noradrenaline, a kind of molecules that fulfill essential biochemical roles. Observing the chemical structure of the catechol ring, it should be noted that it is a reactive species able to act as a weak acid and as a reducing agent easily oxidizable. In addition, the two hydroxyl groups in vicinal positions are ideal for bidentate coordination, hydrogen bonding, and interaction with surfaces of different chemical and physical nature. This remarkable potential has its own downside. Despite the apparent simplicity, catechol chemistry is challenging and functional molecules designed accordingly usually need careful manipulation prior to be used. ${ }^{298}$ 
Catechols can be found as simple molecular systems, in supramolecular structures, coordinated to different metal ions or as macromolecules mostly arising from polymerization mechanisms through covalent bonds. Such versatility has allowed catechols to participate in several natural processes and functions that range from the adhesive properties of marine organisms to the storage of some transition metal ions. ${ }^{298}$ Undoubtedly, catechols play an important role in many natural systems, being essential in living organisms such as mussels, sandcastle worms and squids. A famous example is the mussel that secretes water-resistant adhesive proteins containing levodopa, a catechol-containing compound. ${ }^{299}$ Catechols are also important in food processing such as cocoa fermentation and tea preparation. $^{300}$

As can be inferred, catechol derivatives can be found as active species in a variety of environments, displaying a remarkable degree of chemical and physicochemical versatility and inspiring lots of applications as functional materials. $^{298}$

Specifically, with respect to catechol, resorcinol, and hydroquinone (1,2dihydroxybenzene, 1,3-dihydroxybenzene, and 1,4-dihydroxybenzene, respectively), it is worth noting that these three dihydroxybenzene isomers are commonly used in cosmetics, tanning, pesticides, flavoring agents, medicines, antioxidant, dye, and photography chemicals. However, they are considered as environmental pollutants by the United States Environmental Protection Agency and the European Union due to their high toxicity and low degradability in the ecological environment. ${ }^{301}$ In addition, taking into account these applications, it is easy for them to enter into the environments, existing in industrial effluents and sanitary wastewater. ${ }^{302}$ As can be inferred, their study and determination is necessary. 


\subsubsection{Previous Electrochemical and UV-Vis Spectroelectrochemical Studies}

There are several previous works that allow the determination of catechol using different methodologies among which electrochemistry stands out. The determination of catechol, in many cases in the presence of other similar compounds or potential interfering species, has been performed using graphene, ${ }^{302-304}$ carbon nanotubes, ${ }^{305,306}$ electrospun carbon nanofibers, ${ }^{307}$ PEDOT, ${ }^{308}$ molecularly imprinted polymer-conducting polymer hybrids, ${ }^{309}$ electrochemically synthesized particles, ${ }^{310}$ or biosensors. $^{311}$

Despite of the advantages of UV-Vis absorption spectroelectrochemistry, this powerful technique has been rarely used and few references can be found in literature for the direct study of catechol. Some works include the observation of the absorbance of the oxidation products of catechol around $400 \mathrm{~nm},{ }^{312}$ the monitoring of reaction mechanisms in which catechol is involved, ${ }^{313}$ and the evolution of the whole UV-Vis absorption spectra during the oxidation of catechol. ${ }^{314,315}$ Nevertheless, and taking into account the research framework of the previous cited papers, the deep study of catechol and its determination using spectroelectrochemistry were not the main objectives of these works.

For this reason, during these last years, and although it is not part of the research results section, the detection of catechol using press-transferred SWCNTs electrodes and bare optical fibers was performed. ${ }^{192}$ In this work, a new long optical path length spectroelectrochemistry cell for UV-Vis absorption spectroelectrochemistry was developed to quantify catechol by potentiodynamic and potentiostatic measurements, making use of 
univariate and multivariate calibrations. As can be observed in Figure 4.2, voltabsorptometry helped to understand the mechanism of catechol oxidation in $\mathrm{pH} 7$, showing that the main oxidation product is $o$ benzoquinone, but that other soluble side products are also generated. In addition, catechol was also determined in the presence of hydroquinone at $\mathrm{pH} 2$, demonstrating the usefulness of UV-Vis absorption spectroelectrochemistry to resolve complex mixtures even without information about the amounts of interfering compounds.

a

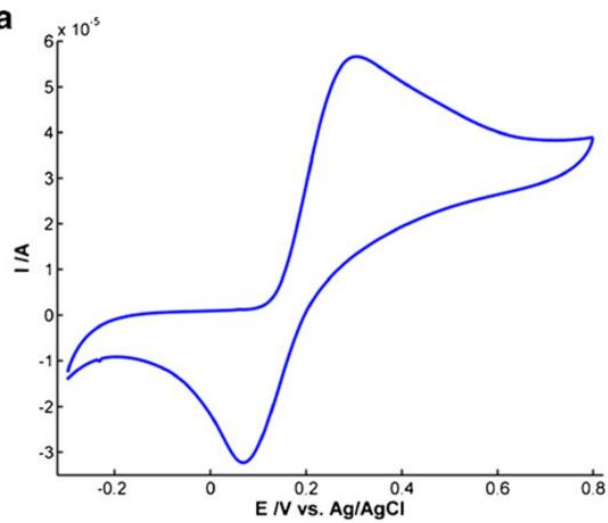

b

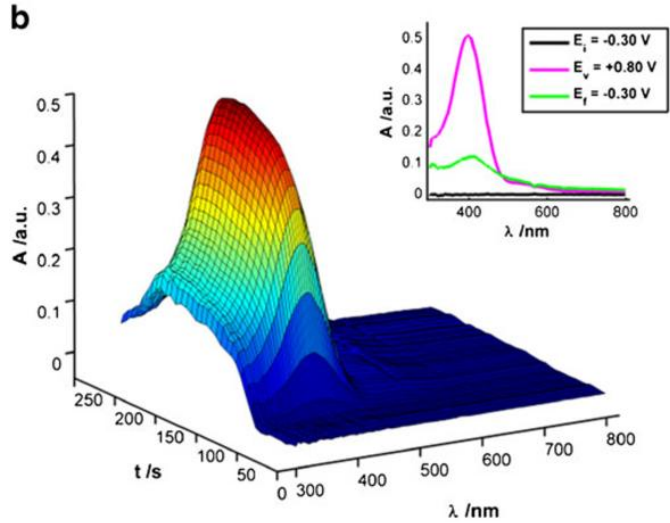

C

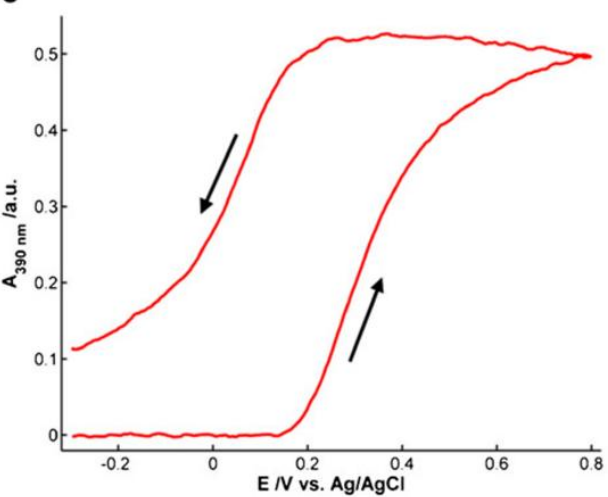

d

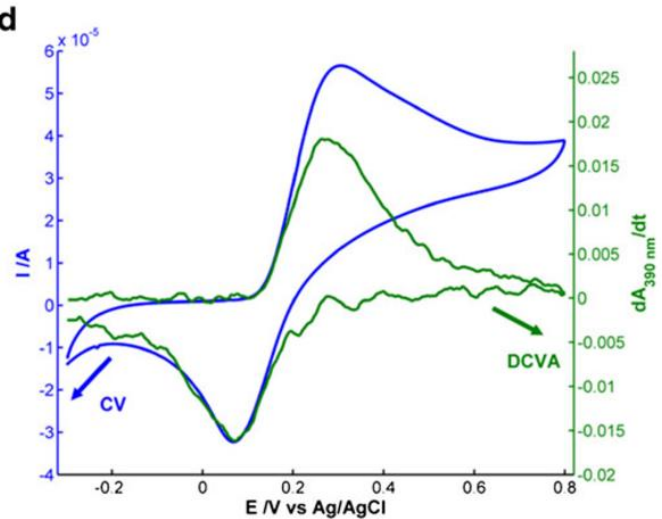

Figure 4.2. (a) Cyclic voltammogram, (b) spectra evolution, (c) voltabsorptogram at $390 \mathrm{~nm}$, and (d) comparison between derivative voltabsorptogram at $390 \mathrm{~nm}$ and cyclic voltammogram. Inset: spectra at the initial $\left(E_{i}\right)$, vertex $\left(E_{v}\right)$, and final potential $\left(E_{f}\right)$. All signals were registered during oxidation of catechol $10^{-3} \mathrm{M}$ in PBS buffer media (pH 7). $E_{i}=E_{f}=-0.30 \mathrm{~V}, E_{v}$ $=+0.80 \mathrm{~V}$, scan rate $=0.01 \mathrm{~V} \cdot \mathrm{s}^{-1} .192$ 
As a continuation of this work and in order to show all the capabilities of spectroelectrochemistry techniques, in this doctoral thesis we propose the quantitative resolution of complex mixtures of catechol and dopamine by spectroelectrochemistry (section 6.6). ${ }^{30}$

\subsection{Dopamine}

\subsubsection{Biochemical Roles}

Figure 4.3 shows the chemical structure of dopamine. This biomolecule is a monoamine catecholamine neurotransmitter whose roles are really interesting due to its importance in behavior, cognition, attention, movement, endocrine, cardiovascular, renal, gastrointestinal and immune functions. ${ }^{316,317}$

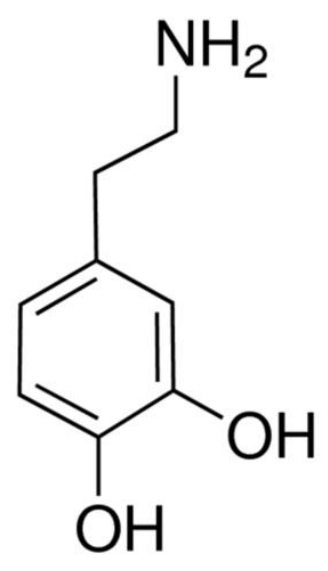

Figure 4.3. Chemical structure of dopamine. ${ }^{318}$ 
What things are good and what things are bad? How can I gain the good things and how can I avoid the bad ones? Dopamine is very important in motivational control, to learn what things in the world are good and bad, and to choose the proper actions to gain the good things and to avoid the bad ones. ${ }^{319}$

The major sources of dopamine in the cerebral cortex and in most subcortical areas are the dopamine-releasing neurons of the ventral midbrain, located in the substantia nigra pars compacta and ventral tegmental area, which transmit dopamine in two modes: ${ }^{319}$

- Tonic mode: dopamine neurons maintain a steady, baseline level of dopamine in downstream neural structures that is vital for enabling the normal functions of neural circuits.

- Phasic mode: dopamine neurons sharply increase or decrease their firing rates for 100-500 ms, causing large changes in dopamine concentrations in downstream structures lasting for several seconds.

Figure 4.4 shows a dopaminergic neuron with its two types of projections attached to the cell body: dendrites and an axon. As can be observed, dopamine can be released at the terminal end of the axon and received by the dendrites of neighboring neurons. Dopamine (purple circles) is synthesized from tyrosine in the neuron and then packaged into vesicles. Neurotransmitter release is initiated by an electrical impulse (action potential or firing) that propagates down the axon to the terminals at a rate of $0.5 \mathrm{~m} \cdot \mathrm{s}^{-1}$, where neurotransmitters relay information to target cells when the vesicles release their contents into the synapse. The extracellular concentration of neurotransmitter depends on the number of vesicles 
released and the amount of neurotransmitter in each vesicle. Dopamine can diffuse out of the synapse, interact with receptors, or be taken up by the dopamine transporter which controls uptake into neurons by pumping dopamine from the extracellular space. ${ }^{320}$

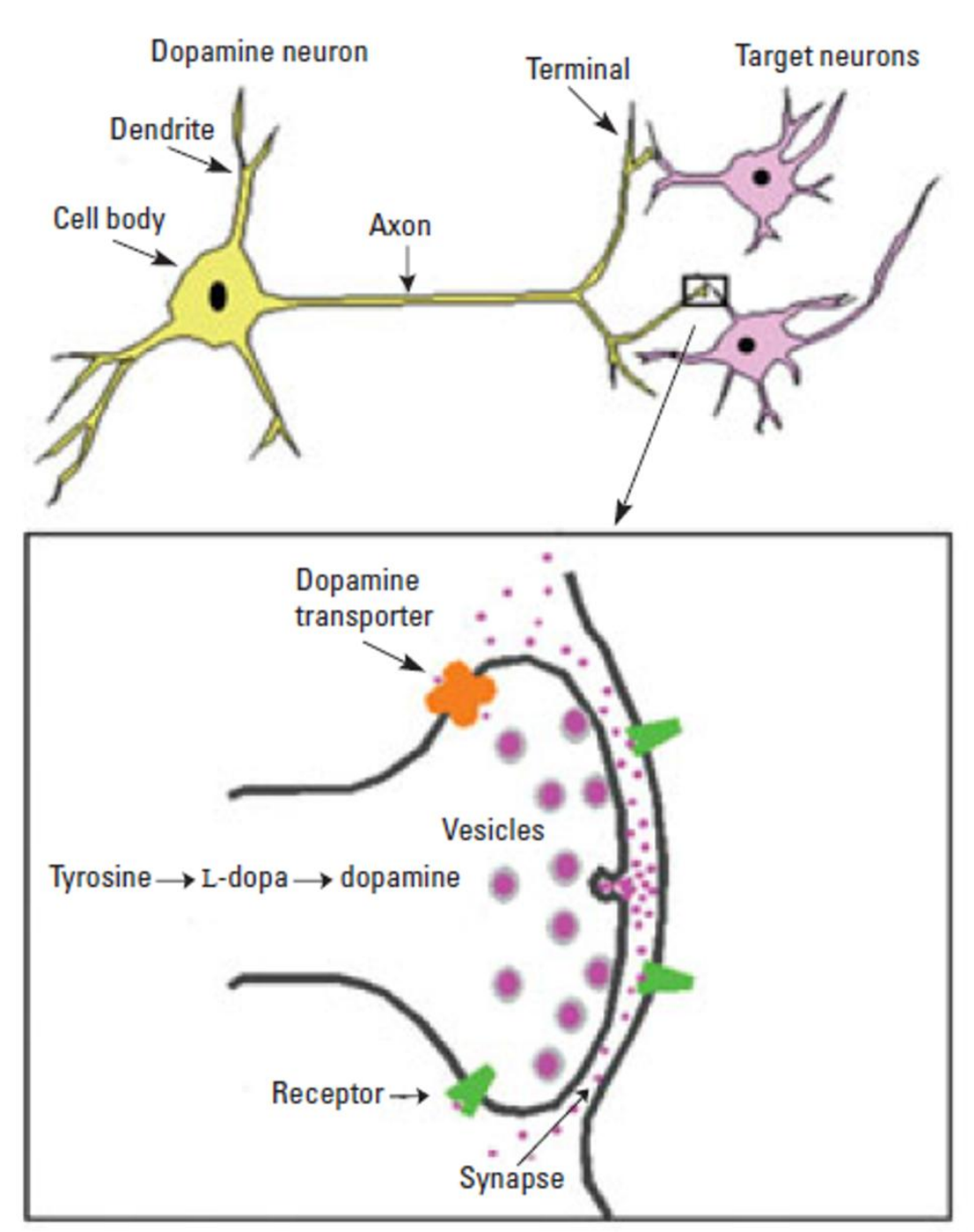

Figure 4.4. Schematic of a dopaminergic neuron. ${ }^{320}$

As can be inferred, abnormal dopamine levels are associated with diseases with high prevalence in the world today, such as schizophrenia ${ }^{321}$ and Parkinson's disease. ${ }^{320,322}$ 


\subsubsection{Schizophrenia}

Schizophrenia is a severe mental and treatable disorder that affects more than 21 million people worldwide, of which more than half do not receive appropriate care for the condition. As the World Health Organization indicates, ${ }^{323}$ schizophrenia is characterized by distortions in thinking, language, perception, emotions, sense of self, and behavior. It often includes psychotic experiences, such as hearing voices and delusions, and is associated with considerable disability, affecting educational and occupational performance.

Dopamine is involved in many abnormal functions associated with schizophrenia, including psychosis, cognitive decline, and reward mechanisms. The striatum of schizophrenia patients displays augmentation of presynaptic dopamine function, indicating an increase in dopamine synthesis capacity and/or an increase in presynaptic dopamine stores. ${ }^{321}$ There is substantial evidence that the dopamine system is hyper-responsive in schizophrenia. All antipsychotic drugs in use today block dopamine D2 receptors at clinically effective doses. Moreover, drugs that drive dopamine release or increase dopamine transmission, such as amphetamine and levodopa, will exacerbate psychosis in patients with schizophrenia and can induce schizophrenia-like symptoms in control individuals if given repeatedly or at high doses. ${ }^{324}$

Schizophrenia can be summarized as a dopamine dysregulation in the context of a compromised brain. The current studies about schizophrenia offer a hypothesis that links risk factors, including pregnancy and obstetric complications, stress and trauma, drug use, and genes, to increased presynaptic striatal dopaminergic function. ${ }^{325}$ 


\subsubsection{Parkinson's Disease}

Parkinson's disease is a common neurodegenerative movement disorder that has an age-dependent prevalence. Around $1 \%$ of the population is affected at 65 years and this percentage is increased to $4-5 \%$ at 85 years. The mean age of onset is 70 years, although $4 \%$ of patients develop earlyonset disease, before the age of $50 .{ }^{326}$

Parkinson's disease is considered a multifactorial disorder that arises owing to a combination of genes and environmental factors. Clinically, it is characterized by motor dysfunction (resting tremor, bradykinesia, rigidity and postural instability). Nonmotor features (dysautonomia, depression, sensory loss and sleep disturbance) are difficult to treat and often manifest before motor disability. Mild cognitive impairment and subsequent dementia is common. ${ }^{326}$

The main pathological feature of this disorder is the pronounced loss of dopamine-producing neurons in the substantia nigra pars compacta, which results in a drastic depletion of dopamine in the striatum, to which these neurons project. ${ }^{322}$ In Parkinson's disease, the loss of dopamine-containing neurons in the midbrain is progressive and affects different parts of the nigral complex to different degrees, the most severe loss occurring in the ventrolateral part of the substantia nigra pars compacta. $^{327}$ For a neuropathological diagnosis of Parkinson's disease, neuronal loss in the substantia nigra pars compacta must be evident, accompanied by Lewy body pathology in surviving neurons. ${ }^{326}$

The standard treatment of Parkinson's disease is based on the administration of levodopa and/or dopamine receptor agonists, resulting in 
an often spectacular improvement in the motor signs of this disease in the vast majority of patients. ${ }^{317}$

\subsubsection{Previous Electrochemical and $\mathrm{UV}-\mathrm{V}$ is Spectroelectrochemical Studies}

As can be inferred, dopamine generates a great interest in the electrochemist community to develop different methods to achieve its determination. $^{328}$ Carbon nanomaterials, such as graphene, ${ }^{329}$ carbon quantum dots, ${ }^{330}$ and carbon nanotubes, ${ }^{331,332}$ have been commonly used to reach this objective, as well as nanoparticles. ${ }^{333}$ It should be noted the importance of chemically modified electrodes to detect dopamine in the presence of electroactive interfering species also present in biological samples, such as uric acid and ascorbic acid, which have very similar oxidation potentials and their concentrations are sometimes several hundred to thousand times higher than dopamine. ${ }^{334}$

Previous UV-Vis absorption spectroelectrochemical experiments about the direct study of dopamine have demonstrated how the spectra evolves during its electrochemical reaction, ${ }^{335,336}$ and the abilities of spectroelectrochemistry to determine oxidation rates by monitoring the absorbance at one wavelength related to dopaminequinone. ${ }^{337} \mathrm{~A}$ work performed in the research group using screen-printed electrodes allowed not only the study of the oxidation mechanism of dopamine but also its spectroelectrochemical detection using the electrochemical and the spectroscopic responses and univariate and multivariate analysis. ${ }^{19}$ 
Different works related to dopamine using UV-Vis absorption spectroelectrochemistry have been performed in this doctoral thesis, including the simultaneous study of the UV-Vis absorption and Raman dispersion spectra evolution of the electrochemical reaction of dopamine on SWCNTs electrodes (section 6.4) ${ }^{76}$ and the quantitative determination of complex mixtures of catechol and dopamine using multivariate analysis (section 6.6). ${ }^{30}$

\subsection{Ascorbic Acid}

\subsubsection{Biochemical Roles}

Structurally, ascorbic acid is one of the simplest vitamins (see Figure 4.5). There is a delocalization of the $\pi$ electrons over the $\mathrm{C}_{2}-\mathrm{C}_{3}$ conjugated enediol system that stabilizes the molecule and causes the hydrogen of the $\mathrm{C}_{3}$ hydroxyl to become highly acidic $\left(\mathrm{pK}_{\mathrm{a}}=4.13\right)$. Therefore, at physiological $\mathrm{pH}$, ascorbic acid exists as ascorbate monoanion. ${ }^{338}$

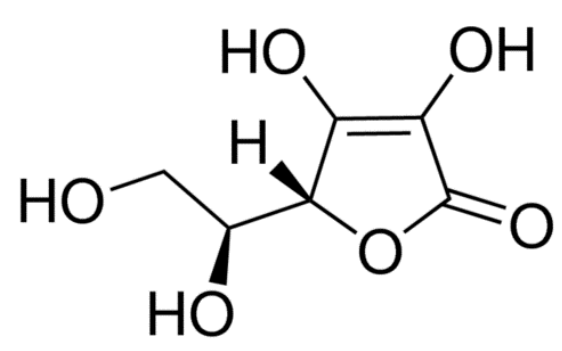

Figure 4.5. Chemical structure of ascorbic acid. ${ }^{339}$ 
Three main biological activities are related to ascorbic acid: ${ }^{338}$

- Function as an enzyme cofactor. Ascorbic acid, in both plant and animal metabolism, modulates important enzymatic reactions maintaining the transition metal ion centers of these enzymes in a reduced form.

- Function as a radical scavenger. Ascorbic acid scavenges reactive species protecting protein and DNA from oxidative damage.

- Function as a donor/acceptor in electron transport either at the plasma membrane or in the chloroplasts.

In general, amphibians, reptiles, birds, and mammals are capable of synthesizing ascorbic acid. A few mammalian species including primates, humans and guinea pigs have lost this capability due to a lack of the terminal, flavo-enzyme, L-gulono-1,4-lactone oxidase. ${ }^{338}$

Therefore, ascorbic acid in the form of fresh fruits, vegetables, or vitamin supplements is an essential nutrient in the human diet because human beings lack the ability to produce ascorbic acid. The sentence "an orange a day keeps the doctor away" should always be remembered. ${ }^{340}$

As is known, the ascorbic acid status of humans influences many metabolic systems, including lipid, steroid and peptide metabolism, collagen synthesis, the immune system, endocrine function, control of blood pressure, iron and copper balance, haemostasis, endothelial function and fatty acid transport. The biochemical mechanism of ascorbic acid action in the different systems appears to be related to its antioxidant properties. ${ }^{338}$ 


\subsubsection{Scurvy}

Scurvy is a disease as old as human existence. It is predominantly connected in history with the voyages of navigators, sailors and explorers of the 15th and 16th centuries. The observations of navigators during these centuries, when scurvy plagued ships' crews, played an important role in clarifying scurvy's etiology. James Lind, for conducting the first clinical trial on the treatment of scurvy with lemon and orange juices, and Albert Szent-Györgyi, for discovering and identifying vitamin C, are two of the most important personalities in the history of this disease. ${ }^{341}$

Nowadays, scurvy tends to become a forgotten disease in developed countries. Nevertheless, rare cases occur especially in people undergoing extreme diet, old people or children with poor diet and patients with malabsorption. Other risk patients are those associated with precarious situations, individuals with allergies to fruits and vegetables, patients with psychiatric disorders or excessive alcohol consumption, persons with gastrointestinal diseases, bariatric surgery, cancer patients on chemotherapy and patients on hemodialysis. ${ }^{342}$

The manifestations of scurvy take place when the body pool of ascorbic acid, normally about $1500 \mathrm{mg}$, falls below $300 \mathrm{mg}$. A serum level below 2 $\mathrm{mg} \cdot \mathrm{L}^{-1}$ suggests scurvy. The earliest symptom of scurvy, occurring only after many weeks of deficient intake, is fatigue. Patients with scurvy exhibit various manifestations: emaciation, myalgias, follicular purpura with hyperkeratosis, spontaneous hematomas, hemorrhages, edema of the legs, ulcerative gingivitis, chronic periodontitis, anemia, cotton-wool spots at the ocular fundus, bone pain, gastrointestinal symptoms and heart failure. ${ }^{342,343}$ 
The recommended requirement of vitamin $\mathrm{C}$ is $75 \mathrm{mg}$ per day for women and $90 \mathrm{mg}$ per day for men. As scurvy can lead to severe complications, nothing should delay vitamin $\mathrm{C}$ supplementation, which is a simple and rapidly effective treatment. ${ }^{342}$

\subsubsection{Previous Electrochemical and UV-Vis Spectroelectrochemical Studies}

The determination of ascorbic acid by electrochemistry is widely known. In fact, an overview of several electrochemical methods for the ascorbic acid determination can be found in a recent review. ${ }^{344}$

However, as it usually happens, there are not many works that use UV-Vis absorption spectroelectrochemistry for the direct study of ascorbic acid. One of the main reasons could be the difficulty to find high-quality devices able to observe the spectral response during the electrochemical reaction in the UV region where the spectral changes take place in this case. It should be highlighted the importance of an article from 1988 about a spectroelectrochemistry device based on optical fibers in normal reflection arrangement capable of roughly observing the spectroscopic changes related to the potentiostatic oxidation of ascorbic acid in gels with presence of dopamine and in animal tissues. ${ }^{345}$ Figure 4.6 is displayed below to show the high degree of inspiration of this work for the present doctoral thesis. Other works include information about ascorbic acid radical species ${ }^{346,347}$ and the evolution of the spectra of an ascorbic acid solution applying different specific potentials. ${ }^{348}$ Finally, it should be noted that the quantification of ascorbic acid has been performed using this in situ technique in an indirect way by using a mediator. ${ }^{349}$ 

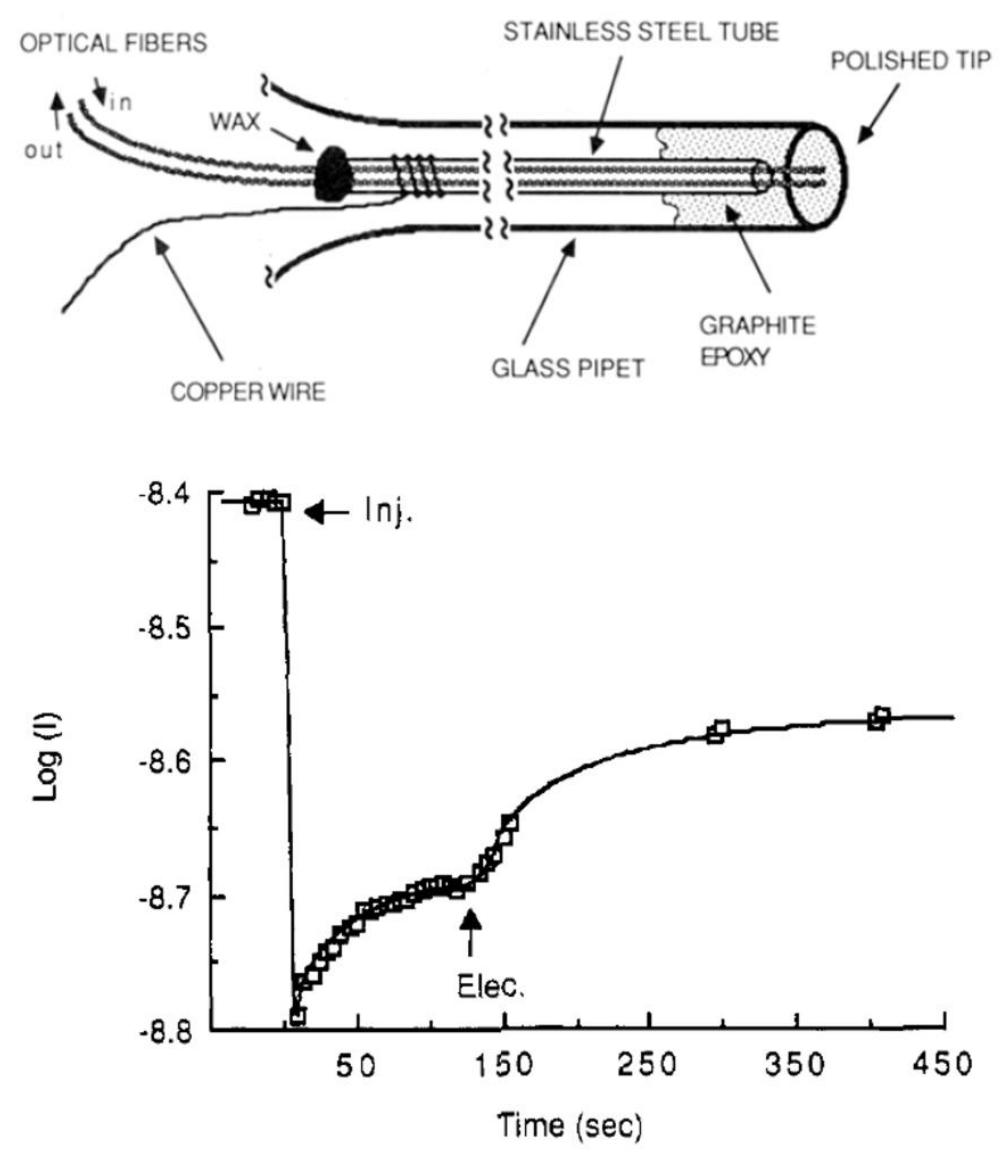

Figure 4.6. (a) Schematic representation of the spectroelectrochemical microprobe. (b) Spectral response at $265 \mathrm{~nm}$ obtained from the central region of an isolated dog brain, after the injection of $10 \mu \mathrm{L}$ of a $10 \mathrm{mM}$ ascorbate solution at the probe tip and after the initiation of a potential step to $+0.5 \mathrm{~V}$. The $y$ axis is the log of PMT photocurrent (in amps). ${ }^{345}$

In this doctoral thesis, after performing an exhaustive study of ascorbic acid by spectroelectrochemistry and demonstrating the abilities of this technique to monitor the evolution of $\mathrm{pH}$ at the electrode-solution interface during its electrochemical reaction (section 6.7$),{ }^{77}$ we propose the direct determination of this biomolecule in a complex matrix such as a grapefruit (section 6.8). ${ }^{31}$ 


\section{Experimental Section}





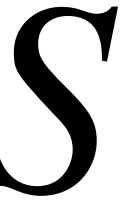

in los medios adecuados para trabajar, léase equipos de investigación y mano de obra cualificada, hacer ciencia es verdaderamente complicado. La investigación necesita de una instrumentación puntera, de unos materiales de vanguardia, de unas instalaciones preparadas y de un personal formado con ganas de trabajar, aprender y descubrir nuevas cosas. Una mezcla de todos estos ingredientes es fundamental para que la ciencia consiga obtener resultados.

Por supuesto, cada uno de nosotros debemos aportar nuestro granito de arena a la causa. Sin embargo, esta reflexión está especialmente dedicada a todas las personas en cuyas manos está la posibilidad de dotar a las universidades, centros de investigación o empresas de los medios adecuados para optimizar recursos y así obtener resultados «rentables», entre comillas, famoso signo ortográfico comúnmente empleado al hablar de rentabilidad en ciencia. Es francamente triste observar la presencia de equipos de desorbitantes precios empolvados, sin utilizar por falta de personal, al igual que conocer a personas luchando por su salario y sin poder realizar ciertos experimentos por falta de medios en algunas ocasiones. Con toda seguridad, una solución a estos despropósitos consiste en aumentar la inversión en ciencia. ¡Se necesita invertir dinero en ciencia! La cantidad de resultados que podrían derivarse de la compra de más y mejores instrumentos así como de la contratación de un mayor número de investigadores es incuestionable.

Mirándonos a nosotros mismos, cabe decir que los científicos debemos valorarnos más, dar a conocer al resto del mundo lo que hacemos y hacer hincapié en la necesidad de nuestro trabajo para el bienestar de la población. En ocasiones, el sentimiento de pasión que ponemos en nuestra actividad diaria nos hace precisamente olvidar que es eso, un trabajo, un trabajo con el que todo el mundo se beneficia a corto, medio y largo plazo. Como bien dice el refrán, «el que no llora, no mama». Eso sí, hay que llorar como se debe en cada situación. 



\subsection{Introduction}

According to the different methodologies used during this work, the general idea of this experimental section can be summarized as follows.

On the one hand, a potentiostat/galvanostat, coupled with the spectroelectrochemistry cell, applies and records the electrical signal throughout the experiment. On the other hand, a light beam, provided by a light source, is collected with optical fibers and sent to the spectroelectrochemistry device. After sampling the system under study, whose characteristics are modified thanks to the electrical signal, the light beam is conducted with another optical fiber to the spectrometer, where the spectral changes are recorded at any time of the experiment. Therefore, we need, at least, a potentiostat/galvanostat, a light source, several optical fibers, a spectroelectrochemistry cell, and a spectrometer.

The potentiostat/galvanostat and the spectrometer are properly synchronized by using a trigger. This fact allows us to guarantee the simultaneous character of all spectroelectrochemistry experiments, enabling us to know exactly the spectra evolution for each potential/time of the electrochemical experiment. As might be expected, several experimental conditions can be easily selected, for instance, the electrochemical parameters of the potentiostat/galvanostat, the lamps of the light source, the type of the optical fibers used, the arrangement of the spectroelectrochemistry cell (normal, parallel, or bidimensional configuration with respect to the electrode surface) as well as its design, and the integration time for the spectrometer (typically in the order of milliseconds). 
Millions of data are usually acquired in a single spectroelectrochemistry experiment. Therefore, software programs powerful enough to analyze this huge amount of information are required, such as MATLAB and R.

\subsection{Instrumentation}

The most common instruments employed during this work to perform spectroelectrochemistry experiments are described below. Although other instruments have been used in some other cases, and are indicated in the corresponding section, their functional principles and main features are the same as those shown below.

\subsubsection{Potentiostat/Galvanostat}

The potentiostat/galvanostat is a device that is coupled with the spectroelectrochemistry cell to control the electrochemical reaction by using, commonly, a three-electrode cell. In this case, the potential is controlled between the WE and the RE, while the current is measured between the WE and the CE.

The potentiostat/galvanostat employed in this work is the model PGSTAT302N $^{350}$ from Metrohm Autolab, ${ }^{351}$ Figure 5.1, controlled by GPES software. Its maximum current is $2 \mathrm{~A}$ and its current resolution is 30 $\mathrm{fA}$ at a current range of $10 \mathrm{nA}$. This device has a potential range of $\pm 10 \mathrm{~V}$ and nine different current ranges from $10 \mathrm{nA}$ to $1 \mathrm{~A}$. 


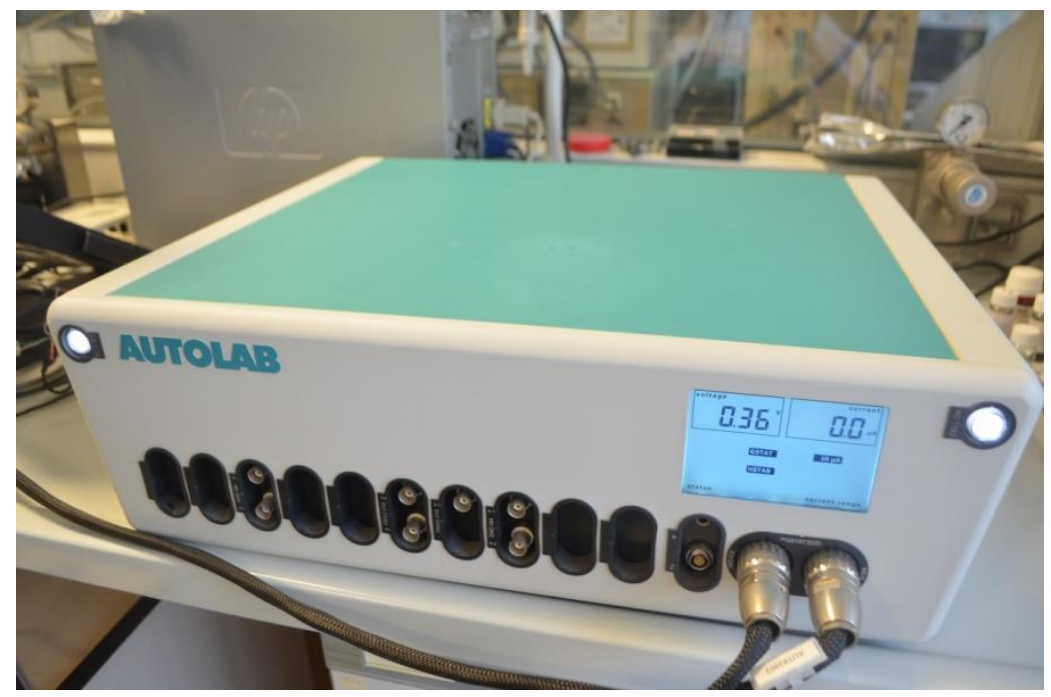

Figure 5.1. Photograph of the PGSTAT302N potentiostat/galvanostat from Metrohm Autolab.

\subsubsection{Light Source}

The light source is required to provide the light beam that follows the spectroscopic evolution of the electrochemical process. Depending on the spectral range needed, different light sources can be used. For UV-Vis absorption spectroelectrochemistry, a deuterium-halogen light source is required to cover the wavelength range from 200 to $800 \mathrm{~nm}$.

In our case, the model AvaLight-DH-S-BAL ${ }^{352}$ from Avantes ${ }^{353}$ (Figure 5.2) has been used. It is a deuterium-halogen continuous light source whose highest stability is in the UV, visible, and NIR range, from 215 to $2500 \mathrm{~nm}$. As is known, the spectrum of deuterium light sources shows numerous peaks, with a prominent one at $656 \mathrm{~nm}$. In order to minimize this peak in particular, a dichroic filter is incorporated by this balanced light source. The connection to the optical fiber is done through a SMA-905 connector, which features an adjustable focusing lens assembly. 


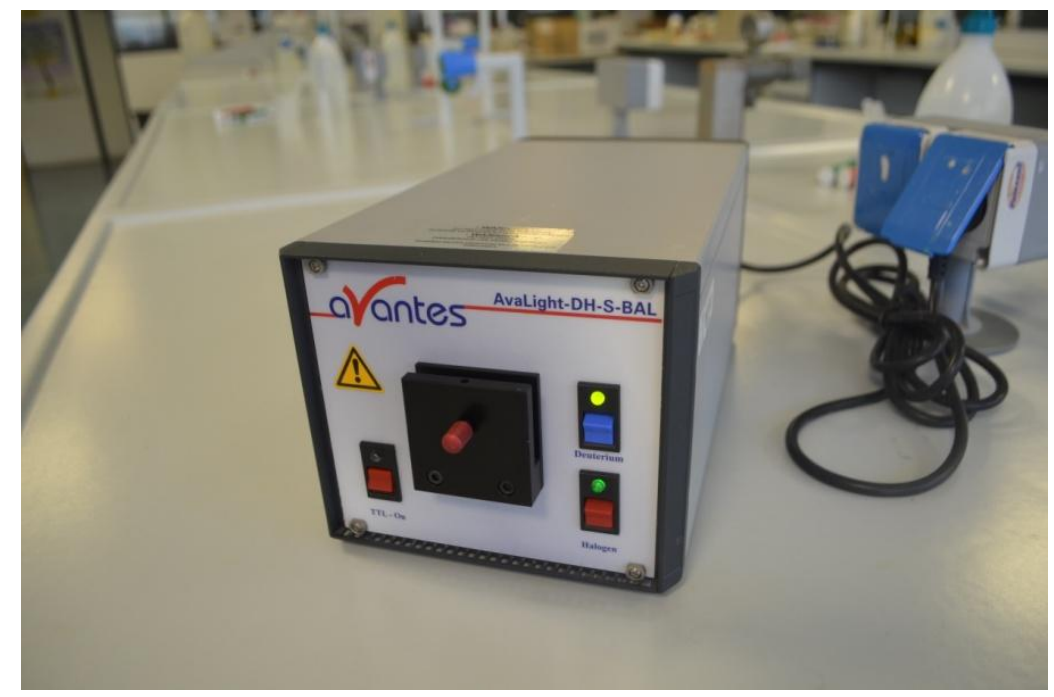

Figure 5.2. Photograph of the AvaLight-DH-S-BAL light source from Avantes.

\subsubsection{Optical Fibers}

Light transport between two different places is easily carried out with optical fibers, which are based on total internal reflection. In our case, optical fibers are employed to conduct the light beam between the light source and the spectroelectrochemistry cell, and from this one to the spectrometer. Different optical fibers can be used depending on the electromagnetic radiation required and the information to be obtained.

High-quality optical fibers for spectroscopic applications are usually made of synthetic fused silica (amorphous silicon dioxide) that can be doped with trace elements to adjust the optical properties of the glass.

The typical design of an optical fiber consists on a pure silica core covered with a cladding material of lower refractive index, for instance, fluorinedoped silica. All this structure is protected with a polyimide or metal buffer layer and, externally, with a jacketing material. 
It should be noted that standard silica fibers with an undoped core and fluorine-doped cladding are frequently damaged by UV radiation below $230 \mathrm{~nm}$. Therefore, if this type of electromagnetic radiation is used, solarization resistant optical fibers must be employed.

Optical fibers from Ocean Optics ${ }^{354,355}$ and Avantes ${ }^{353,356}$ with different diameters from 100 to $600 \mu \mathrm{m}$ with SMA-905 connectors have been used. Standard optical fibers, bifurcated optical fibers, optical fiber probes, and, particularly, bare optical fibers (without jacketing material) were employed depending on the needs of the experiments (Figure 5.3).
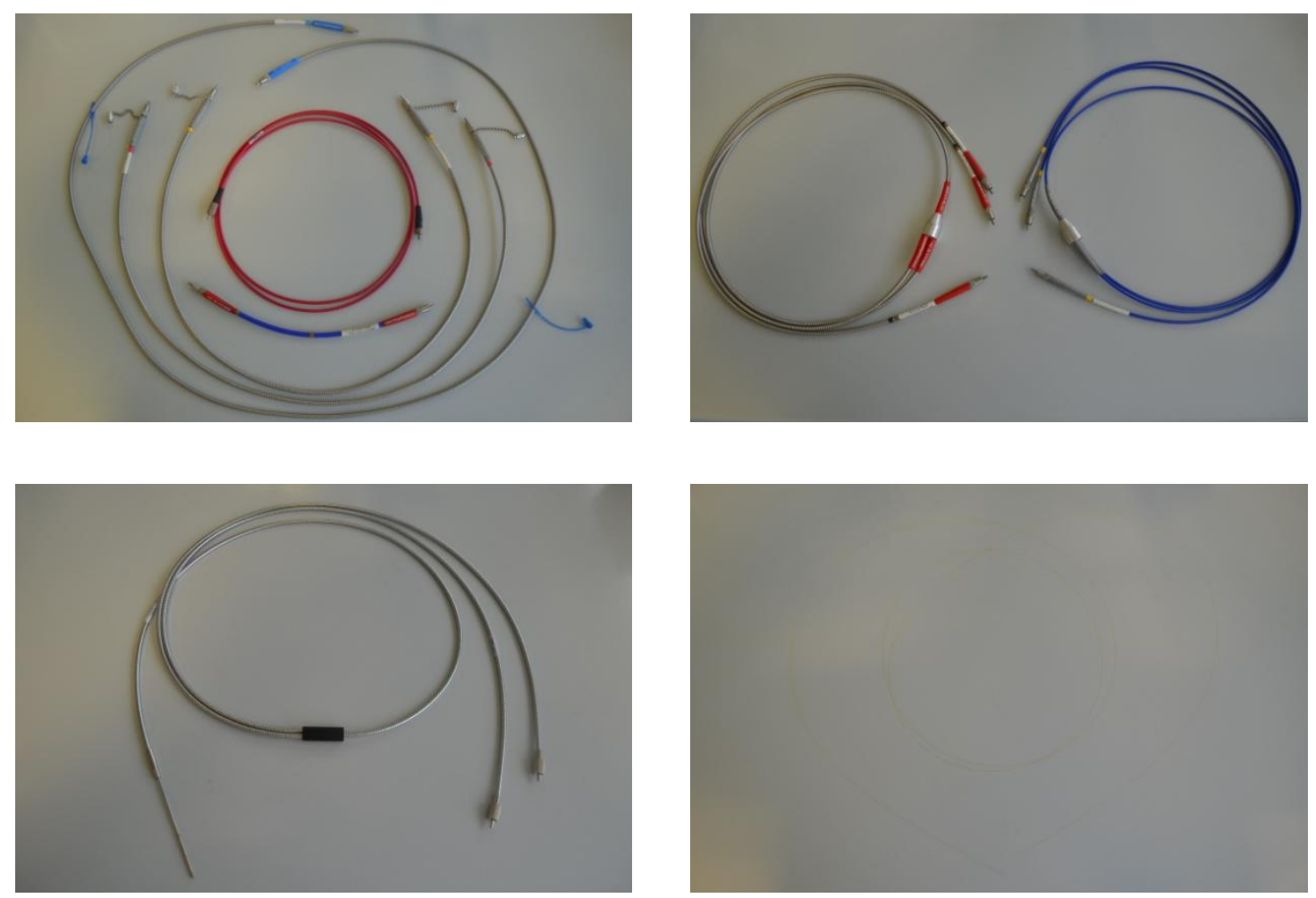

Figure 5.3. Photograph of (a) standard optical fibers from Ocean Optics, (b) bifurcated optical fibers from Ocean Optics, (c) an optical fiber probe from Avantes, and (d) bare optical fibers from Ocean Optics. 


\subsubsection{Spectroelectrochemistry Cell}

Several spectroelectrochemistry cells have been developed in this work. Note that there are several points in common between all of them, for example, the use of three electrodes or the small volume of sample required. However, the different devices have been fabricated to solve specific problems. Therefore, as can be expected, there is a remarkable versatility of selected arrangements or materials employed as electrodes. For this reason, the novel spectroelectrochemistry cells are explained in the corresponding studies carried out with each of them (section 6).

\subsubsection{Spectrometer}

Once the light beam contains information about the system under study after interacting with the sample, a spectrometer is needed to analyze the spectral changes by measuring the amount of photons at each wavelength. The spectrometer transforms the data collected into digital information to record the spectra evolution during the electrochemical experiment. As light sources, different spectrometers can be used depending on the spectral range desired.

For UV-Vis absorption spectroelectrochemistry, the model QE65000 357,358 from Ocean Optics, ${ }^{355}$ Figure 5.4, has been used and it was controlled with SpectraSuite software. It consists on a connection with the optical fiber through a SMA-905 connector, a collimating mirror, a diffraction grating that disperses the electromagnetic radiation, a focusing mirror, and a twodimensional diode array detector with $1044 \times 64$ pixels. This CCD detector is thermoelectrically cooled. The integration times for the data acquisition 
vary from $8 \mathrm{~ms}$ to 15 minutes. Depending on the model, the spectral ranges from 198 to $1006 \mathrm{~nm}$, and from 250 to $1045 \mathrm{~nm}$ have been covered.
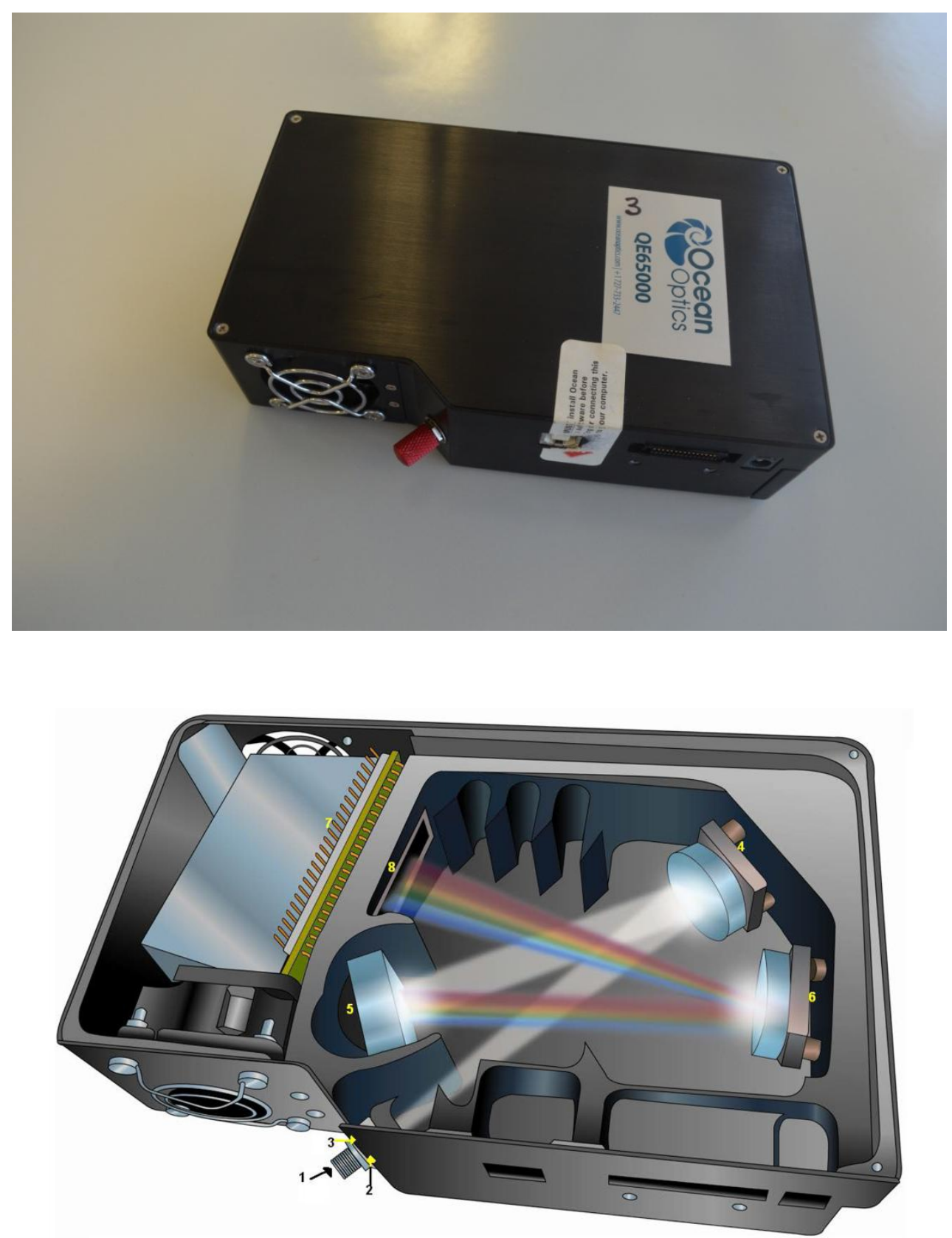

Figure 5.4. (a) Photograph of the QE65000 spectrometer from Ocean Optics. (b) Diagram of how light moves through the optical bench of a QE65000 spectrometer. ${ }^{357}$ 


\subsubsection{SPELEC}

The collaboration between our multidisciplinary research group of Instrumental Analysis and the Spanish company DropSens, S.L., ${ }^{359}$ has made possible the development of the first commercial compact spectroelectrochemistry instrument, called SPELEC ${ }^{93,360}$ (Figure 5.5), available since 2014 . The potentiostat/galvanostat, the light source, and the spectrometer are placed in the same box and are easily controlled by DropView SPELEC software. As can be found in literature, ${ }^{361}$ this instrument provides very good results for spectroelectrochemistry applications in an easy-to-use and easy-to-understand way.

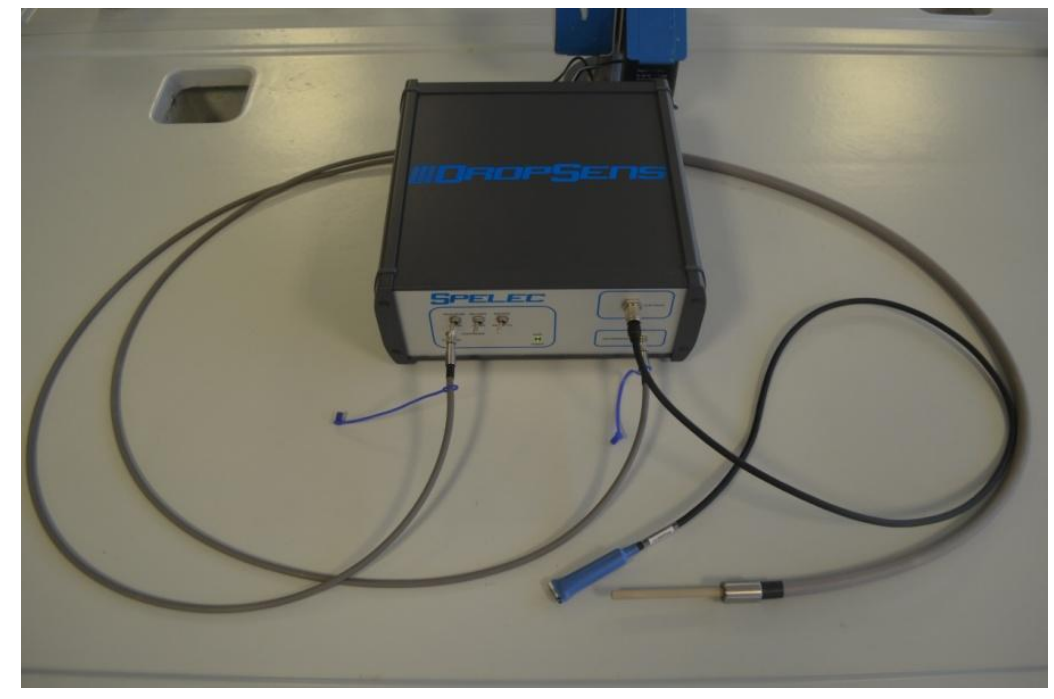

Figure 5.5. Photograph of the SPELEC spectroelectrochemistry instrument from DropSens, S.L.

\subsubsection{Laboratory Work Bench}

Finally, a last photograph is shown below (Figure 5.6) to give an idea about the day-to-day of the laboratory work bench: 


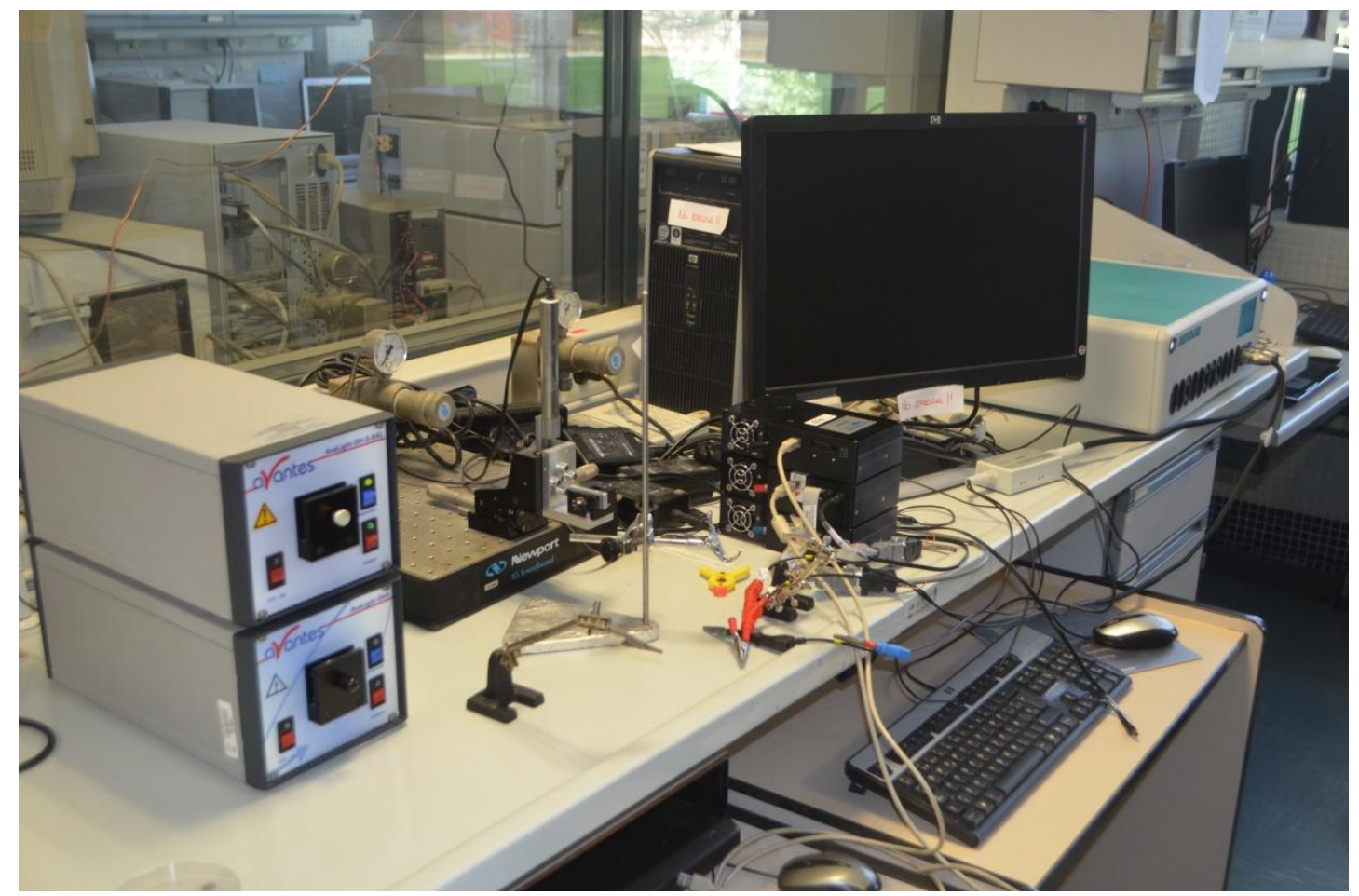

Figure 5.6. Photograph of the laboratory work bench taken any day of the last four years.

\subsection{Data Analysis}

A single spectroelectrochemistry experiment usually provides a high amount of information contained in the millions of data which are often acquired as the sum of both the electrochemical and the spectral responses. For this reason, high performance mathematical software, such as MATLAB and R, has been used in these works to analyze these data.

- MATLAB: ${ }^{362,363}$ It is a proprietary programming language developed by MathWorks, whose name comes from MATrix LABoratory. It is a numerical computing environment that allows matrix manipulations, plotting of functions and data, implementation 
of algorithms, creation of user interfaces, and interfacing with programs written in other languages. MATLAB is commonly used around the world to analyze and design different systems and products, for instance, in automobile active safety systems, spacecrafts, health monitoring devices, smart power grids, LTE cellular networks, machine learning, signal processing, image processing, computer vision, communications, computational finance, control design, or robotics, among many other applications.

There is a vast library of prebuilt toolboxes but the main functions employed in this doctoral thesis to analyze the spectroelectrochemistry data have been developed by our research group. ${ }^{364,365}$

- $\mathrm{R}:^{366}$ It is a language and environment for statistical computing and graphics, and it is highly and easily extensible via packages. It is an integrated suite of software facilities for data manipulation, calculation and graphical display.

$\mathrm{R}$ was inspired by the $\mathrm{S}$ environment which has been principally developed by John Chambers. Initially, $\mathrm{R}$ was written by Robert Gentleman and Ross Ihaka of the University of Auckland. The current $\mathrm{R}$ is the result of a collaborative effort with contributions from all over the world, being available as Free Software under the terms of the Free Software Foundation's GNU General Public License in source code form. $\mathrm{R}$, like $\mathrm{S}$, is designed around a true computer language, and it allows users to add additional functionality by defining new functions. 
Currently, there is the $\mathrm{R}$ Foundation, a not for profit organization working in the public interest and founded by the members of the $\mathrm{R}$ Development Core Team in order to: (i) provide support for the $\mathrm{R}$ project and other innovations in statistical computing, (ii) provide a reference point for individuals, institutions or commercial enterprises that want to support or interact with the R development community, and (iii) hold and administer the copyright of $\mathrm{R}$ software and documentation. Among the goals of the R Foundation are the support of continued development of $\mathrm{R}$, the exploration of new methodology, teaching and training of statistical computing and the organization of meetings and conferences with a statistical computing orientation. 



\section{Research Results}




or fin ha llegado la sección relativa a los resultados derivados de los experimentos llevados a cabo a lo largo de estos últimos años. Una vez que el contexto de la investigación ha quedado enmarcado es necesario ponerse manos a la obra. Hay que preparar experimentos, manejar equipos, probar condiciones, obtener datos, tratar números, optimizar parámetros, repetir experiencias y, si es posible, poner un punto y seguido para escribir un artículo, exponer una presentación o redactar una tesis. El relato de los resultados obtenidos y la narración de las explicaciones de cómo han sido conseguidos deben estar íntimamente acompañados, cómo no, de las motivaciones y de las necesidades existentes, básicas o aplicadas, que, conjuntamente, los han propiciado. En el presente caso, algunos trabajos se encuentran ya publicados. Otros se hallan prácticamente al punto, doraditos, como si esperasen ese toque especial que los haga precisamente eso, especiales. Todo esto no parece fácil. ¿Quién dijo que lo fuera? Tampoco resulta difícil. Es complicado de describir. Es lo que tienen los trabajos apasionantes.

Evidentemente, esta sección es con la que más activamente contribuimos a incrementar el conocimiento de la sociedad. Nunca antes alguien se había dedicado a estos mismos estudios, empleando esta misma metodología y obteniendo estos mismos resultados. Eso es, precisamente, lo que hace que estos resultados sean innovadores. Eso es, particularmente, lo que hace que los resultados de un laboratorio cercano sean novedosos. Eso es, curiosamente, lo que hace que los resultados de un laboratorio situado a mil kilómetros de distancia sean originales. Porque aunque el lugar, el idioma, las personas o las circunstancias cambien, la forma de hacer ciencia tiene unos rasgos muy característicos, muy personales. ¿Deja por ello de ser interesante? Todo lo contrario. Todos los resultados suman. Todas las metodologías contribuyen. Es ciencia. 

6.1. Press-Transfer Optically Transparent Electrodes Fabricated from Commercial Single-Walled Carbon Nanotubes 



\subsubsection{Some Important Points to Keep in Mind}

The development of OTEs is required for several applications in the current world. Particularly, OTEs are required for normal transmission spectroelectrochemistry measurements to obtain simultaneously electrochemical and spectroscopic responses. In these senses, there is a latent need to replace the use of ITO electrodes due to their limitations.

Carbon nanomaterials, in particular carbon nanotubes, constitute a promising alternative to ITO electrodes because of their fascinating electrical and optical properties. However, the need of a CVD reactor or the difficulties associated with the existing methodologies to transfer carbon nanomaterials on different substrates make it difficult to achieve this goal.

Therefore, with the aim of obtaining SWCNTs-OTEs with the best properties for spectroelectrochemical purposes, among others, a simple method for the fabrication of OTEs from commercial SWCNTs, easily, reproducibly, and available for any laboratory, is presented in this work.

We disperse SWCNTs in organic solvents avoiding surfactants that should be removed, for example, after the transfer to the support. SWCNTs films obtained by filtering the SWCNTs dispersion are homogeneously transferred on non-conductive polymer substrates only by pressure, avoiding the chemical removing of the filter and, hence, reducing the risk of contamination. The filter is mechanically removed using tweezers.

The electro-optical properties of the electrodes, which do not request an underlying conductive substrate, have been studied and optimized using an experimental design strategy, concluding that both properties depend on the total mass of SWCNTs transferred to the support. 
In general, well-interconnected SWCNTs networks yield little differences in the electrochemical behavior. However, it has been observed that electrodes with a high mass of SWCNTs produce significant changes in the voltammograms, obtaining unexpected ratios between the anodic and cathodic peak currents.

SWCNTs-OTEs are used to study the electropolymerization of aniline by spectroelectrochemistry, demonstrating their excellent behavior.

\subsubsection{Experimental Section}

\subsubsection{Reagents and Materials}

SWCNTs (Sigma-Aldrich), DCE (Fluka), hydrophilic PTFE filters (pore size $0.1 \mu \mathrm{m}$, JVWP01300, Millipore Omnipore), $175 \mu \mathrm{m}$ thick PET (HiFi Industrial Film), silver conductive paint (Electrolube), and epoxy protective overcoat (242-SB de ESL Europe) were used to produce the SWCNTsOTEs. FcMeOH (Sigma-Aldrich), KCl (Merck), aniline (Sigma-Aldrich), and $\mathrm{HNO}_{3}$ were used as received.

All chemicals were analytical grade. Aqueous solutions were prepared using high-quality water (Milli-Q gradient A10 system, Millipore).

\subsubsection{Instrumentation}

All electrochemical experiments were carried out at room temperature using a potentiostat/galvanostat $\mathrm{CHI} 900$ ( $\mathrm{CH}$ Instruments). A standard 
three-electrode cell was used in all the experiments, consisting of a SWCNTs-OTE as WE, a Au wire as $\mathrm{CE}$ and a homemade $\mathrm{Ag} / \mathrm{AgCl} / \mathrm{KCl} 3$ $\mathrm{M}$ as RE. Transmittance was measured using a S2000 spectrometer (Ocean Optics). The light beam, supplied by a halogen light source (HL-2000, Ocean Optics), was conducted to and collected from the spectroscopic cell (qpod2e, Quantum Northwest) by $200 \mu$ m optical fibers (Ocean Optics).

Spectroelectrochemical setup has been previously described elsewhere. ${ }^{367}$

SWCNTs solutions were dispersed using an ultrasonic generator (CY-500, Optic ivymen System).

For safety considerations, all handling and processing were performed carefully, particularly when DCE is used.

\subsubsection{Electrodes Fabrication}

We have fabricated electrodes using nanotubes from different manufacturers. As a proof of concept, we have selected SWCNTs from Sigma-Aldrich to show our methodology but it has been successfully used with other types of SWCNTs, and even with modified carbon nanotubes. We neither add any surfactant nor functionalize the SWCNTs in the dispersion to produce the SWCNTs-OTEs, that is to say, we do not modify the SWCNTs prior to the fabrication.

Our methodology takes place in six consecutive steps. 1. We disperse 1.5 $\mathrm{mg}$ of SWCNTs in $100 \mathrm{~mL}$ of DCE, as stock solution, being the homogenization a fundamental step. In order to obtain homogeneous films we use a tip-sonicator using a power of $250 \mathrm{~W}$ for $15 \mathrm{~min}$; then we reduce the power to $100 \mathrm{~W}$ and the dispersion is sonicated again for $15 \mathrm{~min}$. 2. We 
prepare dispersions of different SWCNTs concentrations from the stock dispersion. Each one was homogenized again for $15 \mathrm{~min}$ at $100 \mathrm{~W}$. 3. Once we obtain a good dispersion, without any SWCNTs agglomeration, the desired volume of the dispersion is filtered under vacuum using a hydrophilic PTFE filter. Next, the film is dried at room temperature for 5 min. It is noteworthy that for a good transfer, filters should not be in contact with the air for more than $10 \mathrm{~min}$. From our experience, interaction between SWCNTs and PTFE is dependent on time, implying a bad transfer for longer times. 4. Using a laboratory hydraulic press, the film of carbon nanotubes collected on the filter was transferred by pressure to a sheet of PET applying $20 \pm 1$ tons for $60 \mathrm{~s}$. A much lower pressure was enough to transfer the film but we use 20 tons to ensure always a good transference. PET sheets have been previously washed with deionized water and dried. The separation of the filter is performed slowly and carefully pulling it out with tweezers so that the transfer of the SWCNTs to the polymeric support provides a very homogeneous film with an area of $0.785 \mathrm{~cm}^{2} .5$. Electrical contacts were made using conductive silver paint, creating a small line from the origin of the SWCNTs to the end of PET. The silver paint is dried in an oven at $75{ }^{\circ} \mathrm{C}$ for $45 \mathrm{~min}$. 6. After further cooling, conductive silver paint is tested and it is electrically isolated using insulating paint. Finally, the electrode is inserted into the oven at $75{ }^{\circ} \mathrm{C}$ for $120 \mathrm{~min}$.

\subsubsection{Results and Discussion}

Our first experiments demonstrated that SWCNTs films could be transferred on PET supports with very high reproducibility using commercial SWCNTs. Concentration and volume filtered of SWCNTs 
dispersions were the two factors studied to obtain more information about the electro-optical properties of the electrodes and to produce optimal OTEs.

SWCNTs concentration is important because of the difficulty in obtaining highly homogeneous solutions. The study of the volume filtered is also important to understand whether it influences on the homogeneity of the films and, therefore, on the electro-optical properties of the film.

Transparency and conductivity of the electrodes depend on the SWCNTs concentration and the volume filtered. Therefore, it is essential to optimize these parameters to produce highly conductive electrodes with maximum transparency to be used as OTEs in spectroelectrochemistry.

Optical transparency of the electrode was evaluated by measuring transmittance at $550 \mathrm{~nm}$. Evaluation of the conductivity of the SWCNTsOTEs was performed by measuring the voltammetric reversibility of a redox couple with a high standard rate constant, taking into account that the electrodes will be used for spectroelectrochemistry. In our case we have selected $\mathrm{FcMeOH}$, measuring the difference of potential between the anodic and cathodic peak $\left(\Delta E_{p}\right)$ from cyclic voltammograms. Potential was scanned between $-0.20 \mathrm{~V}$ and $+0.60 \mathrm{~V}$ at $0.01 \mathrm{~V} \cdot \mathrm{s}^{-1}$ in a $0.60 \mathrm{mM}$ $\mathrm{FcMeOH}$ and $0.10 \mathrm{M} \mathrm{KCl}$ solution. Charge transfer rate does not depend on the redox pair but on the electrical resistance of the electrode that makes the electrochemical process slow.

Fabrication of the electrodes is relatively costly from the experimental point of view, thus, it is very important to optimize the resources. For this reason a strategy of experimental design was used to optimize both volume filtered and SWCNTs concentration in only 11 experiments. We performed 
a design consisting of a central two-level factorial plus additional star points used to model curvature with respect to each factor. The concentration range was limited to $0.0025-0.0130 \mathrm{mg} \cdot \mathrm{mL}^{-1}$ and the volume filtered was limited to $0.75-3.00 \mathrm{~mL}$.

Analysis of the design indicated that the two factors, SWCNTs concentration and volume filtered, and their interactions were significant. Figure 6.1.1 shows the two superimposed response surfaces obtained for the two variables that provide the optimum concentration and volume filtered. The best conductivity is obtained at the higher values of the factors and the best transparency at the lower values of the factors, as could be expected. As the response changes in the diagonal of the experimental space, we can conclude that the total mass of SWCNTs transferred to the electrode is the most influential factor on the responses.

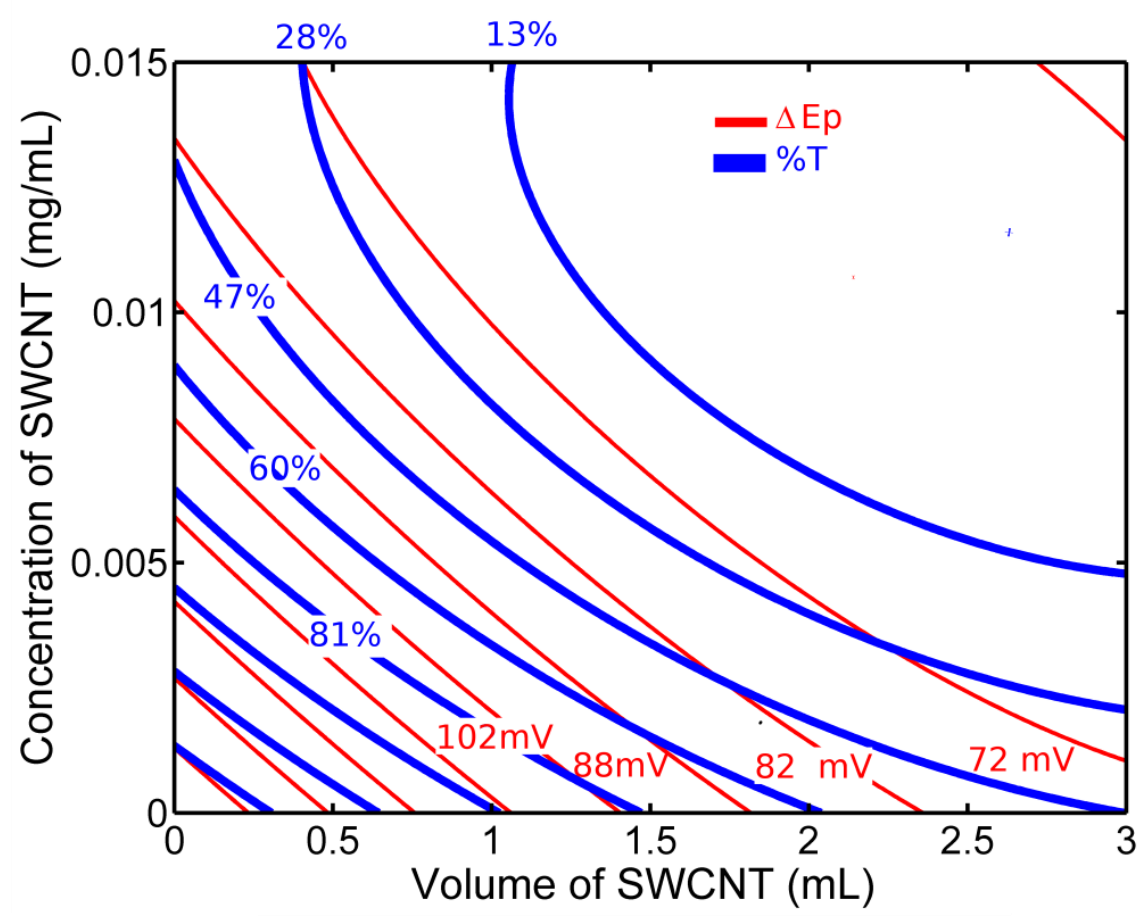

Figure 6.1.1. Response surfaces for transmittance and $\Delta E_{p}$ respect to the concentration of SWCNTs and the volume filtered. 
Figure 6.1.2 shows the logarithmic relationship of the transmittance with respect to the mass of SWCNTs. A linear relationship of absorbance versus mass of SWCNTs is obtained, indicating that we can control the electrode transparency. When the mass of nanotubes is less than $0.03 \mathrm{mg}$ of SWCNTs, the relationship is perfectly linear $\left(R^{2}=0.996\right)$, which leads us to conclude that very high concentrations and volumes filtered do not provide acceptable optical results.

Figure 6.1.2 also shows $\Delta E_{p}$ versus the mass of SWCNTs. As can be seen, the percolation effect is observed. When a good SWCNTs network is formed, $\Delta E_{p}$ is substantially constant. Mass values lower than $0.0022 \mathrm{mg}$ of SWCNTs lead to worse electrical properties, as can be deduced from the significant high value of $\Delta E_{p}$.

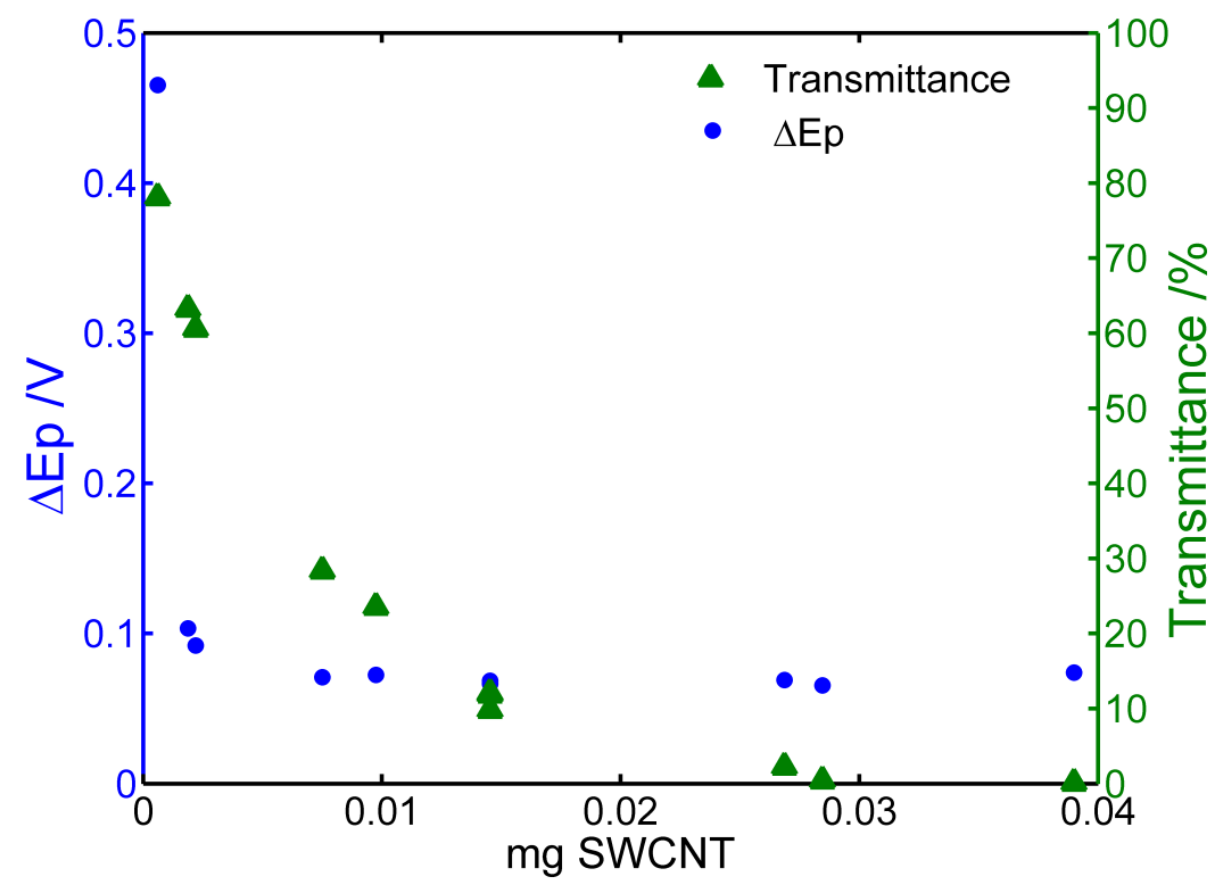

Figure 6.1.2. Transmittance versus mass of SWCNTs (triangles) and $\Delta E_{p}$ versus mass of SWCNTs (points). 
Although good electrical results should be expected when large amounts of nanotubes are used, an unexpected behavior is obtained. In principle, transmittance and $\Delta E_{p}$ seem to be sufficient to explain the behavior of these electrodes, but voltammetric responses contain much more information.

Figure 6.1.3 shows the voltammograms of $\mathrm{FcMeOH}$ registered using two electrodes prepared with different SWCNTs mass. As can be seen, the ratio between the intensity of the anodic and cathodic peaks $\left(I p_{o x} / I p_{\text {red }}\right)$ does not show the expected value for $\mathrm{FcMeOH}\left(I p_{o x} / I p_{\text {red }}=1\right)$ in the experiment with high mass of nanotubes, presenting an ideal behavior at low mass of SWCNTs.

To evaluate the influence of the mass of SWCNTs on $I p_{o x} / I p_{\text {red }}$, a concentration of $0.005 \mathrm{mg} \cdot \mathrm{mL}^{-1}$ of SWCNTs was fixed and the volume filtered was increased from 0.2 to $4 \mathrm{~mL}$. Masses of SWCNTs higher than $0.004 \mathrm{mg}$ yield $I p_{o x} / I p_{\text {red }}$ ratios greater than one, reaching to a ratio value close to 2 at the highest mass of SWCNTs. This result indicates that an excess of nanotubes can lead to a strange electrochemical behavior that could be related to a thin layer electrochemical processes that hinder the normal diffusion in the nanotube network of the product formed in the oxidation process.

Therefore, the electrochemical reversibility is affected not only by a lower limit of mass of nanotubes, but also by the upper limit which determines the peak ratio.

Considering transmittance, $\Delta E_{p}$ and $I p_{o x} / I p_{\text {red }}$ ratio, the ideal electrode for spectroelectrochemical experiments will be one with a mass of $0.004 \mathrm{mg}$ of SWCNTs, whose response is shown in Figure 6.1.3 (blue thin line). 


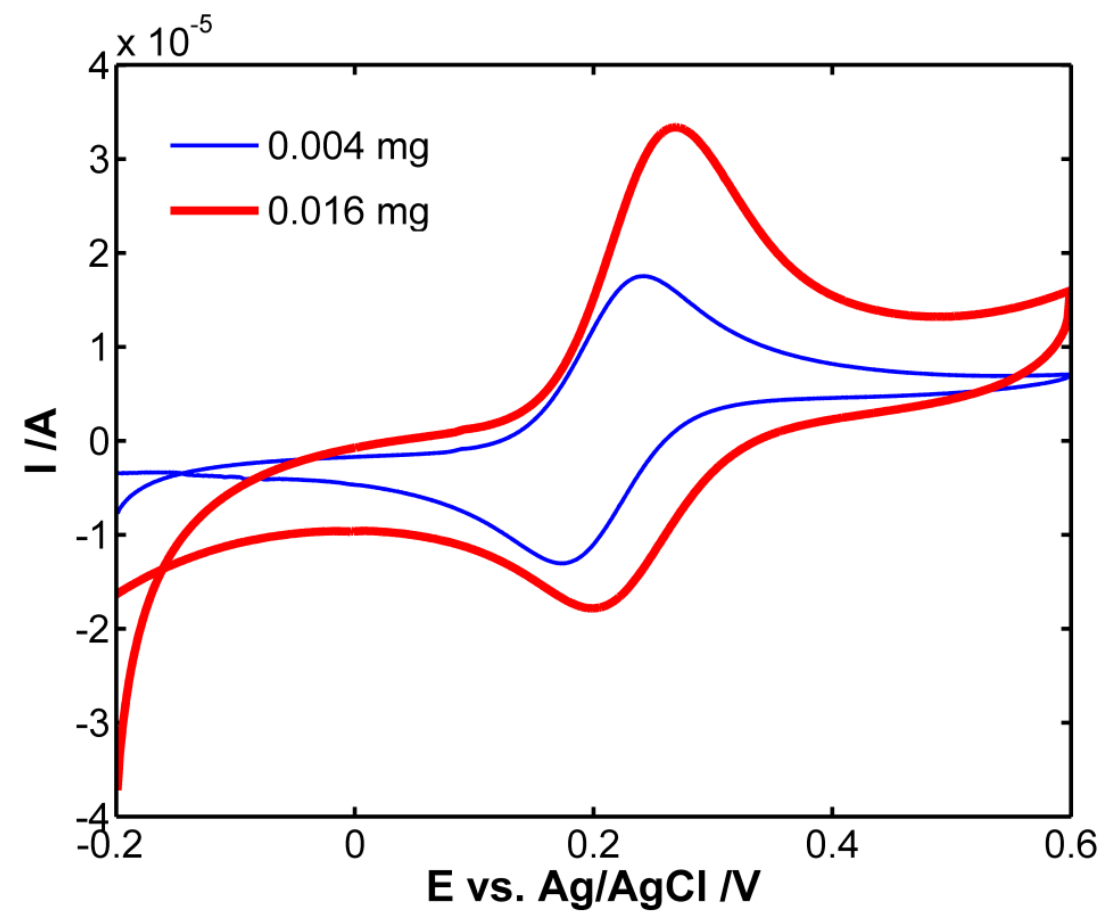

Figure 6.1.3. Voltammograms of $\mathrm{FcMeOH}$ obtained for two electrodes using different mass of nanotubes.

Finally, we used our electrodes to follow the electrosynthesis of PANI. Electropolymerizations were carried out in a $0.1 \mathrm{M}$ aniline and $0.5 \mathrm{M}$ $\mathrm{HNO}_{3}$ aqueous solution. Five potential cycles between $-0.10 \mathrm{~V}$ and +0.90 $\mathrm{V}$ at $0.025 \mathrm{~V} \cdot \mathrm{s}^{-1}$ were performed. Figure 6.1 .4 displays (a) the voltammogram and (b) the spectral changes obtained during aniline electropolymerization. Typical voltammogram and spectra are observed during the polymerization process. ${ }^{224}$ PANI electrosynthesis starts at potentials higher than $+0.80 \mathrm{~V}$, as can be seen in the first anodic cycle (Figure 6.1.4a). In the next cycles, two pairs of peaks are observed related to the evolution of the polymer deposited on the electrode from leucoemeraldine to emeraldine (peaks between $0 \mathrm{~V}$ and $+0.30 \mathrm{~V}$ ) and from emeraldine to pernigraniline (peaks between $+0.30 \mathrm{~V}$ and $+0.60 \mathrm{~V}$ ). These 
electrical changes are correlated with spectral changes (Figure 6.1.4b), and an absorption maximum at $700 \mathrm{~nm}$ that grows with the number of cycles is observed, indicating that PANI is being formed. This maximum increases during anodic sweeps and decreases during the cathodic ones, indicating the electrochromic behavior of this well-known conducting polymer. These results support the good spectroelectrochemical performance of our SWCNTs-OTEs, inset in Figure 6.1.4a.
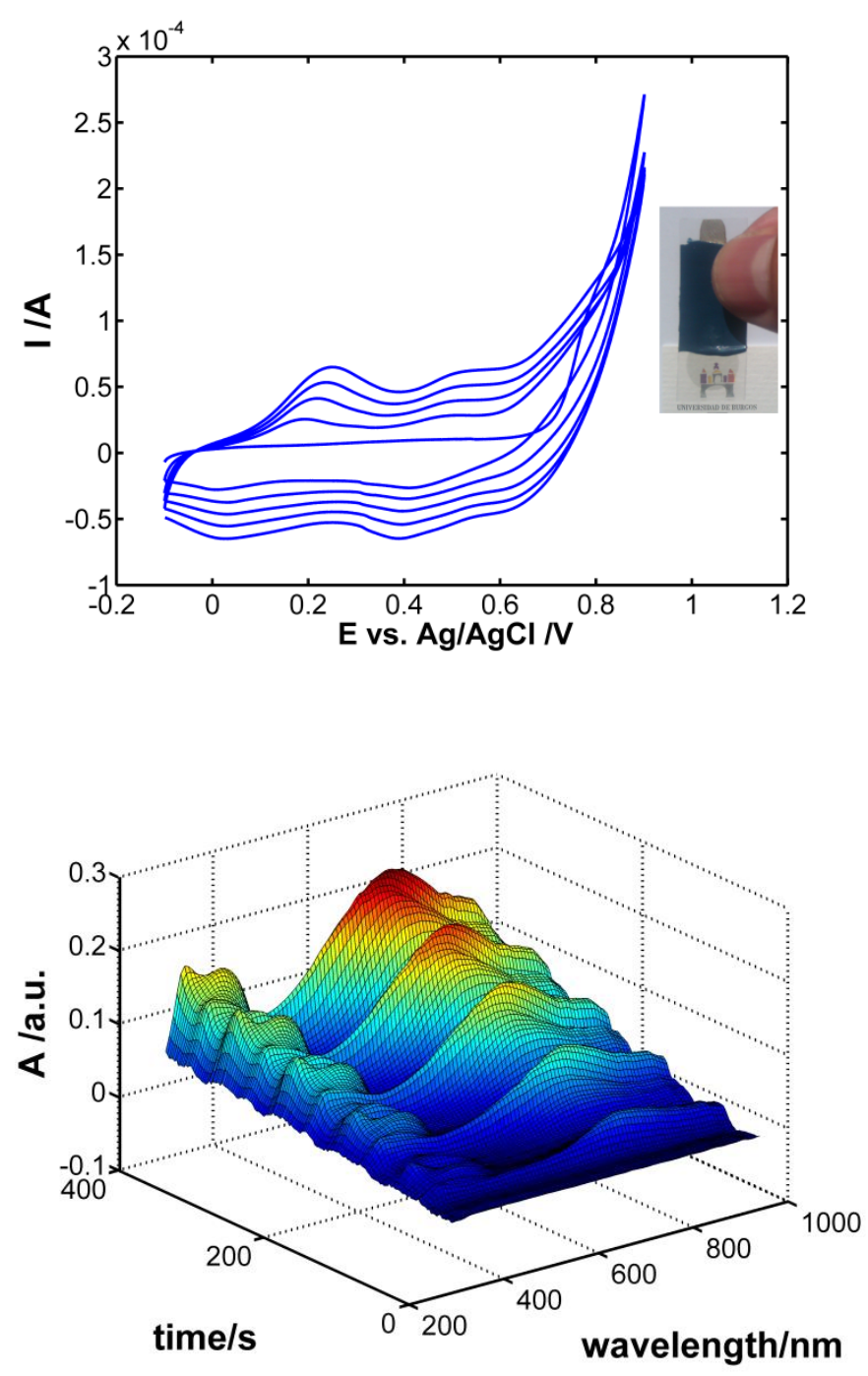

Figure 6.1.4. (a) Cyclic voltammogram. Inset: Photograph of the SWCNTsOTE. (b) Spectra evolution versus time during the electropolymerization of aniline. 


\subsubsection{Conclusions and Future Work}

OTEs have been fabricated from commercial SWCNTs using a simple approach that consists of filtering a SWCNTs dispersion and presstransferring the SWCNTs film formed on the membrane to a PET support, without surfactants, without chemical removing of the filter, and without an underlying conductive substrate.

We have shown that when good dispersions of SWCNTs are available, the main factor to control the electro-optical properties of the electrodes is the total mass of SWCNTs transferred to the PET support, giving a proof of the percolation effect.

Experimental design provides information to make electrodes with the desired electro-optical properties:

Small mass of SWCNTs yields poor electrochemical reversibility and electrodes with little application in spectroelectrochemistry, but it could be used for applications requiring materials with high transparency and some conductivity.

Well-interconnected SWCNTs networks yield little differences in $\triangle E_{p}$. However, the presence of a high mass of SWCNTs produces significant changes in the voltammograms, obtaining in some cases unexpected values of $I p_{o x} / I p_{\text {red }}$.

In general, SWCNTs-OTEs exhibit good optical and electrochemical properties which give them great value to study chemical processes using spectroelectrochemistry. These SWCNTs electrodes have been successfully used in spectroelectrochemistry and this aspect is the basis for the following research results sections. 

6.2. Optically Transparent Electrodes for Spectroelectrochemistry Fabricated with Graphene Nanoplatelets and Single-Walled Carbon Nanotubes 



\subsubsection{Some Important Points to Keep in Mind}

OTEs are needed for different applications such as solar cells, printable electronics, touch screens, light emitting diodes or flexible displays.

The search for new materials with a good transparency and conductivity, the basic requirements for an OTE, is outstanding.

For this reason, carbon allotropes, such as GNPs and SWCNTs, have been used in the present work to fabricate GNPs/SWCNTs-OTEs.

The key point of the present work is the fabrication of homogeneous and hybrid films of carbon nanomaterials in a clean way, trying to overcome the disadvantages related to other methods such as the large number of steps, the long fabrication times, the need of curing processes, the high temperatures, the functionalization of the carbon nanomaterials or the lack of homogeneity, as well as the use of strong etching agents, solvent mixtures, dispersing agents, and high cost techniques or instruments.

The methodology used to fabricate the GNPs/SWCNTs-OTEs, based on the vacuum filtration of the carbon nanomaterial dispersion and the press-transfer of the film formed on the membrane to another support (section 6.1), ${ }^{73}$ has several advantages such as the use of the commercial nanomaterials, the simplicity, the reproducibility, and the availability of the process to almost any laboratory.

GNPs and SWCNTs quantities used to fabricate GNPs/SWCNTsOTEs have been optimized to get the best transparency and conductivity by design of experiments, showing that it is needed to reach a percolation threshold of SWCNTs to ensure a minimum conductivity. 
This method provides a versatile methodology to modify homogeneously films of carbon nanotubes with other carbon allotropes, which could be applied for other materials in an easy way.

The suitable performance of these GNPs/SWCNTs-OTEs has been demonstrated by studying a film of PEDOT:PSS by spectroelectrochemistry, allowing us to characterize the PEDOT behavior.

\subsubsection{Experimental Section}

\subsubsection{Reagents and Materials}

GNPs (average thickness of 8-12 nm, particle diameters less than $2 \mu \mathrm{m}$ and a surface area of $600-750 \mathrm{~m}^{2} \cdot \mathrm{g}^{-1}$, grade three, CheapTubes), SWCNTs (0.7-1.1 nm in diameter, $(7,6)$ chirality, Sigma-Aldrich), DCE (Acros Organics), hydrophilic PTFE membrane (filter pore size $0.1 \mu \mathrm{m}$, JVWP01300, Millipore Omnipore), PET (175 $\mu \mathrm{m}$ thick, HiFi Industrial Film), silver conductive paint (Electrolube), and epoxy protective overcoat (242-SB, ESL Europe) were used to fabricate the GNPs/SWCNTs-OTEs. $\mathrm{FcMeOH}$ (97\%, Sigma-Aldrich) and $\mathrm{KCl}$ (Acros Organics) were used to prepare the solutions. PEDOT:PSS (Sigma-Aldrich) and $\mathrm{LiClO}_{4}$ (Acros Organics) were used to test the spectroelectrochemical performance of the GNPs/SWCNTs-OTEs.

All the reagents were used as received without further purification. All chemicals were of analytical grade. Aqueous solutions were prepared using high purity water (resistivity of $18.2 \mathrm{M} \Omega \cdot \mathrm{cm}$, Milli-Q gradient A10 system, 
Millipore) and they were freshly prepared or stored at $4{ }^{\circ} \mathrm{C}$, when necessary.

\subsubsection{Instrumentation}

All electrochemical experiments were performed using a potentiostat/galvanostat (CHI900, CH Instruments or PGSTAT302N, Metrohm Autolab) and a standard three-electrode cell with a GNPs/SWCNTs-OTE as WE, a gold wire as CE and a homemade $\mathrm{Ag} / \mathrm{AgCl} / \mathrm{KCl} 3 \mathrm{M}$ as $\mathrm{RE}$. Transmittance was measured using a halogen light source (HL-2000, Avantes) and a spectrometer (S2000, Ocean Optics). The light beam, supplied by the halogen light source, was conducted to and collected from the spectroscopic cell (qpod2e, Quantum Northwest) by $200 \mu \mathrm{m}$ optical fibers (Ocean Optics).

Spectroelectrochemistry setup included a potentiostat/galvanostat (PGSTAT302N, Metrohm Autolab), a halogen light source (DH-2000, Ocean Optics), two collimating lenses, a cuvette, two optical fibers (Ocean Optics) and a spectrometer (QE65000 198-1006 nm, Ocean Optics).

A tip-sonicator (CY-500, Optic ivymen System) and a laboratory hydraulic press (SpectroPress, Chemplex Industries, Inc.) were also used to fabricate the electrodes.

Raman characterization was carried out with a Confocal Raman Voyage (BWTEK). A laser wavelength of $532 \mathrm{~nm}$ with a power of $5 \mathrm{~mW}$ was employed to obtain the spectra using a $20 \times$ objective. The spectral resolution was $3.8 \mathrm{~cm}^{-1}$. FE-SEM images were recorded on a Philips XL 30 S FEG microscope. 
For safety considerations, all handling and processing were performed carefully, particularly when DCE was used.

\subsubsection{Electrode Fabrication}

Electrodes have been fabricated according to a methodology based on one of our previous works for SWCNTs-OTEs (section 6.1). ${ }^{73}$ Several modifications have been carried out to allow us to fabricate OTEs with GNPs and SWCNTs together. The whole process is illustrated in Figure 6.2.1 and it consists of seven simple and consecutive steps.

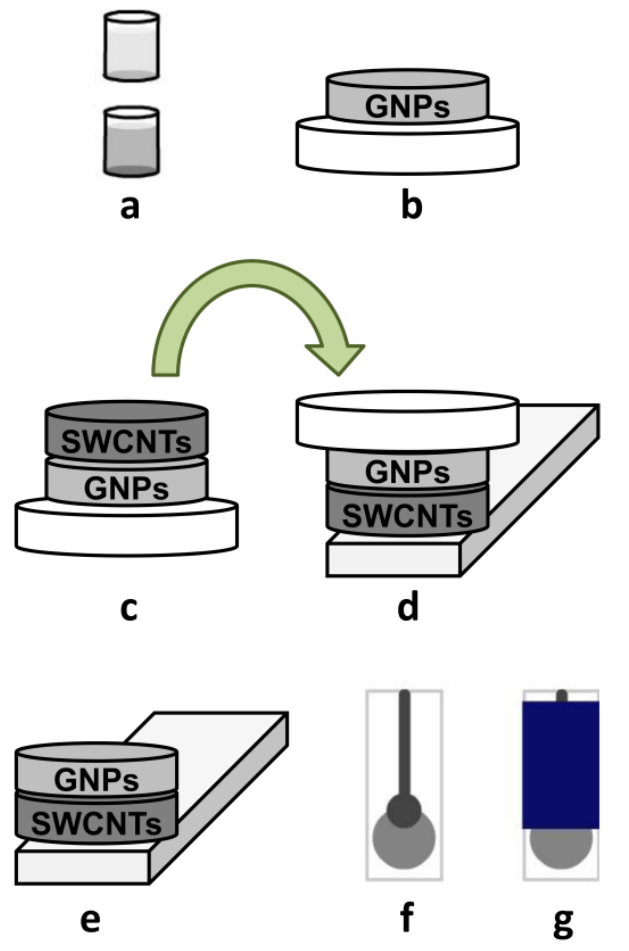

Figure 6.2.1. Fabrication process of GNPs/SWCNTs-OTEs: (a) preparation of the GNPs and SWCNTs dispersions, (b) filtration of the GNPs dispersion, (c) filtration of the SWCNTs dispersion, (d) press-transference of the bilayer film, (e) removing of the PTFE filter, (f) silver electrical contacts and (g) isolation of the silver electrical contacts. 
Firstly, $5 \mathrm{mg} \cdot \mathrm{L}^{-1}$ GNPs and $5 \mathrm{mg} \cdot \mathrm{L}^{-1} \mathrm{SWCNTs}$ dispersions in DCE were prepared (Figure 6.2.1.a). GNPs and SWCNTs dispersions were separately ultrasonicated using a tip-sonicator without adding surfactants. The procedure was slightly different according to each carbon nanomaterial. On the one hand, $80 \mathrm{~mL}$ of DCE were added to $0.5 \mathrm{mg}$ of GNPs. This dispersion was sonicated applying a power of $130 \mathrm{~W}$ for 30 minutes. Then, DCE was added to obtain a dispersion volume of $c a .90 \mathrm{~mL}$ which was sonicated once more at the same power for 5 minutes. Finally, the volume was adjusted to $100 \mathrm{~mL}$. On the other hand, $10 \mathrm{~mL}$ of DCE were added to $0.5 \mathrm{mg}$ of SWCNTs. This dispersion was sonicated applying a power of $250 \mathrm{~W}$ for $15 \mathrm{~min}$. Then, DCE was added to obtain a dispersion volume of ca. $90 \mathrm{~mL}$ which was sonicated again at $100 \mathrm{~W}$ for 20 minutes. This SWCNTs dispersion was sonicated more vigorously at $250 \mathrm{~W}$ for $20 \mathrm{~min}$. Finally, the volume was adjusted to $100 \mathrm{~mL}$. Before using both dispersions the following days to prepare the GNPs/SWCNTs-OTEs, $10 \mathrm{~mL}$ of each dispersion were sonicated for 15 minutes at $100 \mathrm{~W}$ to ensure a proper homogeneity without nanomaterial agglomeration. The fact that no surfactant was needed to prepare these two dispersions avoids the contamination of the electrode with this kind of species.

The second step was the vacuum filtration of the desired volume of the GNPs dispersion to form a film on the PTFE filter (Figure 6.2.1.b).

Two minutes later, the desired volume of the SWCNTs dispersion was filtered through the GNPs/PTFE filter obtaining a second homogeneous film on the GNPs one (Figure 6.2.1.c). This vacuum filtration technique provides highly homogeneous hybrid GNPs/SWCNTs films. The filter with both films was dried at room temperature for five minutes to achieve a proper transference during the next step. 
Next, PET sheets were washed with deionized water and dried. Afterwards, the press-transference of the GNPs/SWCNTs film to the PET sheets was performed by applying $28 \pm 1$ tons for about ten minutes using a hydraulic press (Figure 6.2.1.d).

Then, the filter was carefully separated using tweezers (Figure 6.2.1.e) obtaining a good adhesion of the SWCNTs side of the hybrid film to the PET support and being the GNPs film on its upper side. The use of pressure in the transference step, avoiding the use of chemicals to remove the filter, reduces the contamination sources of the final electrode.

The homogeneity and optical transparency of the $0.785 \mathrm{~cm}^{2}$ films are easily observed in Figure 6.2.2, where films with different composition are shown.

Electrical contacts were made with a line of silver conductive paint from the film to the end of PET that was dried in an oven at $75^{\circ} \mathrm{C}$ for 45 minutes (Figure 6.2.1.f).

Finally, silver conductive paint was electrically isolated by an insulating epoxy protective overcoat which was dried in the oven at the same temperature for 2 hours (Figure 6.2.1.g).

For comparative purposes, electrodes with only GNPs or with only SWCNTs were also prepared.

In conclusion, our proposed methodology has been used to prepare presstransfer commercial GNPs, SWCNTs and hybrid GNPs/SWCNTs films on a flexible, polymeric, non-conductive and optically transparent support in a reproducible, simple and clean way, available for all laboratories. 


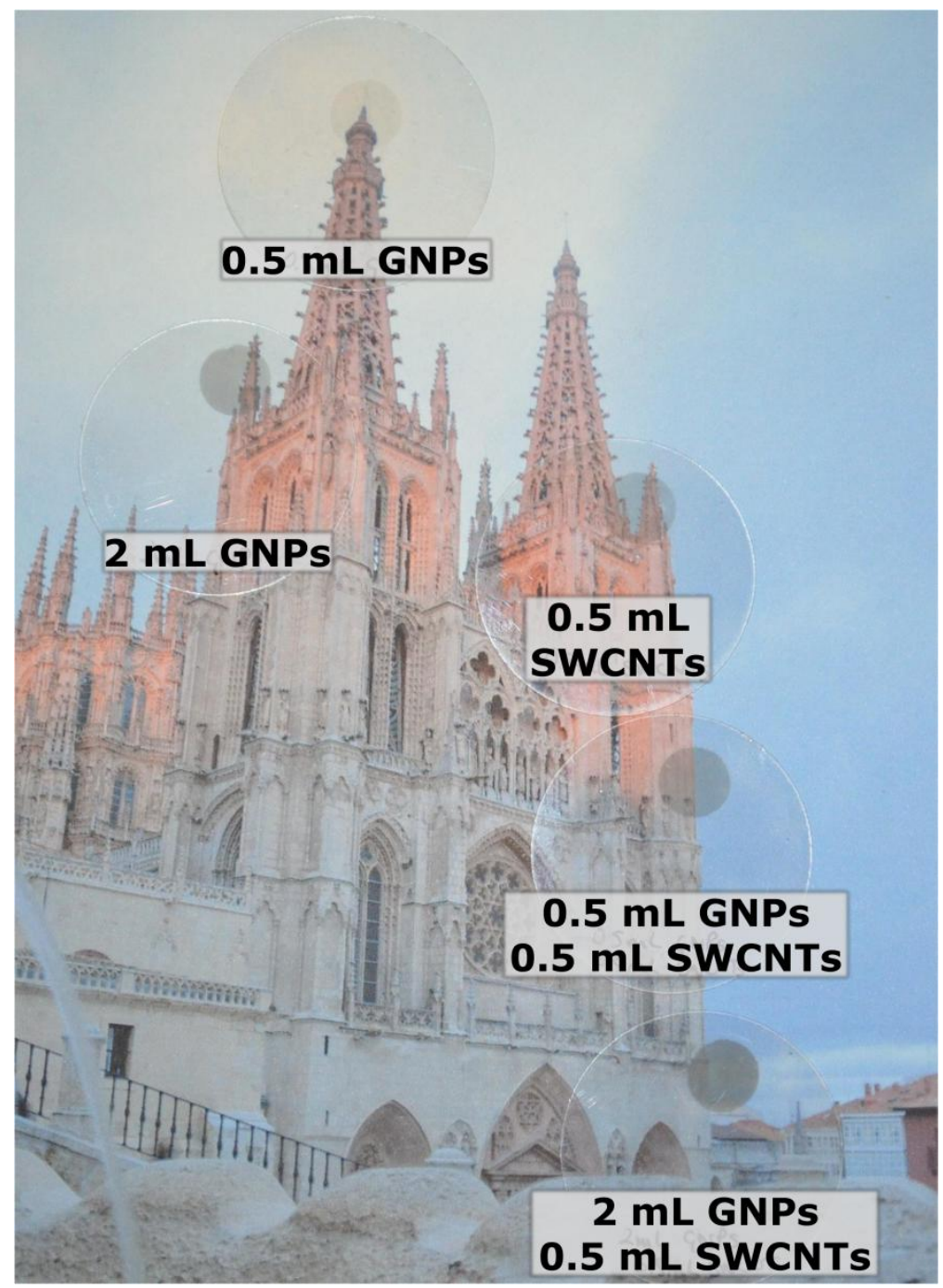

Figure 6.2.2. A Burgos Cathedral photograph is observed through different GNPs/SWCNTs films transferred on PET.

\subsubsection{Electrode Characterization}

A FE-SEM image of a hybrid GNPs/SWCNTs-OTE fabricated by filtration of $0.3 \mathrm{~mL}$ of the GNPs and $0.58 \mathrm{~mL}$ of the SWCNTs dispersions is shown in Figure 6.2.3. As can be observed, GNPs are deposited on the SWCNTs film. It is noteworthy that GNPs are interconnected by the SWCNTs film but not between them. 


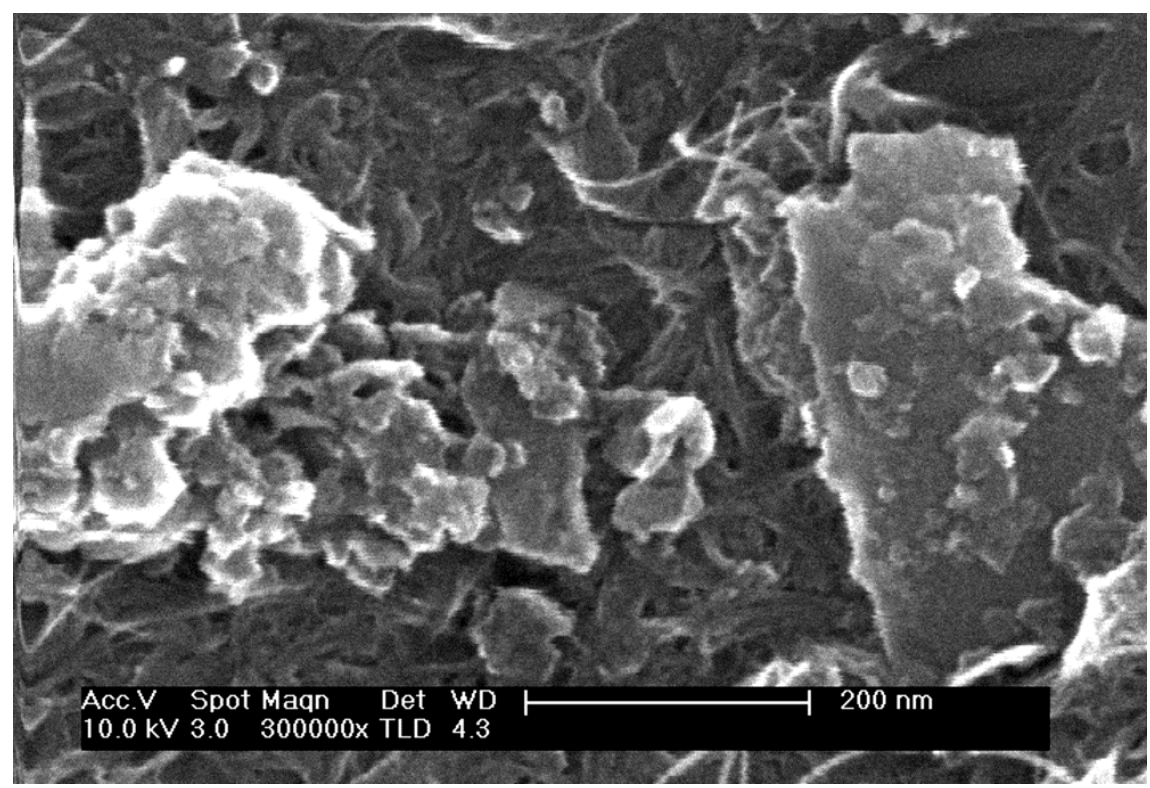

Figure 6.2.3. FE-SEM image of a hybrid GNPs/SWCNTs-OTE fabricated by filtration of $0.3 \mathrm{~mL}$ of the GNPs and $0.58 \mathrm{~mL}$ of the SWCNTs dispersions.

Raman spectroscopy represents one of the most useful characterization techniques for carbon nanomaterials. Figure 6.2.4 shows the spectra of three electrodes fabricated by filtering different volumes of the corresponding nanomaterial dispersions. PET spectrum has been subtracted.

The GNPs/PET film shows three main bands at $1336 \mathrm{~cm}^{-1}, 1577 \mathrm{~cm}^{-1}$ and $2622 \mathrm{~cm}^{-1}$ attributed to the characteristic GNPs D, G and 2D bands, respectively. ${ }^{368}$ The $\mathrm{G}$ band at $1577 \mathrm{~cm}^{-1}$ and the $2 \mathrm{D}$ band centered at 2622 $\mathrm{cm}^{-1}$ indicate that our GNPs are not a high quality graphene. Furthermore, the small band at $2435 \mathrm{~cm}^{-1}$ reveals the presence of graphite. Meanwhile, SWCNTs have also been widely studied by Raman spectroscopy ${ }^{130}$ and Raman spectroelectrochemistry. ${ }^{14,369}$ In agreement with these works, the characteristic Raman bands of SWCNTs are observed on the 
SWCNTs/PET film. The band at $1592 \mathrm{~cm}^{-1}$, so-called G band, corresponds to the tangential displacement modes of SWCNTs, while the band at 1337 $\mathrm{cm}^{-1}$, so-called D band, is related to the disorder induced mode. The band peaking at $2631 \mathrm{~cm}^{-1}$, the so-called $\mathrm{G}^{\prime}$ band, is referred to the high frequency two phonon mode. As might be expected, the GNPs/SWCNTs/PET electrodes show Raman bands related to the two carbon nanomaterials. Therefore, Raman spectra shown in Figure 6.2.4 demonstrate that both materials can be successfully press-transferred to PET substrates, and that GNPs are attached to the SWCNTs layer.

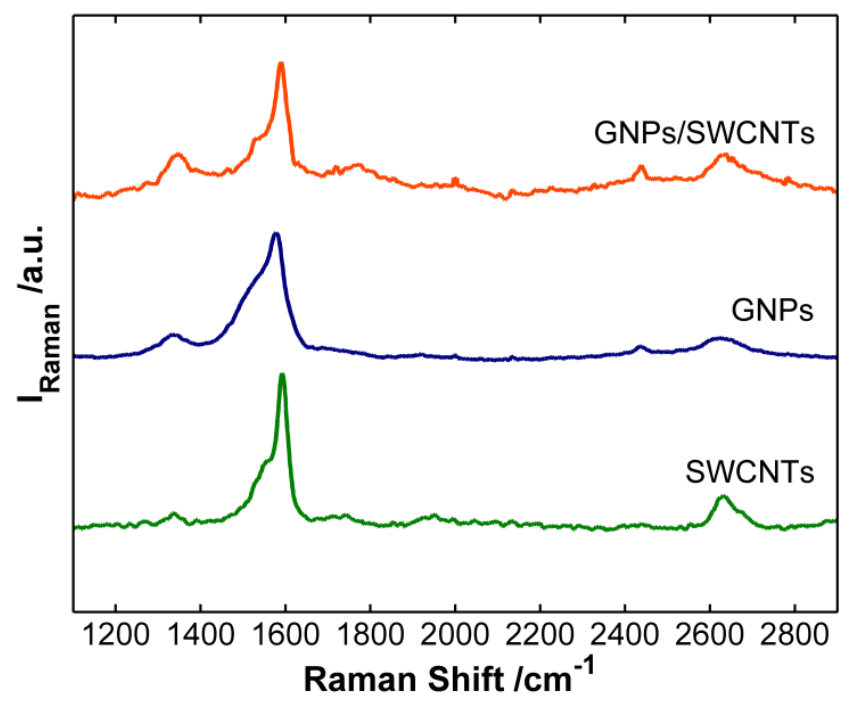

Figure 6.2.4. Raman spectra of three electrodes fabricated, according to the proposed methodology, filtering the following dispersion volumes: $2 \mathrm{~mL}$ of GNPs (blue line), $0.5 \mathrm{~mL}$ of SWCNTs (green line) and, both consecutively, 2 $\mathrm{mL}$ of GNPs and $0.5 \mathrm{~mL}$ of SWCNTs (orange line).

Consequently, the method proposed opens up new avenues in the fabrication of homogeneous hybrid films useful in electrochemistry and spectroelectrochemistry in an easy, reproducible and cost effective way. 


\subsubsection{Results and Discussion}

In order to assess the performance of the OTEs, their electrochemical responses were studied in the boundary conditions, fabricating the electrodes only with GNPs or SWCNTs. Cyclic voltammetry of $6 \times 10^{-4} \mathrm{M}$ FcMeOH in $0.1 \mathrm{M} \mathrm{KCl}$ between $-0.20 \mathrm{~V}$ and $+0.60 \mathrm{~V}$ at $0.01 \mathrm{~V} \cdot \mathrm{s}^{-1}$ was carried out, Figure 6.2.5. The cyclic voltammogram obtained with the SWCNTs electrode shows a good electrochemical behavior where the reversible oxidation of $\mathrm{FcMeOH}$ is observed, as can be inferred from the value of $0.081 \mathrm{~V}$ for the difference between the anodic and the cathodic peak potential $\left(\Delta E_{p}\right)$, close to the expected value of $0.059 \mathrm{~V}$. Actually, $\Delta E_{p}$ depends on the concentration of $\mathrm{FcMeOH}$ for the same electrode, as will be shown below. However, the conductivity of the GNPs electrode was too low as can be inferred from the absence of any redox process. GNPs alone are not able to form an interconnected and conducting network (percolation threshold) with a proper transparency using this methodology.

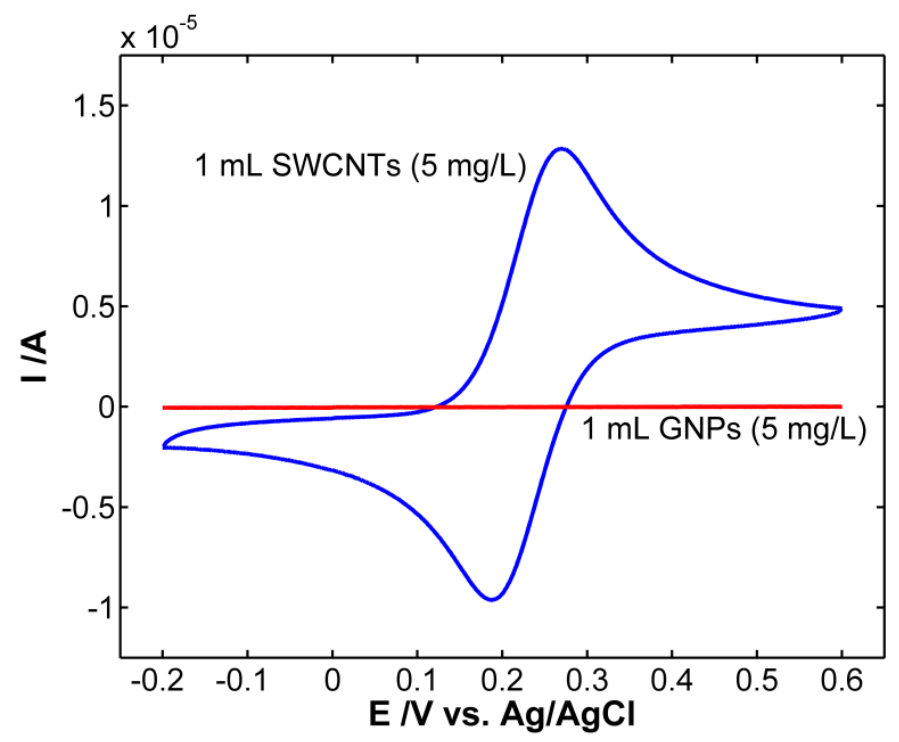

Figure 6.2.5. Cyclic voltammograms obtained with two OTEs made of only GNPs or only SWCNTs. 
This shows that SWCNTs form interconnected networks (see a FE-SEM image in Figure 6.2.6) more easily than GNPs which may be due to the different structure of each carbon nanomaterial.

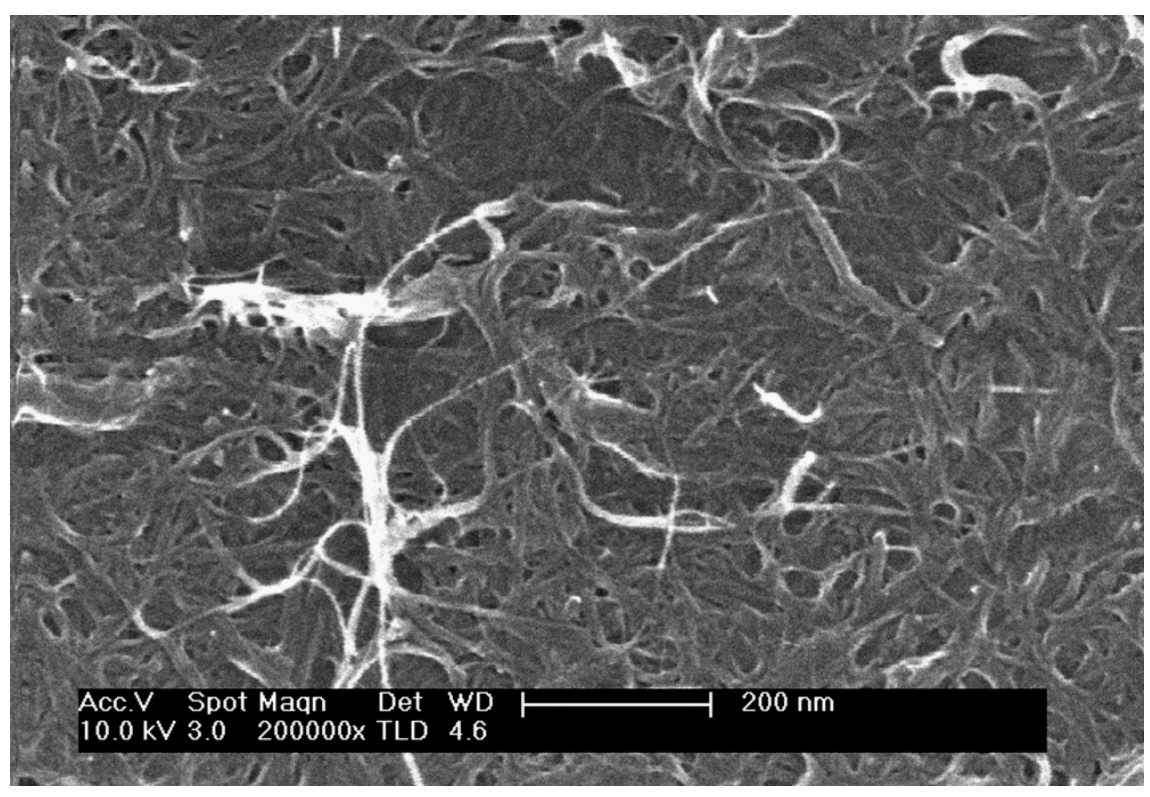

Figure 6.2.6. FE-SEM image of a SWCNTs film fabricated with $0.5 \mathrm{~mL}$ of the SWCNTs dispersion.

Therefore, one-dimensional tubes (SWCNTs) are better than twodimensional platelets (GNPs) to fabricate OTEs on inert surfaces with this methodology. In view of the results depicted in Figure 6.2.5, we can conclude that the fabrication of OTEs made only of these commercial low cost GNPs is not possible. It should be mentioned that when high-quality exfoliated graphene is used, the methodology based on press-transferring graphene films obtained by filtration is capable of fabricating grapheneOTEs with good electrochemical responses. ${ }^{370}$ Nevertheless, GNPs/SWCNTs-OTEs show better electrochemical performance than high- 
quality exfoliated graphene-OTEs reported for similar electrodes in literature $^{370}$ for the same level of transparency.

However, with the methodology proposed in this work it is possible to fabricate good performing OTEs with an external layer of GNPs supported on a conductive SWCNTs film, GNPs/SWCNTs-OTEs. A first methodology was used, filtering the GNPs and SWCNTs dispersions separately in two different filters. Initially, the SWCNTs film was presstransferred on the PET support. Afterwards, the GNPs film was presstransferred on top of the SWCNTs film. This methodology was discarded because it did not show the expected results in terms of homogeneity of the GNPs film on the SWCNTs one. For these reasons, a second methodology based on the filtration of the two nanomaterial dispersions through the same filter sequentially was developed. From this point onwards, this will be the methodology used in this work to fabricate these carbon OTEs, which has been widely explained in the electrode fabrication section. The new methodology provides homogeneous bilayer electrodes of these two carbon nanomaterials (GNPs/SWCNTs-OTEs).

A design of experiments was performed in order to evaluate the influence of the volume of the GNPs $\left(V_{G N P S}\right)$ and SWCNTs $\left(V_{S W C N T S}\right)$ dispersions used in the filtration step, on the spectroscopic and electrochemical behavior of the GNPs/SWCNTs-OTEs, analyzed in terms of transparency and conductivity, respectively. Transparency was evaluated by measuring the transmittance at $550 \mathrm{~nm}\left(T_{550}\right)$ and taking the PET sheet as reference spectrum. Meanwhile, conductivity was evaluated by measuring the voltammetric reversibility, expressed as the peak potential difference between the anodic and the cathodic peak $\left(\Delta E_{p}\right)$. Cyclic voltammetry experiments of $6 \times 10^{-4} \mathrm{M} \mathrm{FcMeOH}$ in $0.1 \mathrm{M} \mathrm{KCl}$ between $-0.20 \mathrm{~V}$ and 
$+0.60 \mathrm{~V}$ at $0.01 \mathrm{~V} \cdot \mathrm{s}^{-1}$ were carried out to measure the voltammetric reversibility. $T_{550}$ and $\Delta E_{p}$ were measured five times for each sample. With the aim of minimizing experimental costs, a response surface with only eleven runs in a rotatable central composite design $2^{2}$ with star and three center points was performed. $V_{G N P S}$ and $V_{S W C N T S}$ were the two experimental factors used to study the response variables $\left(T_{550}\right.$ and $\left.\Delta E_{p}\right)$. The order of the experiments was fully randomized. Preliminary studies were carried out to delimitate the range of variability of the two experimental factors, finding that the best range was between 0.55 and $3.2 \mathrm{~mL}$ for $V_{G N P s}$ (concentration of $5 \mathrm{mg} \cdot \mathrm{L}^{-1}$ ) and between 0.28 and $1.6 \mathrm{~mL}$ for $V_{S W C N T S}$ (concentration of 5 $\left.\mathrm{mg} \cdot \mathrm{L}^{-1}\right)$.

Figure 6.2.7 shows the response surfaces for $T_{550}$ and $\Delta E_{p}$ with respect to the values of $V_{G N P S}$ and $V_{S W C N T S}$. As can be seen in Figure 6.2.7a, $T_{550}$ is affected by both $V_{G N P S}$ and $V_{S W C N T S}$ because the two experimental factors are significant for the response. The optimal transparency is the maximum value of $T_{550}$, being logically achieved at the lowest values of these two factors, $V_{G N P S}$ and $V_{S W C N T S}$. $T_{550}$ decreases with increasing $V_{G N P S}$ and $V_{S W C N T S}$, but not exactly in the same scale. The increase of $V_{S W C N T S}$ contributes more than the increase of $V_{G N P S}$ to decrease the $T_{550}$. Meanwhile, as it is shown in Figure $6.2 .7 \mathrm{~b}$, conductivity follows a different trend. $V_{S W C N T S}$ is the only significant factor. The response surface consists of vertical regions, indicating that the increase of $V_{S W C N T S}$ is responsible for the decrease of $\Delta E_{p}$ which is related to a better conductivity of the electrode. If $V_{S W C N T S}$ is not high enough, there is not an interconnected network of SWCNTs and $\Delta E_{p}$ increases indicating a poor conductivity of the electrode. Besides, the influence of these GNPs to create a conducting interconnected network is really low, being always necessary the presence of SWCNTs. Therefore, the need to reach a percolation threshold of SWCNTs is undoubtedly 
required to allow the GNPs/SWCNTs bilayer to have a minimum conductivity to be used as OTEs. Indeed, the fact that carbon nanotubes act as an efficient supporting and catalytic material to enhance the electrochemical properties of graphene has been previously reported. ${ }^{371}$ Therefore, in terms of $\Delta E_{p}$, conductivity is almost independent of the amount of GNPs for each amount of SWCNTs. Thus, it is possible to fabricate SWCNTs electrodes modified with GNPs just making sure that there is an interconnected SWCNTs network as substrate.
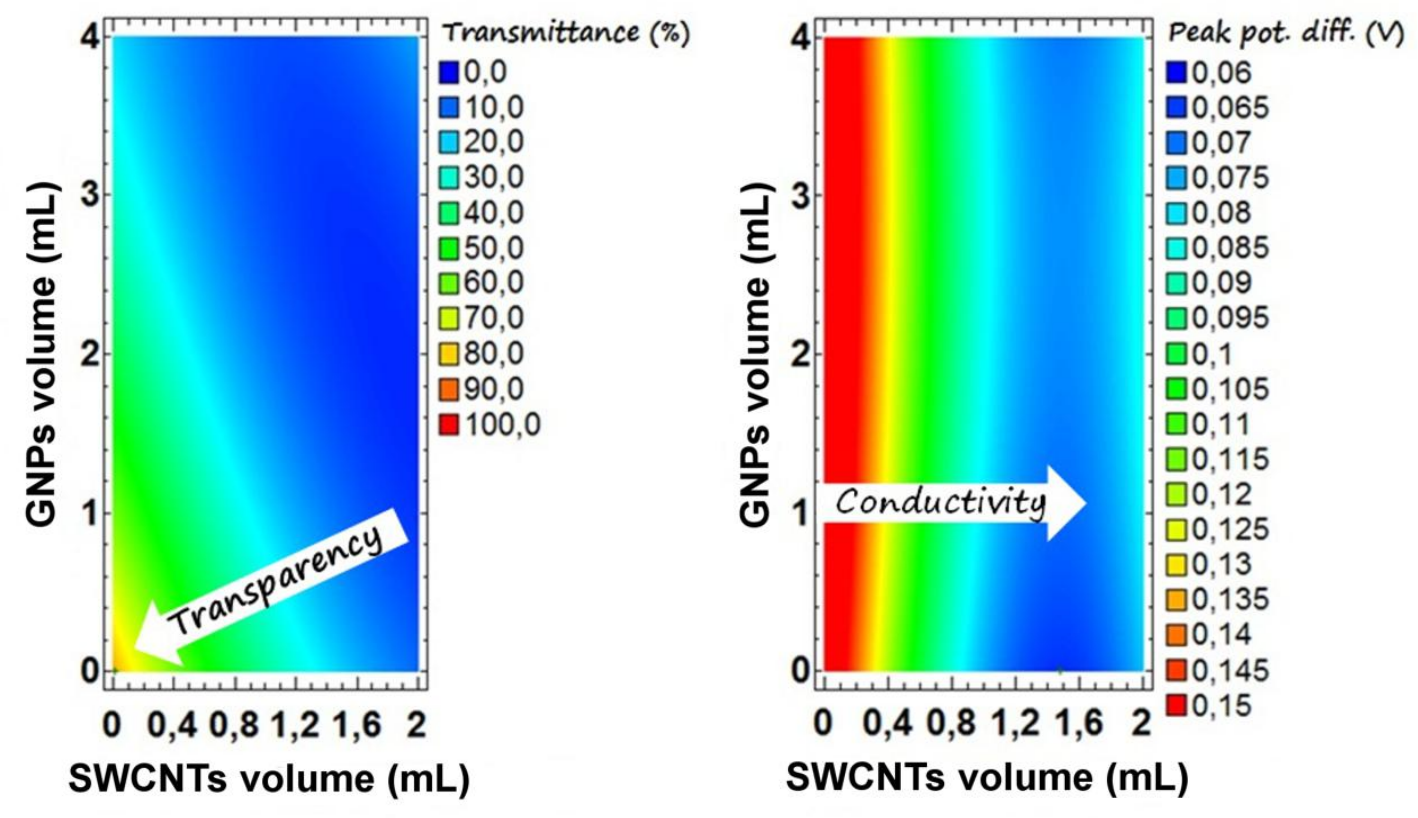

Figure 6.2.7. Response surfaces of the design of experiments for (a) transmittance of the GNPs/SWCNTs-OTEs at $550 \mathrm{~nm}, T_{550}$, and (b) peak potential difference, $\Delta E_{p}$, obtained in the cyclic voltammetry of $\mathrm{FcMeOH}$, with respect to $V_{G N P S}$ and $V_{S W C N T S}$.

It is noteworthy that high amounts of GNPs and SWCNTs provide voltammograms where the ratio between the intensity of the anodic and cathodic peaks is greater than one in reversible one-electron systems. This 
result has been previously reported for SWCNTs (section 6.1), ${ }^{73}$ indicating that the excess of the carbon nanomaterial can lead to unexpected electrochemical behaviors. Moreover, the transparency decreases considerably, leading to worse OTEs. Therefore, experiments performed in this design of experiments indicate that the amount of these carbon nanomaterials should be higher than a lower limit of SWCNTs to achieve a good conductivity of the film, and lower than an upper limit of both, GNPs and SWCNTs, to obtain a good transparency, avoiding unexpected electrochemical behaviors.

The main goal of this work is the fabrication of electrodes for spectroelectrochemistry with different GNPs/SWCNTs ratios, always with a good transparency and conductivity. The design of experiments has allowed us to prove a large number of possibilities to fabricate electrodes changing the amounts of GNPs and SWCNTs. However, $T_{550}$ is lower than $35 \%$ in approximately half of the design shown in Figure 6.2.7a, suitable for many applications but too low to be considered good for OTEs. For this reason, a smaller experimental domain is needed in order to study highly transparent GNPs/SWCNTs-OTEs.

Following the same strategy, a new design of experiments was performed changing both $V_{G N P S}$ and $V_{S W C N T S}$ between 0.1 and $0.5 \mathrm{~mL}$ (concentration of $\left.5 \mathrm{mg} \cdot \mathrm{L}^{-1}\right)$. Again, cyclic voltammetry of $6 \times 10^{-4} \mathrm{M} \mathrm{FcMeOH}$ in $0.1 \mathrm{M}$ $\mathrm{KCl}$ between $-0.20 \mathrm{~V}$ and $+0.60 \mathrm{~V}$ at $0.01 \mathrm{~V} \cdot \mathrm{s}^{-1}$ was performed. Results obtained with this second design of experiments were coherent with those of the previous one, but now they supplied more information. By reducing the experimental domain, $T_{550}$ increased to values between $48 \%$ and $95 \%$, clearly higher than those obtained in the first design of experiments where $T_{550}$ varied between $4 \%$ and $69 \%$. Figure 6.2 .8 shows the cyclic 
voltammograms registered with several GNPs/SWCNTs-OTEs with different conducting and optical properties obtained in this second design of experiments.

Analyzing the results related to the conductivity, two different behaviors were clearly observed depending on the amount of SWCNTs. As can be seen in Figure 6.2.8a, when $V_{S W C N T s}$ was lower than $0.3 \mathrm{~mL}$ ill-defined cyclic voltammograms were registered, indicating that the percolation threshold of the SWCNTs network was not achieved and yielding films with poor conductivity. In this case, increasing the amount of GNPs helps to improve the conductivity as can be observed in Figure 6.2.8a where better responses are obtained at higher $V_{G N P s}$ values for electrodes fabricated with $0.1 \mathrm{~mL}$ of the SWCNTs dispersion. The typical shape of the reversible voltammogram of $\mathrm{FcMeOH}$ is not observed (Figure 6.2.8a), but the higher the $V_{G N P S}$, the better the peak definition and the higher the current intensity. Significantly better electrochemical responses were obtained when $V_{S W C N T S}$ was high enough to establish a good SWCNTs interconnected network that guarantees a proper conductivity to the electrode (Figure 6.2.8b). Percolation threshold was achieved by filtering at least $0.3 \mathrm{~mL}$ of the SWCNTs dispersion, corresponding to $c a .0 .002 \mathrm{mg}$ of SWCNTs per $\mathrm{cm}^{2}$ of electrode area. In this case, all GNPs/SWCNTs-OTEs show a really good electrochemical performance and a high transparency. The presence of a higher $V_{G N P S}$ did not show any significant difference in terms of electrochemical behavior when a good interconnected SWCNTs network made by filtering $0.5 \mathrm{~mL}$ of the SWCNTs dispersion is established. This fact can be explained in terms of achieving a reversible electrochemical behavior. On the contrary, transparency is highly influenced by $V_{G N P S}$. 

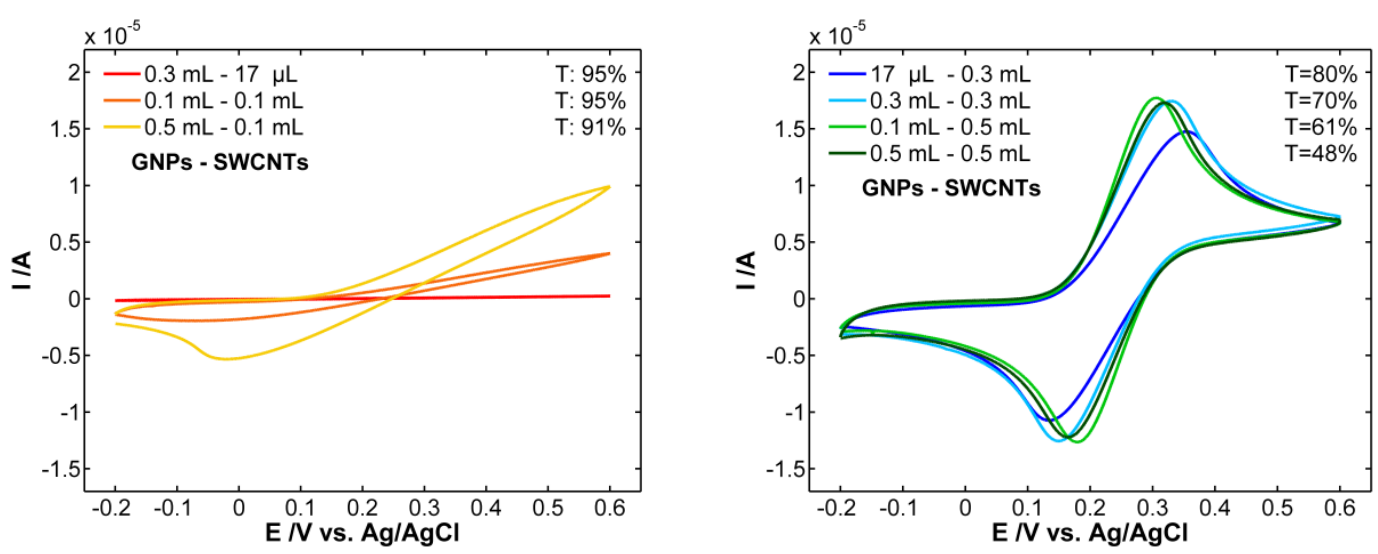

Figure 6.2.8. Cyclic voltammograms of different GNPs/SWCNTs-OTEs (a) below percolation threshold of SWCNTs network, and (b) above percolation threshold of SWCNTs network.

Thus, depending on the specific application of the GNPs/SWCNTs-OTEs, different GNPs/SWCNTs ratios can be selected with, a priori, excellent results. As it is shown in Figure 6.2.8b, the strategy of design of experiments has allowed us to fabricate a collection of GNPs/SWCNTsOTEs easily, with different GNPs/SWCNTs ratios, using our press-transfer methodology and offering suitable transparency and good electrochemical properties.

A set of cyclic voltammetries of $6 \times 10^{-4} \mathrm{M} \mathrm{FcMeOH}$ in $0.1 \mathrm{M} \mathrm{KCl}$ between $-0.20 \mathrm{~V}$ and $+0.60 \mathrm{~V}$ at different scan rates, between $0.002 \mathrm{~V} \cdot \mathrm{s}^{-1}$ and $0.250 \mathrm{~V} \cdot \mathrm{s}^{-1}$, were performed to study the electrochemical behavior of GNPs/SWCNTs-OTEs (Figure 6.2.9). Here, a GNPs/SWCNTs-OTE obtained using $V_{G N P S}=0.1 \mathrm{~mL}$ and $V_{S W C N T S}=0.5 \mathrm{~mL}$ was used. A linear relationship between the anodic peak current $\left(I_{p}\right)$ and the square root of the potential scan rate $\left(v^{1 / 2}\right)$ was obtained. Therefore, the oxidation of $\mathrm{FcMeOH}$ is a diffusion-controlled electrochemical process, and according to 
Randles-Sevcik equation, Equation (6.2.1), the diffusion coefficient of FcMeOH can be estimated:

$$
I_{p}=0.4463\left(\frac{F^{3}}{R T}\right)^{1 / 2} n^{3 / 2} A D^{1 / 2} C \cdot v^{1 / 2}
$$

where $F$ is the Faraday's constant $\left(96485 \mathrm{C} \cdot \mathrm{mol}^{-1}\right), R$ the ideal gas constant $\left(8.314 \mathrm{~J} \cdot \mathrm{mol}^{-1} \cdot \mathrm{K}^{-1}\right), T$ the temperature $(293 \mathrm{~K}), n$ the number of electrons transferred in the redox reaction (1), $A$ the electrode area $\left(0.3925 \mathrm{~cm}^{2}\right), D$ the diffusion coefficient and $C$ the bulk concentration $\left(6 \times 10^{-7} \mathrm{M} \cdot \mathrm{cm}^{-3}\right)$. From the slope of the calibration curve of $I_{p}$ versus $v^{1 / 2}$ (inset of Figure 6.2.9), an experimental value of $5.7 \times 10^{-6} \mathrm{~cm}^{2} \cdot \mathrm{s}^{-1}$ is obtained, very similar to those in literature $\left(6.1 \times 10^{-6} \mathrm{~cm}^{2} \cdot \mathrm{s}^{-1}\right){ }^{372}$

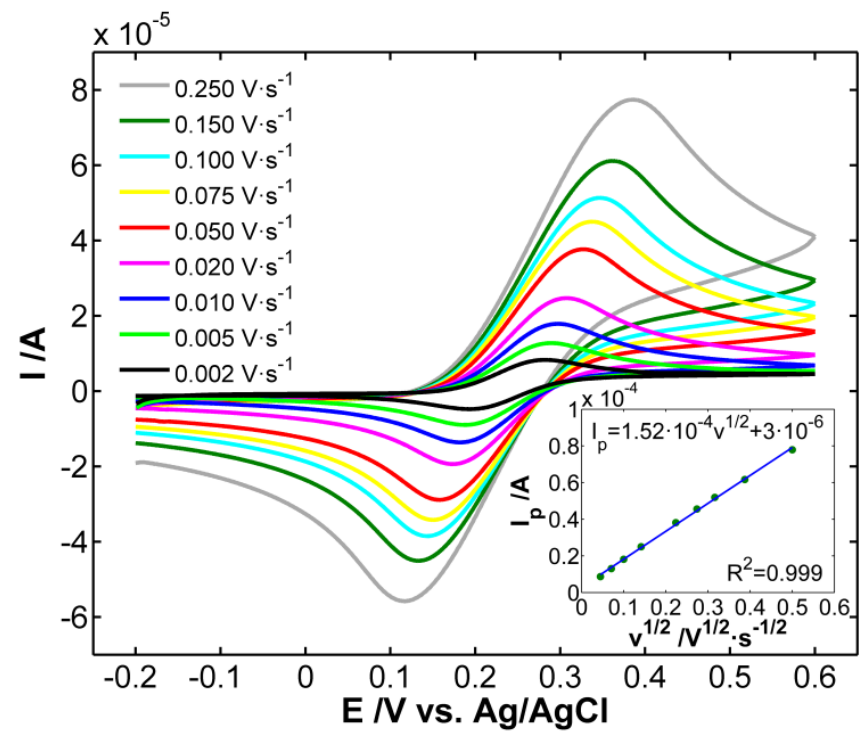

Figure 6.2.9. Cyclic voltammograms of $\mathrm{FcMeOH}$ at different potential scan rates between $0.002 \mathrm{~V} \cdot \mathrm{s}^{-1}$ and $0.250 \mathrm{~V} \cdot \mathrm{s}^{-1}$. Inset: Randles-Sevcik behavior.

Two different applications of this type of OTEs are shown in Figure 6.2.10 and Figure 6.2.12. 
First, a GNPs/SWCNTs-OTE, fabricated with $V_{G N P S}=0.3 \mathrm{~mL}$ and $V_{S W C N T s}$ $=0.58 \mathrm{~mL}$ (FE-SEM image in Figure 6.2.3), was used in order to demonstrate the usefulness of GNPs/SWCNTs-OTEs for electroanalytical purposes. A set of different calibration samples of $\mathrm{FcMeOH}$ in $0.1 \mathrm{M} \mathrm{KCl}$ were prepared and cyclic voltammetry experiments between $-0.20 \mathrm{~V}$ and $+0.60 \mathrm{~V}$ at $0.01 \mathrm{~V} \cdot \mathrm{s}^{-1}$ were performed (Figure 6.2.10). As can be seen in the calibration curve shown in the inset of Figure 6.2.10, the anodic peak current intensity follows a highly linear relationship with $\mathrm{FcMeOH}$ concentration in the $5-216 \mu \mathrm{M}$ range $\left(R^{2}=0.9999, S_{y x}=3.4 \times 10^{-8}\right)$.

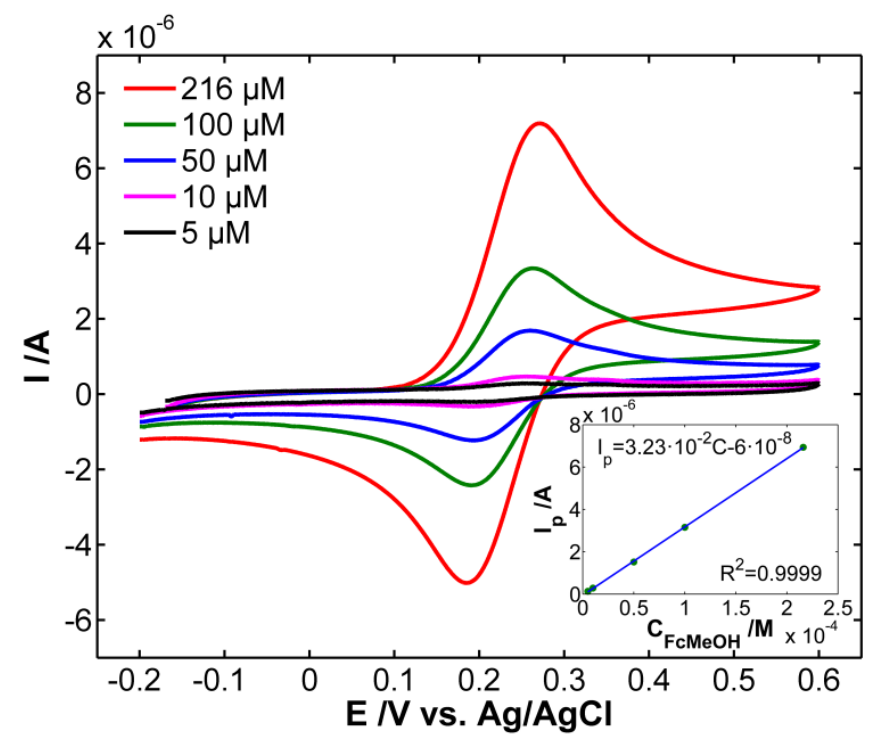

Figure 6.2.10. Cyclic voltammograms carried out with a GNPs/SWCNTs-OTE using FcMeOH concentrations ranged between 5 and $216 \mu \mathrm{M}$. Inset: calibration curve of $\mathrm{FcMeOH}$.

GNPs/SWCNTs films have a resistance that contributes to the measured $\Delta E_{p}$. A plot of $\Delta E_{p}$ versus $\mathrm{FcMeOH}$ concentration, Figure 6.2.11, shows a linear behavior indicating the existence of an uncompensated resistance, according to Ohm's law, because the higher the concentration, the higher 
the current, Figure 6.2.10. At concentrations lower than $10 \mu \mathrm{M}$, there is not influence of this uncompensated resistance of the film because the current is very low and $\Delta E_{p}$ takes the expected value of $0.059 \mathrm{~V}$.

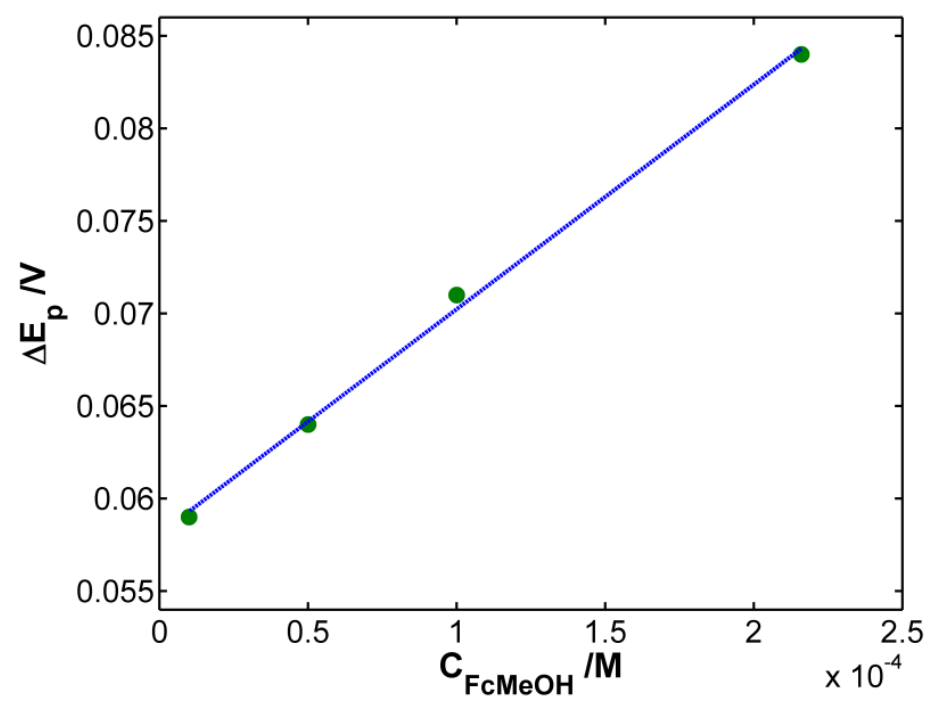

Figure 6.2.11. Peak potential difference versus concentration of $\mathrm{FcMeOH}$ for a GNPs/SWCNTs-OTE fabricated with $V_{G N P S}=0.3 \mathrm{~mL}$ and $V_{S W C N T S}=0.58 \mathrm{~mL}$. Data corresponding to Figure 6.2.10.

In addition, GNPs/SWCNTs-OTEs were also tested with a conducting polymer such as PEDOT which shows color changes associated with its oxidation state. Here, a GNPs/SWCNTs-OTE was fabricated with $V_{G N P s}=$ $0.3 \mathrm{~mL}$ and $V_{S W C N T S}=0.4 \mathrm{~mL}$. A $100 \mu \mathrm{L}$ drop of PEDOT:PSS diluted 1:100 in water was placed on the electrode surface covering it entirely. The electrode was dried at room temperature for two days whereupon a homogeneous and highly transparent GNPs/SWCNTs-OTE modified with PEDOT:PSS was obtained (inset of Figure 6.2.12). Ten cyclic voltammetry scans in $0.2 \mathrm{M} \mathrm{LiClO}_{4}$ between $-0.70 \mathrm{~V}$ and $+0.70 \mathrm{~V}$ at $0.1 \mathrm{~V} \cdot \mathrm{s}^{-1}$ were carried out using a $\mathrm{Pt}$ wire as $\mathrm{CE}$, a homemade $\mathrm{Ag} / \mathrm{AgCl} / \mathrm{KCl} 3 \mathrm{M}$ as $\mathrm{RE}$ 
and the GNPs/SWCNTs-OTE modified with PEDOT:PSS as WE. One spectrum in normal transmission configuration between 450 and $950 \mathrm{~nm}$ was taken every $100 \mathrm{~ms}$ along the experiment. A suitable performance of the GNPs/SWCNTs-OTE modified with PEDOT during the normal transmission spectroelectrochemistry experiment is observed in the threedimensional contour shown in Figure 6.2.12. PEDOT is uncolored in its oxidized and blue in its neutral state. ${ }^{27}$ The spectra evolution with time/potential demonstrates the excellent spectroelectrochemistry behavior of PEDOT in these GNPs/SWCNTs-OTEs, where a great adhesion of the polymer to the GNPs is achieved.

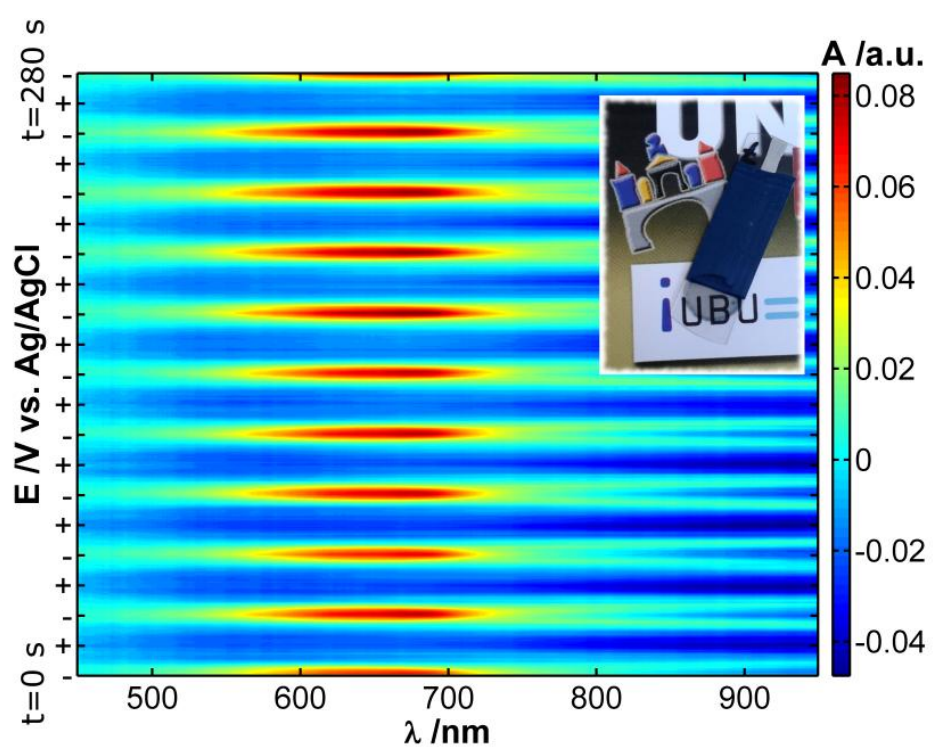

Figure 6.2.12. 3D spectroelectrochemistry contour during ten consecutive doping/dedoping scans of PEDOT in a GNPs/SWCNTs-OTE. In the $y$ axis, "-” is referred to a potential applied of $-0.70 \mathrm{~V}$ and "+" to a potential applied of +0.70 V. Inset: GNPs/SWCNTs-OTE modified with PEDOT by drop casting.

As can be seen, several GNPs/SWCNTs-OTEs have been easily fabricated using the proposed methodology, allowing us to design OTEs with 
different transparency and conductivity depending on the application in a reproducible way.

In order to demonstrate the excellent reproducibility of the GNPs/SWCNTs-OTEs fabrication method, five cyclic voltammograms performed with five different electrodes are plotted in Figure 6.2.13, and their corresponding parameters are displayed in Table 6.2.1. The electrode area was limited to $0.3925 \mathrm{~cm}^{2}$. As can be observed, very reproducible values are obtained, $0.100 \pm 0.005 \mathrm{~V}$ for $\Delta E_{p}$ and $15.54 \pm 0.15 \mu \mathrm{A}$ for the anodic peak current. These GNPs/SWCNTs-OTEs were fabricated with the same experimental conditions $\left(V_{G N P S}=0.4 \mathrm{~mL}\right.$ and $\left.V_{S W C N T S}=0.5 \mathrm{~mL}\right)$. A FE-SEM image of one of these electrodes can be found in Figure 6.2.14.

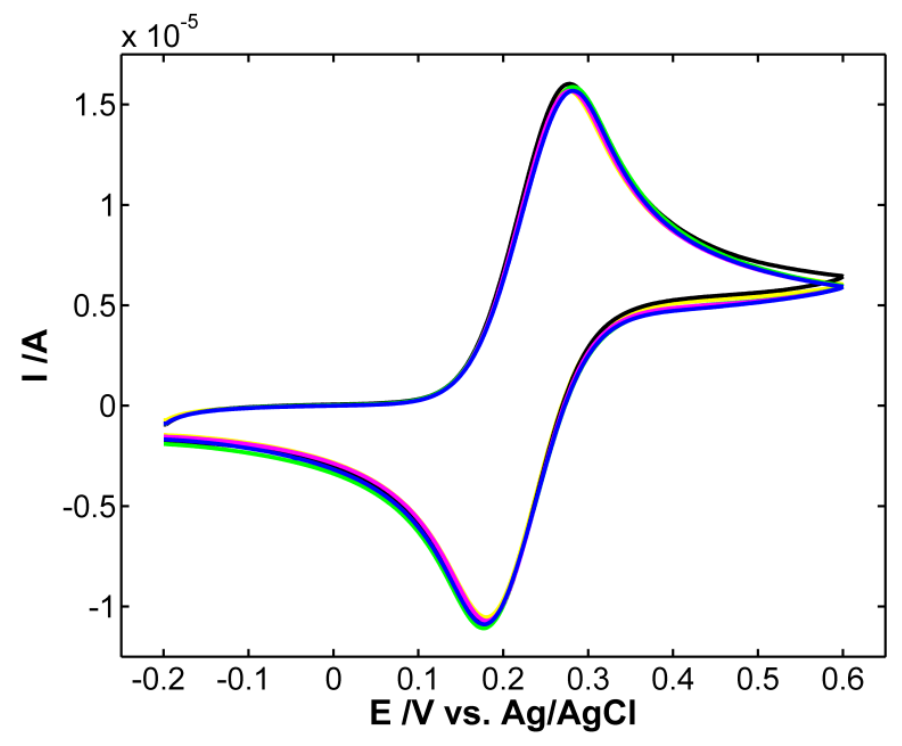

Figure 6.2.13. Five cyclic voltammograms of $6 \times 10^{-4} \mathrm{M} \mathrm{FcMeOH}$ in $0.1 \mathrm{M}$ $\mathrm{KCl}$ between $-0.20 \mathrm{~V}$ and $+0.60 \mathrm{~V}$ at a potential scan rate of $0.01 \mathrm{~V} \cdot \mathrm{s}^{-1}$ obtained with five different GNPs/SWCNTs-OTEs to evaluate the reproducibility of our proposed methodology. All GNPs/SWCNTs-OTEs were fabricated with $V_{G N P s}=$ $0.4 \mathrm{~mL}$ and $V_{S W C N T S}=0.5 \mathrm{~mL}$ and an area of $0.3925 \mathrm{~cm}^{2}$. 
Table 6.2.1. Anodic and cathodic peak potentials, peak potential difference, and anodic and cathodic peak currents of the five cyclic voltammograms plotted in Figure 6.2.13.

\begin{tabular}{cccccc}
\hline Electrode & $\begin{array}{c}\text { Anodic } \\
\text { peak } \\
\text { potential } \\
(\mathbf{V})\end{array}$ & $\begin{array}{c}\text { Cathodic } \\
\text { peak } \\
\text { potential } \\
(\mathbf{V})\end{array}$ & $\begin{array}{c}\text { Peak } \\
\text { potential } \\
\text { difference } \\
(\mathbf{V})\end{array}$ & $\begin{array}{c}\text { Anodic } \\
\text { peak } \\
\text { current } \\
(\boldsymbol{\mu A} \mathbf{A})\end{array}$ & $\begin{array}{c}\text { Cathodic } \\
\text { peak } \\
\text { current } \\
(\boldsymbol{\mu A})\end{array}$ \\
\hline $\mathbf{1}$ & 0.276 & 0.180 & 0.096 & 15.468 & -14.867 \\
$\mathbf{2}$ & 0.278 & 0.180 & 0.098 & 15.711 & -15.304 \\
$\mathbf{3}$ & 0.282 & 0.178 & 0.104 & 15.610 & -15.141 \\
$\mathbf{4}$ & 0.279 & 0.181 & 0.098 & 15.456 & -14.865 \\
$\mathbf{5}$ & 0.282 & 0.178 & 0.104 & 15.448 & -14.706 \\
\hline
\end{tabular}

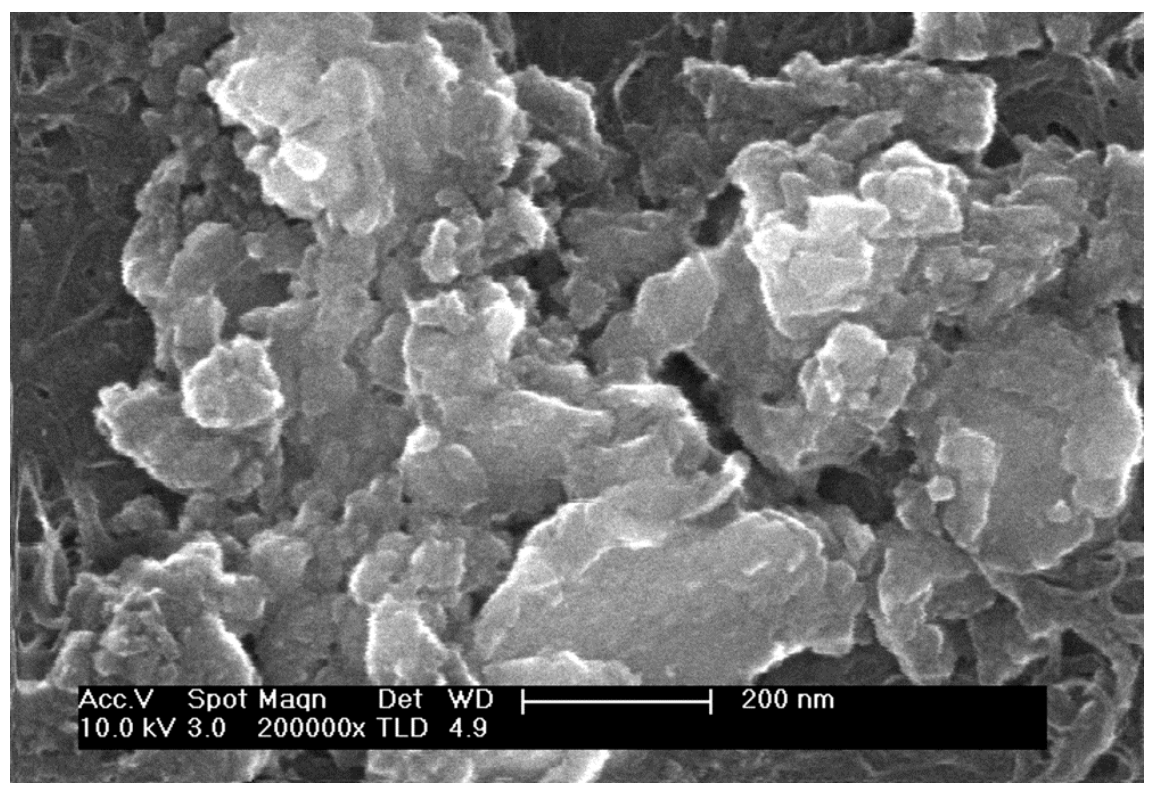

Figure 6.2.14. FE-SEM image of a GNPs/SWCNTs-OTE fabricated with $V_{G N P s}$ $=0.4 \mathrm{~mL}$ and $V_{S W C N T S}=0.5 \mathrm{~mL}$. 


\subsubsection{Conclusions and Future Work}

In this work we have fabricated a new type of hybrid OTEs based on commercial SWCNTs and GNPs, with a methodology that can be easily used to prepare different types of bilayer films. The proposed method is fast, simple, reproducible, versatile, and inexpensive, affording preparation of homogeneous and clean GNPs/SWCNTs-OTEs in any laboratory, while circumventing some disadvantages of previous processing methods.

GNPs/SWCNTs-OTEs have been fabricated by filtration of the GNPs and SWCNTs dispersions, separately, and press-transferring the bilayer film formed on the membrane to a PET support, not requesting an underlying conductive substrate. The SWCNTs side of the hybrid film is in contact with the PET support and the GNPs film is on the upper side.

Transparency and conductivity have been optimized with a strategy based on design of experiments.

Transparency is affected by both carbon nanomaterials but more intensively by SWCNTs because they contribute more than GNPs to decreasing transmittance.

A minimum amount of SWCNTs is needed to establish a wellinterconnected SWCNTs network (percolation threshold) which is undoubtedly required to ensure a good conductivity for these hybrid GNPs/SWCNTs-OTEs.

Therefore, we show the need to create a conducting layer of SWCNTs to allow the GNPs/SWCNTs-OTEs to have a suitable conductivity with a good transparency. 
GNPs/SWCNTs-OTEs with different ratios of both carbon nanomaterials and excellent transparency and conductivity have been fabricated.

Our work lays the groundwork for fabricating a conducting SWCNTs layer that can be homogeneously modified with other materials (in this case GNPs), that are able to form a conducting film or not, such as the particular case of this work.

In order to demonstrate the good performance of these GNPs/SWCNTs-OTEs for different applications, they have been checked by electrochemical quantification procedures and by normal transmission spectroelectrochemistry to observe the PEDOT behavior.

Benefits associated with carbon based OTEs are expected to be improved with the use of GNPs and SWCNTs together.

Currently, we are optimizing electrodes with different types of nanomaterials in order to improve the sensitivity of the OTEs for the detection of neurotransmitters and other compounds of biological interest. In addition, methodologies mixing different nanomaterials in the same dispersion are being tested. 

6.3. Development of a Novel Bidimensional Spectroelectrochemistry Cell Using Transfer Single-Walled Carbon Nanotubes Films as Optically Transparent Electrodes 



\subsubsection{Some Important Points to Keep in Mind}

A really easy method to transfer commercial SWCNTs on different substrates is proposed, based on the one explained in section $6.1,^{73}$ but removing the press-transference step and, thus, impressively increasing the number of substrates on which SWCNTs can be transferred from the filter membrane.

Therefore, homogeneous transferences of SWCNTs films to nonconductor and transparent supports, such as PET, glass, and quartz, and to conductor supports, such as ITO, aluminum, HOPG, and GC, were achieved just with a slight finger pressure, using a very fast, reproducible, versatile, clean, and standard methodology.

In order to test these transferences, SWCNTs films transferred on quartz were used as working UV-Vis OTEs due to their optimal electrical and optical properties, even in the UV region.

Due to the lack of commercially available BSEC cells, probably due to the technical complexity of this technique, a new, easy-to-use, and homemade BSEC cell based on optical fibers is presented in this work.

The use of optical fibers in spectroelectrochemistry attracts great attention mainly due to their multiple advantages to guide the light beam. ${ }^{345,373}$ In addition, it is worth noting the successful use of optical fibers in biochemical applications. ${ }^{374}$

The novel BSEC cell is particularly simple in both the assembly of all parts and the alignment of the light beams, allowing for the measurement in both normal and parallel configuration in the UV-Vis spectral region. 
As is known, $\mathrm{FcMeOH}$ is an electroactive compound that shows a simple, well-defined, one-electron chemically reversible electrochemical process. For these reasons, it has been commonly used in electrochemistry as a redox probe in aqueous solution. However, $\mathrm{FcMeOH}$ has been scarcely studied by spectroelectrochemistry ${ }^{375,376}$ and never by BSEC.

Nevertheless, recently, $\mathrm{FcMeOH}$ has been utilized for interesting applications, to modify carbon nanotubes electrodes in the field of molecular memory ${ }^{377}$ and as a mediator to improve electron transfer, for example, in detection assays of glucose, ${ }^{378,379}$ ascorbic acid, ${ }^{380}$ and lipid hydroperoxides, ${ }^{381}$ and to explore $\mathrm{Ag}^{+}$toxicity on single living fibroblast cells. $^{382}$

For this reason, both the BSEC cell and the SWCNTs-OTEs with quartz support were tested with $\mathrm{FcMeOH}$, which is studied and characterized, demonstrating its abilities to be used as a redox couple probe not only in electrochemistry but also in spectroelectrochemistry.

The differences between the signals obtained in normal transmission and parallel configuration using BSEC have been established.

The molar absorption coefficient of electrogenerated redox substances (in this case $\mathrm{FcMeOH}^{+}$species) can be calculated at any wavelength of the UV-Vis spectrum from the relationship between normal configuration absorbance and charge (without the need to know either the optical path length or the $\mathrm{FcMeOH}$ concentration), and this value can be checked with the absorbance in parallel arrangement, all in a single experiment. 


\subsubsection{Experimental Section}

\subsubsection{Reagents and Materials}

SWCNTs (Sigma-Aldrich), DCE (99.8\% for HPLC, Acros Organics), nitrocellulose membrane (filter pore size $0.8 \mu \mathrm{m}$, Millipore), quartz (Sugelabor), silver conductive paint (Electrolube), and nail polish (Procesos Cosméticos) were used to fabricate the SWCNTs-OTEs. FcMeOH (97\%, Sigma-Aldrich) and $\mathrm{KCl}$ (Acros Organics) were used to prepare the solutions. PET, GC, aluminum foil, HOPG, glass and ITO were the supports used to transfer the SWCNTs films. PMMA, nuts, and bolts were the material to fabricate the cell.

All the reagents were used as received without further purification. All chemicals were analytical grade. Aqueous solutions were prepared freshly using high purity water $\left(18.2 \mathrm{M} \Omega \cdot \mathrm{cm}\right.$ resistivity at $25{ }^{\circ} \mathrm{C}$, Milli-Q A10 system, Millipore).

\subsubsection{Instrumentation}

BSEC setup includes a potentiostat/galvanostat (PGSTAT302N, Metrohm Autolab), a halogen-deuterium light source (AvaLight-DH-S-BAL, Avantes), a bifurcated optical fiber (600 $\mu$, Ocean Optics), bare optical fibers (100 $\mu \mathrm{m}$, Ocean Optics), a collimating lens, an optical fiber probe (200 $\mu \mathrm{m}$, Avantes), and two spectrometers (QE65000 198-1006 nm for parallel configuration and QE65000 250-1045 nm for normal transmission configuration, both from Ocean Optics). A tip-sonicator (CY-500, Optic 
ivymen System) was also used to disperse properly the SWCNTs in DCE. FE-SEM images were recorded on a Zeiss SUPRA 55-VP microscope.

For safety considerations, all handling and processing were performed carefully, particularly when DCE was used. SWCNTs dispersions were stored in tempered glass material, nitrogen flushed and film coated.

\subsubsection{Single-Walled Carbon Nanotubes Film Preparation and Transfer}

The need to transfer commercial carbon nanotubes onto different types of supports in a homogeneous, reproducible, versatile, quick, and inexpensive way makes this step very important. Our new methodology is capable of transferring SWCNTs to many different supports, including conducting/insulating, polymeric/metal/carbon, opaque/transparent, flexible/rigid, and resistant/fragile supports. In this work, the transfers of SWCNTs films have been successfully made to pieces of PET, glass, quartz, ITO, aluminum, HOPG, and GC of different shapes and sizes.

Our methodology begins with the preparation of a dispersion of $0.5 \mathrm{mg}$ of SWCNTs in $100 \mathrm{~mL}$ of DCE $\left(5 \mathrm{mg} \cdot \mathrm{L}^{-1}\right)$. SWCNTs dispersion was performed in three sonication steps: (1) $0.5 \mathrm{mg}$ of SWCNTs were weighed and $10 \mathrm{~mL}$ of DCE added, and it was sonicated at $250 \mathrm{~W}$ for $15 \mathrm{~min}$; (2) DCE was added to obtain a dispersion volume of $c a .90 \mathrm{~mL}$ which was sonicated at $100 \mathrm{~W}$ for $20 \mathrm{~min}$ more; and (3) the dispersion was sonicated more vigorously at $250 \mathrm{~W}$ for another $20 \mathrm{~min}$. Finally, the volume was adjusted to $100 \mathrm{~mL}$. To ensure always a good homogeneity in this dispersion, avoiding SWCNTs agglomeration, $10 \mathrm{~mL}$ of the dispersion were sonicated for $3 \mathrm{~min}$ at $100 \mathrm{~W}$ before preparing the transfers. Then, the 
desired volume, in this case $0.8 \mathrm{~mL}$, was filtered under vacuum through the nitrocellulose filter, where the SWCNTs formed a homogeneous film whose transparency and conductivity depend on the filtered volume of the SWCNTs dispersion (section 6.1). ${ }^{73}$ Immediately afterward, without letting the SWCNTs and the filter dry (this is the key point to transfer the SWCNTs film at very low pressure), the filter was placed on the chosen support with the SWCNTs film in front of it. The back face of the filter was covered with a PET sheet which was slightly pressed just with fingers for no more than $10 \mathrm{~s}$. Finally, the PET sheet was removed, and the filter was dried at room temperature for $5 \mathrm{~min}$. Transfer process was completed when the filter was gently separated from the support using tweezers. Homogeneous and circular SWCNTs films of $10 \mathrm{~mm}$ in diameter were obtained. Homogeneity and transparency of the transferences to different supports are clearly evident in Figure 6.3.1.

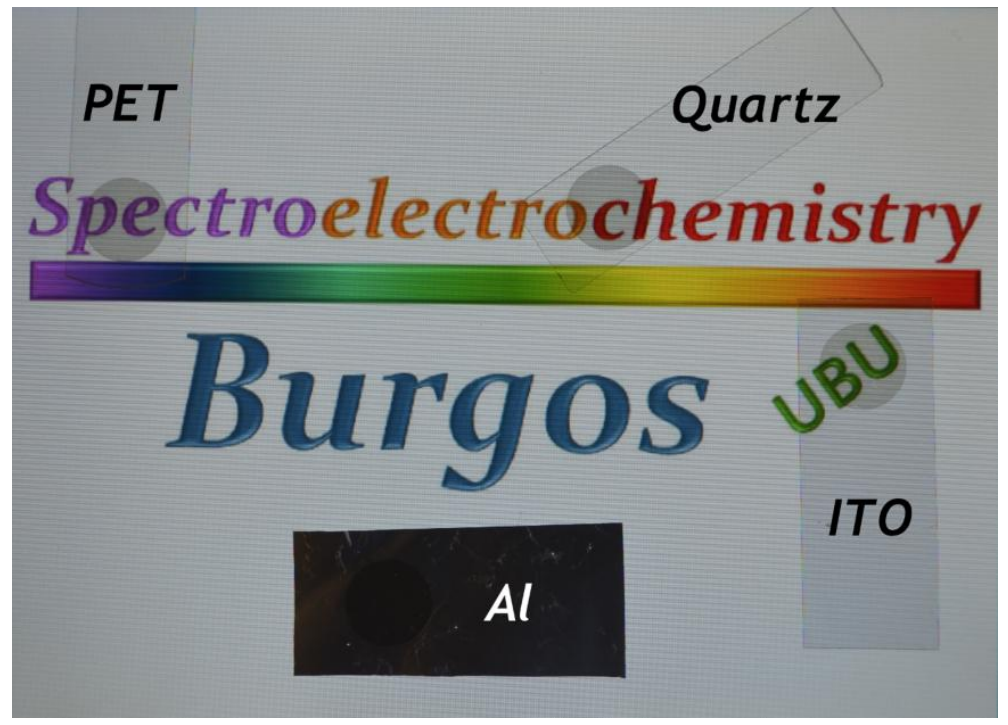

Figure 6.3.1. SWCNTs transferred on PET, quartz, ITO and aluminum. Homogeneity and transparency of the film transferences to different supports are evident. It is even possible to distinguish the different colors of the image through the clearly homogeneous and optically transparent SWCNTs films. 
Several new features and advantages of this methodology can be highlighted when compared to others cited above. A hydraulic press is not needed, which expands greatly the possibility of transferring the SWCNTs film to almost any support, particularly fragile supports such as quartz or glass and supports that deform under pressure. Furthermore, SWCNTs are dispersed in DCE without surfactants, and chemicals are not used to remove the filter from the SWCNTs film. Therefore, very clean, homogeneous, and reproducible films are obtained using this methodology.

As a proof of concept, quartz was chosen as support to fabricate the SWCNTs-OTEs due to its transparency in the UV-Vis region. Moreover, quartz is a rigid and fragile material that breaks under pressure. Thus, our previous press-transfer methodology (section 6.1) ${ }^{73}$ is not useful to transfer the film. Two FE-SEM images of a SWCNTs film transferred on a quartz support using the new methodology are shown in Figure 6.3.2.

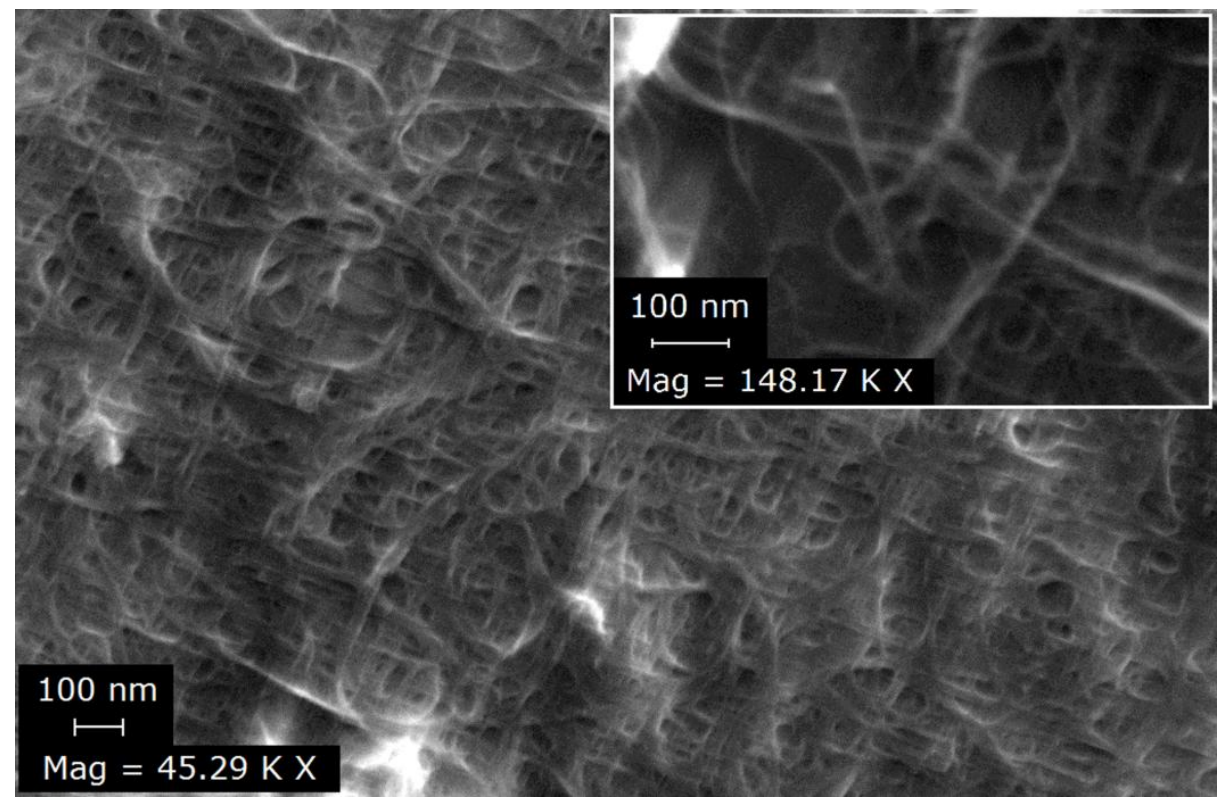

Figure 6.3.2. FE-SEM image of a $0.8 \mathrm{~mL}$ SWCNTs film transferred on quartz. Inset: Higher magnification FE-SEM image to observe SWCNTs in detail. 


\subsubsection{Electrode Fabrication}

Once the SWCNTs film was transferred on the support, the electrical contact was made with silver conductive paint from the SWCNTs film to the edge of the quartz. It was dried in an oven at $75{ }^{\circ} \mathrm{C}$ for $45 \mathrm{~min}$. After cooling, silver was electrically isolated using transparent nail polish, which was also dried at room temperature, ensuring a good covering and resistance to aqueous solutions. Other insulators can be used depending on the application of the electrode.

The SWCNTs-OTE thus fabricated by filtering $0.8 \mathrm{~mL}$ of the SWCNTs dispersion had a transmittance around $60 \%$ at $550 \mathrm{~nm}$, in agreement with the results obtained previously for press-transfer SWCNTs-OTEs (section $6.1)^{73}$

\subsubsection{Design and Fabrication of the Optical Fiber Bidimensional Spectroelectrochemistry Cell}

A photograph, a schematic view of the disassembled cell and a detailed schematic view of the experimental setup are shown in Figure 6.3.3.

The BSEC cell was fabricated in PMMA by using a high precision $\mathrm{CO}_{2}$ laser cutting machine. The cell consists of three different PMMA pieces with holes in the corners to set them with nuts and bolts in a reproducible way. The lateral dimensions are $5 \times 3.5 \mathrm{~cm}$, and the height when the BSEC cell is assembled is $1.6 \mathrm{~cm}$.

The bottom piece of the cell (1 in Figure 6.3.3b) has a cylindrical hole, drilled in its center, to place a collimating lens where the optical fiber from 
the light source is connected for normal transmission configuration measurements.

The middle piece ( 2 in Figure 6.3.3b) has a rectangular space to introduce the electrode. Eleven microchannels were done at each part of the rectangular space to accurately align the optical fiber from the light source with the optical fiber to the spectrometer in parallel arrangement. These microchannels ensure the correct alignment of the optical fibers at any optical path length, offering the opportunity to study spectroscopically the electron transfer at different locations of the electrode surface area. The light beam in parallel configuration passes parallel and close to the electrode surface, sampling only the solution adjacent to the electrode. In the experiments shown in this work, the parallel light beam is collected by a $100 \mu \mathrm{m}$ bare optical fiber placed a known distance away from a $100 \mu \mathrm{m}$ light emitting bare optical fiber. A great advantage of this experimental setup is the fact that the optical fibers diameter and the distance between the fibers can be easily changed.

Finally, the upper piece ( 3 in Figure 6.3.3b) has a rectangular hole to introduce the solution, the RE, the $\mathrm{CE}$, the optical fiber probe to collect the light beam that passes through the OTE, and the solution in normal configuration, and it is conducted to the second spectrometer.

The homemade BSEC cell described here has a simple assembly and is very easy-to-use. It was optimized to be utilized in normal transmission and parallel configurations in a semi-infinite diffusion regime. Little changes in the arrangement of some elements would allow us to work in parallel and normal reflection configuration or in the thin-layer diffusion regime. 

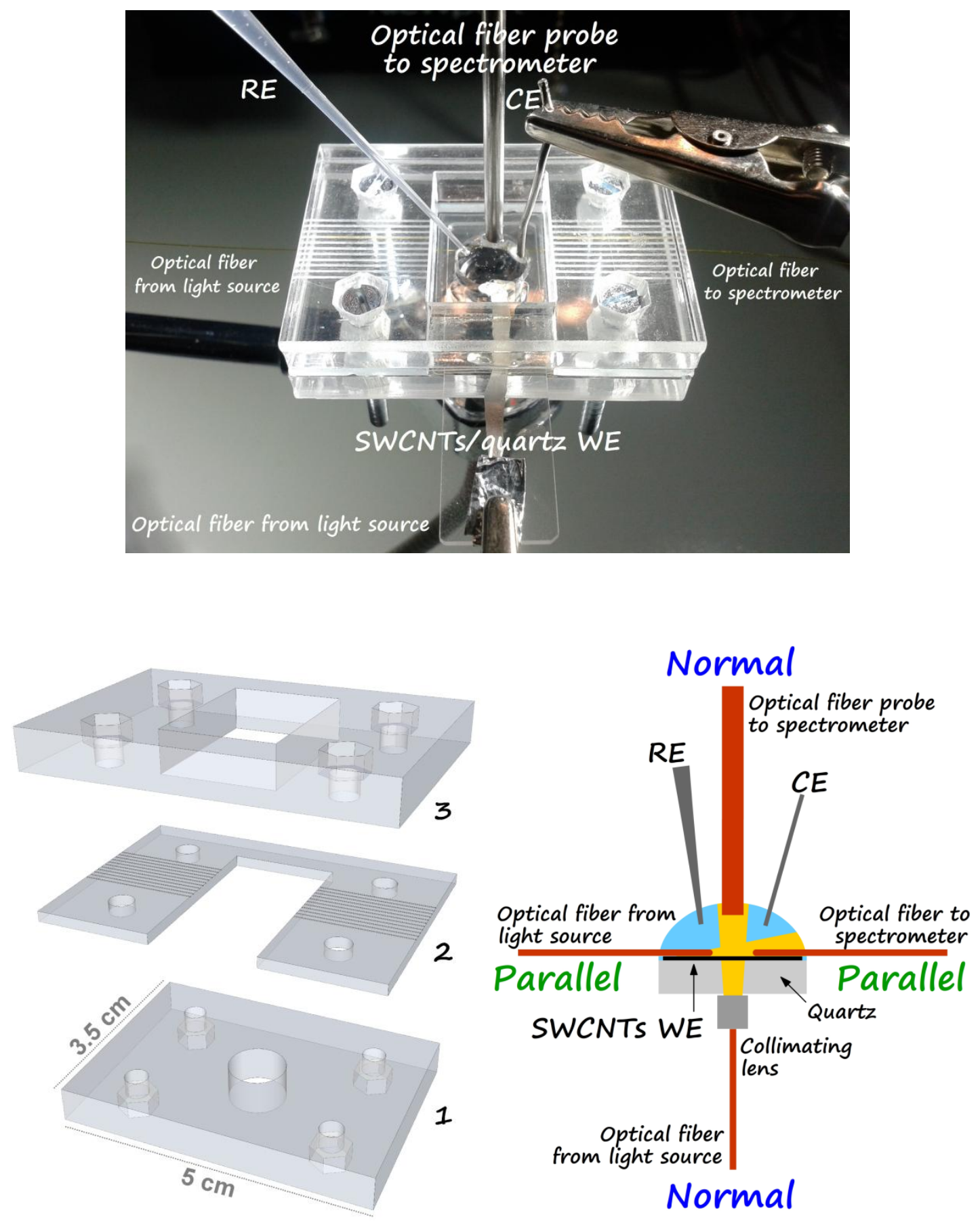

Figure 6.3.3. (a) Photograph of the assembled cell ready to measure, (b) schematic view of the disassembled cell, and (c) detailed schematic view of the experimental setup. 


\subsubsection{Experimental Setup for Bidimensional Spectroelectrochemistry Measurements}

The light beam from the halogen-deuterium source was conducted by a 600 $\mu \mathrm{m}$ bifurcated optical fiber to the BSEC cell, allowing the light to pass through the solution adjacent to the electrode surface in parallel configuration and, simultaneously, to pass through the OTE and the solution in normal transmission configuration.

In parallel arrangement, the bifurcated optical fiber was coupled with a 100 $\mu \mathrm{m}$ bare optical fiber that was placed in one of the 11 microchannels of the cell touching partially the electrode surface. Another $100 \mu \mathrm{m}$ bare optical fiber was placed in the corresponding microchannel, just in front of the previous one, touching also the electrode surface. This second optical fiber was used to collect the light beam after sampling the solution close to the electrode, and it was directly conducted to the spectrometer.

In normal transmission configuration, a lens collimated the light beam from the bifurcated $600 \mu \mathrm{m}$ optical fiber to the electrode, allowing the light to pass through the solution and the OTE. The transmitted light was collected by a $200 \mu \mathrm{m}$ optical fiber probe, and it was conducted to the other spectrometer.

The optical path length in parallel configuration is the distance between the two $100 \mu \mathrm{m}$ bare optical fibers, which was $2.1 \mathrm{~mm}$, while the separation between the optical fiber probe and the electrode surface was $c a .1 .5 \mathrm{~mm}$.

In all experiments, $150 \mathrm{~ms}$ was selected as the integration time for the spectra acquisition in parallel configuration and $50 \mathrm{~ms}$ in normal arrangement. A $100 \mu \mathrm{L}$ solution drop was placed on the WE surface, covering the end of the optical fibers for parallel measurements and the 
optical fiber probe for normal configuration. Finally, a homemade $\mathrm{Ag} / \mathrm{AgCl} / \mathrm{KCl} 3 \mathrm{M} \mathrm{RE}$ and a platinum wire $\mathrm{CE}$ were immersed in the solution drop.

\subsubsection{Results and Discussion}

$\mathrm{FcMeOH}$, as other ferrocene derivatives, is a compound widely used in electrochemistry. We have selected this redox couple to evaluate the performance of the SWCNTs-OTEs, to validate the proposed cell, and to characterize this compound that has been scarcely used in spectroelectrochemistry.

Figure 6.3.4 shows 3D plots of the spectra evolution with time/potential in normal transmission and parallel configuration recorded during a cyclic voltammetry of $5 \times 10^{-4} \mathrm{M} \mathrm{FcMeOH}$ in $0.1 \mathrm{M} \mathrm{KCl}$ between $-0.20 \mathrm{~V}$ and $+0.60 \mathrm{~V}$ at $0.005 \mathrm{~V} \cdot \mathrm{s}^{-1}$, demonstrating the good behavior of the system.

Several implicit similarities and differences can be found when normal transmission and parallel configuration plots are compared. The electrochemical reaction generates a concentration gradient that can be easily studied using our BSEC cell. Absorbance values for parallel configuration $\left(A_{P}\right)$ are higher than normal absorbance values $\left(A_{N}\right)$, due to the longer optical path length. In general, this is one of the main advantages of long optical path cells because they show a higher sensitivity and, therefore, a lower limit of detection. Spectra at the vertex potential, +0.60 $\mathrm{V}$, are plotted in the insets of Figure 6.3.4, exhibiting two sharp absorption bands at 260 and $282 \mathrm{~nm}$ and a smaller one at around $630 \mathrm{~nm}$. 

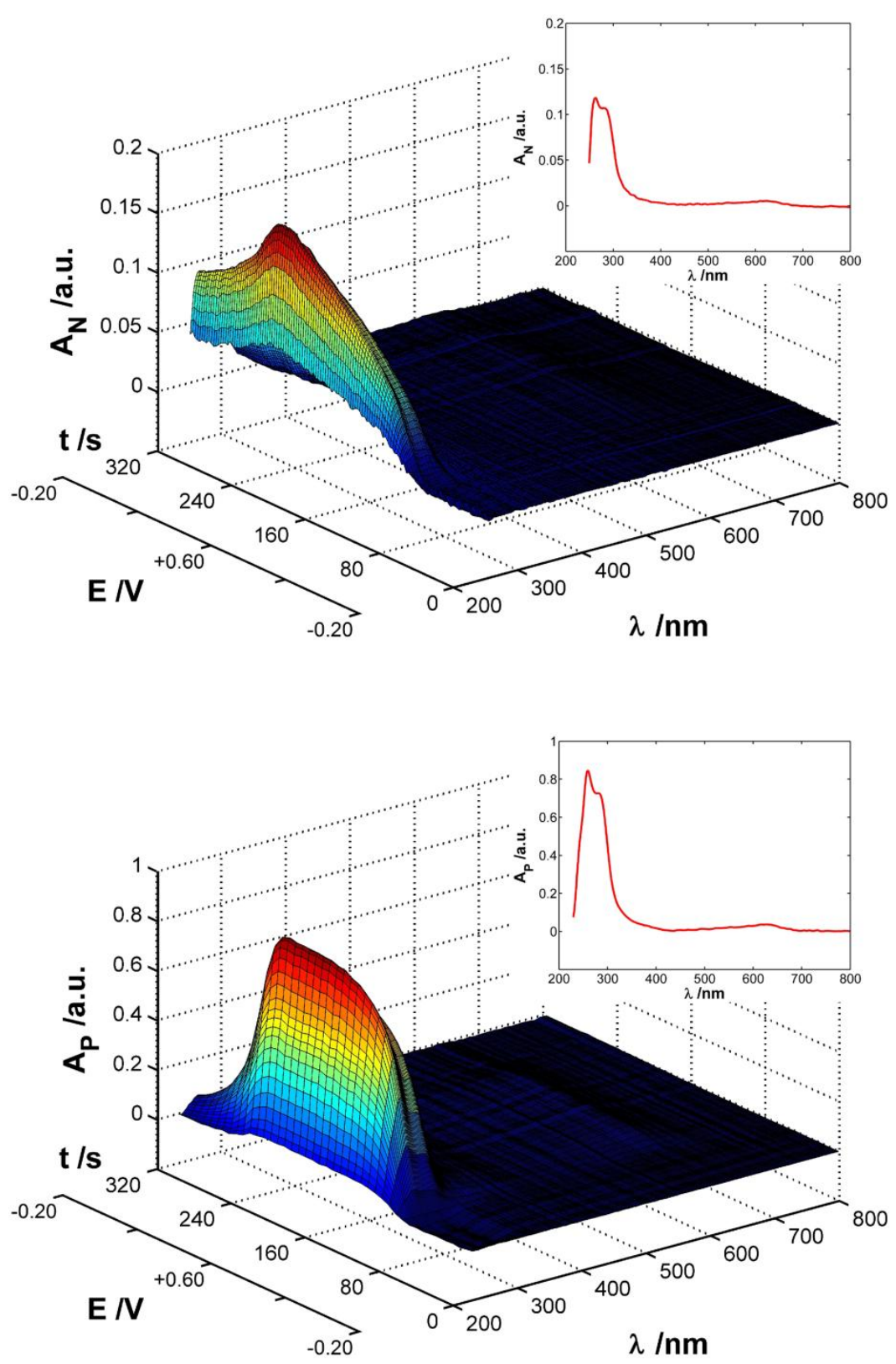

Figure 6.3.4. Spectra evolution with time/potential in (a) normal transmission and (b) parallel configuration recorded during a cyclic voltammetry of $5 \times 10^{-4}$ $\mathrm{M} \mathrm{FcMeOH}$ in $0.1 \mathrm{M} \mathrm{KCl}$ between $-0.20 \mathrm{~V}$ and $+0.60 \mathrm{~V}$ at $0.005 \mathrm{~V} \cdot \mathrm{s}^{-1}$. Insets: spectra at $+0.60 \mathrm{~V}$ for the oxidized form of $\mathrm{FcMeOH}, \mathrm{FcMeOH}^{+}$.

An enlarged view of this small band is plotted in Figure 6.3.5: 

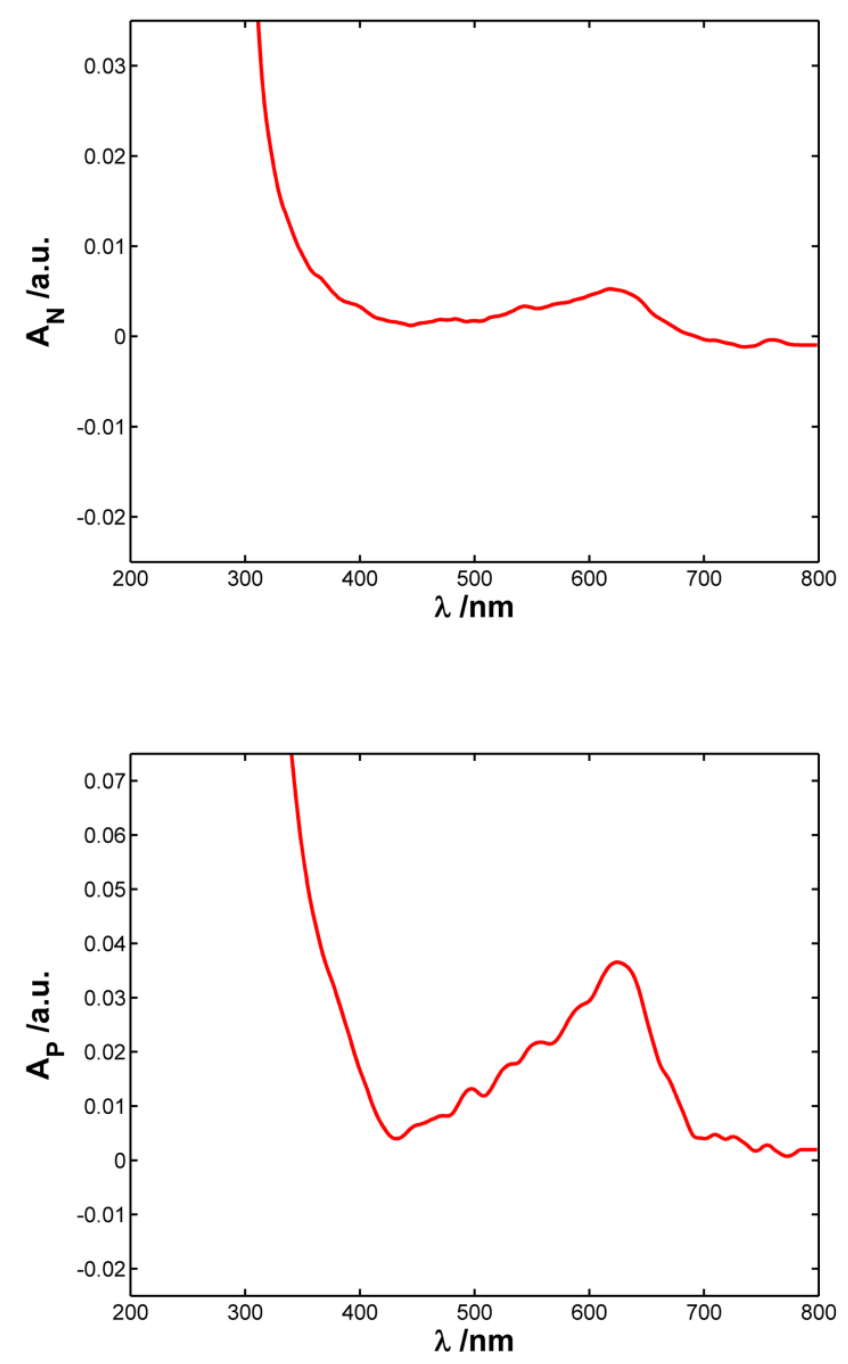

Figure 6.3.5. Enlarged view around $630 \mathrm{~nm}$ of the spectra of the insets shown in Figure 6.3.4 at $+0.60 \mathrm{~V}$ for (a) normal and (b) parallel configuration.

The reduced form of the redox couple, $\mathrm{FcMeOH}$, was taken as reference spectrum of the experiment, and there were no other absorbent compounds in solution. Taking this into account and knowing that the studied reaction follows a simple reversible diffusion regime, these new bands are attributed to the oxidized form of $\mathrm{FcMeOH}, \mathrm{FcMeOH}^{+}$. 
Several cyclic voltammetries at different scan rates between 0.005 and 0.08 $\mathrm{V} \cdot \mathrm{s}^{-1}$ were performed under the same experimental conditions, for which $\mathrm{FcMeOH}$ solution was changed after every measurement (cyclic voltammograms are plotted in Figure 6.3.6). A blank experiment in $0.1 \mathrm{M}$ $\mathrm{KCl}$ at $0.01 \mathrm{~V} \cdot \mathrm{s}^{-1}$ was also performed at the end of all the measurements, demonstrating that there is no change of absorbance with potential in this case.

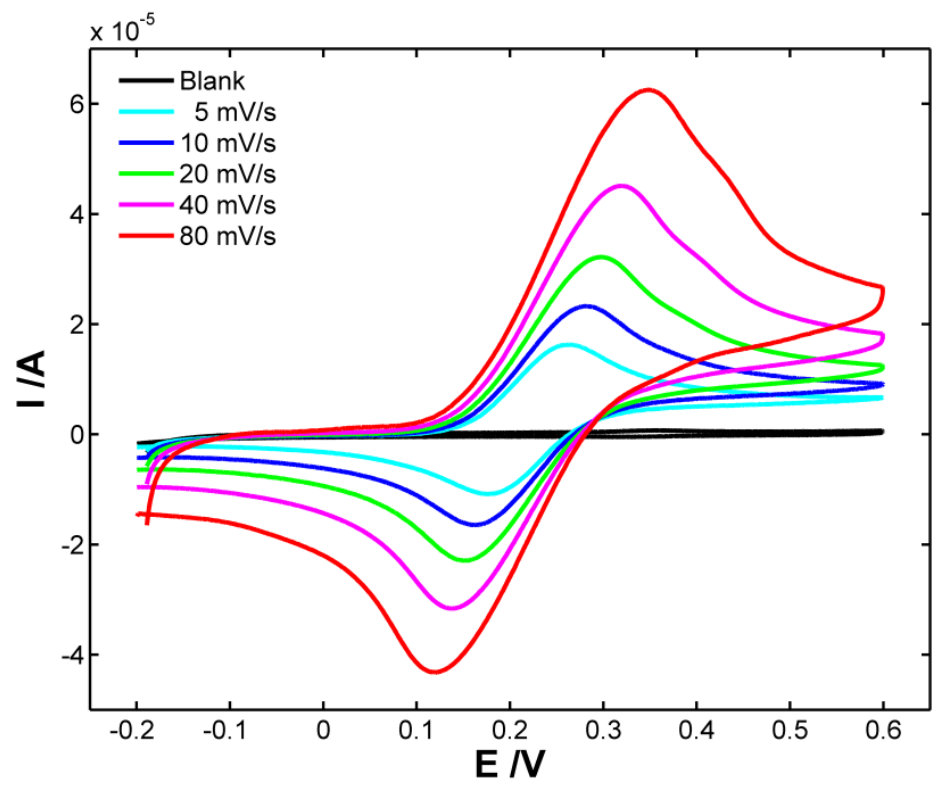

Figure 6.3.6. Cyclic voltammograms of $5 \times 10^{-4} \mathrm{M} \mathrm{FcMeOH}$ in $0.1 \mathrm{M} \mathrm{KCl}$ between $-0.20 \mathrm{~V}$ and $+0.60 \mathrm{~V}$ at different scan rates measured at the SWCNTs electrodes.

Figure 6.3.7 shows the evolution of the charge (Figure 6.3.7a) and the absorbance at $282 \mathrm{~nm}$ in normal transmission (Figure 6.3.7b) and parallel (Figure 6.3.7c) configuration with potential for all the cyclic voltammetry experiments (Figure 6.3.6). 
As can be observed in Figure 6.3.7, charge and $A_{N}$ show a similar behavior but $A_{P}$ response shows a different shape. Absorbance in parallel arrangement is always higher than absorbance in normal configuration. For the three responses, it is observed that charge and absorbance values begin to increase around $+0.20 \mathrm{~V}$ in the forward scan, where $\mathrm{FcMeOH}$ starts to be oxidized, until the vertex potential at $+0.60 \mathrm{~V}$. During the backward scan, differences between the optical signal in normal and parallel configuration are more evident. While charge and $A_{N}$ increase at the beginning of the backward scan for the five scan rates, $A_{P}$ does not increase for the lowest one $\left(0.005 \mathrm{~V} \cdot \mathrm{s}^{-1}\right)$, reaching a constant value of 0.79 au due to the steadystate achieved in the first $100 \mu \mathrm{m}$ sampled by the parallel optical fibers. On the contrary, in the other four experiments at higher scan rates, parallel absorbance increases during the first part of the backward scan because there has been no time to reach a steady-state.

It is also noteworthy that the final values of both $A_{N}$ and charge decrease when the scan rate increases. On the contrary, final $A_{P}$ value increases with the scan rate. These differences can be explained taking into account the solution sampled by the light beams. Although the three responses are related to concentration changes taking place in the diffusion layer, the optical information in parallel arrangement depends only on the nearest solution region to the electrode surface, containing information about the diffusion of the species, ${ }^{383}$ their spatial distribution according to the optical fiber diameter (100 $\mu \mathrm{m}$ in our case), and its position with respect to the electrode surface. Meanwhile, $A_{N}$ and charge include information related to the global amount of $\mathrm{FcMeOH}$ that is oxidized to $\mathrm{FcMeOH}^{+}$and that diffuses away from the diffusion layer. 

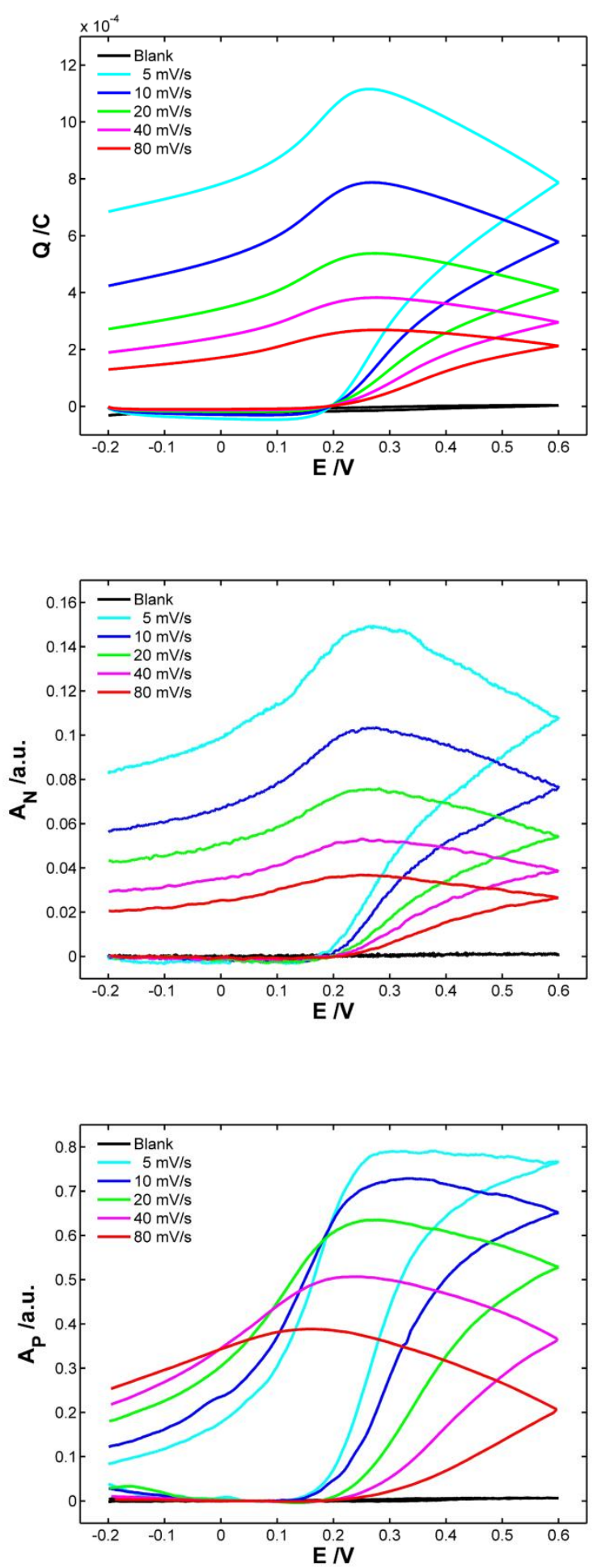

Figure 6.3.7. (a) Evolution of charge versus potential, (b) voltabsorptogram at $282 \mathrm{~nm}$ in normal configuration, and (c) voltabsorptogram at $282 \mathrm{~nm}$ in parallel configuration, at different potential scan rates. Experimental conditions as in Figure 6.3.6. 
The derivative voltabsorptograms at $282 \mathrm{~nm}$ in normal and parallel configuration corresponding to the experiment shown in Figure 6.3.7 can be found in Figure 6.3.8.
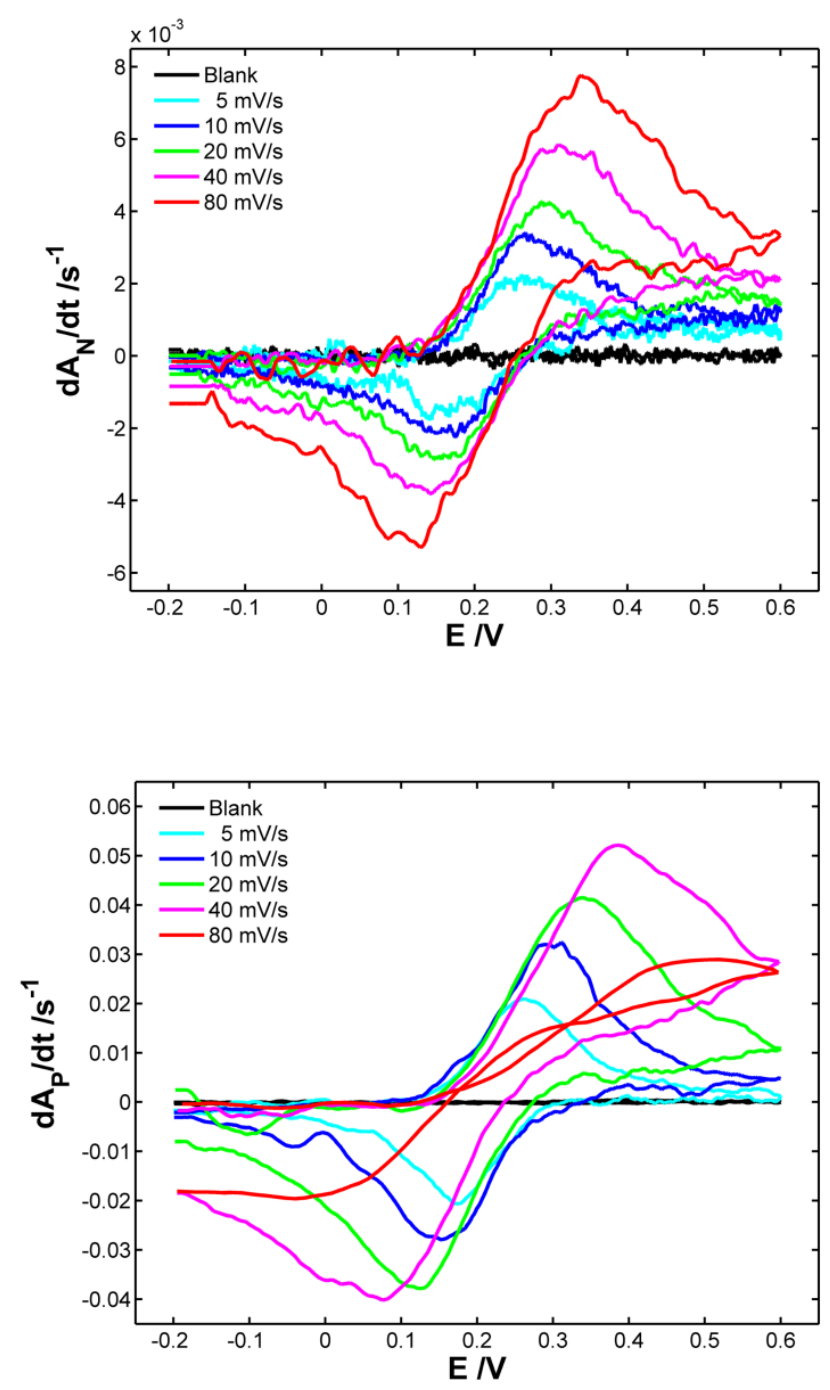

Figure 6.3.8. Derivative voltabsorptograms at $282 \mathrm{~nm}$ measured at different scan rates for (a) normal and (b) parallel configuration, corresponding to the experiment shown in Figure 6.3.7. Experimental conditions as in Figure 6.3.6.

As can be seen in Figure 6.3.8a, derivative voltabsorptograms at $282 \mathrm{~nm}$ in normal transmission configuration show features comparable to the cyclic 
voltammograms (Figure 6.3.6). On the contrary, very contrasting behavior is observed from the corresponding voltabsorptograms in parallel configuration (Figure 6.3.8b) because of the influence of the spatial distribution of $\mathrm{FcMeOH}^{+}$with respect to the optical fibers. Particularly, the $20 \mu \mathrm{m}$ solution closest to the electrode surface cannot be sampled by the parallel light beam due to the cladding material of the optical fibers. In this way, at the higher scan rates, the cladding material provokes a clear change in the optical response. However, at low scan rates this fact does not affect the optical response since the diffusion layer is much bigger.

Thus, $0.005 \mathrm{~V} \cdot \mathrm{s}^{-1}$ is a low enough scan rate to generate an almost homogeneous steady-state distribution of $\mathrm{FcMeOH}^{+}$in the sampled solution in parallel arrangement. In this case, a constant and maximum value of $A_{P}$ is achieved because the optical fiber only samples the first 100 $\mu \mathrm{m}$ of the solution adjacent to the electrode surface. $\mathrm{FcMeOH}^{+}$diffuses far away from the first $100 \mu \mathrm{m}$ to the bulk solution, explaining the behavior of charge and $A_{N}$. The generation of $\mathrm{FcMeOH}^{+}$takes place at potentials over $+0.20 \mathrm{~V}$, growing the diffusion layer and increasing the values of these three signals until the potential is low enough to reduce the $\mathrm{FcMeOH}^{+}$. $\mathrm{FcMeOH}^{+}$consumption rate on the electrode surface during the reduction step is faster than the diffusion rate of this cation in solution. Thus, a fraction of the electrogenerated $\mathrm{FcMeOH}^{+}$remains always in solution and, therefore, $A_{P}$ decreases faster than $A_{N}$. Most of the $\mathrm{FcMeOH}^{+}$that is present in the sampled solution in parallel arrangement can be reduced because it is close to the electrode surface, resulting in a faster decrease of $A_{P}$ than $A_{N}$, with $A_{N}$ related to the whole diffusion layer.

The amount of $\mathrm{FcMeOH}^{+}$generated is lower when the scan rate is increased. In this case, the cation diffuses a shorter distance with respect to 
the electrode surface, and then, a more heterogeneous distribution of $\mathrm{FcMeOH}^{+}$on the $100 \mu \mathrm{m}$ adjacent to the electrode surface is observed. Accordingly, at higher scan rates, the $A_{P}$ voltabsorptograms (Figure 6.3.7c) are more similar to both the charge and the $A_{N}$ voltabsorptograms because almost the whole diffusion layer is sampled in parallel configuration.

The molar absorption coefficient of $\mathrm{FcMeOH}^{+}$is calculated. According to the Beer-Lambert law, absorbance $(A)$ is related to the concentration $(C)$ by the molar absorption coefficient $(\varepsilon)$ and the optical path length $(l)$ :

$A=\varepsilon l C$ Equation (6.3.1)

Absorbance changes in spectroelectrochemistry experiments are related to the concentration changes of redox-active compounds in solution. In this case, both $\mathrm{FcMeOH}$ and $\mathrm{FcMeOH}^{+}$exhibit absorbance in the $\mathrm{UV}-\mathrm{Vis}$ spectral region. Hence, being $C_{F c}$ and $C_{F c}{ }^{+}$the concentration of $\mathrm{FcMeOH}$ and $\mathrm{FcMeOH}^{+}$respectively, the absorbance observed at any time of the experiment is:

$A=\varepsilon_{F c} l C_{F c}+\varepsilon_{F c^{+}} l C_{F C^{+}}$ Equation (6.3.2)

where $\varepsilon_{F c}$ and $\varepsilon_{F c}{ }^{+}$are the molar absorption coefficients of $\mathrm{FcMeOH}$ and $\mathrm{FcMeOH}^{+}$, respectively. The sum of the instantaneous concentrations of the redox couple species must be constant and equal to the initial concentration of $\mathrm{FcMeOH}$, named as $C_{F c}^{*}$ :

$C_{F C}^{*}=C_{F C}+C_{F C^{+}}$

Equation (6.3.3)

Taking $\mathrm{FcMeOH}$ as reference, the absorbance changes are related to the following expression:

$A-\varepsilon_{F c} l C_{F C}^{*}=\varepsilon_{F c} l C_{F C}+\varepsilon_{F C^{+}} l C_{F C^{+}}-\varepsilon_{F C} l C_{F C}^{*} \quad$ Equation (6.3.4) 
Therefore, recorded data from spectroelectrochemistry experiments allow us to obtain the difference between the molar absorption coefficients of the species that is being formed in solution, $\mathrm{FcMeOH}^{+}$, and that of the substance that is concomitantly disappearing, $\mathrm{FcMeOH}$ :

$\Delta A=\varepsilon_{F c} l C_{F c}+\varepsilon_{F C^{+}} l C_{F c^{+}}-\varepsilon_{F c} l\left(C_{F c}+C_{F c^{+}}\right) \quad$ Equation (6.3.5)

$\Delta A=\left(\varepsilon_{F c^{+}}-\varepsilon_{F c}\right) l C_{F c^{+}}=A_{N}$

Equation (6.3.6)

According to Faraday's law of electrolysis, total electric charge passed during the experiment $(Q)$ is related to the number of electrons $(n)$, Faraday's constant $(F)$ and the number of moles $(N)$ of the transformed compound:

$Q=n F N$

Equation (6.3.7)

Concentration of the solution $(C)$ and area of the electrode $(S)$ can be defined as:

$C=\frac{N}{V}$

Equation (6.3.8)

$S=\frac{V}{l}$

Equation (6.3.9)

where $V$ is the volume.

Dividing Equation (6.3.6) by Equation (6.3.7) and taking into account the units in Equation (6.3.8) and Equation (6.3.9), $A_{N}$ and $Q$ are related by: ${ }^{119}$

$A_{N}=\left(\varepsilon_{F C^{+}}-\varepsilon_{F c}\right) \frac{10^{3}}{n F S} Q$

Equation (6.3.10)

Linear regressions of $A_{N}$ versus $Q$ for the experiments at the different scan rates were performed. From the slopes, and being $n=1, F=96485$ $\mathrm{C} \cdot \mathrm{mol}^{-1}$, and $S=0.63 \mathrm{~cm}^{2}$, the difference of the molar absorption 
coefficients of $\mathrm{FcMeOH}^{+}\left(\varepsilon_{F c}{ }^{+}\right)$and $\mathrm{FcMeOH}\left(\varepsilon_{F c}\right)$ can be obtained at any wavelength of the UV-Vis spectral region using Equation (6.3.10).

In order to check the good performance of the new BSEC cell, the molar absorption coefficient of $\mathrm{FcMeOH}^{+}$at $282 \mathrm{~nm}$ has been assessed. The experimental value for the difference of $\varepsilon_{F c}{ }^{+}$and $\varepsilon_{F c}$ from the five slopes was $7880 \pm 510 \mathrm{M}^{-1} \cdot \mathrm{cm}^{-1}$. The molar absorption coefficient at $282 \mathrm{~nm}$ for $\mathrm{FcMeOH}, \varepsilon_{F c}$, obtained by calibration using our spectrometer, was $930 \pm 20$ $\mathrm{M}^{-1} \cdot \mathrm{cm}^{-1}$. This value must be added to the previous difference to obtain the corresponding molar absorption coefficient for $\mathrm{FcMeOH}^{+}$, which is $8810 \pm$ $530 \mathrm{M}^{-1} \cdot \mathrm{cm}^{-1}$.

We used the difference of the molar absorption coefficients to calculate the $A_{P}$ estimated value, using the Beer-Lambert law and assuming that a $\mathrm{FcMeOH}$ concentration of $5 \times 10^{-4} \mathrm{M}$ has been transformed to $\mathrm{FcMeOH}^{+}$ in the $100 \mu \mathrm{m}$ closest to the electrode surface. From our optical path length of $2.1 \mathrm{~mm}$ in parallel configuration, a value of $A_{P}$ of $0.83 \pm 0.05$ au is obtained at $282 \mathrm{~nm}$. This result agrees with the experimental value of 0.79 au obtained for the steady-state reached in the parallel voltabsorptogram, corresponding with the experiment performed at the lowest scan rate, 0.005 $\mathrm{V} \cdot \mathrm{s}^{-1}$, in which all the assumptions are fulfilled (Figure 6.3.7c). In fact, the $A_{P}$ estimated value should be, and is, a little bit higher than the $A_{P}$ theoretical value and, therefore, than the experimental one due to the heterogeneity in the concentration profile. But, for low scan rates and small diameter optical fibers, $A_{P}$ estimated and theoretical values are very close. The good agreement between the $A_{P}$ estimated and experimental values indicates the good performance of our novel BSEC cell and corroborates the trueness of the molar absorption coefficients assessed. 
A chronoabsorptometry was performed to provoke an exhaustive electrolysis in the solution sampled by the optical fiber. Figure 6.3.9 shows the absorbance at $282 \mathrm{~nm}$ versus $t^{1 / 2}$ graph in the two configurations. Absorbance in normal configuration shows a linear behavior, as is expected for a Cottrell response. Meanwhile, absorbance in parallel configuration does not change initially because of the cladding material but an exhaustive electrolysis in the first $100 \mu \mathrm{m}$ next to the electrode surface takes place in less than $120 \mathrm{~s}$.

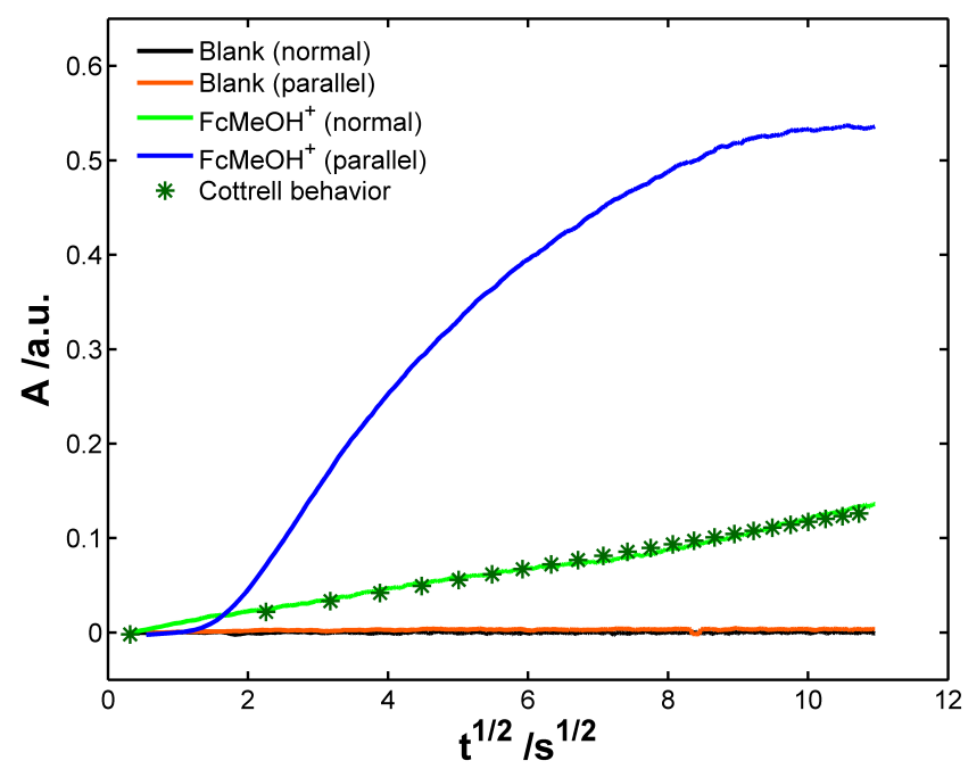

Figure 6.3.9. Absorbance at $282 \mathrm{~nm}$ versus $t^{1 / 2}$ in normal transmission (green line) and parallel (blue line) configuration recorded during a chronoamperometry of $5 \times 10^{-4} \mathrm{M} \mathrm{FcMeOH}$ in $0.1 \mathrm{M} \mathrm{KCl}$ by applying a potential of $+0.60 \mathrm{~V}$ for $120 \mathrm{~s}$. Integration times: $300 \mathrm{~ms}$ in parallel configuration and $100 \mathrm{~ms}$ in normal arrangement. Optical path length: $1.4 \mathrm{~mm}$. Normal configuration absorbance is adjusted to a Cottrell response (green asterisks). Blank responses of $0.1 \mathrm{M} \mathrm{KCl}$ solution in normal transmission (black line) and parallel (orange line) configuration are also shown. 
These results demonstrate that the SWCNTs-OTEs fabricated are very useful for BSEC measurements in the UV-Vis spectral region. Besides, the reduced size of the developed BSEC cell $(5 \times 3.5 \times 1.6 \mathrm{~cm})$, the small volume of sample, the high versatility related to materials, shapes, and sizes of electrodes, the wide spectral region covered, the possibility of fixing simultaneously several optical fibers in parallel arrangement at any optical path length and at different positions with respect to the electrode surface and the possibility of combining different configurations (parallel configuration with normal transmission and/or reflection arrangement) are some important advantages of this easy-to-use BSEC cell. This is definitely a novel, simple, useful, and original option to work with BSEC. The novel experimental setup has been verified with good results obtained with FcMeOH and the SWCNTs-OTEs, demonstrating the good performance of this BSEC cell to obtain qualitative and quantitative information. Moreover, this methodology is very useful to obtain the molar absorption coefficient value of substances at any wavelength of the UV-Vis spectrum. This value can be checked in parallel configuration when a steady-state is reached in the proximity of the electrode, which takes place at slow enough scan rates. Therefore, BSEC is also very useful to obtain and validate the molar absorption coefficient assessed with $A_{N}$ by comparison with the expected $A_{P}$ value.

\subsubsection{Conclusions and Future Work}

A new and simple methodology based on filtering a dispersion of SWCNTs has allowed us to low-press transfer commercial SWCNTs onto a variety of supports in an available way for any laboratory. 
SWCNTs films transferred on quartz supports, impossible to be fabricated using the press-transference method, have been used as OTEs for BSEC, demonstrating the good performance of this type of electrodes for spectroelectrochemistry.

A new optical fiber BSEC cell with an easy assembly, a very simple light beam alignment, a reduced size, and a purposely built low-volume has been fabricated. BSEC was a really complicated technique, but this new device, with the help of the optical fibers, should be very useful in this field due to the easy way to perform this type of experiments.

Absorbance in normal and parallel configuration has allowed us to study the FcMeOH redox behavior in the UV-Vis spectral region, obtaining more information about this redox couple scarcely studied by spectroelectrochemistry. At the same time, the spectral evolution during FcMeOH electron transfer process is used to validate both our pressureless transfer SWCNTs-OTEs prepared on quartz and the performance of the new BSEC device.

Normal configuration measurements are related to the global quantity of $\mathrm{FcMeOH}^{+}$generated, while parallel measurements also include information about the spatial distribution of the absorbent.

The time-resolved evolution of the full spectra in the two optical configurations, normal and parallel, is needed in order to assess and check the molar absorption coefficient of $\mathrm{FcMeOH}^{+}$at any wavelength. This new methodology is an alternative to the more traditional approach to measure molar absorption coefficients that is based on long-optical path thin layer spectroelectrochemistry. 
By using small diameter optical fibers and slow enough scan rates, experiments can be performed generating an almost steady-state concentration of $\mathrm{FcMeOH}^{+}$in the solution closest to the electrode, achieving a maximum and constant absorbance value.

This methodology clearly shows the importance and the advantages of an in situ multiresponse technique such as BSEC to obtain the molar absorption coefficients of electrogenerated redox species. A molar absorption coefficient of $8810 \pm 530 \mathrm{M}^{-1} \cdot \mathrm{cm}^{-1}$ at $282 \mathrm{~nm}$ has been experimentally obtained for $\mathrm{FcMeOH}^{+}$by using the $A_{N} / Q$ ratio and without knowing either the optical path length or the $\mathrm{FcMeOH}$ concentration. This value has been validated in parallel configuration.

This fact implies that $\mathrm{FcMeOH}$ can be used to validate not only electrochemical systems but also spectroelectrochemical set-ups and demonstrates another BSEC advantage.

The novel SWCNTs-OTEs and the BSEC cell open new gates for studying complex chemical systems, such as neurotransmitters, enzymes, or DNA in order to shed more light on their reactions mechanisms. In fact, SWCNTs-OTEs with quartz support are used in the next section (section $6.4)^{76}$ and the use of optical fibers in essential in the results of this doctoral thesis shown from now on.

Our technical developments should be a significant advance in spectroelectrochemistry that could lead to new and interesting future applications because many more researchers will be able to use BSEC. 

6.4. Simultaneous UV-Vis Absorption and Raman Spectroelectrochemistry 



\subsubsection{Some Important Points to Keep in Mind}

Raman spectroelectrochemistry ${ }^{14,384-394}$ is a powerful technique that allows us not only to characterize steady-state systems but also to perform in situ studies of different evolving processes. The dynamic character of time-resolved Raman spectroelectrochemistry provides a large number of full spectra that enables us to describe the spectroscopic evolution of a chemical system with time or potential together with the electrochemical signal. The versatility achieved by Raman spectroelectrochemistry through the development of new devices has allowed researchers to study systems of different nature.

The relevant advantages of $\mathrm{UV}-\mathrm{Vis}$ absorption and Raman spectroelectrochemistry have been widely exploited separately to date. In fact, several devices have been fabricated with the aim of performing $\mathrm{UV}-\mathrm{Vis}$ or Raman spectroelectrochemistry experiments, being even possible to use the same cell for both spectroelectrochemistry disciplines ${ }^{395-398}$ but always separately.

To the best of our knowledge, as of today there are no devices capable of carrying out UV-Vis and Raman spectroelectrochemistry simultaneously.

However, taking into account the advantages of obtaining all data simultaneously, we can affirm that the development of a UV-Vis/Raman spectroelectrochemistry device able to perform this type of experiments is of great interest to shed more light on complex reaction mechanisms.

For these reasons, the development of a new device, based on the use of UV-Vis bare optical fibers in a long optical path length configuration 
(promising results shown in section 6.3) ${ }^{75}$ and the measurement of the Raman response in normal arrangement, that allows us to perform UV-Vis and Raman spectroelectrochemistry simultaneously in a single experiment has been carried out in this work:

On the one hand, a UV-Vis light beam, sent and collected by bare optical fibers, only samples the first micrometers of the solution adjacent to the electrode surface in parallel configuration, without interfering with the Raman signal.

On the other hand, Raman spectra in normal arrangement contain vibrational information about the desired area.

The main objective of this work is to demonstrate the correct performance of the new UV-Vis/Raman spectroelectrochemistry device, showing the capabilities and advantages of this novel technique.

Three electrochemical systems have been selected to illustrate some of the problems that researchers would be able to investigate using the combination of UV-Vis absorption and Raman dispersion spectroelectrochemistry:

Ferricyanide/ferrocyanide redox couple, a one-electron and well-defined electrochemical system often used as a probe in aqueous solution for spectroelectrochemical devices, ${ }^{399}$ has been used to study a process that occurs only in solution.

The oxidation of dopamine on a SWCNTs electrode (section $6.3)^{75}$ and a complex electrochemical reaction as the electropolymerization of EDOT have been used to study the different processes that take place in solution and on the electrode surface. 
Processes that take place in solution can be properly distinguished from processes that occur on the electrode surface during the electrochemical experiment, providing a whole picture of the reactions taking place at the electrode/solution interface.

Therefore, this device allows us to study a larger number of complex electrochemical processes from different points of view taking into account not only the $\mathrm{UV}-\mathrm{Vis}$ spectral changes in the solution adjacent to the electrode but also the Raman signal at any location. Furthermore, complementary information, which could not be unambiguously extracted without considering together the two spectroscopic signals and the electrochemical response, is obtained in a novel way.

This work has been performed in close collaboration with Dr. David Ibáñez.

\subsubsection{Experimental Section}

\subsubsection{Reagents and Materials}

SWCNTs (Sigma-Aldrich), DCE (99.8\% for HPLC, Acros Organics), nitrocellulose membrane (filter pore size $0.8 \mu \mathrm{m}$, Millipore), quartz plate (Sugelabor), silver conductive paint (Electrolube), and transparent nail polish (Procesos Cosméticos) were used to fabricate the SWCNTs WE (section 6.3). ${ }^{75}$ Apart from this electrode, a GC foil (Goodfellow) properly polished to a mirror finish using alumina slurries with different powder size down to $0.5 \mu \mathrm{m}$ was also used as WE. Potassium ferrocyanide (Merck), 
$\mathrm{LiCl}$ (Merck), dopamine (99\%, Acros Organics), $\mathrm{HClO}_{4}$ (60\%, Panreac), EDOT (99\%, Acros Organics), and $\mathrm{LiClO}_{4}$ (Panreac) were used to prepare the solutions. PMMA plates, PTFE (Teflon) plates, O-rings, nuts, and bolts were used to fabricate the cell developed in this work, which was fabricated using a $\mathrm{CO}_{2}$ laser cutting machine.

All reagents were used as received. All chemicals were of analytical grade. Aqueous solutions were freshly prepared, or stored at $4{ }^{\circ} \mathrm{C}$, using ultrapure water $\left(18.2 \mathrm{M} \Omega \cdot \mathrm{cm}\right.$ resistivity at $25^{\circ} \mathrm{C}$, Milli-Q Direct 8 , Millipore).

\subsubsection{Instrumentation}

All spectroelectrochemistry experiments were performed at room temperature. Spectroelectrochemistry setup includes a potentiostat/galvanostat (PGSTAT20, Metrohm Autolab) coupled to the equipment to record the spectral changes. On the one hand, UV-Vis absorption spectra were obtained using a deuterium light source (AvaLightDH-S-BAL, Avantes), bare optical fibers (100 $\mu \mathrm{m}$ in diameter, Ocean Optics), and a spectrometer (QE65000 198-1006 nm, Ocean Optics). On the other hand, dynamic Raman spectra were obtained using a Confocal Raman Voyage (BWTEK). A laser source emitting at the wavelength of $532 \mathrm{~nm}$ with a power of $15 \mathrm{~mW}$ was employed to obtain the spectra, using a $20 \times$ objective. The spectral resolution was $3.8 \mathrm{~cm}^{-1}$. An XYZ piezoelectric positioner (Newport 271) controlled by a Newport motion controller (Newport, ESP 301) was used to focus the laser beam with micrometric resolution. Further details about the dynamic spectroelectrochemical Raman system have been previously reported. ${ }^{14,384}$ 
A tip-sonicator (CY-500, Optic ivymen System) was used to properly disperse the SWCNTs.

For safety considerations, all handling and processing were performed carefully, particularly when DCE was used.

\subsubsection{Electrodes Preparation}

Two different WEs are used in this work.

The first one, a GC foil, was properly polished with alumina, thoroughly rinsed with ultrapure water, and dried.

SWCNTs electrodes are the second type of electrodes used. Briefly, the methodology employed to fabricate these SWCNTs electrodes (section $6.3)^{75}$ involves the filtration under vacuum of $0.8 \mathrm{~mL}$ of a sonicated SWCNTs homogeneous dispersion in DCE $\left(5 \mathrm{mg} \cdot \mathrm{L}^{-1}\right)$ through a nitrocellulose filter. The homogeneous SWCNTs film, whose transparency and conductivity depend on the filtered volume of the SWCNTs dispersion, was immediately low-pressure transferred on a quartz plate applying only a slight finger pressure. After letting the SWCNTs film and the filter dry at room temperature, the filter was carefully separated from the quartz support using tweezers. Therefore, homogeneous, clean, and reproducible SWCNTs films of $10 \mathrm{~mm}$ in diameter on quartz were obtained in a quick and inexpensive way. The electrical contact was made from the SWCNTs film to the edge of the quartz plate with silver conductive paint, which was dried in an oven at $75{ }^{\circ} \mathrm{C}$ for $45 \mathrm{~min}$. Finally, the silver contact was electrically isolated using nail polish, which was dried at room temperature. 


\subsubsection{Fabrication of the Device for UV-Vis/Raman Spectroelectrochemistry Measurements}

Figure 6.4.1 shows the illustrations of the disassembled and assembled UV-Vis/Raman spectroelectrochemistry cell. The device consists of four main parts. The piece placed at the bottom (1) is the WE support and can be made of PTFE or PMMA. In this case, the material employed is not important because this piece is only used as a support and it is not in contact with the solution. An O-ring (2) helps to fix the WE with the two bare optical fibers between the bottom piece (1) and the next one (3), avoiding solution leakages. One of the optical fibers is connected to the light source, and the other one to the spectrometer. The second piece (3) is made of PTFE. A hole of $6.40 \mathrm{~mm}$ in diameter is drilled in its center and a small recess is made for the placement of another O-ring (4), particularly useful for the assembly with the third piece (5) and to prevent a possible leakage of the solution. This third piece (5), also made of PTFE, has a drilled hole of $18.50 \mathrm{~mm}$ in diameter to contain the bulk solution and a small recess for the placement of another O-ring (6). Finally, the last piece (7) is an optical window that is placed on top of the cell. Four small holes of $2.20 \mathrm{~mm}$ in diameter are drilled in this piece (7) for the placement of the $\mathrm{RE}$ and the $\mathrm{CE}$, to facilitate the filling and emptying of the cell (approximate volume of $1.2 \mathrm{~mL}$ ) and to deoxygenate the solution. Although none of the processes studied in this work required deoxygenated solutions, it can be easily performed using the unoccupied holes to introduce an inert gas that removes the oxygen and to allow the gas flow to leave the device. For the experiments shown in this work, this piece is made of PMMA but, taking into account that some organic solvents dissolve the PMMA, a quartz window can be used in these cases. Pieces 1, 3,5 , and 7 have holes in their corners to allow the whole device to be 
assembled with nuts and bolts. In all experiments, a homemade $\mathrm{Ag} / \mathrm{AgCl} / \mathrm{KCl} 3 \mathrm{M}$ is used as $\mathrm{RE}$ and a platinum wire as $\mathrm{CE}$. As previously mentioned, a GC foil (shown in Figure 6.4.1) or a SWCNTs film supported on quartz (section 6.3) ${ }^{75}$ are used as WE. Figure 6.4.2 displays an expanded diagram of the optical fibers, UV-Vis light beam, laser beam, and WE to show how the two beams are interrogating both the solution and the SWCNTs WE. In addition, the bottom piece (1) has a drilled hole in its center to place a commercial electrode if necessary. Many different WEs (gold, platinum, etc.) can be used depending on the desired information to be obtained. The versatility is high for commercial and homemade WEs. The main limitation is that WEs have to be flat to allow the parallel light beam to sample the adjacent solution to the electrode. Therefore, a wire or a mesh, for example, are not intended to be used as WEs. The possibility of using different WEs demonstrates the utility and versatility of this new cell to carry out simultaneously UV-Vis and Raman spectroelectrochemistry measurements.
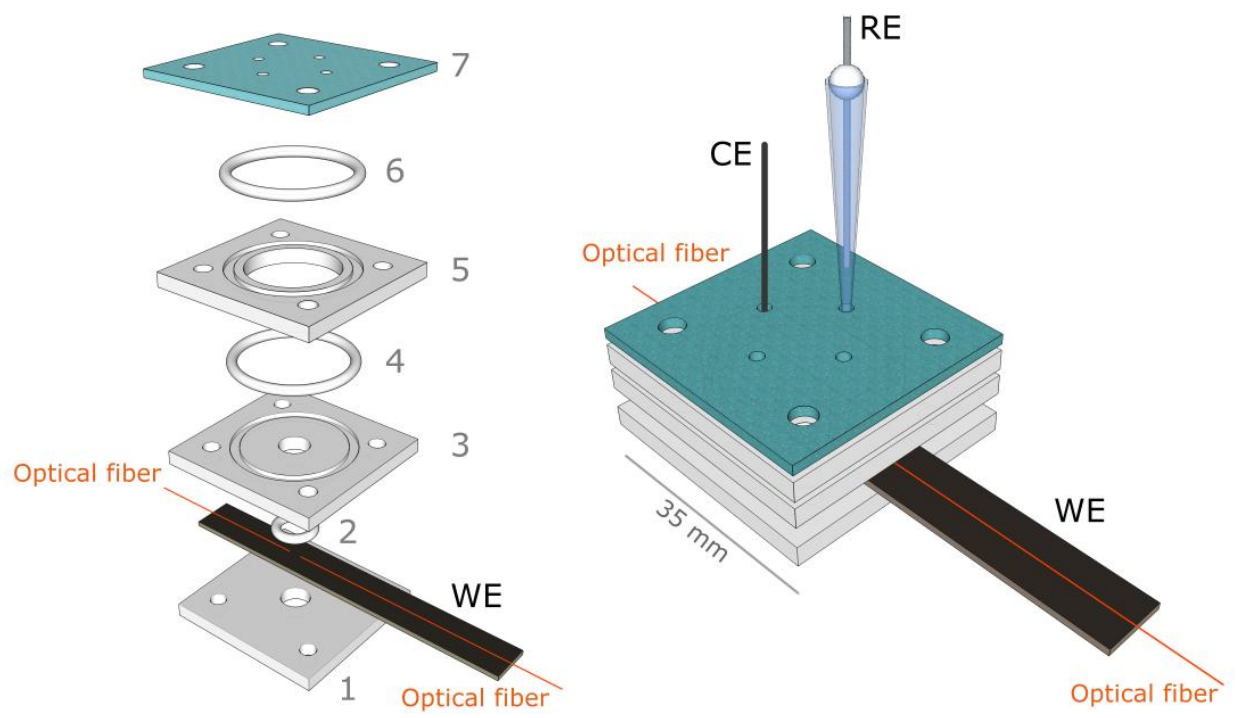

Figure 6.4.1. Schematic view of the (a) disassembled and (b) assembled $\mathrm{UV}-\mathrm{Vis} /$ Raman spectroelectrochemistry cell. 


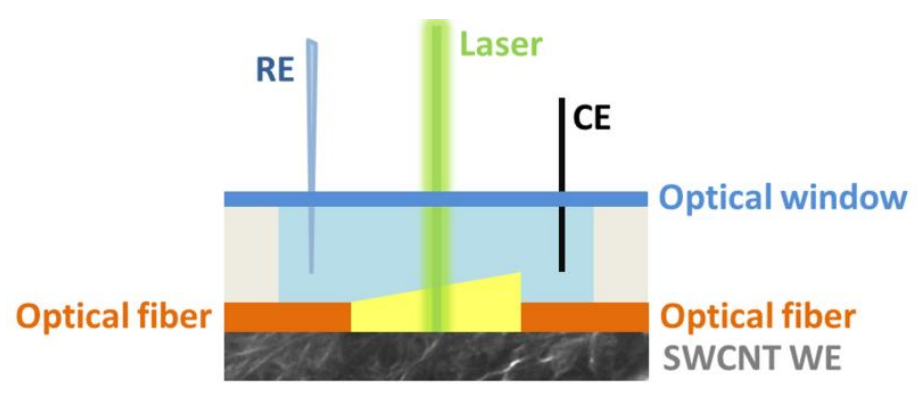

Figure 6.4.2. Expanded diagram of the optical fibers, UV-Vis light beam, laser beam, and the SWCNTs WE to show how the two beams are interrogating both the solution and the SWCNTs WE.

It should be noted that the UV-Vis spectroelectrochemistry setup is based on bare optical fibers of $100 \mu \mathrm{m}$ in diameter. The use of bare optical fibers has clear advantages such as, for example, the facility to align the light beams and to change the optical path length, which is defined as the distance between both optical fibers (section 6.3). ${ }^{75}$ Furthermore, absorptometric measurements in parallel configuration offer several advantages with respect to normal configuration: (i) longer optical path length and thus higher sensitivity, allowing the study of compounds with low molar absorption coefficients; (ii) OTEs are not required; and (iii) the UV-Vis light beam only samples the first $100 \mu \mathrm{m}$ of the solution adjacent to the WE surface, without interfering with the Raman signal. Moreover, the most important features of this novel cell related to the Raman spectroelectrochemistry setup can be summarized as (i) the short distance between the WE surface and the optical window favors the collection of Raman photons; (ii) the flatness required to perform Raman spectroscopy measurements is guaranteed by this optical window (piece 7, Figure 6.4.1a); and (iii) the UV-Vis light beam provided by the optical fibers does not disturb the Raman signal at all. 
Hence, the cell design is optimal to ensure the flatness of the solution needed for Raman measurements, to place the UV-Vis bare optical fibers in parallel configuration, to completely disassemble the device to be cleaned, to avoid solution leakages, and to easily deoxygenate the solution. As is shown below, this device enables us to perform UV-Vis/Raman spectroelectrochemistry simultaneously, providing relevant information for the study of complex electrochemical processes from different points of view.

\subsubsection{Results and Discussion}

\subsubsection{Ferricyanide/Ferrocyanide Redox Couple}

The ferricyanide/ferrocyanide redox couple is an ionic probe commonly used in spectroelectrochemistry because it is a quasi-reversible system whose two redox forms are spectroscopically distinguishable. ${ }^{399}$ For this reason, it was initially used to validate the new cell, allowing us to obtain similar information about the electrochemical process with UV-Vis absorption and Raman responses.

Spectroelectrochemistry measurements of $2.5 \times 10^{-2} \mathrm{M}$ potassium ferrocyanide in $0.1 \mathrm{M} \mathrm{LiCl}$ were performed using the novel $\mathrm{UV}-\mathrm{Vis} /$ Raman spectroelectrochemistry device with a GC foil as WE. Figure 6.4.3 shows the cyclic voltammogram between $-0.20 \mathrm{~V}$ and +0.80 $\mathrm{V}$ at a potential scan rate of $0.02 \mathrm{~V} \cdot \mathrm{s}^{-1}$ (Figure 6.4.3a), and the $3 \mathrm{D}$ spectra evolution with time/potential related to the $\mathrm{UV}-\mathrm{Vis}$ spectral region (Figure 6.4.3b) and to the Raman signal (Figure 6.4.3c). 

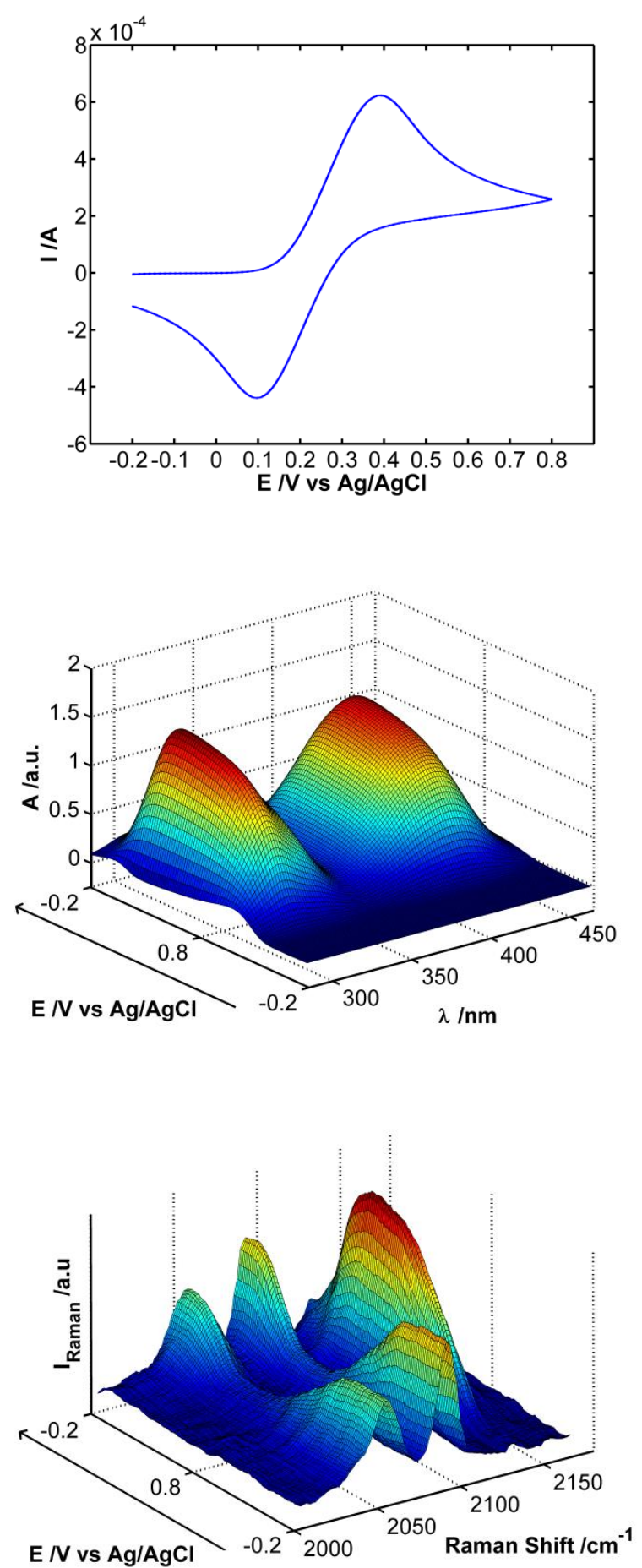

Figure 6.4.3. (a) Cyclic voltammogram of $2.5 \times 10^{-2} \mathrm{M}$ potassium ferrocyanide in $0.1 \mathrm{M} \mathrm{LiCl}$ between $-0.20 \mathrm{~V}$ and +0.80 at $0.02 \mathrm{~V} \cdot \mathrm{s}^{-1}$ on a GC foil as WE. Three-dimensional spectra evolution with potential of (b) UV-Vis absorptometric measurements and of (c) Raman signal during the potentiodynamic experiment. 
The integration time for UV-Vis absorptometric spectra was $500 \mathrm{~ms}$ and for Raman spectra was $800 \mathrm{~ms}$. These values indicate the high timeresolved data acquisition offered by this experimental setup. The optical path length was $0.5 \mathrm{~mm}$. The spectrum of the initial solution was taken as reference for the UV-Vis absorption spectra, and the spectra evolution of both UV-Vis and Raman spectral regions was recorded concomitantly with the electrochemical signal in a single experiment.

Ferrocyanide undergoes the electrochemical process illustrated in the cyclic voltammogram of Figure 6.4.3a. The anodic peak is observed at $+0.392 \mathrm{~V}$, while the reduction peak occurs at $+0.097 \mathrm{~V}$. In addition, on the one hand, two UV-Vis absorption bands related to ferricyanide emerge at 310 and $420 \mathrm{~nm}$ (Figure 6.4.3b). On the other hand, the Raman spectra evolution (Figure 6.4.3c) shows the spectral changes in the band centered at 2132 $\mathrm{cm}^{-1}$, related to ferricyanide, as well as in the bands centered at 2056 and $2093 \mathrm{~cm}^{-1}$, associated with ferrocyanide. The corresponding UV-Vis cyclic voltabsorptograms at the wavelengths of interest and the evolution of the Raman bands with potential are illustrated, respectively, in Figure 6.4.4 and Figure 6.4.5. The oxidation of ferrocyanide to ferricyanide occurs from $+0.15 \mathrm{~V}$ of the forward scan up to $+0.35 \mathrm{~V}$ of the backward scan taking into account the three simultaneous responses. The absorbance of the UV-Vis bands at 310 and $420 \mathrm{~nm}$, and the Raman intensity of the band at 2132 $\mathrm{cm}^{-1}$, related to ferricyanide species, increase in this potential range in accordance with the oxidation process of ferrocyanide to ferricyanide, which diffuses from the electrode surface to the bulk solution. As expected, the intensity of the Raman bands centered at 2056 and $2093 \mathrm{~cm}^{-1}$, related to ferrocyanide, simultaneously decreases throughout the same time frame. Finally, a decrease of the absorbance at 310 and $420 \mathrm{~nm}$ (clearly observed in the corresponding cyclic voltabsorptograms shown in Figure 6.4.4), the 
simultaneous bleaching of the intensity at $2132 \mathrm{~cm}^{-1}$, as well as an increase of the intensity at 2056 and $2093 \mathrm{~cm}^{-1}$ are observed from $+0.35 \mathrm{~V}$ of the backward scan onward, due to the consumption of the electrogenerated ferricyanide that is reduced to ferrocyanide.

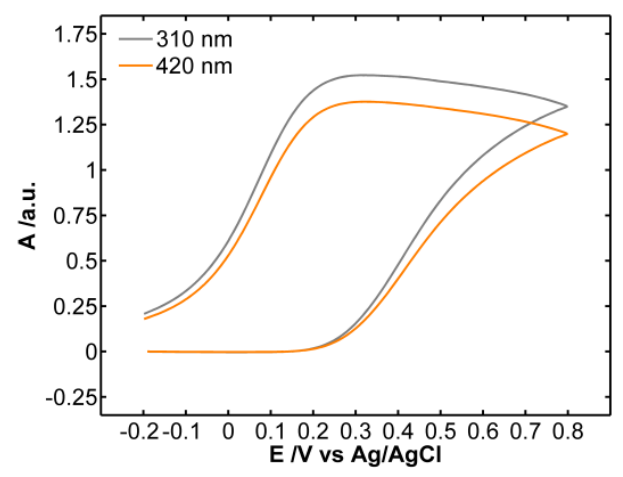

Figure 6.4.4. UV-Vis cyclic voltabsorptograms at 310 and $420 \mathrm{~nm}$ recorded during a cyclic voltammetry of $2.5 \times 10^{-2} \mathrm{M}$ potassium ferrocyanide in $0.1 \mathrm{M}$ $\mathrm{LiCl}$ between $-0.20 \mathrm{~V}$ and $+0.80 \mathrm{~V}$ at $0.02 \mathrm{~V} \cdot \mathrm{s}^{-1}$ on a $\mathrm{GC}$ foil as WE, corresponding to the experiment shown in Figure 6.4.3.

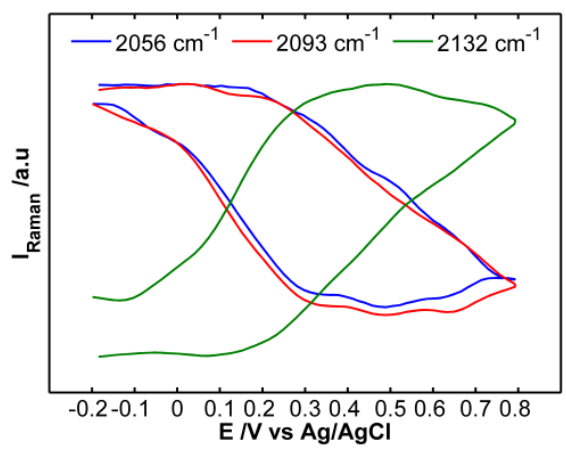

Figure 6.4.5. Evolution of the Raman bands centered at 2056, 2093, and 2132 $\mathrm{cm}^{-1}$ with potential during a cyclic voltammetry of $2.5 \times 10^{-2} \mathrm{M}$ potassium ferrocyanide in $0.1 \mathrm{M} \mathrm{LiCl}$ between $-0.20 \mathrm{~V}$ and $+0.80 \mathrm{~V}$ at $0.02 \mathrm{~V} \cdot \mathrm{s}^{-1}$ on a GC foil as WE, corresponding to the experiment shown in Figure 6.4.3. 
Therefore, the same conclusions can be extracted from the UV-Vis and Raman responses about the electrochemical process of the ferricyanide/ferrocyanide redox couple during this spectroelectrochemistry experiment.

To sum up, the suitable performance of this UV-Vis/Raman spectroelectrochemistry device has been properly validated taking into account the results obtained in this experiment.

\subsubsection{Oxidation of Dopamine on a Single-Walled Carbon Nanotubes Electrode}

UV-Vis/Raman spectroelectrochemistry was used to study the electrochemical reaction of dopamine on a SWCNTs electrode. In this case, different and complementary information was obtained with both spectroscopic responses. The integration times were 150 and $1440 \mathrm{~ms}$ for $\mathrm{UV}-\mathrm{Vis}$ and Raman signals, respectively, and the optical path length in $\mathrm{UV}-\mathrm{V}$ is measurements was set to $0.4 \mathrm{~mm}$.

Spectroelectrochemistry measurements were carried out using a SWCNTs WE prepared on quartz. Figure 6.4.6a shows the cyclic voltammogram of $6.6 \times 10^{-4} \mathrm{M}$ dopamine in $1 \mathrm{M} \mathrm{HClO}_{4}$ between $+0.10 \mathrm{~V}$ and +1.00 at 0.01 $\mathrm{V} \cdot \mathrm{s}^{-1}$. UV-Vis and Raman spectra obtained during the oxidation scan are plotted in parts $\mathrm{b}$ and $\mathrm{c}$ of Figure 6.4.6, respectively. The corresponding spectra evolution during the reduction scan can be found in Figure 6.4.7 and Figure 6.4.8. As in the previous experiment, the spectrum of the initial solution was taken as reference for the UV-Vis absorption spectra. 

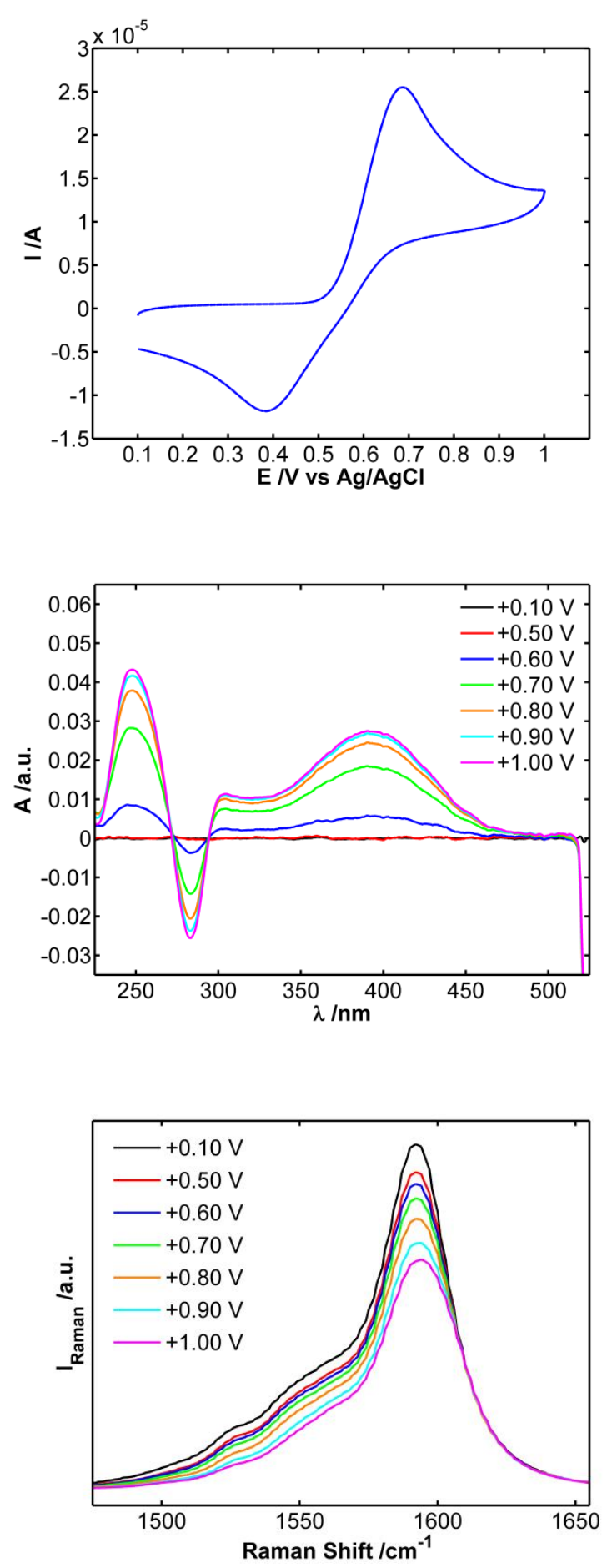

Figure 6.4.6. (a) Cyclic voltammogram of $6.6 \times 10^{-4} \mathrm{M}$ dopamine in $1 \mathrm{M}$ $\mathrm{HClO}_{4}$ between $+0.10 \mathrm{~V}$ and +1.00 at $0.01 \mathrm{~V} \cdot \mathrm{s}^{-1}$ on a SWCNTs WE prepared on quartz. (b) UV-Vis and (c) Raman spectra evolution recorded during the oxidation scan. 
The electrochemical reaction of dopamine is a well-known process that can generate different products depending on the $\mathrm{pH}$ value. The cyclic voltammogram, Figure 6.4.6a, displays one oxidation peak, which involves a two-electron transfer, related to the generation of dopaminequinone as a single product, as was expected under these experimental acidic conditions. ${ }^{400}$ The peak potential difference takes a value of $0.303 \mathrm{~V}$, indicating a quasi-reversible electrochemical behavior.

The UV-Vis spectra evolution recorded during the oxidation scan shows, in accordance with the electrochemical signal, the evolution of three bands at 248, 283, and $391 \mathrm{~nm}$ from $+0.50 \mathrm{~V}$ onward (Figure 6.4.6b). UV-Vis bands at 248 and $391 \mathrm{~nm}$ are related to the electrogeneration of dopaminequinone, and the one at $283 \mathrm{~nm}$ is associated with the consumption of dopamine. ${ }^{19,336}$ As can be seen in Figure 6.4.7, the spectral changes evolve in the opposite way during the cathodic scan due to the reduction of the electrogenerated dopaminequinone and regeneration of dopamine. It should be noted that an excellent spectral resolution is achieved, not only in the visible but also in the UV spectral region.

Moreover, a maximum and constant value of absorbance is reached due to the steady-state achieved when dopaminequinone diffuses beyond the first $100 \mu \mathrm{m}$ of the solution closest to the SWCNTs electrode surface sampled by the optical fibers. A first approximation of the molar absorption coefficient value of dopaminequinone can be calculated using the Beer-Lambert law $(A=\varepsilon l C)$ and assuming that a dopamine concentration of $6.6 \times 10^{-4} \mathrm{M}$ is converted to dopaminequinone in the $100 \mu \mathrm{m}$ of the solution adjacent to the electrode surface sampled by the optical fibers. From the maximum and constant value of absorbance at $391 \mathrm{~nm}(0.0275$ $\mathrm{au})$, the concentration of dopamine $\left(6.6 \times 10^{-4} \mathrm{M}\right)$, and the optical path 
length in parallel configuration $(0.04 \mathrm{~cm})$, an experimental value of roughly $1040 \mathrm{M}^{-1} \cdot \mathrm{cm}^{-1}$ is estimated for the molar absorption coefficient of dopaminequinone at $391 \mathrm{~nm}$.

In order to obtain Raman information about this system, the laser was focused on the SWCNTs electrode surface, but there is no Raman signal related to dopamine at this low concentration. Nevertheless, Raman spectra provide essential information about the behavior of SWCNTs with potential during the experiment (Figure 6.4.6c and Figure 6.4.8). The behavior of the SWCNTs during the electron transfer is not easily obtained using other analytical techniques. Raman spectrum of SWCNTs (Figure 6.4.9) shows four main bands: $:^{369,401}$ the radial breathing mode (RBM) at 150-300 $\mathrm{cm}^{-1}$; the disorder induced mode (D) at $1300-1400 \mathrm{~cm}^{-1}$; the tangential displacement mode $(\mathrm{G})$ at $1550-1600 \mathrm{~cm}^{-1}$; and the highfrequency two-phonon mode $\left(\mathrm{G}^{\prime}\right.$ or $\left.2 \mathrm{D}\right)$ at $2550-2750 \mathrm{~cm}^{-1}$. In order to illustrate the behavior of SWCNTs during the electrochemical oxidation of dopamine, the most intense band (G-band) was analyzed (Figure 6.4.6c). Oxidation (p-doping) of SWCNTs leads to a decrease of the G-band Raman intensity. During the cathodic scan, the G-band intensity returns to approximately the initial value (Figure 6.4.8). All these changes in the Raman intensity are only related to the electrochemical doping/dedoping of the SWCNTs WE. ${ }^{14,369}$

In addition, only the generation of dopaminequinone is allowed under these acidic conditions, avoiding the formation of dopaminechrome that could polymerize on the SWCNTs WE. The absence of the dopaminechrome absorption around $470 \mathrm{~nm}$ in the UV-Vis spectra ${ }^{19}$ and of the characteristic bands in Raman spectroscopy when dopaminechrome polymerizes on the electrode confirms, with two independent techniques in the same 
experiment, that the oxidation of dopamine under these acidic conditions only generates dopaminequinone.

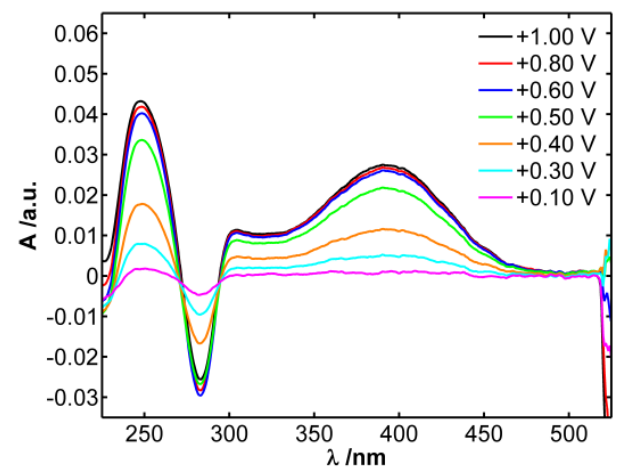

Figure 6.4.7. UV-Vis spectra evolution recorded during the reduction scan of a cyclic voltammetry of $6.6 \times 10^{-4} \mathrm{M}$ dopamine in $1 \mathrm{M} \mathrm{HClO}_{4}$ between $+0.10 \mathrm{~V}$ and $+1.00 \mathrm{~V}$ at $0.01 \mathrm{~V} \cdot \mathrm{s}^{-1}$ on a SWCNTs WE prepared on quartz, corresponding to the experiment shown in Figure 6.4.6.

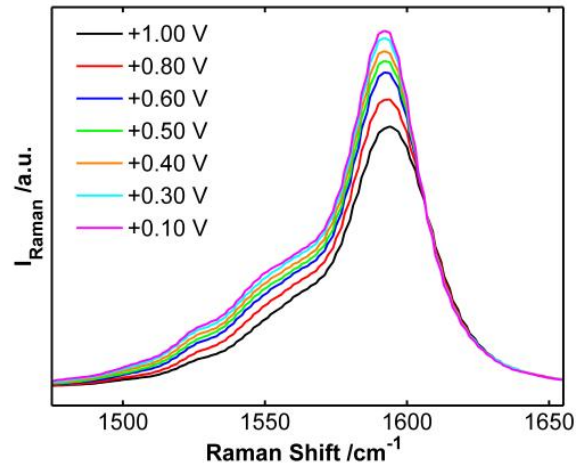

Figure 6.4.8. Raman spectra evolution of the G-band of SWCNTs recorded during the reduction scan of a cyclic voltammetry of $6.6 \times 10^{-4} \mathrm{M}$ dopamine in 1 $\mathrm{M} \mathrm{HClO}_{4}$ between $+0.10 \mathrm{~V}$ and $+1.00 \mathrm{~V}$ at $0.01 \mathrm{~V} \cdot \mathrm{s}^{-1}$ on a SWCNTs WE prepared on quartz, corresponding to the experiment shown in Figure 6.4.6. 


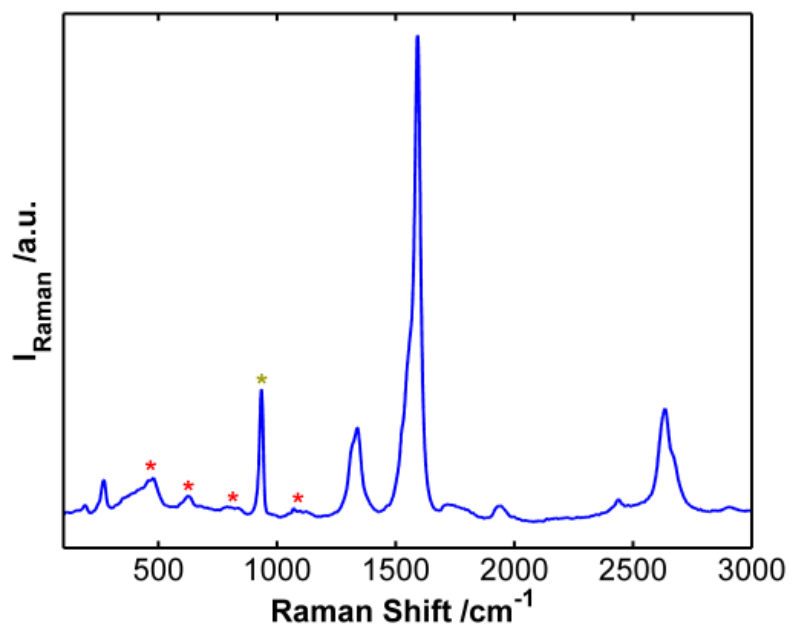

Figure 6.4.9. Raman spectrum of SWCNTs, corresponding to the experiment shown in Figure 6.4.6. ${ }^{(*)}$ Raman bands associated with quartz and ${ }^{(*)}$ Raman band related to $\mathrm{ClO}_{4}{ }^{-}$.

In summary, this spectroelectrochemistry experiment allows us to obtain different information depending on the spectroscopic technique used. Information extracted from UV-Vis spectral evolution is mainly related to spectroscopic changes that take place in the solution adjacent to the electrode, which are associated with compounds present in the solution (dopamine and products derived from its electrochemical reaction). Moreover, the evolution of the Raman spectra is related to the oxidation state of the SWCNTs WE surface.

Therefore, we can conclude that we are able to observe two different processes in a single electrochemical experiment taking into account both spectroscopic signals. This is a great advantage of this device because the parallel UV-Vis light beam does not sample the SWCNTs surface and Raman spectroscopy is not capable of following the electrochemical reaction of dopamine. Nevertheless, as has been demonstrated, this 
experimental device allows us to study both processes simultaneously without interference between the two optical techniques.

\subsubsection{Electropolymerization of 3,4-Ethylenedioxythiophene in Aqueous Solution}

This experiment was performed to observe an electrochemical process from two different but correlated spectroscopic points of view. PEDOT, the electrogenerated conducting polymer, is widely used for many applications $^{402-406}$ and it has been previously studied by spectroelectrochemistry. $^{227}$

Cyclic voltammetry of $3 \times 10^{-3} \mathrm{M}$ EDOT in $0.2 \mathrm{M} \mathrm{LiClO}_{4}$ was performed at a scan rate of $0.025 \mathrm{~V} \cdot \mathrm{s}^{-1}$ on a SWCNTs WE prepared on quartz, using the following potentials: initial and final potential $\left(E_{i}=E_{f}=0.00 \mathrm{~V}\right)$; anodic vertex potential $\left(E_{v 1}=+1.00 \mathrm{~V}\right)$; and cathodic vertex potential $\left(E_{v 2}=\right.$ $-0.50 \mathrm{~V})$. UV-Vis and Raman spectra were recorded every 300 and 1920 ms, respectively. The optical path length in UV-Vis measurements was 1.1 $\mathrm{mm}$. As in the previous cases, the spectrum of the initial solution was taken as reference for the UV-Vis absorption spectra.

The cyclic voltammogram is plotted in Figure 6.4.10a. An increase in the anodic current is observed from $\sim+0.70 \mathrm{~V}$ onward, according to the oxidation process of EDOT. The UV-Vis cyclic voltabsorptogram at 254 $\mathrm{nm}$ (main band of the UV-Vis spectrum of EDOT), ${ }^{407,408}$ Figure 6.4.10b, and the evolution of the Raman bands centered at 1110 and $1134 \mathrm{~cm}^{-1}$ with potential, Figure $6.4 .10 \mathrm{c}$, show optical changes that are correlated with the electrochemical response. 

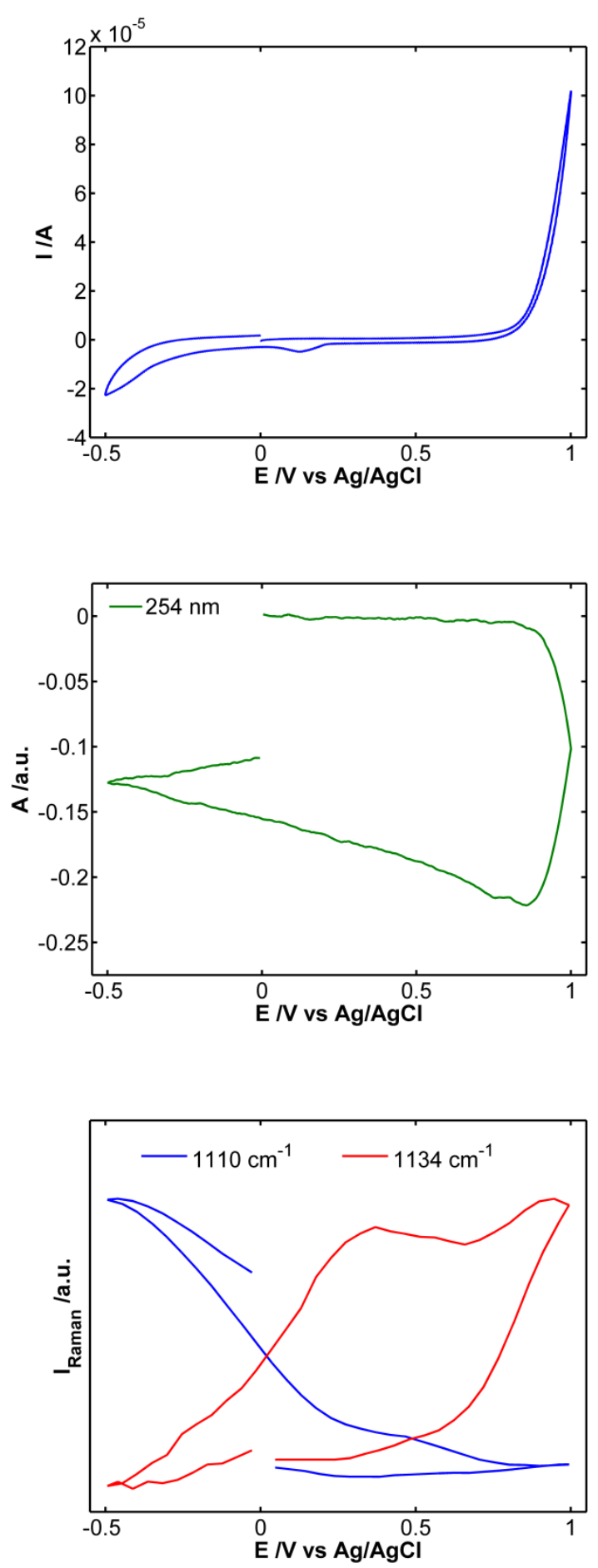

Figure 6.4.10. (a) Cyclic voltammogram of $3 \times 10^{-3} \mathrm{M}$ EDOT in $0.2 \mathrm{M} \mathrm{LiClO}_{4}$ $\left(E_{i}=E_{f}=0.00 \mathrm{~V}, E_{v 1}=+1.00 \mathrm{~V}\right.$, and $\left.E_{v 2}=-0.50 \mathrm{~V}\right)$ at $0.025 \mathrm{~V} \cdot \mathrm{s}^{-1}$ on a SWCNTs WE prepared on quartz. (b) UV-Vis cyclic voltabsorptogram at 254 $\mathrm{nm}$ and (c) evolution of the Raman bands at 1110 and $1134 \mathrm{~cm}^{-1}$ recorded during the reaction. 
The evolution of the UV band at $254 \mathrm{~nm}$ (Figure 6.4.10b) indicates that the consumption of the monomer takes place from $+0.85 \mathrm{~V}$ onward, concomitantly with the oxidation process appreciated in the electrical signal (Figure 6.4.10a). Thus, in the potential window between $+0.85 \mathrm{~V}$ and $+1.00 \mathrm{~V}$ in the anodic and cathodic scan, absorbance at $254 \mathrm{~nm}$ decreases because of the consumption of EDOT in the solution closest to the WE surface. Once absorbance at $254 \mathrm{~nm}$ reaches a minimum value, its evolution is only related to the diffusion of EDOT from the bulk solution to the electrode/solution interface.

As can be observed in Figure 6.4.10c, Raman signal provides complementary information about this process. The evolution of the Raman spectra was also recorded simultaneously with the cyclic voltammetry. Figure 6.4.11a and Table 6.4.1 display, respectively, the Raman spectra and the vibrational assignment of the main bands corresponding to neutral $(-0.50 \mathrm{~V})$ and doped $(+1.00 \mathrm{~V})$ PEDOT. ${ }^{230}$ In the Raman spectra registered (Figure 6.4.11a), it can also be observed the characteristic bands of SWCNTs, some of them overlapped with those of PEDOT. Although more intense bands are observed in the Raman spectra, Figure 6.4.11b displays the contour plot of only the Raman signal in a Raman shift frame where less interference of SWCNTs is appreciated. Here it can be observed the evolution of the 1110 and $1134 \mathrm{~cm}^{-1}$ bands with time. These two Raman bands were studied, specifically because the $1110 \mathrm{~cm}^{-1}$ band is related to the neutral PEDOT and the $1134 \mathrm{~cm}^{-1}$ band is associated with the doped PEDOT (Figure 6.4.10c). Analyzing the Raman band at $1110 \mathrm{~cm}^{-1}$ with potential (Figure 6.4.10c), we can observe that initially, from $0.00 \mathrm{~V}$ to $+0.70 \mathrm{~V}$, this band is not detected. This band is clearly observed when electropolymerization have occurred and the electrogenerated polymer is being neutralized. This process of PEDOT dedoping lasts up to the second 
vertex potential, $-0.50 \mathrm{~V}$. Next, Raman intensity decreases indicating that PEDOT is starting to be doped again. The evolution of the band centered at $1134 \mathrm{~cm}^{-1}$ is more sensitive to the doped polymer and it shows a clearly different behavior. The intensity of this Raman band increases from $\sim+0.65 \mathrm{~V}$ onward because of the doping of PEDOT. Next, the intensity of the $1134 \mathrm{~cm}^{-1}$ band decreases when the neutral form begins to be generated.
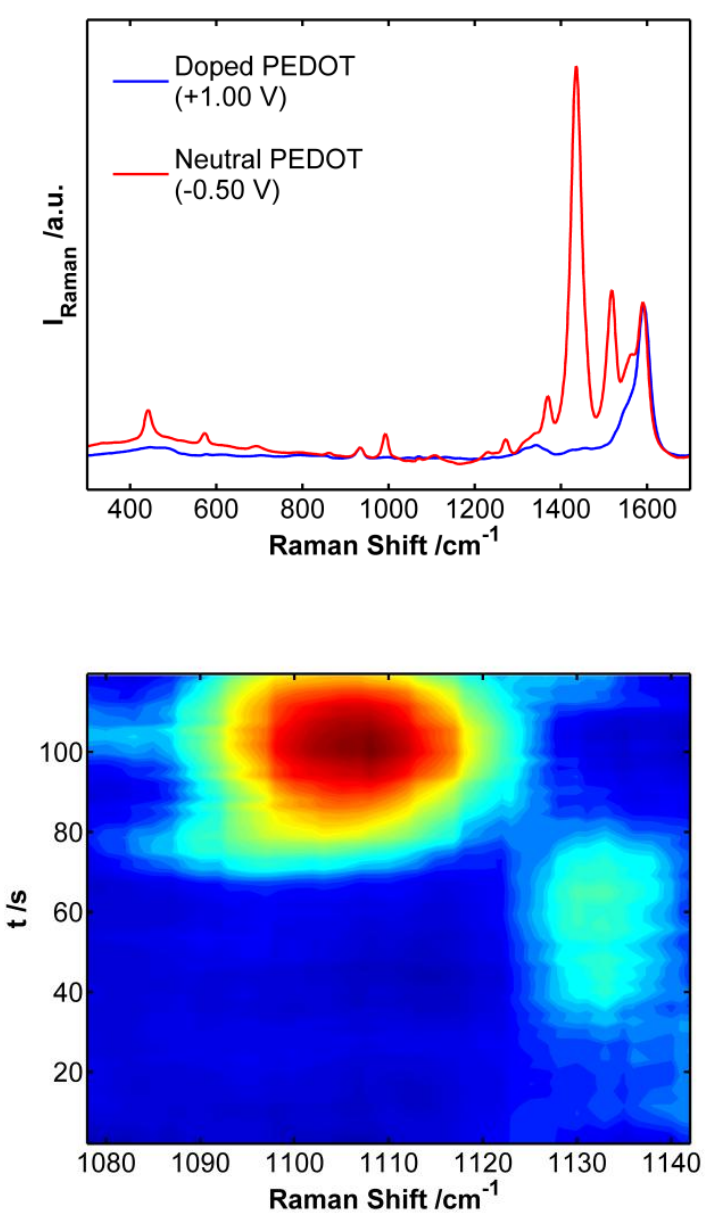

Figure 6.4.11. (a) Raman spectra of PEDOT in neutral (red line) and doped (blue line) states recorded in a second scan, neutral PEDOT at $-0.50 \mathrm{~V}$ and doped PEDOT at +1.00 V. (b) Contour plot of the evolution of the Raman bands centered at 1110 and $1134 \mathrm{~cm}^{-1}$ with time, corresponding to the experiment shown in Figure 6.4.10. 
Table 6.4.1. Vibrational assignment of the main bands corresponding to neutral $(-0.50 \mathrm{~V})$ and doped $(+1.00 \mathrm{~V})$ PEDOT electrodeposited by cyclic voltammetry on a SWCNTs WE prepared on quartz, corresponding to the experiment shown in Figure 6.4.10.

\begin{tabular}{|c|c|c|c|}
\hline Mode & $\begin{array}{r}\text { Raman shi } \\
\text { Neutral PEDOT } \\
\end{array}$ & $\begin{array}{l}\text { ift }\left(\mathrm{cm}^{-1}\right) \\
\text { Doped PEDOT }\end{array}$ & Description \\
\hline 1 & 443 & 450 & Oxyethylene ring deformation \\
\hline 2 & 573 & 578 & Oxyethylene ring deformation \\
\hline 3 & 695 & 705 & $\begin{array}{l}\text { Symmetric } \mathrm{C}_{\alpha}-\mathrm{S}-\mathrm{C}_{\alpha}, \text { ring } \\
\text { deformation }\end{array}$ \\
\hline 4 & - & 780 & Oxyethylene ring deformation \\
\hline 5 & 866 & 853 & $\mathrm{O}-\mathrm{C}-\mathrm{C}$ deformation \\
\hline 6 & 994 & 992 & Oxyethylene ring deformation \\
\hline 7 & 1110 & 1134 & $\mathrm{C}-\mathrm{O}-\mathrm{C}$ deformation \\
\hline 8 & 1232 & 1230 & $\begin{array}{l}\mathrm{C}_{\alpha}-\mathrm{C}_{\alpha} \text {, interring stretching }+ \\
\mathrm{C}_{\beta}-\mathrm{H} \text { bending }\end{array}$ \\
\hline 9 & - & 1244 & $\mathrm{CH}_{2}$ twisting \\
\hline 10 & 1274 & - & $\mathrm{C}_{\alpha}-\mathrm{C}_{\alpha}$, interring stretching \\
\hline 11 & 1372 & 1370 & $\mathrm{C}_{\beta}-\mathrm{C}_{\beta}$, stretching \\
\hline 12 & 1436 & 1458 & $\begin{array}{l}\text { Symmetric } \mathrm{C}_{\alpha}=\mathrm{C}_{\beta}(-\mathrm{O}) \\
\text { stretching }\end{array}$ \\
\hline 13 & 1520 & 1528 & Asymmetric $\mathrm{C}_{\alpha}=\mathrm{C}_{\beta}$ stretching \\
\hline 14 & 1565 & 1578 & Quinoid structure \\
\hline
\end{tabular}

The charge involved in the polymerization process can be extracted from the cyclic voltammogram (Figure 6.4.10a). However, the electrochemical signal does not provide a well-defined response to determine the potentials at which the polymerization takes place. Evolution of the Raman intensity (Figure 6.4.10c) allows us to define the potentials when the doped PEDOT 
is electrogenerated and, in this way, to calculate the charge involved in this electrochemical process. According to the evolution of the $1134 \mathrm{~cm}^{-1}$ band in the Figure 6.4.10c, the polymerization occurs from $\sim+0.65 \mathrm{~V}$ (anodic scan) to $+0.90 \mathrm{~V}$ (cathodic scan). The charge involved in the polymerization is calculated from the cyclic voltammogram, obtaining 5.1 $\times 10^{-4} \mathrm{C}$ as the experimental value of the charge involved in the EDOT oxidation during the polymerization.

This last experiment allows us to follow the evolution of an electropolymerization process by means of UV-Vis and Raman spectroscopic responses, which enables us to observe two different perspectives on the same electrochemical process. Thus, the UV-Vis spectra evolution with potential is associated with the consumption of EDOT in the solution layer adjacent to the SWCNTs WE. However, the Raman response is related to the generation of PEDOT electrodeposited on the SWCNTs WE giving also information about its doping level at each potential. In conclusion, the EDOT electropolymerization process is studied by UV-Vis and Raman spectroscopy, obtaining complementary, useful, and valuable information.

\subsubsection{Conclusions and Future Work}

In this work, a novel and easy-to-use device, based on UV-Vis bare optical fibers in long optical path arrangement and on measuring the Raman signal in normal configuration, has been fabricated, allowing us to carry out UV-Vis absorption and Raman dispersion spectroelectrochemistry simultaneously. 
To the best of our knowledge, this is the first time that a spectroelectrochemistry device is able to record both spectroscopic responses at the same time, allowing us to obtain much more high-quality information in a single experiment. Its excellent performance has been clearly demonstrated with the electrochemical, UV-Vis, and Raman responses obtained simultaneously in all cases.

A GC foil or a SWCNTs film transferred on quartz have been used as WEs, and good results have been achieved with three different electrochemical reactions using this hybrid UV-Vis/Raman spectroelectrochemistry device:

Ferrocyanide has been employed to validate the device because the same spectral information about its electrochemical process was obtained with the two spectroscopic techniques.

The electrochemical reaction of dopamine in acidic media has been studied on a SWCNTs electrode. The generation of dopaminequinone as the single oxidation product has been observed by the evolution of the UV-Vis spectra in the solution layer, while the electrochemical behavior of the SWCNTs WE has been followed using the Raman response.

The electropolymerization of EDOT has been studied in aqueous solution on a SWCNTs WE. The EDOT consumption in the first $100 \mu \mathrm{m}$ of the solution adjacent to the WE was studied by the parallel UV-Vis light beam, and the information about the electrogeneration of PEDOT on the WE was extracted from the Raman signal. 
Each spectroscopic technique can be used to follow a different process, and, therefore, completely different but complementary information can be obtained during the electrochemical reaction.

This UV-Vis/Raman spectroelectrochemistry device, which is definitely a significant advance in this research field, greatly increases the multiresponse, in situ, versatile, and real-time character of spectroelectrochemistry.

This spectroelectrochemistry cell could be widely used by the scientific community in the near future to shed more light about complex reactions and their mechanisms, as well as to characterize new materials.

A question is able to give an idea about the large number of potential applications: Why look for a single signal when you can study three simultaneous and complementary responses in a simple way? 
6.5. Development of a New Multipurpose Spectroelectrochemistry Device 



\subsubsection{Some Important Points to Keep in Mind}

By combining all the advantages demonstrated in the previous works of this doctoral thesis, the inherent advantages of $\mathrm{UV}-\mathrm{Vis}$ absorption spectroelectrochemistry should overcome some difficulties related to: (i) quantitative analysis; (ii) monitoring the $\mathrm{pH}$ at interfaces; and (iii) direct measurements in complex matrices, among others.

For this reason, a singular and multipurpose spectroelectrochemistry device has been fabricated and validated. The novel cell is based on SWCNTs, which are filtered from a dispersion (excellent results in all previous sections of this doctoral thesis, 6.1, 6.2, 6.3, and 6.4) $)^{73-76}$. However, in the present method, the SWCNTs film formed on the filter membrane is subsequently press-transferred on a PET support using a stencil with a custom design, allowing us to select the shape of the SWCNTs transferences.

With this new methodology, WE, CE, and RE are completely flat on the support where two bare optical fibers are attached in a long optical path length configuration. In the previous sections $6.3^{75}$ and $6.4^{76}$ of this doctoral thesis, we have demonstrated the important advantages of bare optical fibers without cladding material to conduct the light beams for spectroelectrochemistry applications, particularly for long optical path length arrangement.

The fact of fixing the optical fibers in a device that contains the three electrodes guarantees an excellent reproducibility between spectroelectrochemical measurements and a fascinating mobility of the whole device. 
This UV-Vis absorption spectroelectrochemistry device is used to fulfill the main goals of this doctoral thesis from now on, which are: (i) the quantitative resolution of complex mixtures of catechol and dopamine using multivariate analysis (section 6.6) ${ }^{30}$ (ii) the monitoring of the evolution of $\mathrm{pH}$ at the electrode-solution interface during electrochemical reactions (section 6.7); ${ }^{77}$ and (iii) the direct determination of ascorbic acid in a grapefruit (section 6.8). ${ }^{31}$ The ease to fabricate the device, the advantages related to its use, and the excellent results obtained on these topics demonstrate the usefulness of this device in a wide range of fields.

\subsubsection{Experimental Section}

\subsubsection{Reagents and Materials}

SWCNTs (Sigma-Aldrich), DCE (99.8\% for HPLC, Acros Organics), PTFE membranes (filter pore size $0.1 \mu \mathrm{m}$, JVWP01300, Millipore Omnipore), PET (175 $\mu \mathrm{m}$ thick, HiFi Industrial Film), silver conductive paint (Electrolube), $\mathrm{HCl}$ (35\%, VWR), and transparent nail polish (Essence) were used to fabricate the electrodes. Two bare optical fibers (100 $\mu \mathrm{m}$ in diameter, Ocean Optics) were needed to fabricate the spectroelectrochemistry device. $\mathrm{FcMeOH}$ (97\%, Acros Organics) and $\mathrm{KCl}$ (Acros Organics) were used to prepare the solutions to validate the device.

All reagents were used as received without further purification. All chemicals were of analytical grade. Aqueous solutions were freshly prepared using ultrapure water $\left(18.2 \mathrm{M} \Omega \cdot \mathrm{cm}\right.$ resistivity at $25{ }^{\circ} \mathrm{C}$, Milli-Q Direct 8, Millipore). 


\subsubsection{Instrumentation}

Spectroelectrochemistry setup includes a potentiostat/galvanostat (PGSTAT302N, Metrohm Autolab), a halogen-deuterium light source (AvaLight-DH-S-BAL, Avantes), and a spectrometer (QE65000 198-1006 nm, Ocean Optics). A tip-sonicator (CY-500, Optic ivymen System) was also used to disperse the SWCNTs in DCE. Stencils were made of PMMA (Maniplastic) using a high-precision $\mathrm{CO}_{2}$ laser cutting machine. A laboratory hydraulic press (SpectroPress, Chemplex Industries, Inc.) was also used to transfer the SWCNTs film, obtained by filtration, on the PET substrate.

For safety considerations, all handling and processing were performed carefully, particularly when DCE was used.

\subsubsection{Transference of Single-Walled Carbon Nanotubes Using a Stencil}

The transference of carbon nanotubes films of different shapes on many supports is required for several applications. Herein, we present a methodology based on filtering a SWCNTs dispersion and presstransferring the SWCNTs film formed to a PET sheet using a stencil with the desired shape.

The first step to achieve a good SWCNTs transference is to obtain a homogeneous dispersion of $0.5 \mathrm{mg}$ of SWCNTs in $100 \mathrm{~mL}$ of DCE. The procedure followed in this work has been described in section $6.3 .^{75}$ Briefly, $0.5 \mathrm{mg}$ of SWCNTs were weighed and sonicated in increasing volumes of DCE applying different sonication power levels. Ten milliliters 
of the final dispersion were sonicated before preparing the transfers to avoid SWCNTs agglomeration and to ensure a good homogeneity.

Subsequently, $0.8 \mathrm{~mL}$ of the SWCNTs dispersion were filtered under vacuum through a PTFE filter, resulting in a homogeneous film of SWCNTs on the membrane surface. By filtering $0.8 \mathrm{~mL}$ of the dispersion through a membrane area of $0.785 \mathrm{~cm}^{2}$, the amount of SWCNTs that remained in the membrane was enough to form an interconnected network of SWCNTs with highlighted conductivity (section 6.1). ${ }^{73}$

Next, filter was dried at room temperature for only five minutes because longer times imply wrong transferences.

Afterward, the filter was placed between the stencil and the PET support, which was previously washed with water and dried, taking care that the polymeric substrate did not acquire static electricity because it decreases the transference quality. Figure 6.5.1 shows an illustration about the experimental setup used to fabricate the SWCNTs press-transfers with a stencil. The filter with the SWCNTs film (a) was oriented with the SWCNTs in contact with the PET surface (b) and the filter membrane in contact with the PMMA stencil with the desired shape (c). The assembly of the pieces described above together with (d) and (e) was placed on the hydraulic press and 8 tons were applied for 15 minutes. During this time period, the stencil pressed the SWCNTs film to the PET support only in the regions where PMMA was present, while SWCNTs remained in the filter in the stencil regions where there was no PMMA.

Finally, the filter was carefully detached using tweezers. As a result, SWCNTs were transferred on the PET support according to the chosen shape of the stencil. 


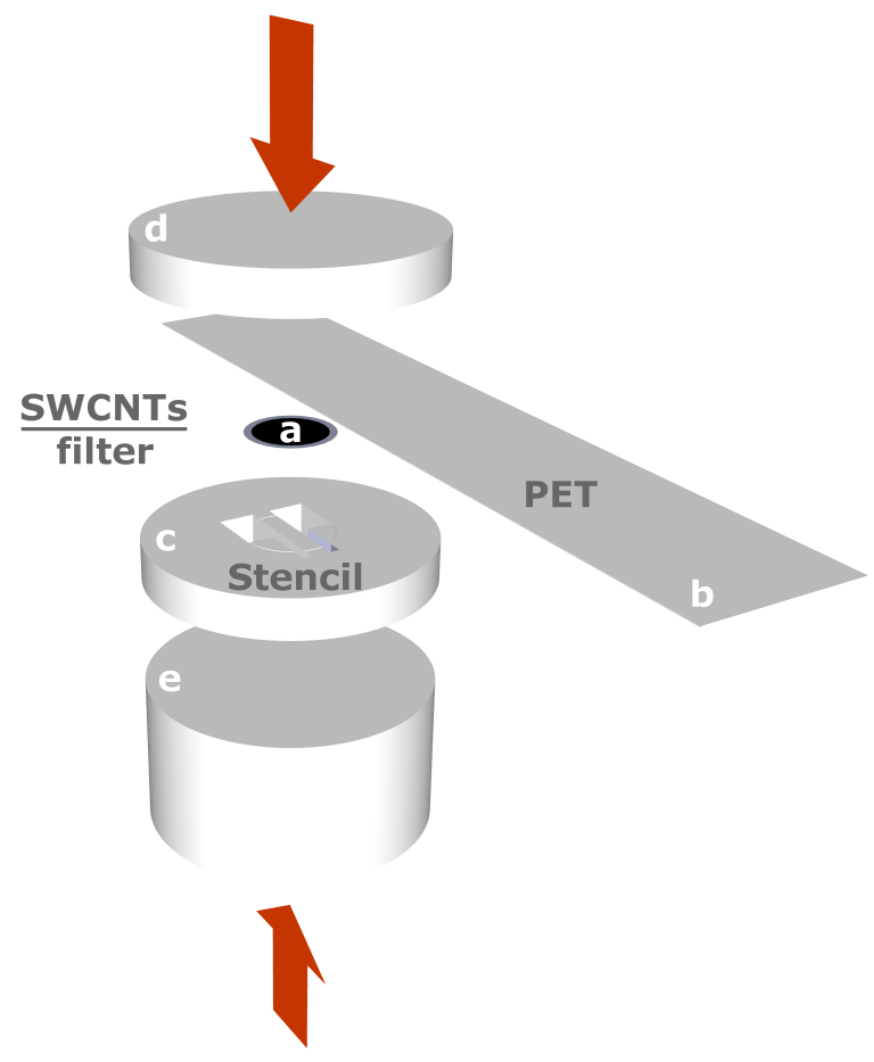

Figure 6.5.1. Illustration about the experimental setup used to fabricate the SWCNTs press-transfers on a PET surface with a stencil.

\subsubsection{Fabrication of the Electrochemical Device}

The preparation process of the electrodes is quite simple. Electrical contacts were made with silver conductive paint. One of the small transfers was also covered with this material aiming to constitute the RE. Next, silver conductive paint was dried at $75^{\circ} \mathrm{C}$ for 45 minutes. A drop of $\mathrm{HCl}$ in water, 1:10 dilution, was added to the silver $\mathrm{RE}$ to form a $\mathrm{Ag} / \mathrm{AgCl} \mathrm{RE}$. Finally, the electrical contacts were electrically isolated with nail polish which was dried at room temperature. This insulator is also used to control the WE area. The excellent reproducibility of electrodes based on the presstransference of carbon nanomaterials was demonstrated in one of our 
previous works (section 6.2) ${ }^{74}$ Therefore, a three-electrode cell with a WE and a $\mathrm{CE}$ of SWCNTs and a $\mathrm{Ag} / \mathrm{AgCl} \mathrm{RE}$ has been fabricated.

\subsubsection{Fabrication of the Spectroelectrochemistry Device}

Two bare optical fibers of $100 \mu \mathrm{m}$ in diameter were easily and perfectly aligned, opposite one another, and fixed with nail polish to the PET support, allowing the parallel light beam to pass only through the first 100 $\mu \mathrm{m}$ of solution layer adjacent to the SWCNTs WE. The optical path length is defined as the distance between the ends of the two bare optical fibers, which can be easily controlled with the use of a piece of the desired length, helping to study the electron transfer of compounds with very different molar absorption coefficients. For the sake of clarity, Figure 6.5.2 shows an illustration to scale of the final spectroelectrochemistry device. In addition, a photograph of the spectroelectrochemistry device with the different steps of its fabrication can be observed in Figure 6.5.3.

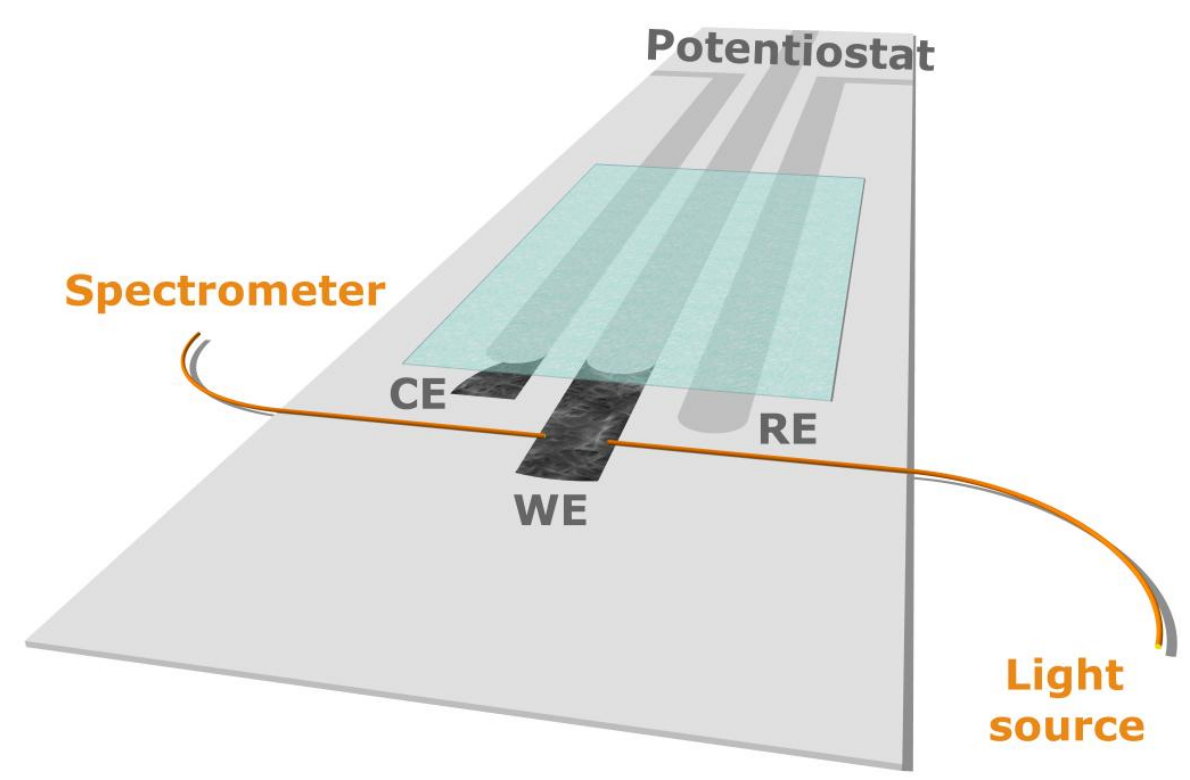

Figure 6.5.2. Illustration of the spectroelectrochemistry device. 


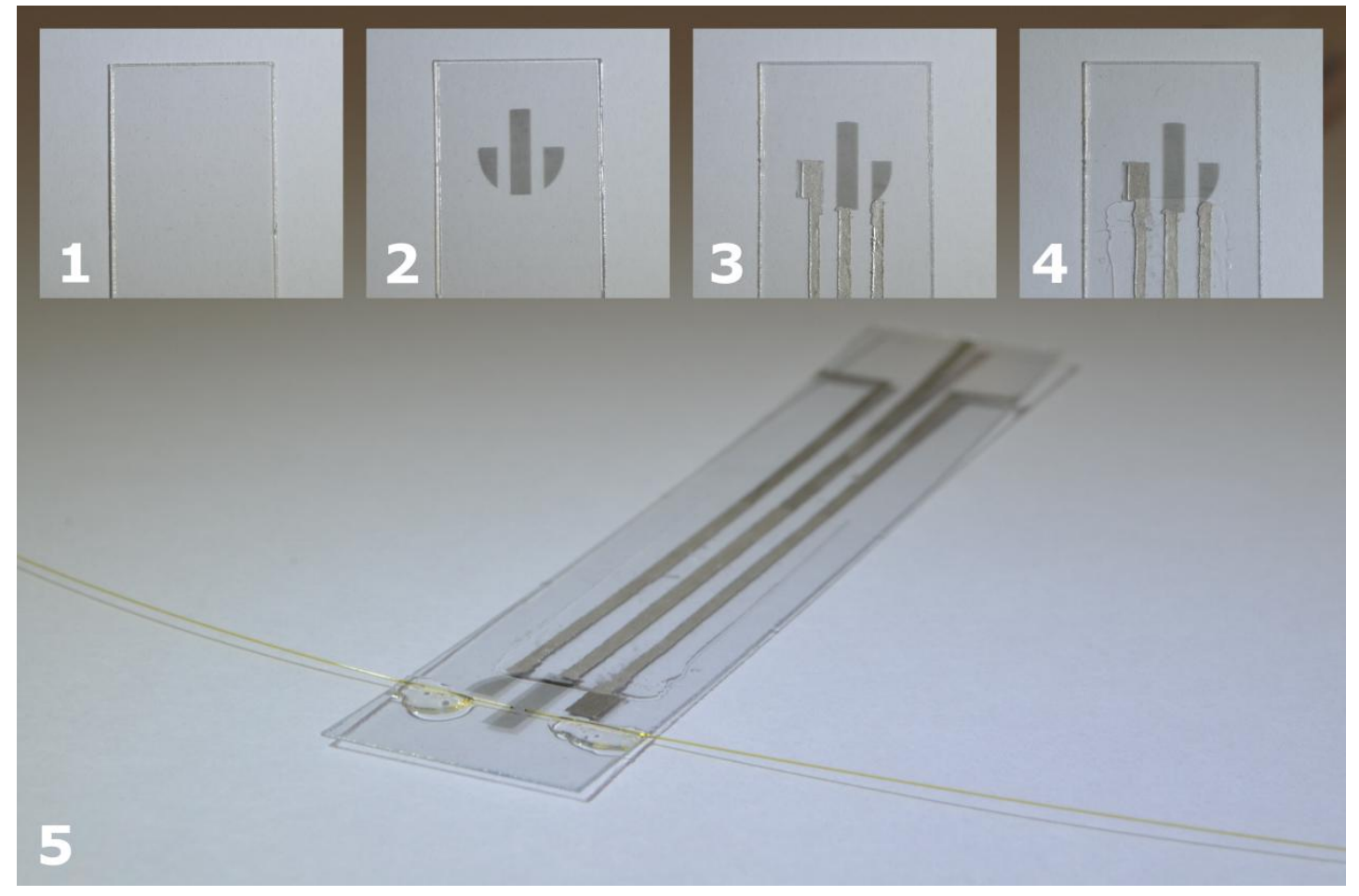

Figure 6.5.3. Photograph of the spectroelectrochemistry device with the different steps of its fabrication.

\section{Initial PET support.}

2. SWCNTs were transferred on the PET substrate according to the custom design of the stencil.

3. Electrical contacts were made with silver conductive paint. One of the small transfers was also covered with this material aiming to constitute the RE. A drop of $\mathrm{HCl}$ in water, 1:10 dilution, was added to the silver $\mathrm{RE}$ to form a $\mathrm{Ag} / \mathrm{AgCl}$ RE.

4. The electrical contacts were isolated with nail polish. If necessary, the WE area can be controlled with this insulator or using a mask.

5. Two bare optical fibers of $100 \mu \mathrm{m}$ in diameter were perfectly aligned and attached with nail polish to the PET support. 


\subsubsection{Experimental Setup for $U V-V$ is Absorption Spectroelectrochemistry Measurements}

The ease to perform spectroelectrochemistry measurements is one of the key points of this device.

As is shown in Figure 6.5.2, the electrical contacts are connected to the potentiostat, one of the optical fibers to the UV-Vis light source and the other one to the spectrometer. The transmitted parallel light beam collects the spectral changes that occur between the optical fibers and that are related to the processes that take place only in the first $100 \mu \mathrm{m}$ of the electrode-solution interface, being the electrochemical signal simultaneously recorded in a single experiment. The potentiostat and the spectrometer are properly synchronized using a trigger that guarantees the simultaneous character of all spectroelectrochemistry experiments.

The detection mechanism of the device toward the target molecules is based on the principles of spectroelectrochemistry in long optical path length arrangement. The analyte is oxidized or reduced in the surface of the WE, where is electrochemically detected, and, simultaneously, the oxidized or reduced analyte is spectroscopically detected when it diffuses from the WE surface to the bulk solution. In our case, as the diameter of the bare optical fibers, which are fixed to the support, is $100 \mu \mathrm{m}$, the oxidized or reduced analyte is spectroscopically detected in the first $100 \mu \mathrm{m}$ of the diffusion layer of the solution adjacent to the WE surface.

Inherent advantages associated with long optical path length spectroelectrochemistry devices such as the one developed herein, should be highlighted instead of common normal configuration devices: (i) a higher sensitivity and, thus, lower limits of detection; (ii) the use of OTEs 
is not required; and (iii) the light beam only samples the first micrometers of the solution adjacent to the electrode surface, so the spectral changes recorded during the electrochemical reaction are only related to the electrode-solution interface.

Several great advantages related to the new transfer methodology and the spectroelectrochemistry device presented in this work should be mentioned. Filtering SWCNTs dispersions without surfactants and removing the filter without chemicals allow us to obtain homogeneous, reproducible, and clean SWCNTs transferences. Furthermore, the use of stencils with a customized design guarantees a great versatility about the number, shapes, and sizes of the transferences, and, in this case, of the electrodes. Any stencil can be designed; hence, any three-electrode spectroelectrochemistry cell can be fabricated. Moreover, the different transferences made at the same time with the stencil serve to remove the typical homemade $\mathrm{Ag} / \mathrm{AgCl} / \mathrm{KCl} 3 \mathrm{M}$ $\mathrm{RE}$ and the platinum or gold wire CE used in other works, making it possible to perform spectroelectrochemistry experiments in a simpler way. In addition, the three electrodes are completely flat on the surface of the PET support where the bare optical fibers are strongly attached, allowing a good reproducibility and an easy mobility of the whole device. One of the main advantages of this spectroelectrochemistry device and this experimental setup is the high versatility. A lot of parameters, such as the optical path length or the integration time, can be selected by the researcher for each problem to be solved. For example, the control of the optical path length allows us to improve the sensitivity and the capability of detection of the device for spectroelectrochemical sensor applications. Next, it is validated to be used for different spectroelectrochemistry purposes. 


\subsubsection{Results and Discussion}

\subsubsection{Validation of the Spectroelectrochemistry Device}

$\mathrm{FcMeOH}$ has been used to validate the device. This compound undergoes a reversible electrochemical process of one electron in a simple, welldefined, and diffusion-controlled way, being widely used as a probe in electrochemistry and recently in spectroelectrochemistry (section 6.3). ${ }^{75}$

Several spectroelectrochemistry experiments of $5 \times 10^{-4} \mathrm{M} \mathrm{FcMeOH}$ in 0.1 $\mathrm{M} \mathrm{KCl}$ between $-0.20 \mathrm{~V}$ and $+0.50 \mathrm{~V}$ at different potential scan rates are represented in Figure 6.5.4 and Figure 6.5.5. The optical path length was set at $1.45 \mathrm{~mm}$ and a full spectrum was taken every $250 \mathrm{~ms}$, for which the halogen-deuterium light source was employed because the spectral changes related to $\mathrm{FcMeOH}$ take place in the $\mathrm{UV}$ (deuterium) and in the visible (halogen) region. A $100 \mu \mathrm{L}$ solution drop, which was changed after every measurement, was placed in the spectroelectrochemistry device covering the three electrodes and the ends of the optical fibers, allowing us to work in a semi-infinite diffusion regime.

Figure 6.5.4a shows the 3D plot of the spectra evolution with time/potential recorded during a cyclic voltammetry performed at $0.010 \mathrm{~V} \cdot \mathrm{s}^{-1}$. The corresponding cyclic voltammogram (blue line of Figure 6.5.4b) shows an anodic peak at $+0.185 \mathrm{~V}$ and a reduction peak at $+0.099 \mathrm{~V}$. As shown in section $6.3,{ }^{75}$ the three absorption bands observed in Figure 6.5.4a at 260, 282 , and $630 \mathrm{~nm}$ evolve according to the potentiodynamic experiment, and are attributed to the electrogeneration of the oxidized form of the redox couple, $\mathrm{FcMeOH}^{+}$, taking into account that the reduced form, $\mathrm{FcMeOH}$ 
(initial solution), was taken as reference spectrum. In order to compare both the electrochemical and spectroscopic responses, the cyclic voltammogram at $0.010 \mathrm{~V} \cdot \mathrm{s}^{-1}$ is overlapped with the corresponding voltabsorptogram at $282 \mathrm{~nm}$ (blue and green lines of Figure 6.5.4b, respectively). The great agreement between the two signals assures that the light beam passes through the first $100 \mu \mathrm{m}$ of the solution layer closest to the SWCNTs WE and that both the potentiostat and spectrometer are properly synchronized.
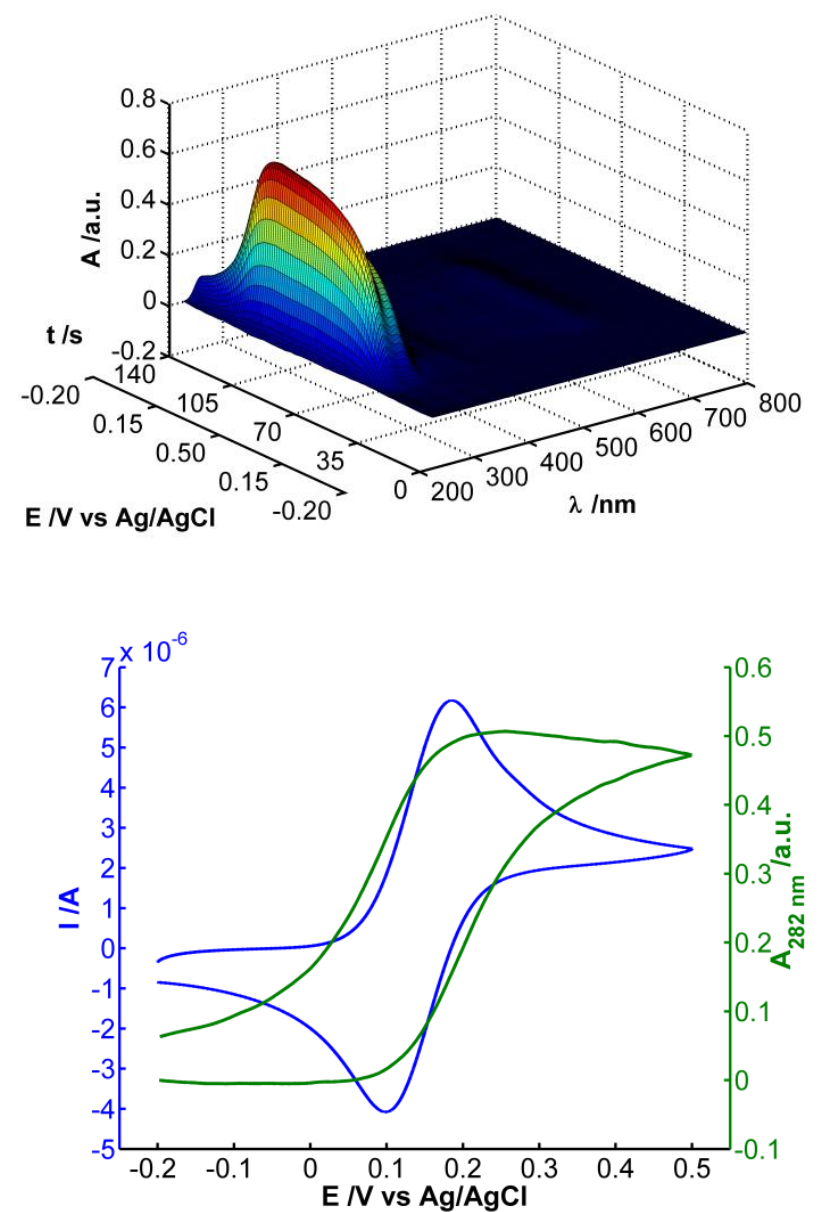

Figure 6.5.4. Spectroelectrochemistry experiments of $5 \times 10^{-4} \mathrm{M} \mathrm{FcMeOH}$ in $0.1 \mathrm{M} \mathrm{KCl}$ between $-0.20 \mathrm{~V}$ and $+0.50 \mathrm{~V}$ at $0.010 \mathrm{~V} \cdot \mathrm{s}^{-1}$. (a) $3 \mathrm{D}$ plot of the spectra evolution with time/potential recorded during the cyclic voltammetry (cyclic voltammogram plotted in panel b). (b) Comparison between the cyclic voltammogram and the voltabsorptogram at $282 \mathrm{~nm}$. 
The electrochemical reaction produces a concentration gradient that is observed in the voltabsorptograms at $282 \mathrm{~nm}$ at different potential scan rates shown in Figure 6.5.5. As can be observed, absorbance values at 282 $\mathrm{nm}$ start to increase at $+0.05 \mathrm{~V}$ according to the oxidation process of $\mathrm{FcMeOH}$ to $\mathrm{FcMeOH}^{+}$indicated in the cyclic voltammogram. $\mathrm{FcMeOH}^{+}$is reduced to $\mathrm{FcMeOH}$ when potential is low enough, explaining the decrease in absorbance at $282 \mathrm{~nm}$. Both compounds diffuse from the WE surface, where are electrogenerated, to the bulk solution, explaining the increase and decrease in absorbance when $\mathrm{FcMeOH}^{+}$and $\mathrm{FcMeOH}$ are respectively produced.

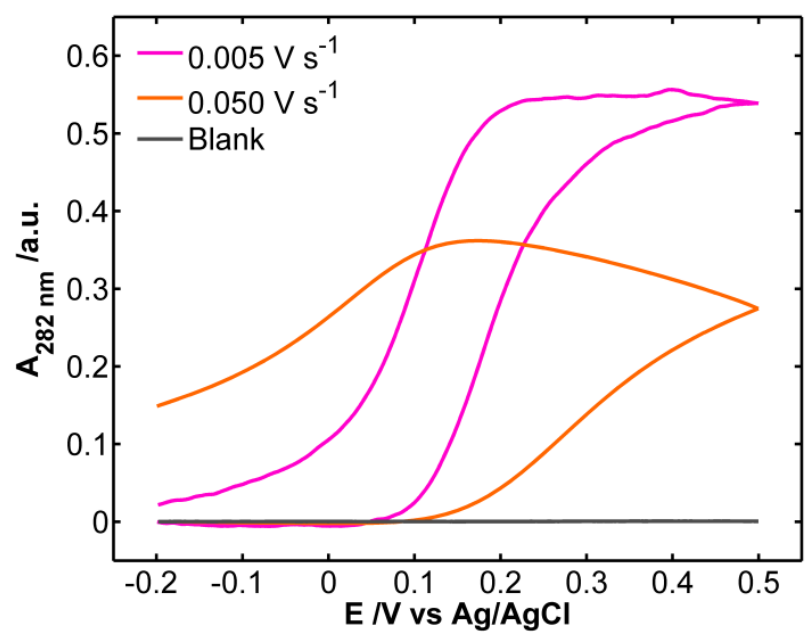

Figure 6.5.5. Voltabsorptograms at $282 \mathrm{~nm}$ of $5 \times 10^{-4} \mathrm{M} \mathrm{FcMeOH}$ in $0.1 \mathrm{M}$ $\mathrm{KCl}$ between $-0.20 \mathrm{~V}$ and $+0.50 \mathrm{~V}$ at different potential scan rates. An experiment of $0.1 \mathrm{M} \mathrm{KCl}$ (blank solution) at $0.010 \mathrm{~V} \cdot \mathrm{s}^{-1}$ is also plotted in gray line.

Two different behaviors can be observed taking into account the potential scan rate. On the one hand, a maximum and constant absorbance value of $0.55 \mathrm{au}$ is achieved during the backward scan at $0.005 \mathrm{~V} \cdot \mathrm{s}^{-1}$ (pink line). 
This potential scan rate is low enough to establish an almost homogeneous steady-state distribution of $\mathrm{FcMeOH}^{+}$in the first $100 \mu \mathrm{m}$ of solution closest to the SWCNTs WE surface sampled by the parallel light beam. Assuming that a $\mathrm{FcMeOH}$ concentration of $5 \times 10^{-4} \mathrm{M}$ has been transformed to $\mathrm{FcMeOH}^{+}$in these $100 \mu \mathrm{m}$ of the diffusion layer, we are able to estimate the difference of the molar absorption coefficients of $\mathrm{FcMeOH}^{+}$and FcMeOH $\left(\varepsilon=\varepsilon_{F c}{ }^{+}-\varepsilon_{F c}\right)$ using the Beer-Lambert law $(A=\varepsilon l C)$. From the maximum and constant absorbance value achieved during the backward scan $(0.55 \mathrm{au})$, the optical path length $(0.145 \mathrm{~cm})$, and the concentration of FcMeOH $\left(5 \times 10^{-4} \mathrm{M}\right)$, an experimental value of $7586 \mathrm{M}^{-1} \cdot \mathrm{cm}^{-1}$ is assessed for the difference of the molar absorption coefficients of $\mathrm{FcMeOH}^{+}$and $\mathrm{FcMeOH}$. The good agreement between this experimental and the reference value obtained in section $6.3\left(7880 \pm 510 \mathrm{M}^{-1} \cdot \mathrm{cm}^{-1}\right)^{75}$ indicates the suitable performance of this spectroelectrochemistry device. On the other hand, the amount of $\mathrm{FcMeOH}^{+}$electrogenerated at $0.050 \mathrm{~V} \cdot \mathrm{s}^{-1}$ (orange line) is less than in the previous case. The higher the potential scan rate, the less the amount of $\mathrm{FcMeOH}^{+}$. This assertion is confirmed by the lower absorbance values achieved at $0.050 \mathrm{~V} \cdot \mathrm{s}^{-1}$. Actually, a maximum and constant absorbance value is not achieved throughout the experiment because there is not enough time to reach a steady-state. In fact, $\mathrm{FcMeOH}^{+}$ diffuses a shorter distance and the distribution of $\mathrm{FcMeOH}^{+}$and $\mathrm{FcMeOH}$ in the $100 \mu \mathrm{m}$ closest to the SWCNTs WE is obviously more heterogeneous. It is appreciated that the absorbance values at the end of the experiments increase with the scan rate. It makes sense considering the solution sampled by the optical fibers. The light beam in parallel arrangement only samples the solution of the diffusion layer next to the electrode, attesting concentration changes that take place in the first 100 $\mu \mathrm{m}$ adjacent to the SWCNTs WE and missing information about what 
happens in the rest of the diffusion layer far from the electrode, especially at low scan rates. At higher scan rates, almost the whole diffusion layer is sampled by the parallel light beam, explaining the behavior of the voltabsorptograms. In addition, an experiment of $0.1 \mathrm{M} \mathrm{KCl}$ at $0.010 \mathrm{~V} \cdot \mathrm{s}^{-1}$ was carried out at the end of all the measurements to demonstrate that there are no spectral changes with potential in a blank solution. Therefore, parallel measurements include information about the global quantity of $\mathrm{FcMeOH}^{+}$present at the electrode-solution interface, its diffusion, its spatial distribution, and its position with respect to the electrode surface.

All these observations are entirely consistent with the previous results obtained in section $6.3 .^{75}$ The validation of this novel spectroelectrochemistry device demonstrates its excellent performance.

\subsubsection{Conclusions and Future Work}

A versatile, inexpensive and quick methodology to transfer SWCNTs films using customized stencils is proposed, enabling us to choose the best shape of the SWCNTs transferences for each particular case.

A new UV-Vis absorption spectroelectrochemistry device based on these SWCNTs transfers on a PET support and two bare optical fibers fixed in parallel arrangement in the same substrate to sample the spectral changes that occur in the solution closest to the SWCNTs WE has been developed.

Taking into account that $\mathrm{WE}, \mathrm{CE}$, and $\mathrm{RE}$ are flat on the substrate and the two bare optical fibers are fixed in the same support, this device is characterized by its reduced size and the small sample volume, as well as by its reproducibility between experiments and its mobile nature. 
The spectroelectrochemistry device has been properly validated with $\mathrm{FcMeOH}$ in accordance with the results obtained in section $6.3{ }^{75}$

The need to simplify and improve the existing methodologies to carry out UV-Vis absorption spectroelectrochemistry measurements in a suitable manner for the expected experiments of the XXI century, as well as the powerful features associated with spectroelectrochemistry techniques, have led us to perform this work and to carry out the different projects presented in this doctoral thesis from now on, which are:

The use of PARAFAC to resolve complex mixtures of neurotransmitters and compounds of biological interest with overlapping electrochemical and spectroscopic signals (section $6.6){ }^{30}$

The monitoring of the evolution of $\mathrm{pH}$ at the electrode-solution interface during electrochemical reactions (section 6.7). ${ }^{77}$

The direct determination of compounds of biological interest in real samples without any previous sample pretreatment (section $6.8){ }^{31}$

Undoubtedly, this easy-to-use device provides independent and complementary information and brings together the best features of both electrochemistry and spectroscopy to contribute to the use of spectroelectrochemistry in different fields, opening new avenues for studying many chemical systems in different situations, and making spectroelectrochemistry friend of more researchers for multipurpose applications. 

6.6. Quantitative Resolution of Complex

Mixtures by Spectroelectrochemistry: The

Case of Catechol and Dopamine 



\subsubsection{Some Important Points to Keep in Mind}

The amount of qualitative and quantitative information provided by a $\mathrm{UV}-\mathrm{Vis}$ absorption spectroelectrochemistry experiment is sometimes wasted. However, practically all electrochemical and spectroscopic data can provide valuable information to achieve very different objectives.

In this work, potentiodynamic and potentiostatic spectroelectrochemistry measurements are initially performed to study the electrochemical reaction mechanism of dopamine in acidic media and to demonstrate the ability of these autovalidated techniques to predict the dopamine concentration in a test sample simply using univariate analysis, obtaining low detection limits with both electrochemical and spectroscopic calibration curves.

Furthermore, the main objective achieved in this work is the resolution of a complex mixture formed by catechol and dopamine using $\mathrm{UV}-\mathrm{Vis}$ absorption spectroelectrochemistry. These two compounds of biological interest, whose study and determination are obviously necessary according to their biological importance, show very similar electrochemical and spectroscopic responses, making it impossible to determine the concentration of each chemical in mixtures of these analytes using only univariate regression models.

For this reason, we employ multivariate regression to resolve this problem using a powerful statistical tool such as PARAFAC. PARAFAC enables us to obtain much more accurate information, allowing us to quantify the amount of both catechol and dopamine in samples of varying concentration of these compounds with low detection limits. 
PARAFAC is a generalization of principal component analysis to higher order arrays. As for bilinear principal component analysis, the outcome of a PARAFAC model can be used as input to other models, most often for regression. PARAFAC has an important property not possessed by the two-way model: if the latent factors show adequately distinct patterns of three-way variation, the model is fully identified. ${ }^{409,410}$ In the present work, the quantitative resolution of mixtures by UV-Vis absorption spectroelectrochemistry using PARAFAC is based on the fact that this technique contains the trilinear character required. ${ }^{19}$

Taking into account all this information, we propose two objectives in this work:

The first one is the study of the reaction mechanism of dopamine as well as its quantification by potentiodynamic and potentiostatic spectroelectrochemistry measurements, demonstrating the capabilities of these autovalidated techniques to estimate the concentration of dopamine in a test sample using univariate analysis.

The second one is the resolution of complex mixtures of compounds of biological interest, namely catechol and dopamine, using PARAFAC as statistical tool.

In addition to being important biological molecules, catechol and dopamine have also been selected due to other two reasons: (i) the quantitative resolution of mixtures of catechol and dopamine is of general interest $^{194,411-413}$ and (ii) catechol and dopamine exhibit a large overlap of both electrochemical and spectroscopic signals, a fact that greatly increases the difficulty in the resolution of this mixture and, thus, requires a creative solution. 
To the best of our knowledge, UV-Vis absorption spectroelectrochemistry in long optical path length arrangement is used here for the first time to resolve mixtures of catechol and dopamine in acidic medium, where electrical and optical signals are completely overlapped. This technique enables researchers to resolve this type of mixtures without the need to perform any separation step and in an easy, inexpensive and elegant way.

The importance of the present work is highlighted because overcomes some problems related to experiments with presence of interfering compounds in an imaginative way.

The UV-Vis absorption spectroelectrochemistry device employed in this work has been developed in section $6.5^{31}$ and demonstrates the capabilities of UV-Vis absorption spectroelectrochemistry to resolve problems of the current world, showing the potential of this technique for quantitative analysis and thus expanding the horizons of spectroelectrochemistry.

\subsubsection{Experimental Section}

The reagents and materials used to fabricate the whole spectroelectrochemistry device, as well as the instrumentation used in this work, were indicated in section $6.5,{ }^{31}$ along with the experimental setup employed. In this case, the filtered volume of the SWCNTs dispersion was $2 \mathrm{~mL}$ and the silver conductive paint of the RE was not covered with the drop of $\mathrm{HCl}$ in water 1:10 dilution because the experiments are already performed in $1 \mathrm{M} \mathrm{HCl}$. Dopamine (99\%, Acros Organics), catechol (Acros 
Organics), and $\mathrm{HCl}$ (37\%, Acros Organics) were used to prepare the solutions.

All reagents were used as received without further purification. All chemicals were of analytical grade. Aqueous solutions were freshly prepared using ultrapure water $\left(18.2 \mathrm{M} \Omega \cdot \mathrm{cm}\right.$ resistivity at $25^{\circ} \mathrm{C}$, Milli-Q A10 system, Millipore).

In order to work in a semi-infinite diffusion regime, a $200 \mu \mathrm{L}$ solution drop was placed on the cell, covering the three electrodes and the ends of the optical fibers. The integration time for the spectrometer was $200 \mathrm{~ms}$. The initial solution is taken as reference spectrum for every experiment.

Both the fabrication of the whole spectroelectrochemistry device (another illustration can be observed in Figure 6.6.1), as well as its validation, were explained in section $6.5^{31} \mathrm{Next}$, it is used for quantitative analysis, enabling us to resolve complex mixtures of catechol and dopamine.

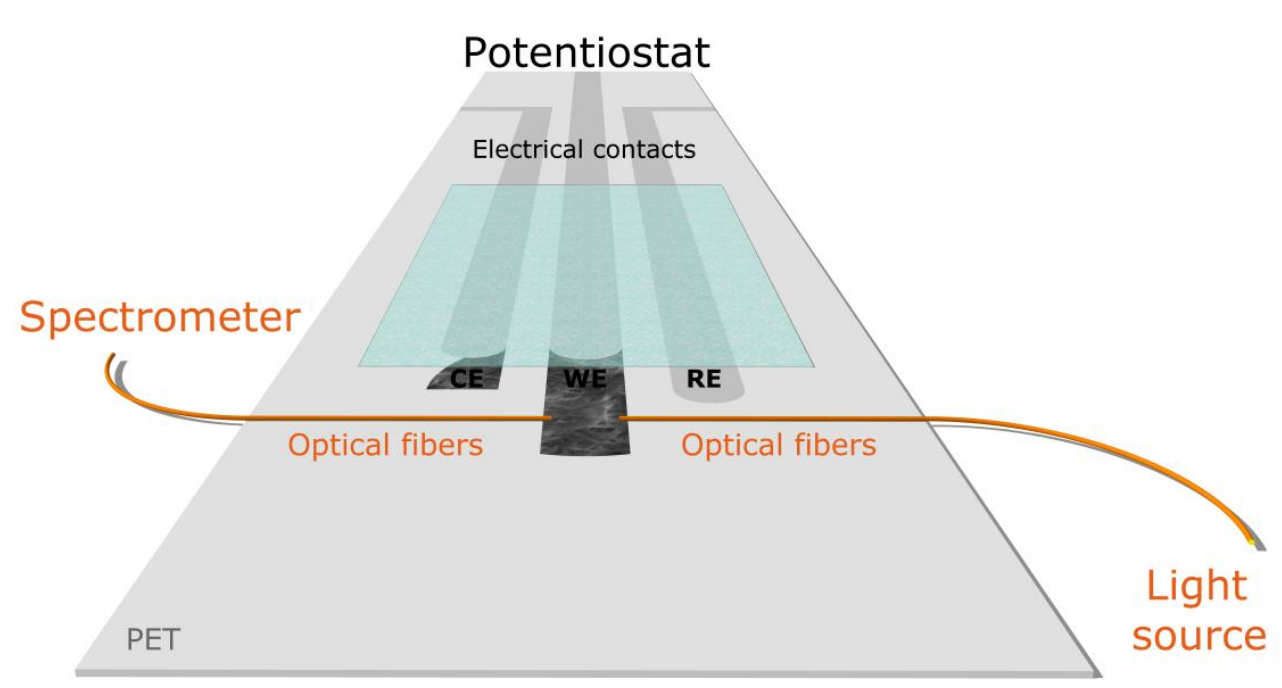

Figure 6.6.1. UV-Vis absorption spectroelectrochemistry device, based on SWCNTs and bare optical fibers, used in this work. 


\subsubsection{Results and Discussion}

\subsubsection{Determination of Dopamine by Potentiodynamic UV-Vis}

\section{Absorption Spectroelectrochemistry}

First of all, the reaction mechanism of dopamine in acid solution has been studied. The oxidation of dopamine, as other catecholamines, is related to a complex two-electron two-proton electrochemical reaction, however, the oxidation of dopamine under this acidic media (all experiments are performed in $1 \mathrm{M} \mathrm{HCl}$ ) is much simpler because only dopaminequinone is electrogenerated. ${ }^{336,400}$

A spectroelectrochemistry experiment of $7.5 \times 10^{-4} \mathrm{M}$ dopamine in $1 \mathrm{M}$ $\mathrm{HCl}$ between +0.30 and $+0.80 \mathrm{~V}$ at $0.01 \mathrm{~V} \cdot \mathrm{s}^{-1}$ is shown in Figure 6.6.2.

Figure 6.6.2a represents the cyclic voltammogram, where the anodic and the cathodic peaks can be observed at +0.664 and $+0.445 \mathrm{~V}$, respectively.

The 3D plot of the spectra evolution with time/potential recorded during the cyclic voltammetry is displayed in Figure 6.6.2b, showing the evolution of three bands at 250,283 , and $391 \mathrm{~nm}$, in agreement with section $6.4 .^{76}$ These bands are associated to the electrochemical oxidation of dopamine to generate dopaminequinone ${ }^{76}$ particularly the band at $391 \mathrm{~nm}$ which is only related to this last compound. ${ }^{336,337}$

Finally, the evolution of these three bands is shown in Figure 6.6.2c. The corresponding cyclic voltabsorptograms indicate that, according to the cyclic voltammogram, the oxidation of dopamine takes place from $+0.50 \mathrm{~V}$ onwards. 

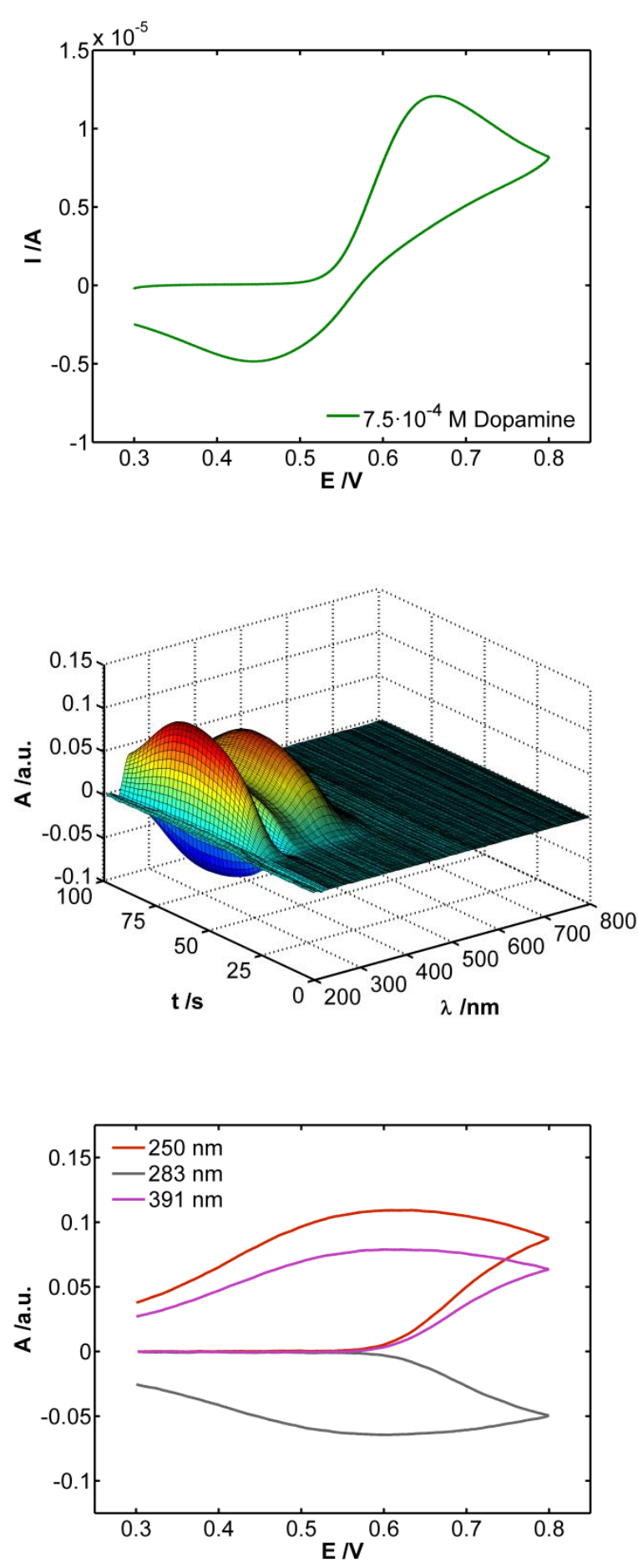

Figure 6.6.2. Spectroelectrochemistry experiment of $7.5 \times 10^{-4} \mathrm{M}$ dopamine in $1 \mathrm{M} \mathrm{HCl}$ between +0.30 and $+0.80 \mathrm{~V}$ at a potential scan rate of $0.010 \mathrm{~V} \cdot \mathrm{s}^{-1}$. (a) Cyclic voltammogram, (b) 3D plot of the spectra evolution with time/potential recorded simultaneously with the cyclic voltammogram, and (c) cyclic voltabsorptogram at 250, 283, and $391 \mathrm{~nm}$. 
Besides information about the reaction mechanism, spectroelectrochemistry allows us to perform quantitative analysis. Aiming to show the potential of this technique for the analysis of dopamine, a set of calibration samples between $1 \times 10^{-5}$ and $1 \times 10^{-3} \mathrm{M}$ were analyzed. The results can be observed in Figure 6.6.3 and in the first two rows of Table 6.6.1.

Spectroelectrochemistry experiments were carried out in $1 \mathrm{M} \mathrm{HCl}$ between +0.30 and $+0.80 \mathrm{~V}$ at $0.01 \mathrm{~V} \cdot \mathrm{s}^{-1}$. Cyclic voltammograms and cyclic voltabsorptograms at $250 \mathrm{~nm}$ are plotted in Figure 6.6.3a and Figure 6.6.3b, respectively. As can be observed, the higher the dopamine concentration, the higher the current intensity and the higher the absorbance. Two univariate calibration curves were obtained, using OLS models, for the current intensity at the anodic peak potential and absorbance at $250 \mathrm{~nm}$ at $+0.80 \mathrm{~V}$ versus dopamine concentration (Figure 6.6.3c and Figure 6.6.3d, respectively). Anodic peak current intensity and absorbance at $250 \mathrm{~nm}$ at $+0.80 \mathrm{~V}$ were selected with the aim of obtaining good sensitivities for these methods. Taking into account the concentration values equal or less than 1 $\times 10^{-4} \mathrm{M}$, the limits of detection obtained were $6 \times 10^{-6}$ and $1.9 \times 10^{-5} \mathrm{M}$ for the electrochemical and the spectroscopic calibration curves, respectively.

The autovalidated character of spectroelectrochemistry was demonstrated by plotting the predicted concentrations with the electrochemical calibration curve versus the predicted concentrations with the spectroscopic calibration curve. A slope of $1.00 \pm 0.02$ and an intercept of $[-0.03 \pm 9.59]$ $\times 10^{-6}$ were obtained, demonstrating that both responses determine the dopamine concentration without distinction.

Finally, the dopamine concentration in a test sample $2.5 \times 10^{-4} \mathrm{M}$ dopamine was estimated using both calibration curves. All data are shown 
in the first two rows of Table 6.6.1 where can be observed the very good figures of merit obtained.
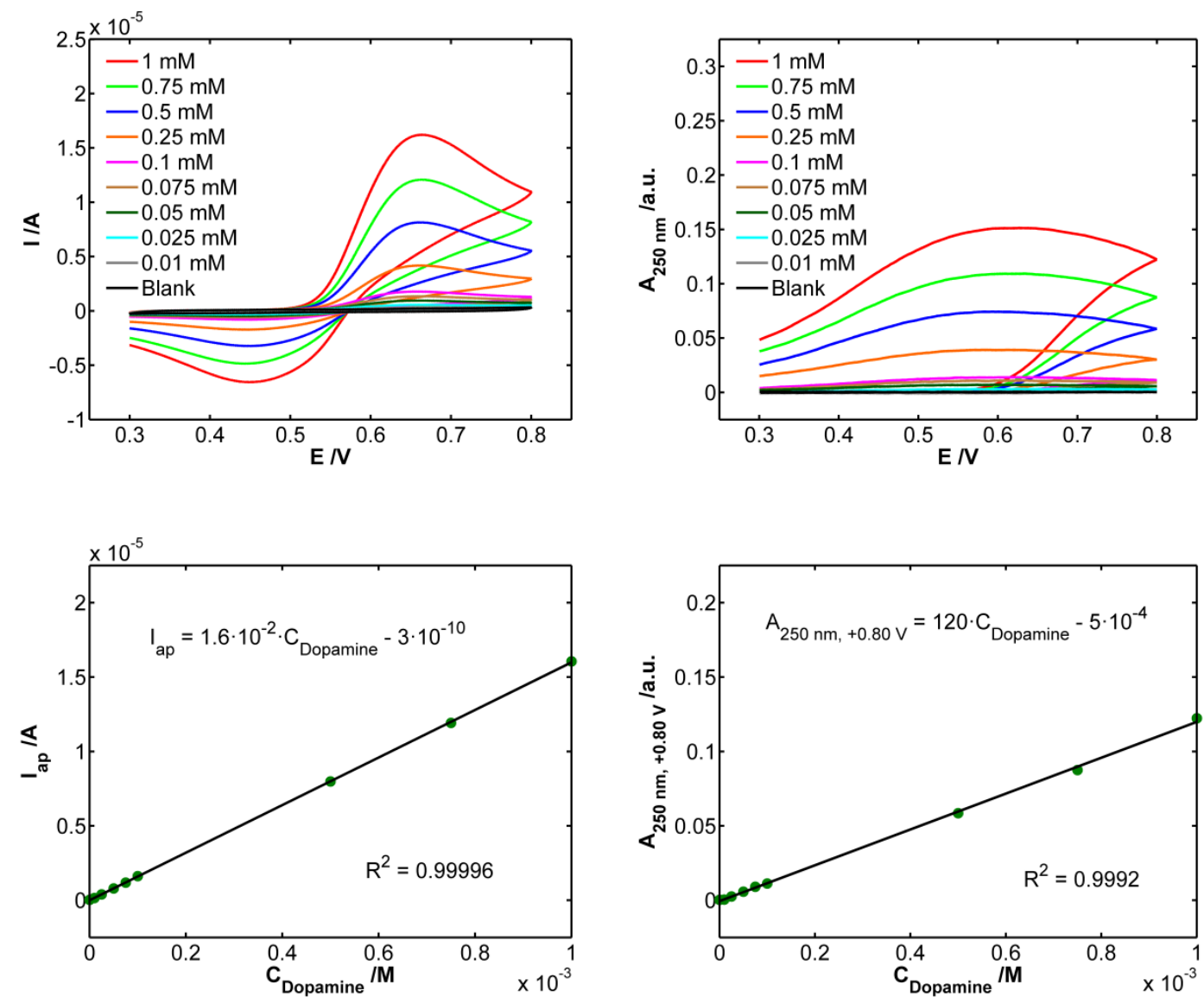

Figure 6.6.3. Set of calibration samples of dopamine between $1 \times 10^{-5}$ and $1 \times$ $10^{-3} \mathrm{M}$. Spectroelectrochemistry experiments were carried out in $1 \mathrm{M} \mathrm{HCl}$ between $+0.30 \mathrm{~V}$ and +0.80 at $0.01 \mathrm{~V} \cdot \mathrm{s}^{-1}$. (a) Cyclic voltammograms and (b) cyclic voltabsorptograms at $250 \mathrm{~nm}$. Univariate calibration curves obtained using OLS models of (c) current intensity at the anodic peak potential and (d) absorbance at $250 \mathrm{~nm}$ at $+0.80 \mathrm{~V}$ versus dopamine concentration.

As can be observed, the test sample of $2.5 \times 10^{-4} \mathrm{M}$ dopamine is included in the figures related to the cyclic voltammograms and the cyclic voltabsorptograms at $250 \mathrm{~nm}$ but obviously excluded from the univariate calibration curves. 


\subsubsection{Determination of Dopamine by Potentiostatic UV-Vis} Absorption Spectroelectrochemistry

Once the electrochemical reaction mechanism of dopamine in acidic media has been studied and that its determination has been carried out potentiodynamically, potentiostatic spectroelectrochemistry was performed to show that very good results can also be obtained using this technique. A spectroelectrochemistry experiment of $7.5 \times 10^{-4} \mathrm{M}$ dopamine in $1 \mathrm{M} \mathrm{HCl}$ applying a constant potential of $+0.80 \mathrm{~V}$ during $100 \mathrm{~s}$ is shown in Figure 6.6.4. As can be inferred from the previous section, the potential of +0.80 $\mathrm{V}$ is high enough to produce the oxidation of dopamine. Figure $6.6 .4 \mathrm{a}$ represents the amperogram related to the oxidation of dopamine to dopaminequinone. The 3D plot of the spectra evolution with time recorded during the amperometric experiment is displayed in Figure 6.6.4b, showing, as expected, the evolution of the three bands at 250, 283, and 391 $\mathrm{nm}$ corresponding to the electrogeneration of dopaminequinone since the beginning of the experiment (Figure 6.6.4c) due to the constant application of $+0.80 \mathrm{~V}$. In this case, a maximum and constant absorbance value of $0.097 \mathrm{au}$ at $391 \mathrm{~nm}$ is achieved from $60 \mathrm{~s}$ onwards. $60 \mathrm{~s}$ is a long enough time to establish an almost homogeneous steady-state distribution of dopaminequinone/dopamine in the first $100 \mu \mathrm{m}$ of the solution closest to the SWCNTs WE sampled by the light beam. Assuming that a dopamine concentration of $7.5 \times 10^{-4} \mathrm{M}$ has been transformed to dopaminequinone in these $100 \mu \mathrm{m}$ of the diffusion layer, we are able to estimate the optical path length (distance between the optical fibers) using the Beer-Lambert law ( $A$ $=\varepsilon l C) .{ }^{192}$ From the maximum and constant absorbance achieved $(0.097$ $\mathrm{au})$, the dopamine concentration $\left(7.5 \times 10^{-4} \mathrm{M}\right)$, and the molar absorption coefficient of dopaminequinone at $391 \mathrm{~nm}\left(1040 \mathrm{M}^{-1} \cdot \mathrm{cm}^{-1}\right.$, section 6.4) ${ }^{76}$ a value of $0.124 \mathrm{~cm}$ is assessed for the optical path length. 

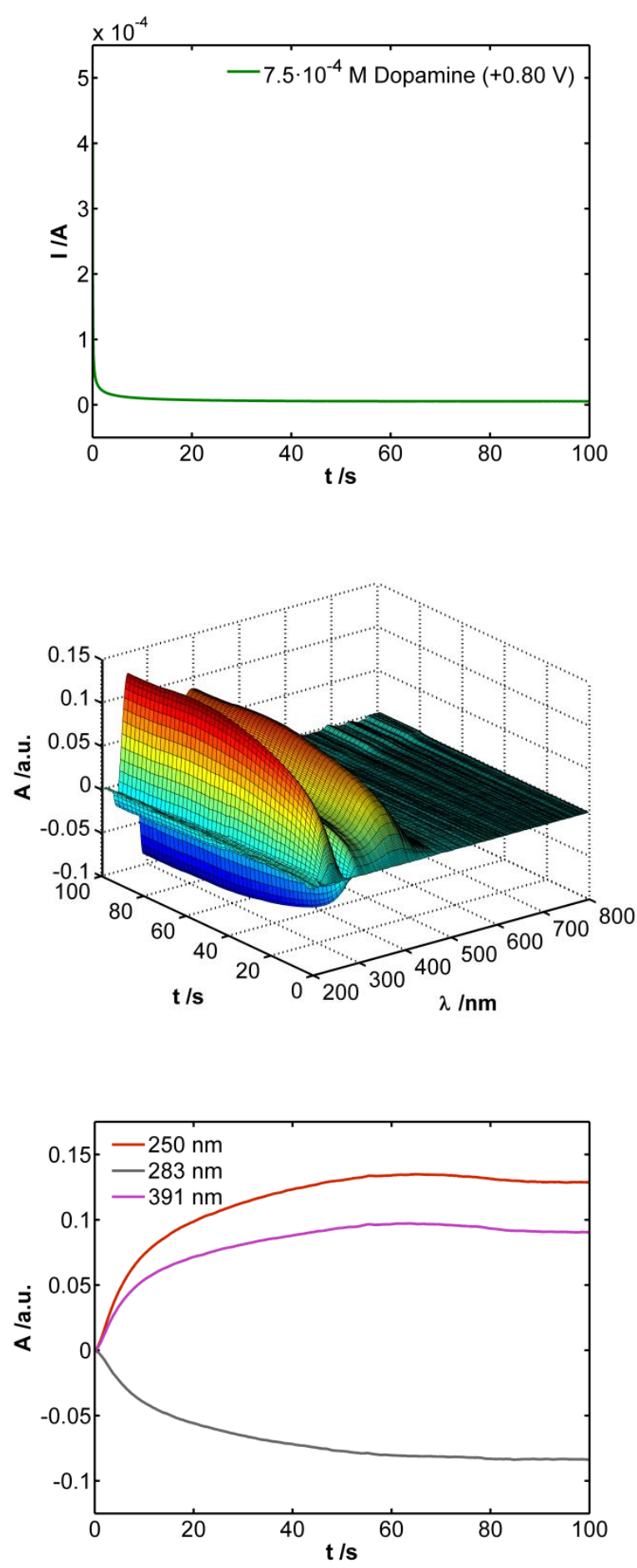

Figure 6.6.4. Spectroelectrochemistry experiment of $7.5 \times 10^{-4} \mathrm{M}$ dopamine in $1 \mathrm{M} \mathrm{HCl}$ applying a constant potential of $+0.80 \mathrm{~V}$ during $100 \mathrm{~s}$. (a) Amperogram, (b) 3D plot of the spectra evolution with time recorded during the amperometry, and (c) evolution of the absorbance at 250, 283, and $391 \mathrm{~nm}$. 
The quantification of dopamine has also been performed by potentiostatic spectroelectrochemistry. A set of calibration samples between $1 \times 10^{-5}$ and $1 \times 10^{-3} \mathrm{M}$ were analyzed (Figure 6.6.5 and the last two rows of Table 6.6.1).

Spectroelectrochemistry measurements were performed in $1 \mathrm{M} \mathrm{HCl}$ applying a constant potential of $+0.80 \mathrm{~V}$ during $100 \mathrm{~s}$. The amperograms and the corresponding evolution of the absorbance at $250 \mathrm{~nm}$ are plotted in Figure 6.6.5a and Figure 6.6.5b, respectively. As in the previous case, the higher the dopamine concentration, the higher the current intensity and the higher the absorbance. An electrochemical and a spectroscopic univariate calibration curves were obtained, using OLS models, to correlate the current intensity at $5 \mathrm{~s}$ and the absorbance at $250 \mathrm{~nm}$ at $40 \mathrm{~s}$ versus dopamine concentration (Figure 6.6.5c and Figure 6.6.5d, respectively). Taking into account the concentration values equal or less than $1 \times 10^{-4} \mathrm{M}$, the detection limits obtained were $5 \times 10^{-6}$ and $1.2 \times 10^{-5} \mathrm{M}$ for the electrochemical and the spectroscopic calibration curves, respectively, demonstrating an improvement with respect to the sensitivities obtained by potentiodynamic spectroelectrochemistry measurements.

The autovalidated character of spectroelectrochemistry was also demonstrated in this case by comparing the estimated concentrations with the electrochemical calibration curve versus the estimated concentrations with the spectroscopic calibration curve. A slope of $1.00 \pm 0.01$ and an intercept of $[-0.01 \pm 6.83] \times 10^{-6}$ were obtained, demonstrating that both responses are able to predict the dopamine concentration with no difference.

Finally, the dopamine concentration in a test sample $2.5 \times 10^{-4} \mathrm{M}$ dopamine was predicted using both calibration curves. All data are shown 
in the last two rows of Table 6.6.1, where the excellent figures of merit obtained are indicated.
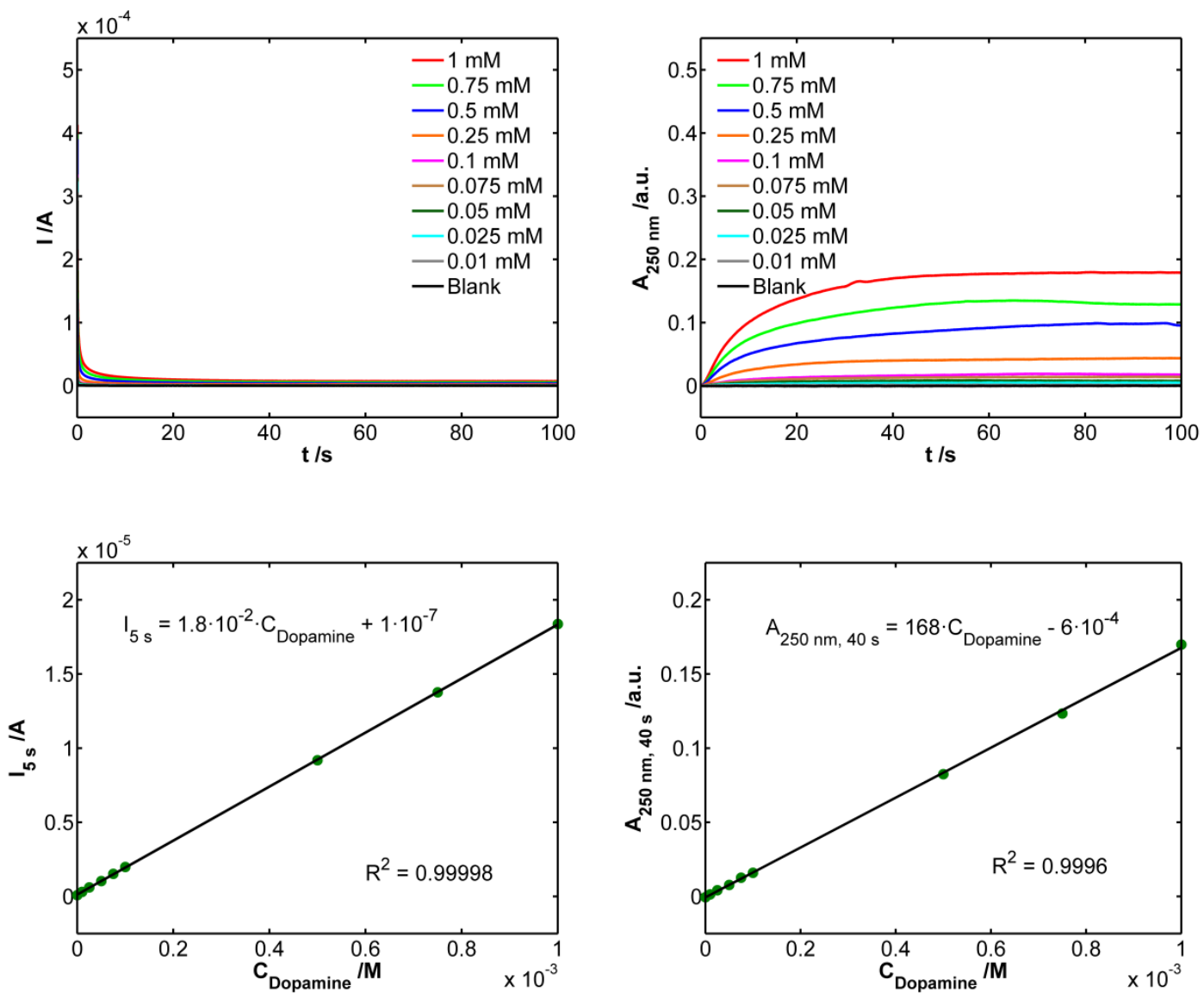

Figure 6.6.5. Set of calibration samples of dopamine between $1 \times 10^{-5}$ and $1 \times$ $10^{-3} \mathrm{M}$. Spectroelectrochemistry measurements were performed in $1 \mathrm{M} \mathrm{HCl}$ applying a constant potential of +0.80 during 100 s. (a) Amperograms and (b) evolution of the absorbance at $250 \mathrm{~nm}$. Univariate calibration curves obtained using OLS models of (c) current intensity at $5 \mathrm{~s}$ and (d) absorbance at $250 \mathrm{~nm}$ at 40 s versus dopamine concentration.

As can be observed, the test sample of $2.5 \times 10^{-4} \mathrm{M}$ dopamine is included in the figures related to the amperograms and the evolution of the absorbance at 250 $\mathrm{nm}$ but obviously excluded from the univariate calibration curves. 
Table 6.6.1. Regression parameters obtained for the determination of dopamine in $1 \mathrm{M} \mathrm{HCl}$ in the $1 \times 10^{-5} \mathrm{M}-1 \times 10^{-3} \mathrm{M}$ concentration range and concentration estimated from univariate (OLS) calibration curves for a test sample of dopamine.

\begin{tabular}{|c|c|c|c|c|}
\hline \multirow[b]{2}{*}{ Analysis Method } & \multirow[b]{2}{*}{$R^{2}$} & \multirow[b]{2}{*}{$S_{y x}$} & \multicolumn{2}{|c|}{$\mathrm{C}_{\text {Dopamine }}=2.5 \times 10^{-4} \mathrm{M}$} \\
\hline & & & CI (M) & $\operatorname{RSD}(\%)$ \\
\hline$I_{a p}$ & 0.99996 & $3.9 \times 10^{-8}$ & {$[2.52 \pm 0.06] \times 10^{-4}$} & 1.03 \\
\hline 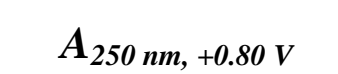 & 0.9992 & $1.4 \times 10^{-3}$ & {$[2.56 \pm 0.29] \times 10^{-4}$} & 4.81 \\
\hline$I_{5 s}$ & 0.99998 & $3.4 \times 10^{-8}$ & {$[2.49 \pm 0.05] \times 10^{-4}$} & 0.79 \\
\hline$A_{250 n m, 40 s}$ & 0.9996 & $1.3 \times 10^{-3}$ & {$[2.40 \pm 0.20] \times 10^{-4}$} & 3.44 \\
\hline
\end{tabular}

Analysis methods correlate current intensity at the anodic peak $\left(I_{a p}\right)$ and absorbance at $250 \mathrm{~nm}$

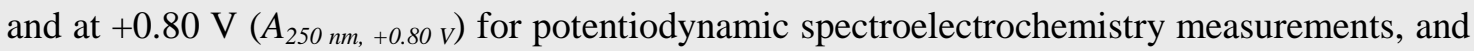
current intensity at $5 \mathrm{~s}\left(I_{5 s}\right)$ and absorbance at $250 \mathrm{~nm}$ and at $40 \mathrm{~s}\left(A_{250 \mathrm{~nm}, 40 \mathrm{~s}}\right)$ for potentiostatic spectroelectrochemistry measurements, versus dopamine concentration. $R^{2}$, coefficient of determination; $S_{y x}$, residual standard deviation; $\mathrm{C}_{\text {Dopamine, }}$ concentration of dopamine in the test sample; CI, confidence interval; and RSD, relative standard deviation $(\mathrm{n}=9, \alpha=0.05)$.

\subsubsection{Quantitative Resolution of Mixtures of Catechol and Dopamine by Spectroelectrochemistry}

Figure 6.6.6 indicates the difficulty of resolving the mixture of catechol and dopamine in acidic media. First, Figure 6.6.6a shows the cyclic voltammograms of $5 \times 10^{-4} \mathrm{M}$ catechol or $5 \times 10^{-4} \mathrm{M}$ dopamine in $1 \mathrm{M}$ $\mathrm{HCl}$ between +0.30 and $+0.80 \mathrm{~V}$ at $0.01 \mathrm{~V} \cdot \mathrm{s}^{-1}$, where can be observed that the difference between the anodic peak potentials of both compounds is only 0.008 V. Secondly, Figure $6.6 .6 \mathrm{~b}$ represents the initial spectra of $5 \times$ $10^{-4} \mathrm{M}$ catechol or $5 \times 10^{-4} \mathrm{M}$ dopamine in $1 \mathrm{M} \mathrm{HCl}$, where the difference 
in the position of the spectral band is $4 \mathrm{~nm}$, a value very close to the spectral resolution of the spectrometer. In third place, Figure 6.6.6c displays the spectra at $+0.80 \mathrm{~V}$ during the spectroelectrochemistry experiments of $5 \times 10^{-4} \mathrm{M}$ catechol or $5 \times 10^{-4} \mathrm{M}$ dopamine in $1 \mathrm{M} \mathrm{HCl}$ between +0.30 and $+0.80 \mathrm{~V}$ at $0.01 \mathrm{~V} \cdot \mathrm{s}^{-1}$, where can be observed that the maximum separation between the spectral bands at $+0.80 \mathrm{~V}$ is only $6 \mathrm{~nm}$.
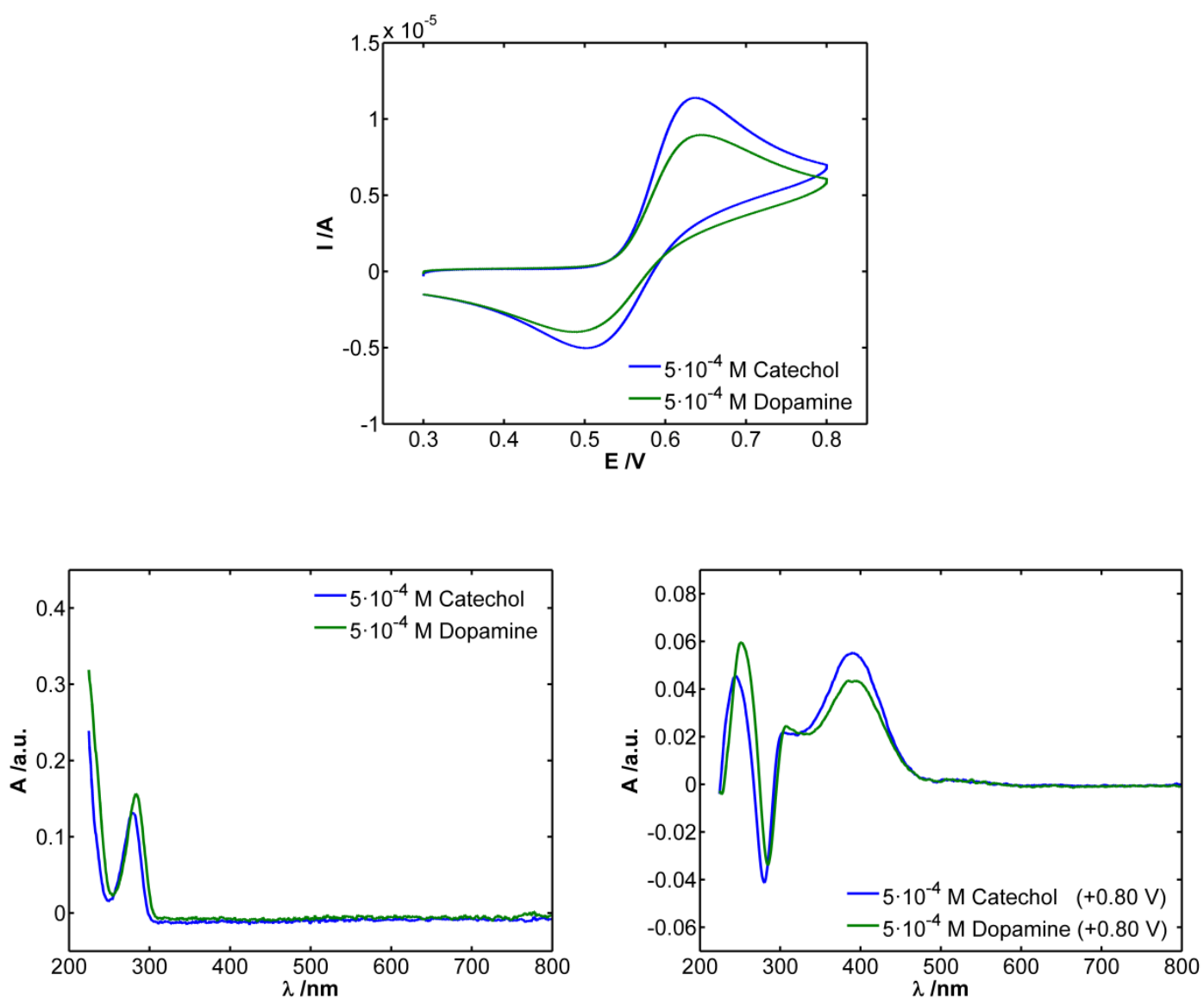

Figure 6.6.6. (a) Cyclic voltammograms of $5 \times 10^{-4} \mathrm{M}$ catechol or $5 \times 10^{-4} \mathrm{M}$ dopamine in $1 \mathrm{M} \mathrm{HCl}$ between +0.30 and $+0.80 \mathrm{~V}$ at $0.01 \mathrm{~V} \cdot \mathrm{s}^{-1}$. (b) Initial spectra of $5 \times 10^{-4} \mathrm{M}$ catechol or $5 \times 10^{-4} \mathrm{M}$ dopamine in $1 \mathrm{M} \mathrm{HCl}$. (c) Spectra at $+0.80 \mathrm{~V}$ during the spectroelectrochemistry experiments of $5 \times 10^{-4} \mathrm{M}$ catechol or $5 \times 10^{-4} \mathrm{M}$ dopamine in $1 \mathrm{M} \mathrm{HCl}$ between +0.30 and $+0.80 \mathrm{~V}$ at $0.01 \mathrm{~V} \cdot \mathrm{s}^{-1}$. 
Therefore, the overlap between the electrochemical and the spectroscopic responses of catechol and dopamine is remarkably high.

In fact, Figure 6.6.7 is analogous to Figure 6.6.6 but using a solution mixture of $5 \times 10^{-4} \mathrm{M}$ catechol and $5 \times 10^{-4} \mathrm{M}$ dopamine in $1 \mathrm{M} \mathrm{HCl}$. As can be observed, there seems to be a single compound.
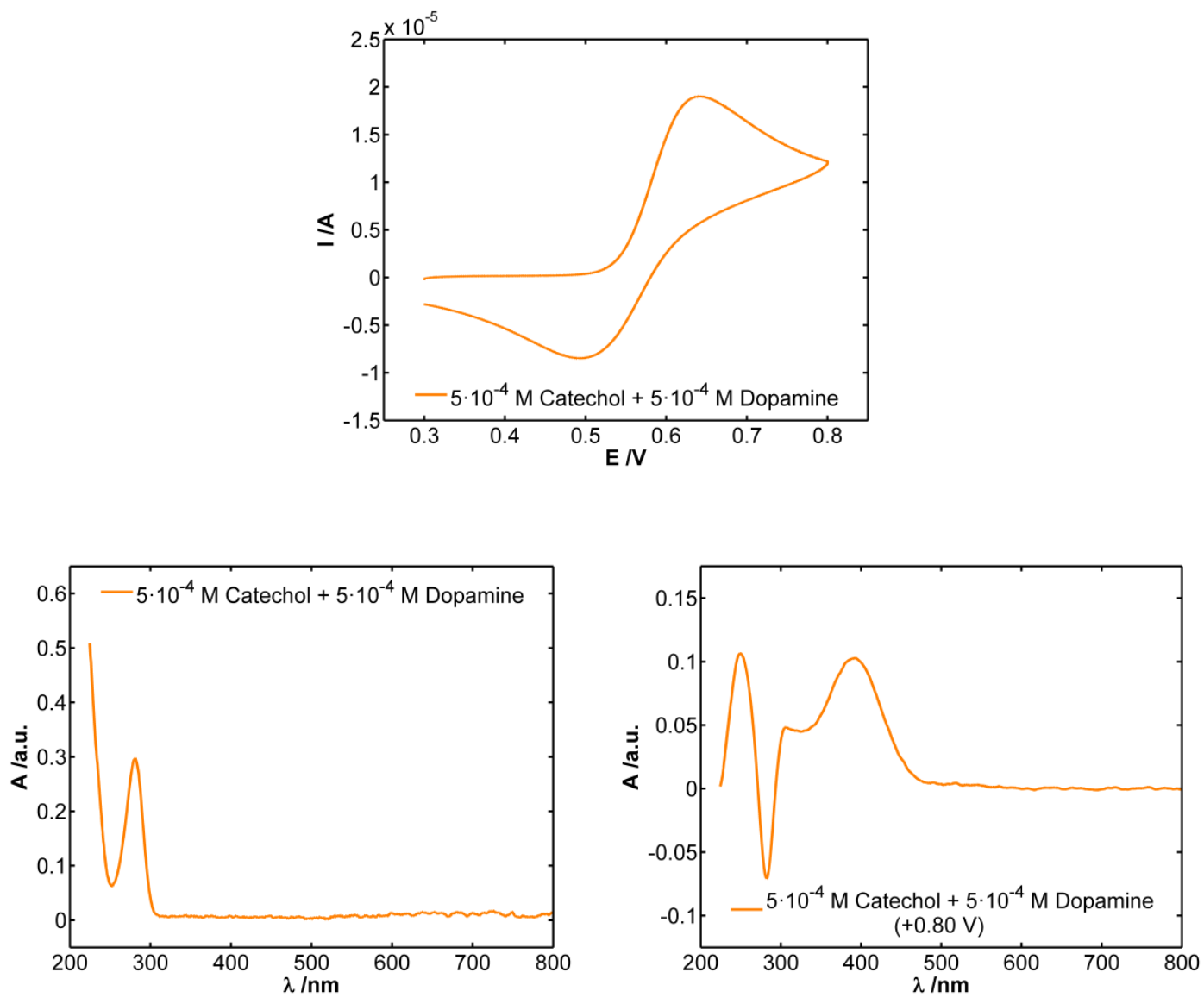

Figure 6.6.7. (a) Cyclic voltammograms of a solution $5 \times 10^{-4} \mathrm{M}$ catechol and 5 $\times 10^{-4} \mathrm{M}$ dopamine in $1 \mathrm{M} \mathrm{HCl}$ between +0.30 and $+0.80 \mathrm{~V}$ at $0.01 \mathrm{~V} \cdot \mathrm{s}^{-1}$. (b) Initial spectra of a solution $5 \times 10^{-4} \mathrm{M}$ catechol and $5 \times 10^{-4} \mathrm{M}$ dopamine in $1 \mathrm{M}$ $\mathrm{HCl}$. (c) Spectra at $+0.80 \mathrm{~V}$ during the spectroelectrochemistry experiment of a solution $5 \times 10^{-4} \mathrm{M}$ catechol and $5 \times 10^{-4} \mathrm{M}$ dopamine in $1 \mathrm{M} \mathrm{HCl}$ between +0.30 and $+0.80 \mathrm{~V}$ at $0.01 \mathrm{~V} \cdot \mathrm{s}^{-1}$. 
In conclusion, electrochemistry, spectroscopy, and spectroelectrochemistry at fixed potentials are not able to resolve this mixture for themselves, even less using univariate regression. Thus, time-resolved UV-Vis absorption spectroelectrochemistry and powerful multivariate analytical tools are required to solve this issue. A first resolution of this mixture at $\mathrm{pH}=7$ was previously performed using a reflection probe in normal arrangement to obtain the optical response, ${ }^{19}$ however, the overlap between the spectroscopic responses of catechol and dopamine at $\mathrm{pH}=7$ is much less pronounced than in the present case.

Two major reasons led us to perform this work: (i) some analysis need to be performed in acidic media and (ii) the resolution of this mixture in acid solution is much more complicated due to the high overlap between the electrochemical and the spectroscopic responses of catechol and dopamine, allowing us to demonstrate all the advantages offered by UV-Vis absorption spectroelectrochemistry for solving complex problems like this one. It should be noted that the interesting thing about UV-Vis absorption spectroelectrochemistry is its ability to simultaneously record two different kinds of information in one single experiment that can be analyzed using multivariate statistical tools to obtain more reliable information.

As previously mentioned, UV-Vis absorption spectroelectrochemistry enables us to obtain information about physicochemical processes from different points of view. In this work, a full spectrum between 198 and $1006 \mathrm{~nm}$ is recorded every $200 \mathrm{~ms}$ during the whole electrochemical experiment, resulting in a huge amount of data. Therefore, the selection of about 10 values to perform univariate calibration curves is enough in the case of relatively simple problems, but, in the case of complex systems such as the mixture of catechol and dopamine, it makes more sense to use 
the large amount of data offered by spectroelectrochemistry with the aim of addressing the problem and providing a solution. As shown below, multivariate analysis using PARAFAC will allow us to obtain amazing results. For this purpose, a three-dimensional data matrix containing the absorbance values between +0.50 and $+0.80 \mathrm{~V}$ and between 225 and 600 $\mathrm{nm}$ for the 16 experiments with different concentrations of catechol and dopamine was constructed to develop the PARAFAC model. Table 6.6.2 lists the experiments conducted to accomplish this goal.

Table 6.6.2. The sixteen UV-Vis absorption spectroelectrochemistry experiments performed for the multivariate quantitative analysis of dopamine and catechol in mixtures of varying concentrations of both analytes in $1 \mathrm{M} \mathrm{HCl}$.

\begin{tabular}{ccc}
\hline Experiment Number & $\mathbf{C}_{\text {Dopamine }}(\mathbf{m M})$ & $\mathbf{C}_{\text {Catechol }}(\mathbf{m M})$ \\
\hline $\mathbf{1}$ & 0 & 0 \\
$\mathbf{2}$ & 0.25 & 0.05 \\
$\mathbf{3}$ & 0.75 & 0.075 \\
$\mathbf{4}$ & 0.075 & 1 \\
$\mathbf{5}$ & 0.5 & 0.5 \\
$\mathbf{6}$ & 0.05 & 0.75 \\
$\mathbf{7}$ & 0.01 & 0.025 \\
$\mathbf{8}$ & 1 & 0.25 \\
$\mathbf{9}$ & 0.1 & 0.01 \\
$\mathbf{1 0}$ & 0.025 & 0.1 \\
$\mathbf{1 1}$ & 0 & 0 \\
$\mathbf{1 2}$ & 0.5 & 0 \\
$\mathbf{1 3}$ & 0 & 0.5 \\
$\mathbf{1 4}$ (TS) & 0.34 & 0.22 \\
$\mathbf{1 5}$ (TS) & 0.09 & 0.12 \\
$\mathbf{1 6}$ & 0 & 0 \\
\hline
\end{tabular}

$\mathrm{C}_{\text {Dopamine, }}$ concentration of dopamine; $\mathrm{C}_{\text {Catechol }}$, concentration of catechol; and TS, test sample. 
As can be seen, the set of calibration samples includes concentrations between $1 \times 10^{-5}$ and $1 \times 10^{-3} \mathrm{M}$ for both catechol and dopamine. Potentiodynamic measurements were selected, instead of potentiostatic experiments, attempting to obtain a better resolution in terms of potential/time dependency. For this reason, spectroelectrochemistry experiments were carried out in $1 \mathrm{M} \mathrm{HCl}$ between +0.30 and $+0.80 \mathrm{~V}$ at $0.01 \mathrm{~V} \cdot \mathrm{s}^{-1}$. The width of the potential window (absorbance values between +0.50 and $+0.80 \mathrm{~V}$ ) and the range of wavelengths (absorbance values between 225 and $600 \mathrm{~nm}$ ) were selected according to the regions where the significant changes of absorbance take place. It should be highlighted that the matrix dimensions $(151$ potentials $\times 473$ wavelengths $\times 16$ concentrations) indicate that up to 1142768 values of absorbance were considered to build the PARAFAC model, selecting two components according to the two compounds present in the mixture (catechol and dopamine), a convergence criterion of $1 \times 10^{-25}$, no constraint and no scaling. The outputs of the PARAFAC model were the three factors (dimensions of $151 \times 2,473 \times 2$, and $16 \times 2$ ) shown in Figure 6.6.8, obtained after 299 iterations and with a corcondia value of $100 \%$.

Loadings and scores of catechol and dopamine obtained from PARAFAC are plotted in Figure 6.6.8. Figure 6.6.8a represents the loadings with respect to potential. As expected, the loadings with respect to the wavelengths (Figure 6.6.8b) show a very similar behavior with respect to the spectra displayed in Figure 6.6.6c. The most striking results are shown in Figure 6.6.8c and Figure 6.6.8d, where the scores of catechol and dopamine corresponding to the concentration of catechol and dopamine, respectively, are plotted. Clearly, the higher the catechol and the dopamine concentration, the higher the scores obtained from PARAFAC for each molecule. 

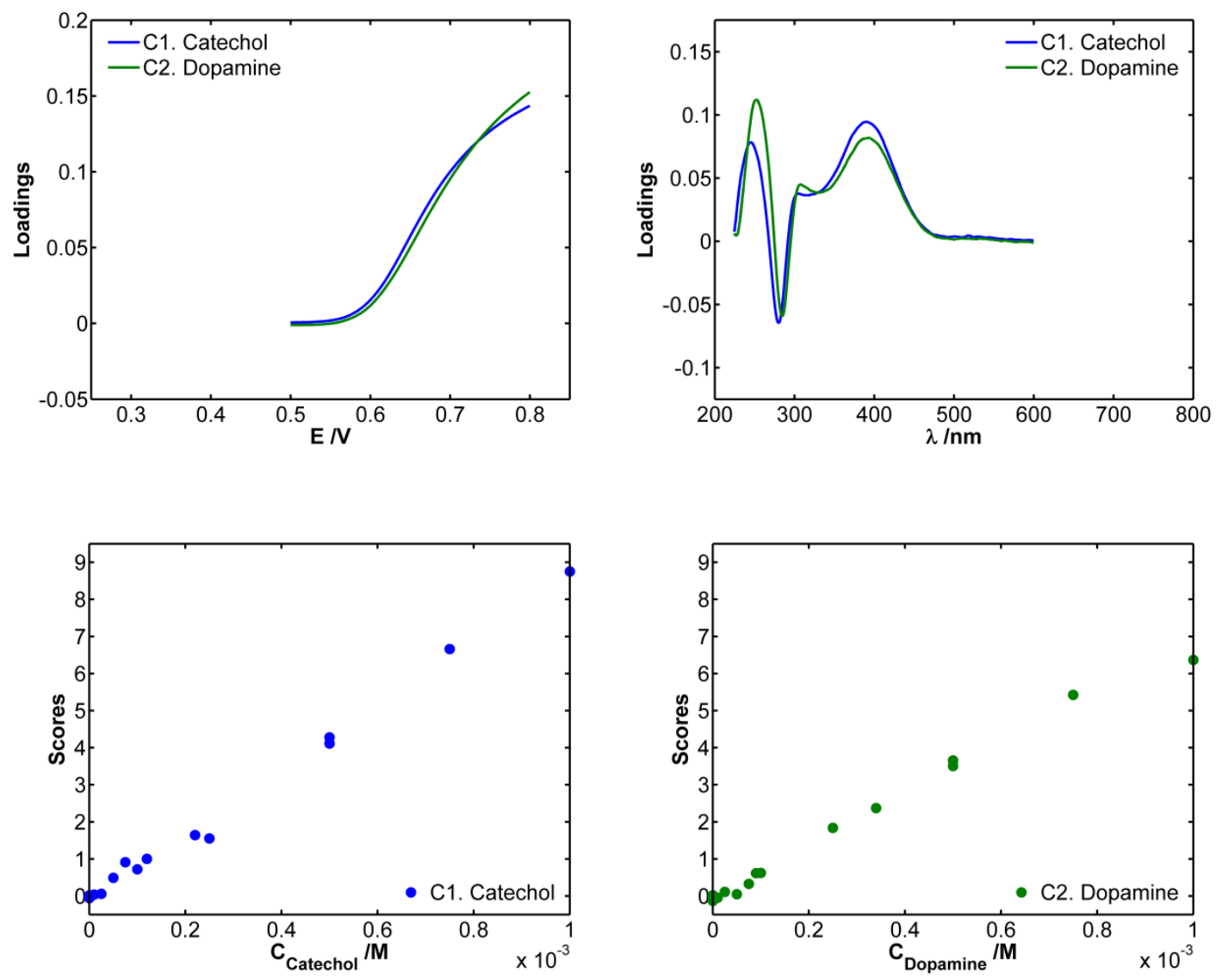

Figure 6.6.8. (a) Loadings of catechol and dopamine with respect to potential. (b) Loadings of catechol and dopamine with respect to the wavelengths. Raw scores of (c) catechol and (d) dopamine with respect to the concentration of catechol and dopamine, respectively.

The coefficients of determination of the scores versus catechol and dopamine concentration obtained from the raw data using OLS models (see Figure 6.6.9a and Figure 6.6.9b) demonstrate the complete deconvolution of the mixture with respect to each analyte, allowing us to determine the concentration of catechol and dopamine in mixtures containing varying concentrations of both compounds. At first sight, it seems that UV-Vis absorption spectroelectrochemistry enables us to perform quantitative 
analysis using the scores obtained from PARAFAC. In order to construct the calibration curves of catechol and dopamine, two test samples (see Table 6.6.2), which were obviously included to build the PARAFAC model to obtain their corresponding scores, were excluded. Afterwards, detection of outliers was performed with LMS regression. Curiously, experiment number 8 is an outlier in the calibration curves of catechol and dopamine. As can be seen in Figure 6.6.9c and Figure 6.6.9d, its scores are lower than expected in both cases.
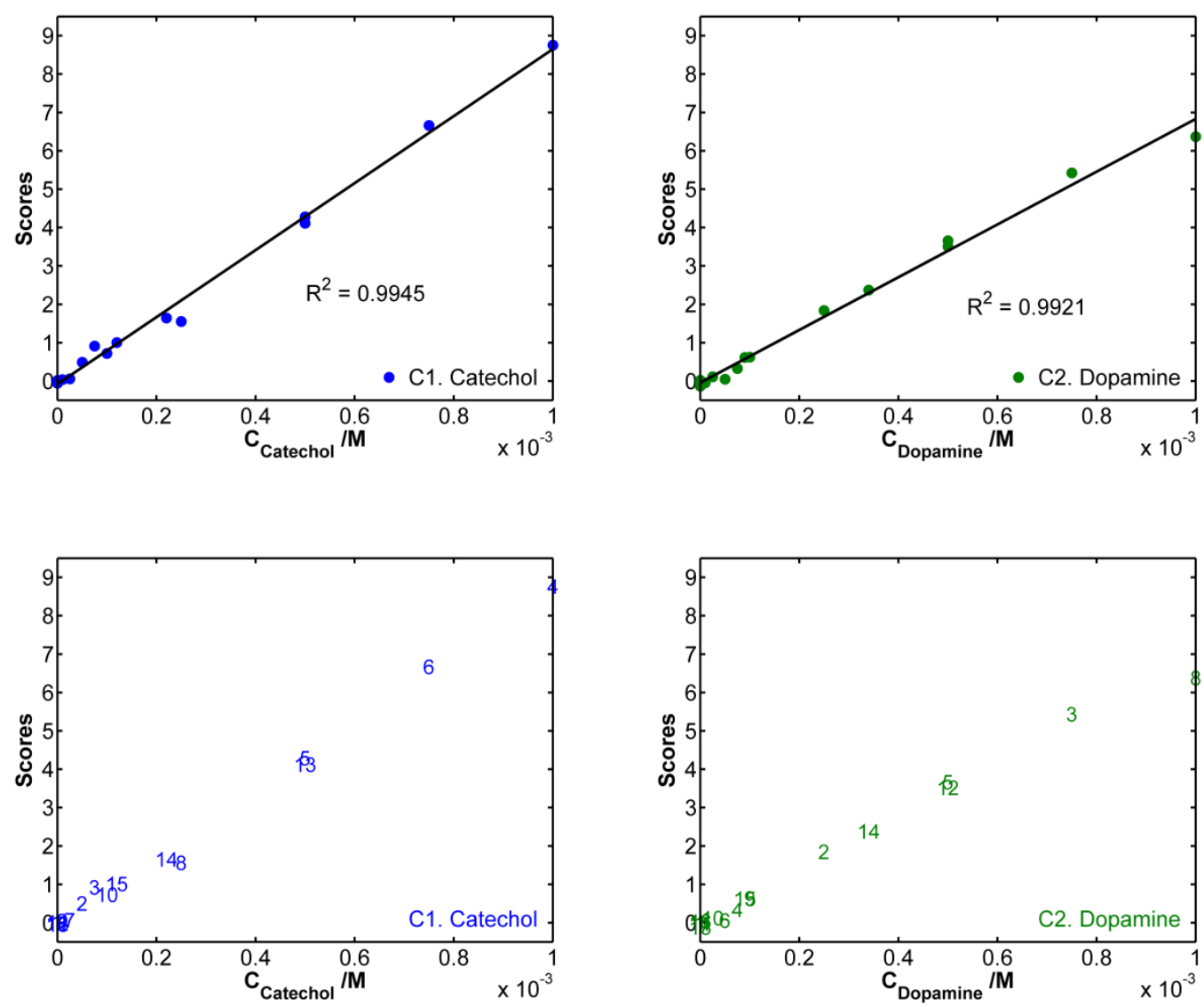

Figure 6.6.9. Representation of the linear behavior of the raw scores obtained with PARAFAC with respect to the concentration of (a) catechol and (b) dopamine. Identification of each sample with respect to the concentration of (c) catechol and (d) dopamine. 
For this reason, it can be deduced that there has been an error in the preparation of sample 8, probably by excess of solvent. Therefore, the analysis of the UV-Vis absorption spectroelectrochemistry data with PARAFAC gives an idea of anomalous points.

Figure 6.6.10 represents the two calibration curves of scores of catechol and dopamine versus catechol and dopamine concentration, respectively, obtained using OLS regression models after removal of outliers. The limits of detection obtained were $4.6 \times 10^{-5}$ and $4.1 \times 10^{-5} \mathrm{M}$ for the determination of catechol and dopamine, respectively.
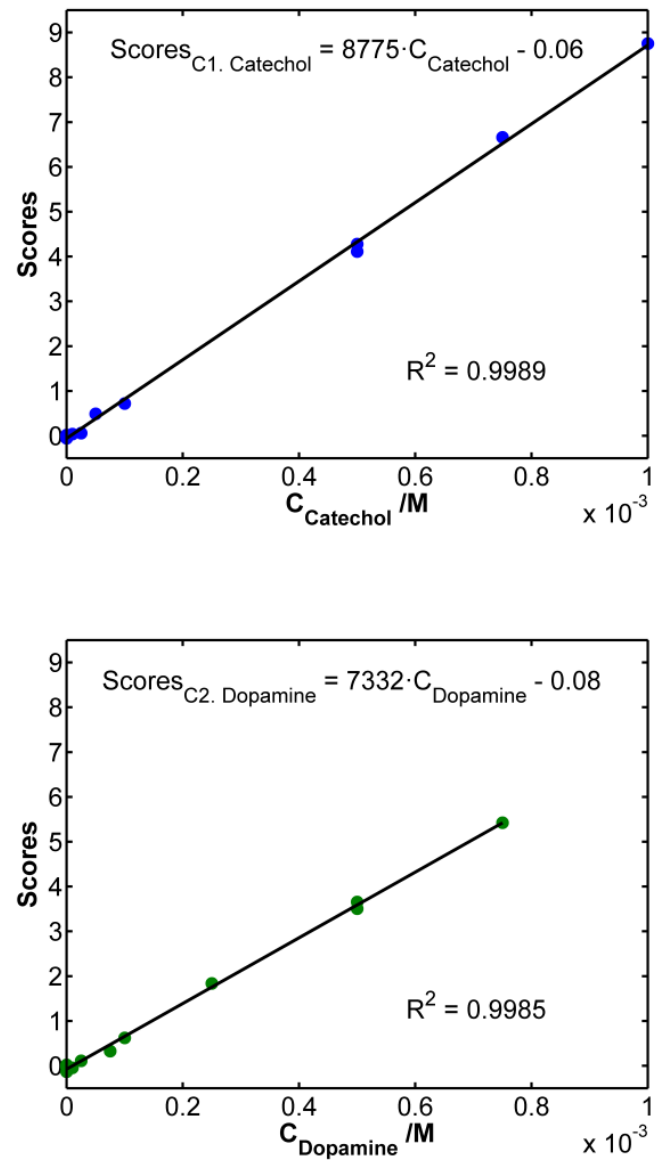

Figure 6.6.10. Calibration curves obtained of (a) scores of catechol versus catechol concentration and (b) scores of dopamine versus dopamine concentration. 
Finally, the last step is to evaluate the prediction capability of these calibration curves. For this purpose, the concentrations of catechol and dopamine of two test samples of $2.2 \times 10^{-4} \mathrm{M}$ catechol $3.4 \times 10^{-4} \mathrm{M}$ dopamine and $1.2 \times 10^{-4} \mathrm{M}$ catechol $9 \times 10^{-5} \mathrm{M}$ dopamine were estimated, obtaining satisfactory values for the predicted concentrations in all cases. All data are listed in Table 6.6.3, where the very high figures of merit obtained can be observed.

Table 6.6.3. Regression parameters of the calibration curves constructed after PARAFAC analysis (Figure 6.6.10) for the determination of catechol and dopamine in $1 \mathrm{M} \mathrm{HCl}$ by $\mathrm{UV}-\mathrm{Vis}$ absorption spectroelectrochemistry in the concentration ranges of $1 \times 10^{-5} \mathrm{M}-1 \times 10^{-3} \mathrm{M}$ and $1 \times 10^{-5} \mathrm{M}-7.5 \times 10^{-4}$, respectively, and estimated concentrations for two test samples.

\begin{tabular}{ccc}
$\mathbf{C}$ & $\boldsymbol{R}^{2}$ & $\boldsymbol{S}_{\boldsymbol{y x}}$ \\
\hline $\mathbf{C} 1$ & 0.9989 & $1.1 \times 10^{-1}$ \\
$\mathbf{C 2}$ & 0.9985 & $7.8 \times 10^{-2}$ \\
\hline
\end{tabular}

\begin{tabular}{ccccc}
\hline & \multicolumn{2}{c}{$\mathbf{C}_{\text {Catechol }}=\mathbf{2 . 2} \times \mathbf{1 0}^{-4} \mathbf{M}$} & \multicolumn{2}{c}{$\mathbf{C}_{\text {Catechol }}=\mathbf{1 . 2} \times \mathbf{1 0}^{-4} \mathbf{M}$} \\
$\mathbf{C}_{\text {Dopamine }}=\mathbf{3 . 4} \times \mathbf{1 0}^{-4} \mathbf{M}$ & \multicolumn{2}{c}{$\mathbf{C}_{\text {Dopamine }}=\mathbf{9} \times \mathbf{1 0}^{-5} \mathbf{M}$} \\
\cline { 2 - 5 } $\mathbf{C}$ & $\mathbf{C I}(\mathbf{M})$ & $\mathbf{R S D}(\boldsymbol{\%})$ & $\mathbf{C I}(\mathbf{M})$ & $\mathbf{R S D}(\boldsymbol{\%})$ \\
\hline $\mathbf{C 1}$ & {$[1.94 \pm 0.33] \times 10^{-4}$} & 6.88 & {$[1.21 \pm 0.33] \times 10^{-4}$} & 11.12 \\
$\mathbf{C 2}$ & {$[3.34 \pm 0.26] \times 10^{-4}$} & 3.22 & {$[9.4 \pm 2.6] \times 10^{-5}$} & 11.39 \\
\hline
\end{tabular}

$\mathrm{C} 1$, related to catechol, and $\mathrm{C} 2$, related to dopamine, correlate the scores of catechol and dopamine versus catechol and dopamine concentration, respectively. C, component; $R^{2}$, coefficient of determination; $S_{y x}$, residual standard deviation; $\mathrm{C}_{\text {Catechol }}$, concentration of catechol in the test sample; $\mathrm{C}_{\text {Dopamine, }}$ concentration of dopamine in the test sample; $\mathrm{CI}$, confidence interval; and RSD, relative standard deviation $(\mathrm{n}=12, \alpha=0.05)$. 
Finally, it should be mentioned that, although there are many works related to the quantitative determination of a specific compound in presence of interfering species (sometimes at constant concentration), our work demonstrates the importance of UV-Vis absorption spectroelectrochemistry to simultaneously determine the concentration of all compounds present in mixtures of varying concentrations, bringing quantitative analysis a step closer to reality.

\subsubsection{Conclusions and Future Work}

In this work, we have demonstrated the exciting possibilities associated with UV-Vis absorption spectroelectrochemistry techniques for the quantitative analysis of mixtures of different molecules of biological interest with really similar electrochemical and spectroscopic properties.

Firstly, UV-Vis absorption spectroelectrochemistry has been demonstrated to be really useful in the quantitative analysis of dopamine in acidic media by potentiodynamic and potentiostatic measurements. This goal has been achieved using univariate regression, showing the in situ, autovalidated, and multiresponse features of UV-Vis absorption spectroelectrochemistry.

The use of bare optical fibers to acquire the spectral signal in long optical path length configuration concomitantly with the electrochemical response obtained using SWCNTs electrodes is highly promising in the field of quantitative analysis. This setup allows us to obtain an excellent potential, temporal, and spectral resolution from 200 to $900 \mathrm{~nm}$, requiring only a very small volume of solution. Taking advantage of all this large 
amount of information that can be extracted from a single spectroelectrochemistry experiment, it is possible to resolve very complex mixtures and to obtain good detection limits using multivariate analysis.

For these reasons, in order to demonstrate the effectiveness of UV-Vis absorption spectroelectrochemistry for quantitative analysis, complex mixtures of catechol and dopamine in acidic media have been resolved using PARAFAC, allowing us to determine the concentration of each analyte in mixtures of varying concentration of both of them.

Therefore, our work demonstrates the particular advantages of $\mathrm{UV}-\mathrm{V}$ is absorption spectroelectrochemistry compared to other techniques, including versatility, low cost, fast measurements and the possibility of obtaining not only quantitative information but also the understanding of electrochemical processes, for the analysis of complex mixtures without the need to separate their components.

In view of these results, we are currently working in the resolution of mixtures of more than two compounds of biological interest, obtaining relevant information. This work opens new possibilities and interesting perspectives in the study of reaction mechanisms, in the study of interfering substances, and in clinical and environmental analysis, expanding the scope of applications of UV-Vis absorption spectroelectrochemistry, which can be considered as a real-time technique with practical uses not only in qualitative but also in quantitative analysis. 
6.7. Monitoring the Evolution of $\mathrm{pH}$ at the Electrode-Solution Interface by

Spectroelectrochemistry 



\subsubsection{Some Important Points to Keep in Mind}

As is known, interfaces are everywhere, particularly in our own human body. In addition, proton concentration and its changes represent one of the key factors in multiple chemical and electrochemical processes.

For these reasons, the monitoring of $\mathrm{pH}$ at interfaces during electrochemical reactions is really necessary and interesting in accordance with its importance in the current world. Undoubtedly, following the evolution of $\mathrm{pH}$ in these reduced spaces will open new avenues in multiple research areas.

Despite being a molecule with important biological activity, ${ }^{338}$ ascorbic acid has been scarcely studied by UV-Vis spectroelectrochemistry. ${ }^{345-348}$

This work is focused on measuring how the $\mathrm{pH}$ evolves at the electrode-solution interface during the electrochemical oxidation of ascorbic acid, using the UV-Vis absorption spectroelectrochemistry device developed in section 6.5. ${ }^{31}$ According to the electrochemical oxidation mechanism of ascorbic acid, this process involves the transfer of two protons, acidifying the solution where the electrochemical reaction takes place.

$\mathrm{UV}-\mathrm{Vis}$ absorption spectroelectrochemistry is a very powerful technique to solve the main objective proposed in this work because the different species related to ascorbic acid with respect to $\mathrm{pH}$ have slight spectral differences. Therefore, recording the evolution of the full UV-Vis spectra during the electrochemical reaction of ascorbic acid is an elegant strategy to monitor the $\mathrm{pH}$ during this electrochemical reaction because 
there is a relationship between the $\mathrm{pH}$ and the wavelength of the UV band associated with ascorbic acid.

As demonstrated below, the evolution of $\mathrm{pH}$ is easily monitored by spectroelectrochemistry, achieving a very high resolution in terms of both time/potential and $\mathrm{pH}$ units by taking into account the spectral changes that occur in the solution adjacent to the WE, concomitantly with the electrochemical reaction.

This fact will shed more light in the comprehension of mechanisms in which the $\mathrm{pH}$ plays a key role such as, for example, those of biochemical reactions.

\subsubsection{Experimental Section}

The reagents and materials used to fabricate the whole spectroelectrochemistry device, as well as the instrumentation used in this work, were indicated in section $6.5,{ }^{31}$ along with the experimental setup employed. Ascorbic acid (L(+)-ascorbic acid, Acros Organics) and $\mathrm{LiClO}_{4}$ (Panreac) were used to prepare the solutions. $\mathrm{pH}$ values of the different solutions were measured using a pH meter (micropH 2002, Crison).

All reagents were used as received without further purification. All chemicals were of analytical grade. Aqueous solutions were freshly prepared using ultrapure water $\left(18.2 \mathrm{M} \Omega \cdot \mathrm{cm}\right.$ resistivity at $25^{\circ} \mathrm{C}$, Milli-Q Direct 8, Millipore).

To work in a semi-infinite diffusion regime, a $200 \mu \mathrm{L}$ solution drop was placed on the cell, covering the three electrodes and the ends of the optical 
fibers. The optical path length was set at $0.75 \mathrm{~mm}$ and the integration time for the spectra acquisition was $350 \mathrm{~ms}$. The UV-Vis light beam, provided by the deuterium light source, was collected with the optical fibers to the spectroelectrochemistry cell, and, after sampling the system, to the spectrometer.

Both the fabrication of the whole spectroelectrochemistry device, as well as its validation, were explained in section $6.5 .^{31} \mathrm{Next}$, it is used to monitor the evolution of $\mathrm{pH}$ at the electrode-solution interface during the electrochemical reaction of ascorbic acid.

\subsubsection{Results and Discussion}

\subsubsection{Spectroscopic Properties of Species Related to Ascorbic Acid}

According to the literature, ${ }^{414-416}$ the different species of ascorbic acid with respect to $\mathrm{pH}$ show different spectra. For example, the spectrum of ascorbic acid displays a maximum around $247 \mathrm{~nm}$ while the maximum of ascorbate monoanion is approximately at $265 \mathrm{~nm}$.

This was confirmed in our laboratory by preparing different solutions of ascorbic acid in $0.1 \mathrm{M} \mathrm{LiClO}_{4}$, recording their spectra and measuring their $\mathrm{pH}$ value. The whole information is shown in Figure 6.7.1, which is very similar to that found in the literature, ${ }^{416}$ confirming the reliability of the results obtained in the present work. 
As was expected, the UV band suffers a hypsochromic shift with the increase of the ascorbic acid concentration, due to the decrease in the $\mathrm{pH}$ value which is related to a higher presence of the ascorbic acid species instead of the ascorbate monoanion species.

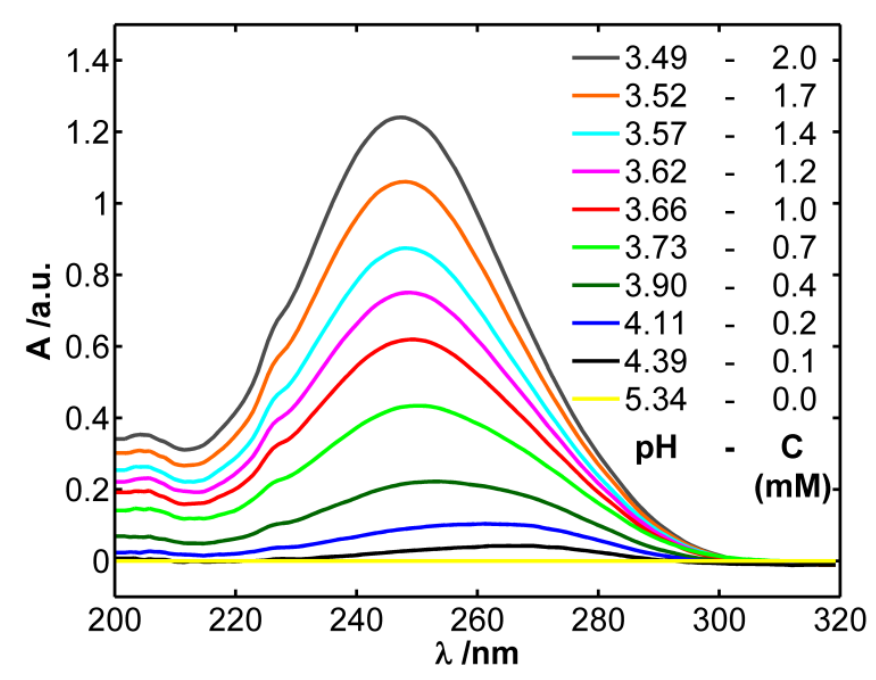

Figure 6.7.1. Spectra of solutions of different concentrations of ascorbic acid between $1 \times 10^{-4} \mathrm{M}$ and $2 \times 10^{-3} \mathrm{M}$ in $0.1 \mathrm{M} \mathrm{LiClO}_{4}$. The spectrum of a blank solution is also shown in yellow line.

Graphics of $\mathrm{pH}$ versus ascorbic acid concentration as well as wavelength of the UV band versus ascorbic acid concentration (data obtained from Figure 6.7.1) are shown in Figure 6.7.2a and Figure 6.7.2b, respectively. As can be observed, the increase of the ascorbic acid concentration is related to a lower value of the $\mathrm{pH}$ (Figure 6.7.2a). In the same way, the increase of the ascorbic acid concentration is related to a blue shift of the UV band to shorter wavelengths with increasing acidity (Figure 6.7.2b). It is noteworthy the great similarity between both figures that suggests a relationship between both variables. 

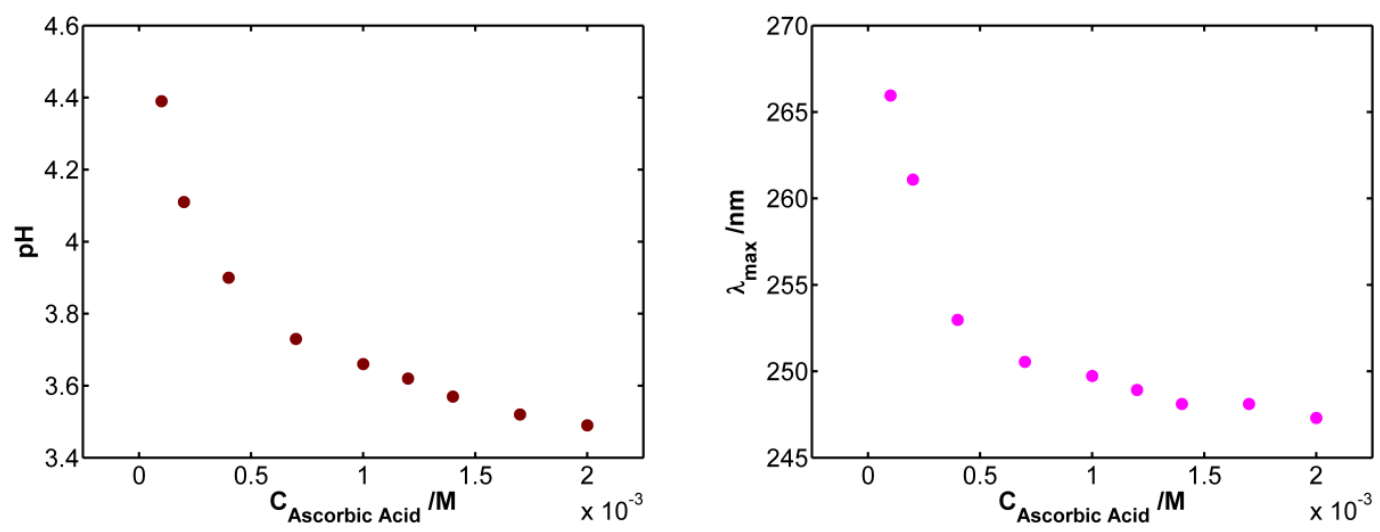

Figure 6.7.2. Graphics of (a) $\mathrm{pH}$ and (b) wavelength of the UV band versus ascorbic acid concentration, corresponding to the spectra shown in Figure 6.7.1.

For this reason, the relationship between the $\mathrm{pH}$ value and the wavelength of the UV band was studied. In this concentration range, this behavior is clearly fitted according to a linear model which allows us to correlate the $\mathrm{pH}$ and the wavelength of the UV band of the spectra (see Figure 6.7.3).

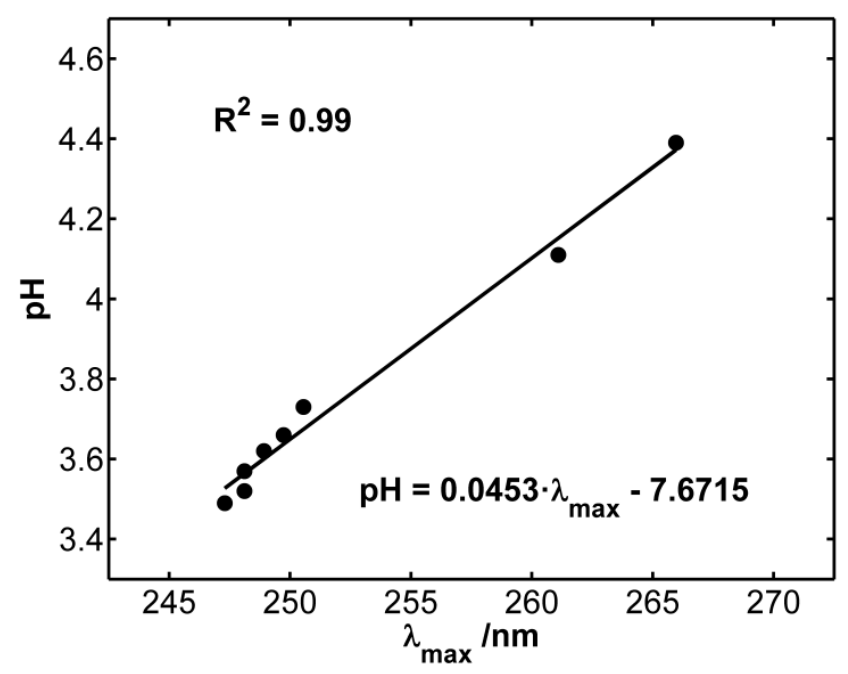

Figure 6.7.3. Correlation between the $\mathrm{pH}$ value and the wavelength of the UV band of the spectra of the solutions of different concentrations of ascorbic acid. 
In conclusion, it is possible to indirectly assess the $\mathrm{pH}$ value of a solution of ascorbic acid by measuring the wavelength of the UV band of its spectra. As can be expected, the UV-Vis absorption spectroelectrochemistry device, with the optical fibers sampling only the solution adjacent to the WE, should be a powerful tool to monitor the evolution of $\mathrm{pH}$ during the electrochemical oxidation of ascorbic acid at the electrode-solution interface, as demonstrated below.

\subsubsection{Following the Evolution of $\mathrm{pH}$ at the Electrode-Solution Interface by Spectroelectrochemistry}

In this work, the changes of the $\mathrm{pH}$ value during the electrochemical experiment of ascorbic acid are monitored by measuring the spectra evolution at the electrode-solution interface.

The spectroelectrochemical potentiodynamic behavior of ascorbic acid is shown in Figure 6.7.4. The spectra evolution during a cyclic voltammetry of $7 \times 10^{-4} \mathrm{M}$ ascorbic acid in $0.1 \mathrm{M} \mathrm{LiClO}_{4}$ between $-0.50 \mathrm{~V}$ and $+0.90 \mathrm{~V}$ at a potential scan rate of $0.010 \mathrm{~V} \cdot \mathrm{s}^{-1}$ was recorded. A solution $0.1 \mathrm{M}$ $\mathrm{LiClO}_{4}$ without ascorbic acid was taken as reference spectrum for the absorption spectra measurements.

Figure 6.7.4a illustrates the 3D plot of the spectra evolution with time/potential related to the cyclic voltammogram, which is shown in the inset. The oxidation process of ascorbic acid is simultaneously observed with both electrochemical and spectroscopic responses: (i) by the increase of the current intensity in the forward scan of the cyclic voltammogram from $-0.15 \mathrm{~V}$ onwards (anodic peak at $+0.125 \mathrm{~V}$ ) and (ii) by the simultaneous decrease of the absorbance of the UV band in the 3D plot of 
the spectra evolution that indicates the consumption of species related to ascorbic acid at the electrode-solution interface. The absence of a reduction peak in the backward scan proves the irreversibility of this electrochemical process. It should be noted that an increase of the absorbance is observed at the end of the cathodic scan due to the diffusion of ascorbic acid species from the bulk solution to the electrode-solution interface.

The irreversible electrochemical reaction corresponds to the oxidation of ascorbic acid (AA) to dehydro-L-ascorbic acid (DHA) whose carbonyl groups undergo hydration yielding an electroinactive product: ${ }^{344,417}$
$\mathrm{AA} \rightleftarrows \mathrm{DHA}+2 \mathrm{H}^{+}+2 \mathrm{e}^{-}$
Reaction (6.7.1)

$\mathrm{DHA}+\mathrm{H}_{2} \mathrm{O} \rightarrow \mathrm{C}$

Reaction (6.7.2)

This process involves not only the transfer of two electrons but also two protons, acidifying the solution where the electrochemical reaction takes place.

In fact, more detailed information about this chemical aspect of the process can be extracted from Figure $6.7 .4 \mathrm{~b}$, where the spectra evolution is depicted only in the UV spectral region in a bidimensional way (red lines correspond to the anodic scan and green lines to the cathodic scan). As expected, the position of the UV absorption band changes during the spectroelectrochemistry experiment, according to the evolution of the different ascorbic acid species present in the solution adjacent to the WE. The more the reaction proceeds, the more the medium is acidified, causing the band to shift to shorter wavelengths corresponding to the ascorbic acid itself. This hypsochromic shift is due to the decrease of the $\mathrm{pH}$ level during the experiment in accordance with the ascorbic acid oxidation mechanism. 
This statement is more easily observable in the inset of Figure 6.7.4b, where the evolution of the wavelength corresponding to the maximum of the UV band is plotted during the spectroelectrochemical experiment, demonstrating that the UV absorption band changes its position during the experiment according to the different species of ascorbic acid with respect to $\mathrm{pH}$ present at each time/potential. This fact indicates that, according to the electrochemical mechanism of ascorbic acid, there are changes in the $\mathrm{pH}$ value during the electrochemical reaction at the electrode-solution interface and these changes can be easily monitored by spectroelectrochemistry. Particularly, the hypsochromic shift observed during the anodic scan is due to the decrease of the $\mathrm{pH}$ level because of the release of two protons that acidify the solution where the reaction takes place.

Previously, in the section associated with the spectroscopic properties of species related to ascorbic acid, a linear relationship between the $\mathrm{pH}$ value and the wavelength of the UV band was found. Therefore, it is possible to follow the evolution of $\mathrm{pH}$ at the electrode-solution interface taking into account the wavelength of the UV band during the whole electrochemical experiment (Figure 6.7.4c). In this case, the decrease of $\mathrm{pH}$ in a solution 7 $\times 10^{-4} \mathrm{M}$ ascorbic acid in $0.1 \mathrm{M} \mathrm{LiClO}_{4}$ is about $0.15 \mathrm{pH}$ units, and simultaneously occurs with the oxidation process, demonstrating the main objective proposed in this work.

It should be highlighted that the evolution of $\mathrm{pH}$ is measured by the spectra evolution recorded during the electrochemical experiment at the electrodesolution interface because this space is sampled by the $100 \mu \mathrm{m}$ in diameter bare optical fibers. Furthermore, it must be noted that really slight changes of $\mathrm{pH}$ are observed, impossible to be measured using a common $\mathrm{pH}$ meter. 

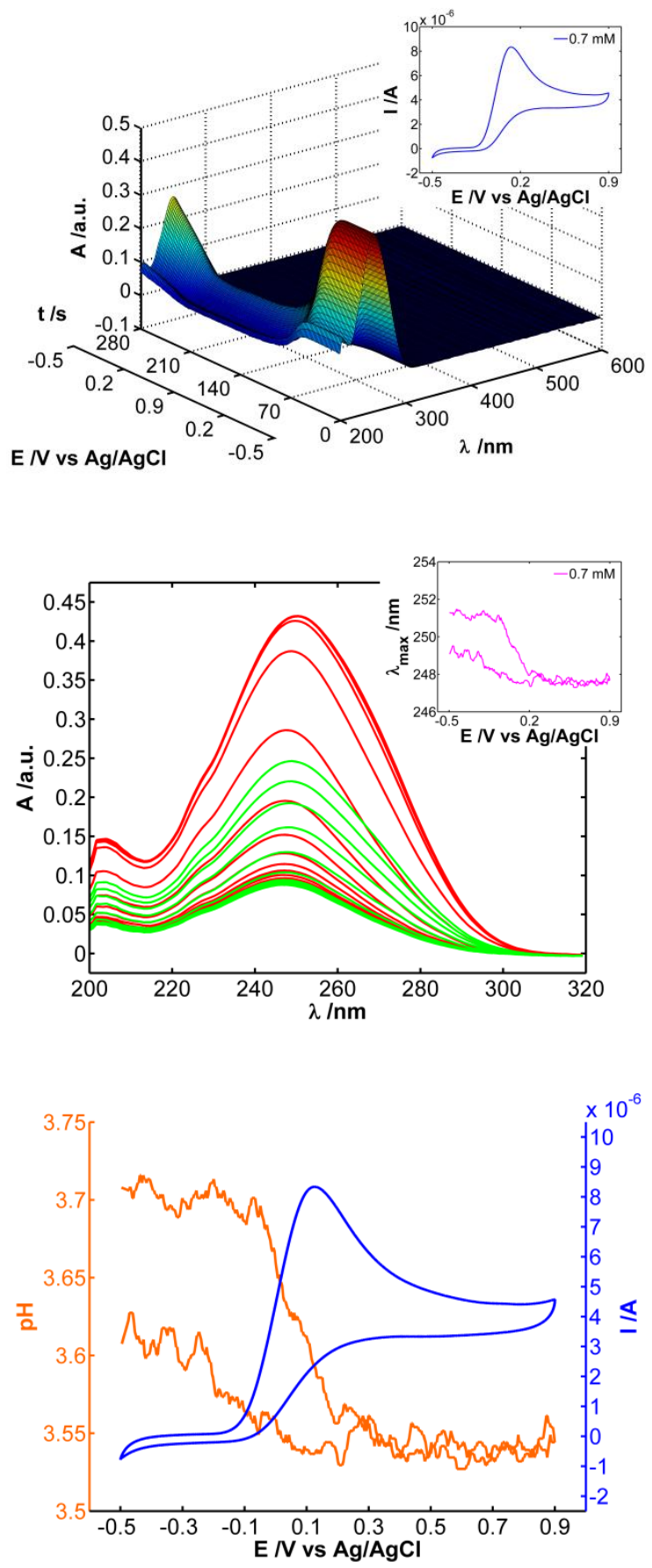

Figure 6.7.4. Spectroelectrochemistry of $7 \times 10^{-4} \mathrm{M}$ ascorbic acid in $0.1 \mathrm{M}$ $\mathrm{LiClO}_{4}$ between $-0.50 \mathrm{~V}$ and $+0.90 \mathrm{~V}$ at $0.010 \mathrm{~V} \cdot \mathrm{s}^{-1}$. (a) $3 \mathrm{D}$ spectra evolution during the cyclic voltammetry. Inset: Cyclic voltammogram. (b) UV spectra evolution (red lines, anodic scan; green lines, cathodic scan). Inset: Evolution of the wavelength of the UV band. (c) $\mathrm{pH}$ evolution at the electrode-solution interface. 
Aiming to compare both electrochemical and spectroscopic responses and to demonstrate the high-quality information obtained, now in terms of simultaneity, the cyclic voltammogram is represented with the voltabsorptogram at $252 \mathrm{~nm}$ (Figure 6.7.5a) and with the derivative voltabsorptogram at $252 \mathrm{~nm}$ with respect to time (Figure 6.7.5b). This wavelength was selected because $252 \mathrm{~nm}$ is an isosbestic point where the molar absorption coefficients of ascorbate monoanion and ascorbic acid have the same value. ${ }^{414,415}$ The good agreement between both signals should be highlighted in both cases.

On the one hand, as can be seen in Figure 6.7.5a, the increase in the current intensity and, concomitantly, the decrease of the absorbance at $252 \mathrm{~nm}$ confirm the ascorbic acid oxidation from $-0.15 \mathrm{~V}$ onwards. The oxidation process lasts until the potential is so low that ascorbic acid cannot be oxidized. From that moment on, the increase of the absorbance at $252 \mathrm{~nm}$ is due to the diffusion of ascorbic acid species from the bulk solution to the solution closest to the electrode surface that is sampled by the optical fibers.

On the other hand, as can be observed in Figure 6.7.5b, the great agreement between the cyclic voltammogram and the derivative voltabsorptogram at $252 \mathrm{~nm}$ with respect to time assures that the light beam passes through the first $100 \mu \mathrm{m}$ closest to the SWCNTs WE surface and that the potentiostat and the spectrometer are properly synchronized.

In summary, it is possible to corroborate the ascorbic acid electrochemical behavior taking into account the spectral response, which allows us to obtain more information about the evolution of the $\mathrm{pH}$ value during the spectroelectrochemistry experiment. 

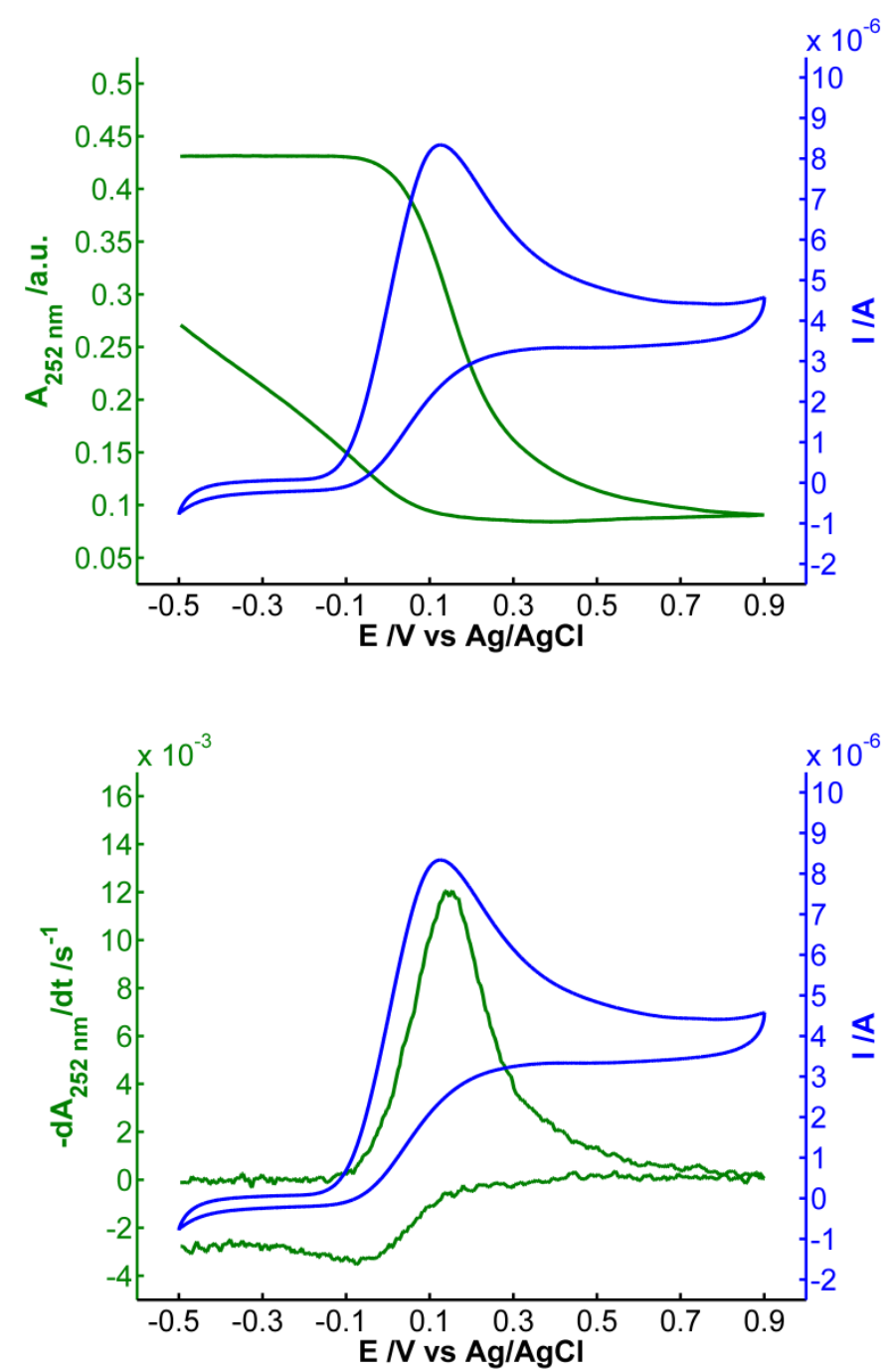

Figure 6.7.5. Representation of the cyclic voltammogram (a) with the voltabsorptogram at $252 \mathrm{~nm}$ and (b) with the derivative voltabsorptogram at 252 $\mathrm{nm}$ with respect to time, corresponding to Figure 6.7.4.

Once demonstrated that the $\mathrm{pH}$ can be monitored during an electrochemical reaction, Figure 6.7.6 displays the evolution of (i) the absorbance at $252 \mathrm{~nm}$ and (ii) the $\mathrm{pH}$ value during the spectroelectrochemistry experiment corresponding to Figure 6.7.4. As can be observed, absorbance at $252 \mathrm{~nm}$ and $\mathrm{pH}$ follow the same behavior, and, hence, both curves also evolve concomitantly with the oxidation wave of the cyclic voltammogram. 


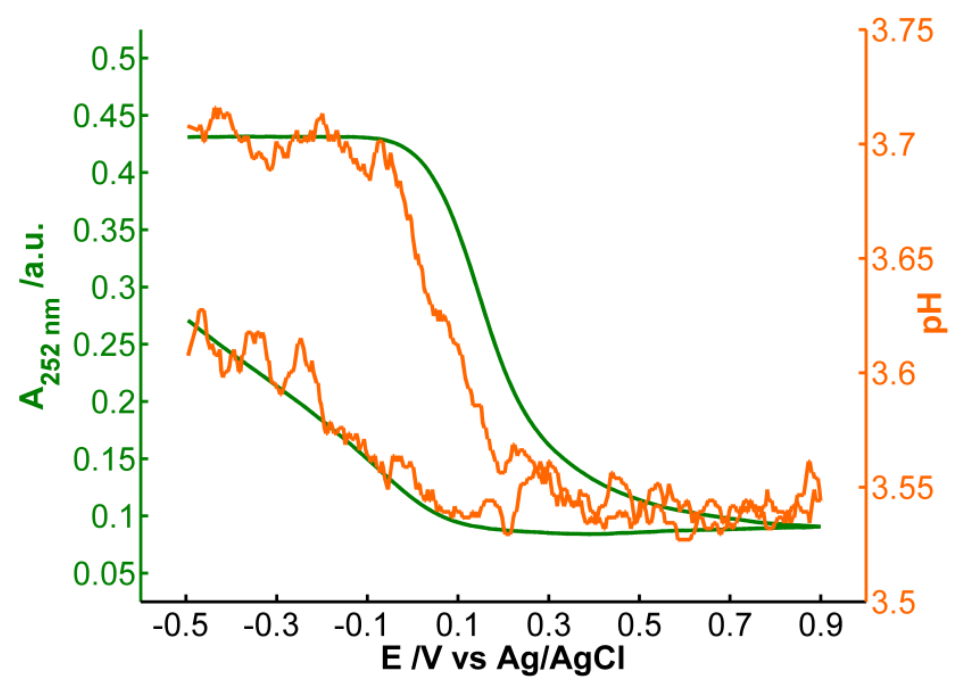

Figure 6.7.6. Evolution of the absorbance at $252 \mathrm{~nm}$ and evolution of the $\mathrm{pH}$ value during the spectroelectrochemistry experiment corresponding to Figure 6.7.4.

Finally, the evolution of the absorbance at $252 \mathrm{~nm}$ and of $\mathrm{pH}$ during the oxidation scan of many experiments with different concentrations of ascorbic acid between $1 \times 10^{-4} \mathrm{M}$ and $2 \times 10^{-3} \mathrm{M}$ in $0.1 \mathrm{M} \mathrm{LiClO}_{4}$ is plotted in Figure 6.7.7 (all other experimental conditions are the same as before).

On the one hand, we can observe that low concentrations of ascorbic acid are related to small changes of absorbance. On the other hand, the $\mathrm{pH}$ associated with the higher concentrations of ascorbic acid does not change so much during the experiment because these solutions are almost buffered.

The most interesting results are obtained using the intermediate concentrations, which present remarkable changes in both absorbance and wavelength of the UV absorption band, and, thus, $\mathrm{pH}$. 


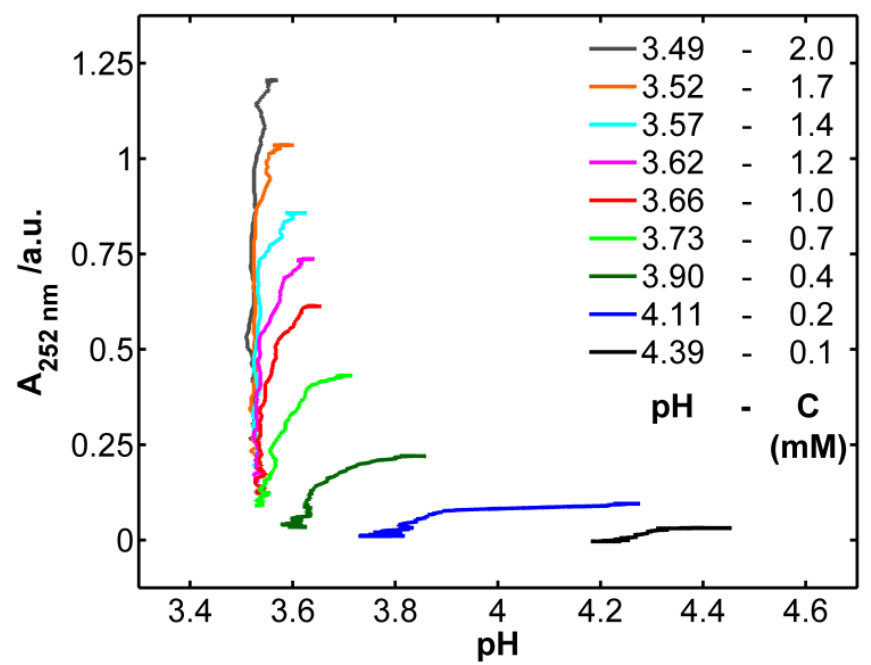

Figure 6.7.7. Evolution of the absorbance at $252 \mathrm{~nm}$ and of $\mathrm{pH}$ during the oxidation scan of many experiments with different concentrations of ascorbic acid between $1 \times 10^{-4} \mathrm{M}$ and $2 \times 10^{-3} \mathrm{M}$ in $0.1 \mathrm{M} \mathrm{LiClO}_{4}$.

\subsubsection{Conclusions and Future Work}

This work has demonstrated the fruitful use of UV-Vis absorption spectroelectrochemistry to monitor the evolution of $\mathrm{pH}$ at the electrodesolution interface during electrochemical reactions.

The ascorbic acid potentiodynamic mechanism has been deeply studied by spectroelectrochemistry.

As a proof of concept, ascorbic acid has been used to study how the $\mathrm{pH}$ evolves during its electrochemical reaction, being able to distinguish changes of $\mathrm{pH}$ of around $0.05 \mathrm{pH}$ units, thanks to the slight spectroscopic differences associated with the different species of ascorbic acid with respect to $\mathrm{pH}$. 
The recording of the spectra with an outstanding sensitivity and an excellent time and wavelength resolution has enabled us to observe these slight UV spectral changes between ascorbate monoanion and ascorbic acid species, whose presence in a sample depends on the $\mathrm{pH}$ value along the electrochemical reaction.

Therefore, UV-Vis absorption spectroelectrochemistry has proven to be an excellent technique to follow the evolution of $\mathrm{pH}$ during reactions involving compounds of biological interest, and, therefore, to a better understanding of this type of processes, a truly important fact very difficult to achieve using different techniques.

This work opens up a world of possibilities for the future. One of the most important perspectives to achieve is the study of different reactions with molecules that show different spectra with $\mathrm{pH}$ but that do not oxidize at potentials where compounds of interest. Other interesting biomolecules, such as neurotransmitters, are suggested to be studied with this methodology, yielding interesting results by monitoring the $\mathrm{pH}$ value of their electrochemical reactions by spectroelectrochemistry, directly or indirectly. 
6.8. Direct Determination of Ascorbic Acid

in a Grapefruit: Paving the Way for In Vivo

Spectroelectrochemistry 



\subsubsection{Some Important Points to Keep in Mind}

Ascorbic acid, as other vitamins, is an essential biomolecule. It must be ingested through diet, for which fruits are a good choice. Deficiency of ascorbic acid is related to scurvy, ${ }^{418}$ thus, its determination, for example by electrochemical methods, ${ }^{344}$ is highlighted. As mentioned in the previous section, ascorbic acid has been scarcely studied by UV-Vis spectroelectrochemistry, ${ }^{34-348}$ and its quantification by this in situ technique has been performed in an indirect way by using a mediator. ${ }^{349}$

The study of real samples is more complicated than the study of other systems. The main difficulties in complex sample detection are the presence of interfering species, the absence of the in situ character, the high cost of the equipment, the long analysis times, or the difficulty of the experimental devices. However, the competitive advantages of UV-Vis absorption spectroelectrochemistry should overcome some difficulties related to direct measurements in complex matrices.

As is well known, there are interesting works about electrochemistry in complex samples, being even possible to perform in vivo electrochemistry. ${ }^{419-423}$ Nevertheless, although spectroelectrochemistry offers inherent advantages and provides more information about physicochemical processes than electrochemistry, the promising field of the study of complex matrices and living or real samples by spectroelectrochemistry ${ }^{424-426}$ is still taking its first steps.

Actually, to the best of our knowledge, and apart from few very interesting devices, ${ }^{345,427,428}$ there is a lack of UV-Vis absorption spectroelectrochemistry devices that allow us to perform direct measurements in complex matrices, probably because of the intrinsic 
difficulties to develop devices able to carry out such experiments. Aiming to solve these problems and to shed more light in these scientific areas, the UV-Vis absorption spectroelectrochemistry device proposed in section $6.5,{ }^{31}$ which is totally movable and capable of being inserted in in vivo samples, is used in this last part of the research results section to demonstrate its abilities to overcome the drawbacks mentioned before.

To show the usefulness of this device and the power of spectroelectrochemistry techniques to solve problems of the current world, this device is used to quantitatively detect, as a proof of concept, the ascorbic acid concentration in a complex matrix such as a fruit, directly, without any previous sample pretreatment. According to the particular features of this device, to the best of our knowledge this is the first spectroelectrochemical sensor that can be inserted in a biological matrix, laying the groundwork to perform in vivo measurements in a near future.

The advantages related to this device and the excellent results obtained with univariate and multivariate analysis, shed more light on the analysis of samples as they occur in nature, significantly contributing to the necessary use of spectroelectrochemistry in real environments.

\subsubsection{Experimental Section}

The reagents and materials used to fabricate the whole spectroelectrochemistry device, as well as the instrumentation used in this work, were indicated in section $6.5,{ }^{31}$ along with the experimental setup employed. Ascorbic acid (L(+)-ascorbic acid, Acros Organics), $\mathrm{LiClO}_{4}$ (Panreac), and DCIP (Sigma-Aldrich) were used to prepare the solutions. 
All reagents were used as received without further purification. All chemicals were of analytical grade. Aqueous solutions were freshly prepared using ultrapure water $\left(18.2 \mathrm{M} \Omega \cdot \mathrm{cm}\right.$ resistivity at $25^{\circ} \mathrm{C}$, Milli-Q Direct 8, Millipore).

The fabrication of the whole spectroelectrochemistry device and its validation were shown in section $6.5 .^{31} \mathrm{Next}$, it is used to quantify directly the amount of ascorbic acid in a complex matrix such as a grapefruit.

\subsubsection{Results and Discussion}

\subsubsection{Determination of Ascorbic Acid in a Complex Matrix}

Potentiostatic spectroelectrochemistry measurements of different concentrations of ascorbic acid between $1 \times 10^{-4} \mathrm{M}$ and $3.5 \times 10^{-3} \mathrm{M}$ in 0.1 $\mathrm{M} \mathrm{LiClO}_{4}$, applying a constant potential of $+0.90 \mathrm{~V}$ during $60 \mathrm{~s}$, were performed to construct a calibration curve, assuring that the electrochemical oxidation of ascorbic acid was taking place independently of the matrix studied, as will be indicated below. Seven cycles in a cyclic voltammetry experiment in $0.1 \mathrm{M} \mathrm{LiClO}_{4}\left(E_{i}=-0.50 \mathrm{~V}, E_{v 1}=+1.40 \mathrm{~V}\right.$, and $E_{v 2}=-1.40 \mathrm{~V}$ ) at $0.050 \mathrm{~V} \cdot \mathrm{s}^{-1}$ were performed prior to the calibration curve to condition the SWCNTs WE. Spectral changes related to ascorbic acid only occur in the UV spectral range, especially around $252 \mathrm{~nm}$, so that only the deuterium light source was used. As the ascorbic acid concentration in the grapefruit is presumably high, the optical path length was shortened to $0.45 \mathrm{~mm}$, allowing to reduce the integration time to 110 $\mathrm{ms}$ to obtain more data, compared to the parameters of $1.45 \mathrm{~mm}$ and 250 
ms of the previous validation (section 6.5). ${ }^{31}$ A $200 \mu \mathrm{L}$ solution drop was placed in the spectroelectrochemistry device and the initial ascorbic acid solution of each experiment was taken as reference spectrum. This set of calibration samples was employed to evaluate the capability of the spectroelectrochemistry device to quantify ascorbic acid. An example of the results obtained using a solution $1 \times 10^{-3} \mathrm{M}$ ascorbic acid in $0.1 \mathrm{M}$ $\mathrm{LiClO}_{4}$ and applying a constant potential of $+0.90 \mathrm{~V}$ during $60 \mathrm{~s}$ is shown in Figure 6.8.1.

The chronoamperogram shown in Figure 6.8.1a is associated with the electrochemical reaction corresponding to the oxidation of ascorbic acid (AA) to dehydro-L-ascorbic acid (DHA) whose carbonyl groups undergo hydration yielding an electroinactive product. ${ }^{344,417}$ As in section $6.7,{ }^{77}$ the overall reaction can be summarized in the following simplified mechanism:
$\mathrm{AA} \rightleftarrows \mathrm{DHA}+2 \mathrm{H}^{+}+2 \mathrm{e}^{-}$
Reaction (6.8.1)
$\mathrm{DHA}+\mathrm{H}_{2} \mathrm{O} \rightarrow \mathrm{C}$
Reaction (6.8.2)

This process involves not only the transfer of two electrons but also two protons, acidifying the solution where the electrochemical reaction takes place, as we have observed by spectroelectrochemistry in section $6.7 .^{77}$

The inset of Figure 6.8.1a shows the 3D plot of the spectra evolution with time obtained during the amperometric experiment. It displays the decrease of the absorbance in the UV region, concomitantly with the electrochemical signal, that is related to the consumption of ascorbic acid, according to the reaction mechanism. Therefore, the oxidation process of ascorbic acid to dehydro-L-ascorbic acid is observed both in the chronoamperogram and, simultaneously, in the UV region, by the decrease of the absorbance. 
The evolution of the absorbance at $252 \mathrm{~nm}$ is represented in Figure 6.8.1b. This wavelength was selected because $252 \mathrm{~nm}$ is an isosbestic point where ascorbate monoanion and ascorbic acid have the same molar absorption coefficient. ${ }^{414,415}$ As can be seen, the decrease of the absorbance at $252 \mathrm{~nm}$ from the beginning of the experiment confirms the oxidation of ascorbic acid to dehydro-L-ascorbic acid and its diffusion from the SWCNTs WE surface to the bulk solution when a potential of $+0.90 \mathrm{~V}$ is applied.
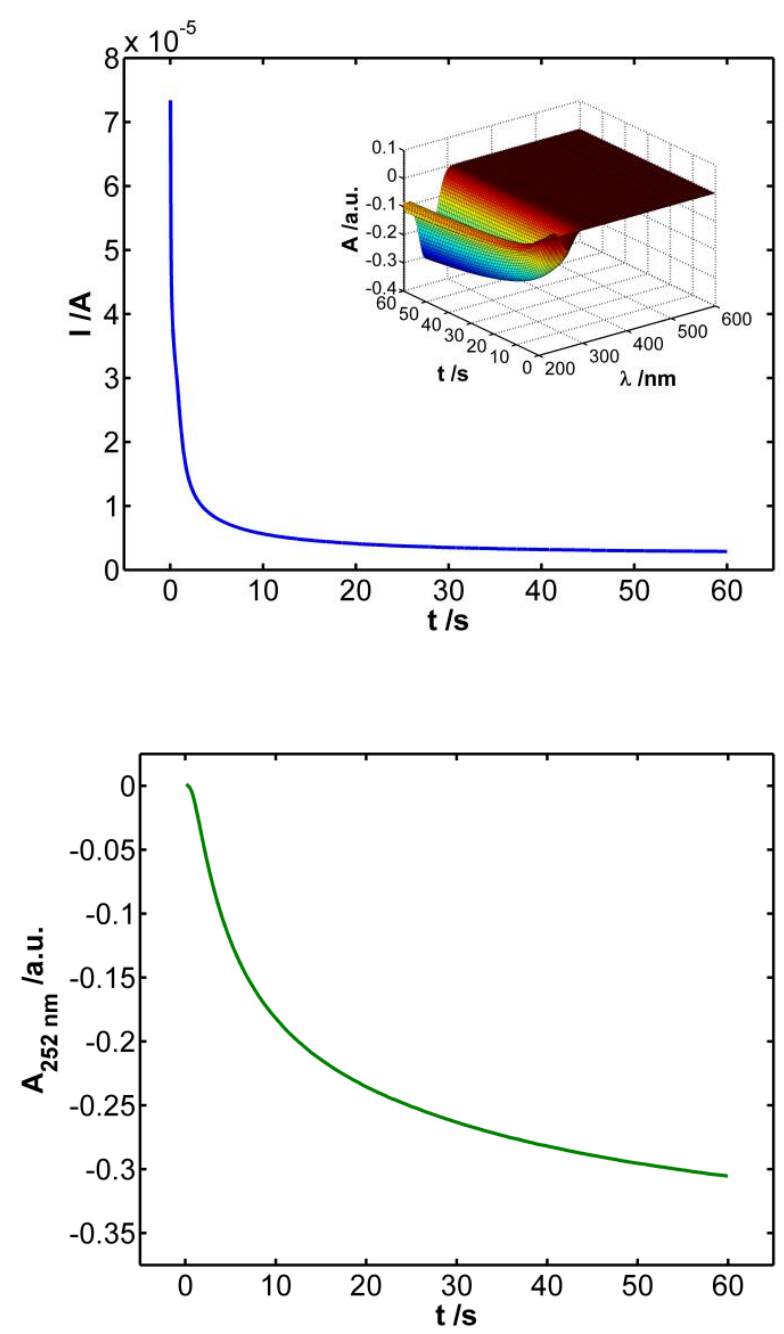

Figure 6.8.1. Spectroelectrochemistry experiment of $1 \times 10^{-3} \mathrm{M}$ ascorbic acid in $0.1 \mathrm{M} \mathrm{LiClO}_{4}$ applying a constant potential of $+0.90 \mathrm{~V}$ during $60 \mathrm{~s}$. (a) Chronoamperogram obtained. Inset: 3D spectra evolution with time recorded during the electrochemical signal. (b) Evolution of the absorbance at $252 \mathrm{~nm}$. 
Once again, the good agreement between electrochemical and spectroscopic signals using this device should be highlighted, making it possible to corroborate the electrochemical behavior of ascorbic acid taking into account the spectral response.

When a set of calibration samples of ascorbic acid, such as the one outlined above, is analyzed, the higher current intensities and the higher absorbance changes at $252 \mathrm{~nm}$ are related to the increase in the ascorbic acid concentration. In view of the electrochemical and optical signals shown in Figure 6.8.1, short times are associated with a better sensitivity for an electrochemical calibration while long times are related to a better sensitivity for a spectroscopic calibration. Then, $25 \mathrm{~s}$ was selected as an optimal time to provide good results, aiming to sample both signals at the same time.

Therefore, two univariate calibration curves in the $1 \times 10^{-4} \mathrm{M}-3.5 \times 10^{-3}$ $\mathrm{M}$ concentration range were obtained using an OLS regression model and taking (i) the current intensity at $25 \mathrm{~s}$ and (ii) the absorbance at $252 \mathrm{~nm}$ at the same time, for the electrochemical and the spectroscopic signals, respectively, versus ascorbic acid concentration. Both electrochemical and spectroscopic univariate calibration curves (panels a and b of Figure 6.8.2, respectively) were tested to evaluate their prediction capability. For this purpose, the prediction of the concentration of a test sample of $1.6 \times 10^{-3}$ $\mathrm{M}$ ascorbic acid in $0.1 \mathrm{M} \mathrm{\textrm {LClO } _ { 4 }}$ was performed under the same experimental conditions described above. The regression parameters of these calibration curves along with the predicted concentrations obtained with both of them for the test sample of ascorbic acid are displayed in Figure 6.8.2 and in the first two rows of Table 6.8.1. As can be observed, good relationships between the two variables and ascorbic acid 
concentration were obtained. In addition, both electrochemical and spectroscopic calibration curves correctly estimate the concentration of the test sample of ascorbic acid, whose value is included in the corresponding confidence intervals for the prediction, being the RSD for the estimations lower than $4 \%$. All these good figures of merit demonstrate the suitability of both electrochemical and spectroscopic univariate calibration curves for the quantitative analysis of ascorbic acid by spectroelectrochemistry.
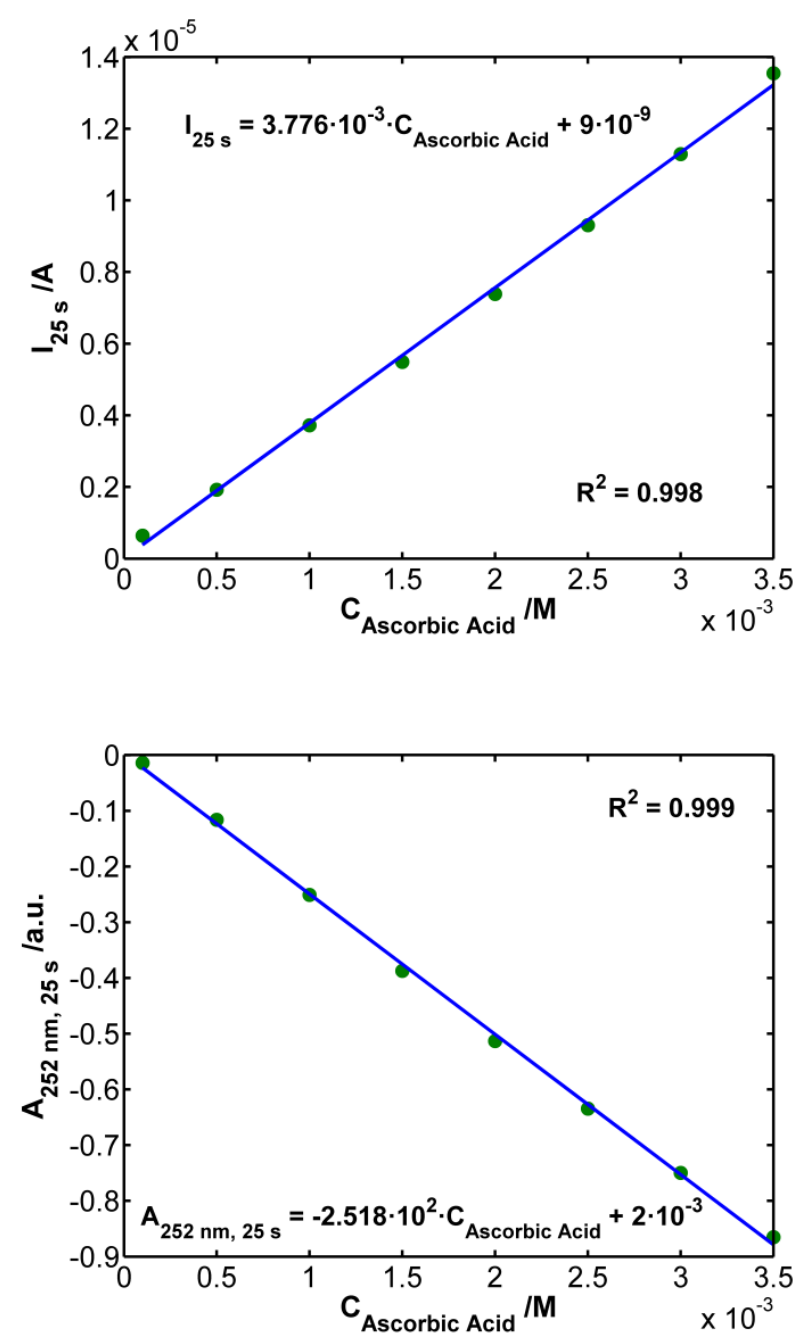

Figure 6.8.2. Univariate calibration curves obtained simultaneously taking into account (a) the current intensity at $25 \mathrm{~s}$ and (b) the absorbance at $252 \mathrm{~nm}$ at the same time, for the electrochemical and the spectroscopic signals, respectively, versus ascorbic acid concentration. 
Detection limits were 250 and $100 \mu \mathrm{M}$ for the electrochemical and spectroscopic calibration curves, respectively. Nevertheless, detection limits of this method are lower, 7 and $4 \mu \mathrm{M}$, respectively. However, as shown below, the ascorbic acid concentration in the grapefruit is relatively high and the calibration curves were constructed accordingly.

After demonstrating that both electrochemical and spectroscopic methods provide valid calibration curves for the determination of ascorbic acid independently of each other, the predicted concentrations with both of them are compared to corroborate that spectroelectrochemistry is an autovalidated analytical method. This autovalidated character is related to the two independent responses obtained simultaneously for each sample, which is very useful for analytical purposes. By plotting the predicted concentrations obtained with the electrochemical calibration curve versus the predicted concentrations calculated with the spectroscopic calibration curve, the regression parameters were $1.00 \pm 0.07$ for the slope and $[0.05 \pm$ $1.5] \times 10^{-4}$ for the intercept $\left(R^{2}=0.995, S_{y x}=9.5 \times 10^{-5}\right)$. Consequently, with the slope being equal to unity and the intercept equal to zero, both electrochemical and spectroscopic signals determine ascorbic acid without distinction, proving that $\mathrm{UV}-\mathrm{V}$ is absorption spectroelectrochemistry is an autovalidated method for quantitative analysis. Thus, the trueness of this analytical method has been demonstrated according to IUPAC suggestions that indicate that results obtained with a method should be validated with a second and independent one.

Finally, the quantification of ascorbic acid in a complex matrix, such as a grapefruit, was performed without any previous pretreatment of the sample. An incision was made in the equatorial region of the fruit and the spectroelectrochemistry device was placed inside. Before all 
measurements, experiments using cyclic voltammetry were performed in the grapefruit, allowing us to conclude that $+0.90 \mathrm{~V}$ is a potential high enough to make sure that the electrochemical oxidation of ascorbic acid takes place in the grapefruit. Figure 6.8.3 displays a photograph of the experimental setup with the spectroelectrochemistry cell placed inside the grapefruit, not only to show this new methodology but also to give an idea about the great novelty, ease, robustness, and the analytical possibilities opened up by this spectroelectrochemistry device in comparison with traditional spectroelectrochemistry experiments.

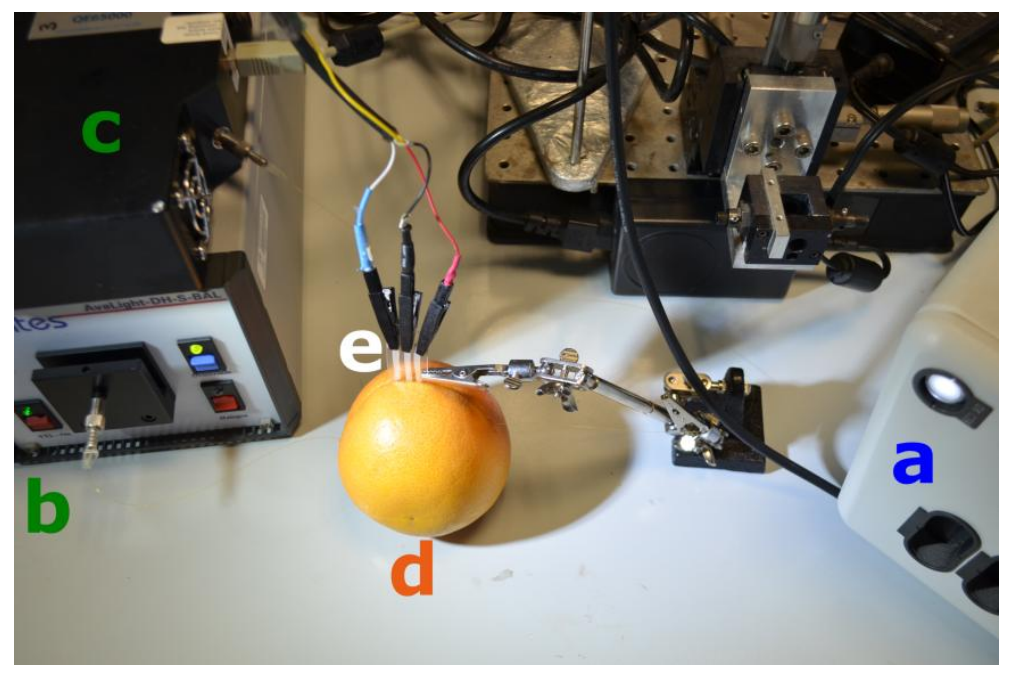

Figure 6.8.3. Device placed inside the grapefruit to perform a spectroelectrochemistry measurement. Setup only requires the (a) potentiostat, (b) light source, (c) spectrometer, (d) grapefruit, and (e) spectroelectrochemistry device.

Figure 6.8.4 shows the spectroelectrochemistry measurements in the grapefruit, under the same experimental potentiostatic conditions as before. In this figure, the oxidation of ascorbic acid is easily observed in both electrochemical and spectroscopic responses, exhibiting a behavior very 
similar to that indicated in Figure 6.8.1. As can be observed in the first two rows of Table 6.8.1, values of $[1.99 \pm 0.14] \times 10^{-3} \mathrm{M}$ and $[2.06 \pm 0.11] \times$ $10^{-3} \mathrm{M}$ are obtained for the concentration of ascorbic acid in the grapefruit, using the electrochemical and spectroscopic univariate calibration curves, respectively. These two values demonstrate the excellent results achieved.
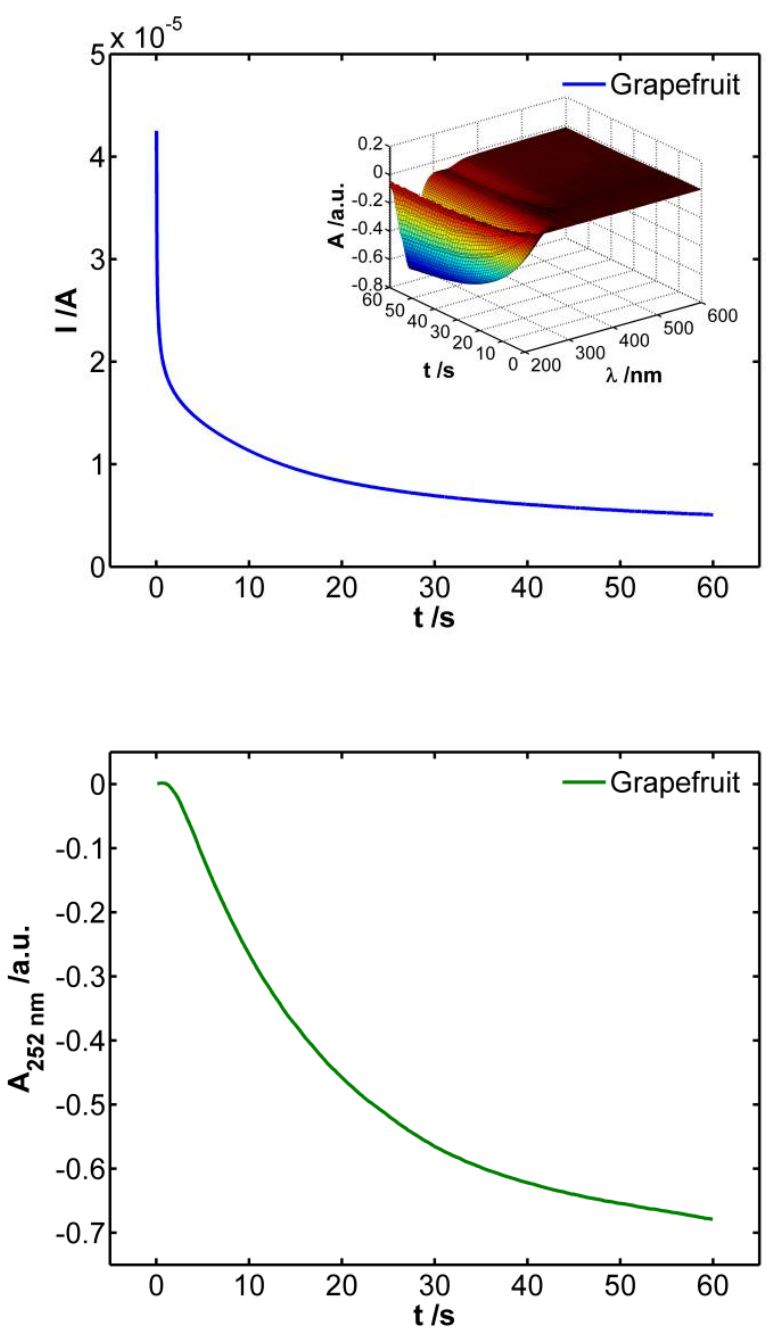

Figure 6.8.4. Spectroelectrochemistry experiment when the device is inserted in the grapefruit applying a constant potential of $+0.90 \mathrm{~V}$ during 60 s. (a) Chronoamperogram obtained. Inset: 3D plot of the spectra evolution with time recorded during the electrochemical signal. (b) Evolution of the absorbance at $252 \mathrm{~nm}$. 
Furthermore, in order to triple check these two values, autovalidated in itself, measurements based on an AOAC official method of titration of ascorbic acid with DCIP $^{429}$ were carried out immediately after performing the spectroelectrochemistry measurement, obtaining a value of $[2.08 \pm$ $0.06] \times 10^{-3} \mathrm{M}$ for the concentration of ascorbic acid in the grapefruit juice. This last result verifies the reliability of the results obtained by UV-Vis absorption spectroelectrochemistry for the determination of the ascorbic acid concentration inside the grapefruit without performing any previous sample pretreatment.

In order to prove the innovation related to the spectroelectrochemistry method, two main advantages should be mentioned: spectroelectrochemistry provides two simultaneous and autovalidated results and (ii) a titration is impossible to be carried out directly in a grapefruit.

Specificity and anti-interference properties are inherent to spectroelectrochemistry experiments due to the impossibility of finding two compounds that exhibit exactly the same electrochemical behavior and identical spectroscopic properties. Excellent results in terms of specificity and anti-interference have been achieved using the spectroelectrochemical sensor to determine the ascorbic acid concentration directly in a grapefruit, as demonstrated by the two values obtained by spectroelectrochemistry and the result obtained with the AOAC method. Being aware of the great variety of compounds present in a fruit sample and its complexity, the spectroelectrochemistry method has proven to be a powerful tool to quantify the amount of an analyte avoiding interferences.

Actually, the 3D plot of the spectra evolution with time recorded during the spectroelectrochemistry experiment in the grapefruit (inset of panel a of 
Figure 6.8.4) shows a slight decrease of the absorbance around $325 \mathrm{~nm}$. This wavelength does not interfere at all with the absorption at $252 \mathrm{~nm}$ taken for the spectroscopic univariate calibration curve of ascorbic acid, but, nevertheless, this situation could have happened.

It should be noted that much more information can be extracted from spectroelectrochemistry experiments because the electrochemical signal is recorded during $60 \mathrm{~s}$ and a full spectrum between 198 and $1006 \mathrm{~nm}$ is registered with high resolution every $110 \mathrm{~ms}$. For these reasons, PLS multivariate regression supplies valuable information, improving the reliability of the univariate determination of ascorbic acid.

Three different PLS regression models were built, selecting one latent variable, to obtain three different multivariate calibration curves. On the one hand, current intensities from 25 to $50 \mathrm{~s}$ (1251 electrochemical times) were selected versus ascorbic acid concentration for the electrochemical calibration. On the other hand, two PLS regression analysis were performed for the spectroscopic calibration selecting (i) absorbances in the spectral range between 200 and $350 \mathrm{~nm}$ at $25 \mathrm{~s}$ (187 wavelengths) and (ii) absorbances at $252 \mathrm{~nm}$ from 25 to $50 \mathrm{~s}$ (228 spectral times), versus ascorbic acid concentration. The regression parameters of these multivariate calibration curves, as well as the predicted concentrations of ascorbic acid in the test sample and in the grapefruit obtained with them, are shown in the last three rows of Table 6.8.1. The autovalidated character of spectroelectrochemistry is also present in these PLS models.

These multivariate models, constructed for quantitative purposes, are more useful than the univariate models to solve complex analytical problems. 
Table 6.8.1. Regression parameters obtained for the determination by spectroelectrochemistry of ascorbic acid in the concentration range of $1 \times 10^{-4}$ $\mathrm{M}-3.5 \times 10^{-3} \mathrm{M}$ and concentration estimated from univariate (OLS) and multivariate (PLS) calibration curves for a test sample of $1.6 \times 10^{-3} \mathrm{M}$ ascorbic acid in $0.1 \mathrm{M} \mathrm{LiClO}_{4}$ and for a grapefruit as real sample.

\begin{tabular}{ccccc}
\multicolumn{2}{c}{ Analysis Method } & $\boldsymbol{R}^{2}$ & $\boldsymbol{S}_{\boldsymbol{y} \boldsymbol{x}}$ & RMSEP \\
\hline OLS & $\boldsymbol{I}_{25 \mathrm{~s}}$ & 0.998 & $2.1 \times 10^{-7}$ & \\
OLS & $\boldsymbol{A}_{252 \mathrm{~nm}, 25 \mathrm{~s}}$ & 0.999 & $1.1 \times 10^{-2}$ & \\
PLS & $\boldsymbol{I}_{25-50 \mathrm{~s}}$ & 0.998 & & $4.7 \times 10^{-5}$ \\
PLS & $\boldsymbol{A}_{200-350 \mathrm{~nm}, 25 \mathrm{~s}}$ & 0.999 & & $3.5 \times 10^{-5}$ \\
PLS & $\boldsymbol{A}_{252 \text { nm, 25-50s }}$ & 0.999 & & $3.6 \times 10^{-5}$ \\
AOAC $^{429}$ & Titration & & & \\
\hline
\end{tabular}

\begin{tabular}{|c|c|c|c|}
\hline \multirow{2}{*}{\multicolumn{2}{|c|}{ Analysis Method }} & \multirow{3}{*}{$\begin{array}{c}\mathbf{C}_{\text {test }}=1.6 \times 10^{-3} \mathbf{M} \\
\text { CI }(\mathbf{M}) \\
{[1.57 \pm 0.14] \times 10^{-3}}\end{array}$} & \multirow{3}{*}{$\begin{array}{c}\text { Grapefruit } \\
\text { CI }(\mathbf{M}) \\
{[1.99 \pm 0.14] \times 10^{-3}}\end{array}$} \\
\hline & & & \\
\hline OLS & $I_{25 \mathrm{~s}}$ & & \\
\hline OLS & $A_{252 \mathrm{~nm}, 25 \mathrm{~s}}$ & {$[1.65 \pm 0.11] \times 10^{-3}$} & {$[2.06 \pm 0.11] \times 10^{-3}$} \\
\hline PLS & $I_{25-50 s}$ & {$[1.61 \pm 0.14] \times 10^{-3}$} & {$[1.92 \pm 0.14] \times 10^{-3}$} \\
\hline PLS & $A_{200-350 n m, 25 s}$ & {$[1.65 \pm 0.11] \times 10^{-3}$} & {$[2.04 \pm 0.11] \times 10^{-3}$} \\
\hline PLS & $A_{252 n m, 25-50 s}$ & {$[1.67 \pm 0.11] \times 10^{-3}$} & {$[2.19 \pm 0.11] \times 10^{-3}$} \\
\hline $\mathbf{A O A C}^{429}$ & Titration & & {$[2.08 \pm 0.06] \times 10^{-3}$} \\
\hline
\end{tabular}

Analysis methods correlate current intensity at $25 \mathrm{~s}\left(I_{25} \mathrm{~s}\right)$, absorbance at $252 \mathrm{~nm}$ and at $25 \mathrm{~s}$ $\left(A_{252 \mathrm{~nm}, 25 \mathrm{~s}}\right)$, current intensity from 25 to $50 \mathrm{~s}\left(I_{25}-50 \mathrm{~s}\right)$, absorbance between 200 and $350 \mathrm{~nm}$ at $25 \mathrm{~s}\left(A_{200}-350 \mathrm{~nm}, 25 \mathrm{~s}\right)$, and absorbance at $252 \mathrm{~nm}$ from 25 to $50 \mathrm{~s}\left(A_{252 \mathrm{~nm}, 25-50 \mathrm{~s}}\right)$ versus ascorbic acid concentration. $R^{2}$, coefficient of determination; $S_{y x}$, residual standard deviation; RMSEP, root mean squared error of prediction; $\mathrm{C}_{\text {test }}$, concentration of the test sample of ascorbic acid; CI, confidence interval. 


\subsubsection{Conclusions and Future Work}

The potentiostatic reaction mechanism of ascorbic acid was studied by UV-Vis absorption spectroelectrochemistry.

To assess the potential of this movable spectroelectrochemistry device, the determination of ascorbic acid in a grapefruit has been performed without any pretreatment of the sample, directly placing the device inside this complex matrix.

Quantification of ascorbic acid has been carried out in solution and inside the grapefruit, using univariate and multivariate analysis with both the electrochemical and the spectral signals, and making use of the autovalidated character of this hybrid technique.

Therefore, our long optical path length device has solved many problems to bring spectroelectrochemistry to real life.

Based on these results, we are working on new projects related to $\mathrm{UV}-\mathrm{Vis}$ absorption spectroelectrochemistry for the near future: (i) the miniaturization of the device and (ii) the study of other analytes in aqueous solution and in real samples such as tissues and biological fluids.

Summarizing, the multiple advantages of this device open new perspectives for spectroelectrochemistry. Excellent and promising results with complex matrices have been achieved using univariate and multivariate statistical tools, enabling researchers from different disciplines to use spectroelectrochemistry in a simpler way. 
This work definitely represents a significant advance in this field and serves as a starting point for future in vitro experiments, paving the way for in vivo spectroelectrochemistry experiments.

Not long ago, all this was unthinkable. Now, all qualitative and quantitative information obtained by spectroelectrochemistry demonstrates that this technique is fundamental to address new challenges. 



\section{Conclusions}



«A veces creo que hay vida en otros planetas, y a veces creo que no. En cualquiera de los dos casos la conclusión es asombrosa».

Carl Sagan 

The main conclusions extracted after each research results section can be summarized as follows:

1. Several methodologies have been developed to transfer films of carbon nanotubes and other carbon nanomaterials prepared by filtration on different supports to be used as OTEs, optimizing both transparency and electrochemical behavior.

2. The use of bare optical fibers for spectroelectrochemistry applications, especially in parallel arrangement, is definitely successful.

3. A new and easy-to-use BSEC cell has been fabricated, allowing us to study the spectroelectrochemistry behavior of $\mathrm{FcMeOH}$, and to assess and check the molar absorption coefficients of electrogenerated species.

4. UV-Vis absorption and Raman dispersion spectroelectrochemistry has been carried out simultaneously for the first time, allowing us to distinguish processes that take place in the solution from processes occurring on the electrode surface with three responses of three different natures.

5. A novel and movable multipurpose device with the three electrodes flat on the support where two bare optical fibers are fixed in a long optical path length configuration has allowed us:

5.1. To quantitatively resolve high complex mixtures of compounds of biological interest using multivariate analysis.

5.2. To monitor the evolution of $\mathrm{pH}$ at the electrode-solution interface during electrochemical reactions.

5.3. To quantify a biomolecule in a fruit, directly placing the device in this complex matrix without any pretreatment of the sample. 



\section{Future Perspectives}





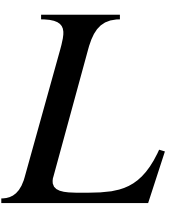

legados a este punto, un mundo ilimitado de posibilidades se abre ante mis ojos. La investigación realizada hasta ahora ha permitido cumplir multitud de metas programadas y conseguir resultados ni siquiera planteados. Estos hechos hacen que surjan nuevas ideas y grandes desafios teniendo como punto de partida lo aprendido hasta la fecha.

El desarrollo de nuevas metodologías para optimizar electrodos basados en diferentes nanomateriales de carbono que sean buenos sensores de compuestos de interés biológico, el estudio de nuevas sustancias de elevada importancia, la resolución cuantitativa de mezclas de tres, cuatro o más analitos simultáneamente y el análisis de diferentes moléculas en matrices biológicas son algunas de las ideas que surgen actualmente para seguir trabajando en el campo de la espectroelectroquímica tras la realización de la presente tesis doctoral. Sin duda alguna, seguir aprendiendo y continuar disfrutando de la ciencia son algunos de los objetivos que se pueden proponer a partir de ahora.

Sin embargo, cuando llevas trabajando mucho tiempo con una técnica para lograr conseguir unos objetivos planteados, y aunque en ocasiones te salgas del camino propuesto para hacer variadas experiencias en función de nuevas ideas y resultados, en muchas ocasiones no dejas de mirar al frente sin ser capaz de parar y ver nuevos caminos que tal vez se presenten a los lados. Tal vez, como buenos revisores de esta tesis, nuevas ideas ronden por vuestra cabeza, nuevas ideas que ayuden a incrementar las posibilidades de una técnica tan bondadosa como es la espectroelectroquímica en los más variados campos. ¿Colaboramos? 
Finaliza el doctorado, termina un periodo muy importante para mi presente y futura biografía. Personalmente, reconozco que es muy positivo observar cómo van sucediendo las diferentes etapas que se le ofrecen a uno en la vida aunque, en muchas ocasiones, ello implique unas sinceras lágrimas cayendo por la mejilla.

Sin duda alguna, el doctorado ha sido una etapa muy especial. Deseo con todas mis fuerzas que esta fantasía hecha realidad pueda, de un modo u otro, continuar. Continuar en la investigación, seguir en la universidad. Que se compagine con otras disciplinas: la música, la escritura, la docencia, el voluntariado, el emprendimiento o la divulgación son algunas que merecen la pena reseñar.

La confianza que me habéis demostrado únicamente por haber llegado a leer hasta esta página me invita a descubrir un pequeño secreto: mi interior, en muchas ocasiones, me estimula a ser profesor, a dedicarme a la interesante profesión de la docencia. Ahora mismo todo es un misterio, meras hipótesis de cuando te sitúas frente a un nuevo reto siendo consciente de que el doctorado me ha preparado muy adecuadamente para el futuro, sea cual sea. Confío en que tanto el soñar como el esfuerzo contribuyan a que todas estas aspiraciones tan atractivas y buenas se hagan realidad. Hay tantas cosas interesantes por hacer en la vida y el tiempo transcurre tan deprisa...

Siento felicidad. Todos los objetivos científicos, profesionales y personales relativos a los estudios de doctorado han sido cumplidos con creces. Como bien auguraba en la reflexión inicial de esta tesis doctoral, ha sido un auténtico placer. Espero que, científicamente, hayáis disfrutado esta tesis tanto como yo y que estas pequeñas reflexiones os hayan ayudado a apreciar lo que yo he sentido durante la misma. Gracias, por triplicado, y actitud protónica hacia el futuro corto, medio y lejano. 


\section{References}





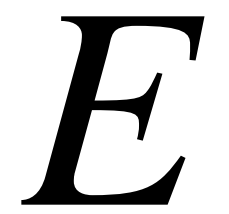
stas páginas constituyen indudablemente un importante apartado de la tesis doctoral. La bibliografía, los estudios llevados a cabo por ciertos investigadores que, de un modo u otro, han sentado las bases para realizar este trabajo. La química, como la vida misma, nunca dejará de sorprendernos, es continua y va in crescendo conforme pasa el tiempo.

Cuando tuvo lugar el comienzo de esta tesis doctoral, los nanotubos de carbono ya habían sido descubiertos De forma análoga, la fibra óptica estaba ya siendo utilizada en diferentes aplicaciones. Por supuesto, la espectroelectroquímica era ya entonces una técnica desarrollada y empleada en ciertas investigaciones. ¿Hacen estas afirmaciones disminuir la importancia de los resultados obtenidos en la presente tesis doctoral? En mi humilde y sincera opinión, todo lo contrario.

La ciencia en general y la química en particular se fortalecen cuando los avances publicados por unos investigadores en un determinado instante de la historia son apoyados por trabajos posteriores. Las diferentes formas de mezclar y unir conceptos previamente desarrollados dan lugar a novedosas ideas y, por ende, a ingeniosos avances, los cuales podrán volver a ser mezclados y unidos con otros, comenzando, de nuevo, un ciclo sin fin. Tal y como se mencionaba en el párrafo anterior, los nanotubos de carbono, al igual que las fibras ópticas y la espectroelectroquímica ya existían al empezar la presente tesis doctoral, gracias a que ciertos investigadores habían dedicado en el pasado parte de su tiempo a cumplir unos objetivos concretos. Es ahora cuando este documento mezcla y une diversos conceptos relacionados con esos trabajos previos para conseguir nuevas metas y dar diversos frutos, frutos que se presume serán objeto de interés por otros investigadores en un futuro a corto, medio o largo plazo.

Más de cuatrocientas referencias, las cuales constituyen una muestra representativa de todas las que podrían haber sido citadas, pueden encontrarse a continuación. Con que esta tesis doctoral o los artículos derivados de la misma reciban este "premio" en trabajos futuros, esta investigación habrá sido científicamente recompensada. 

(1) Kuwana, T.; Darlington, R. K.; Leedy, D. W. Electrochemical Studies Using Conducting Glass Indicator Electrodes. Anal. Chem. 1964, 36 (10), 2023-2025.

(2) Heineman, W. R. Spectroelectrochemistry. Combination of Optical and Electrochemical Techniques for Studies of Redox Chemistry. Anal. Chem. 1978, 50 (3), 390A - 402A.

(3) Keyes, T. E.; Forster, R. J. Spectroelectrochemistry. In Handbook of Electrochemistry; Zoski, C. G., Ed.; Elsevier: Amsterdam, 2007; pp 591-635.

(4) Dunsch, L. Recent Advances in In Situ MultiSpectroelectrochemistry. J. Solid State Electrochem. 2011, 15 (7), 1631-1646.

(5) Heineman, W. R. Spectroelectrochemistry: The Combination of Optical and Electrochemical Techniques. J. Chem. Educ. 1983, 60 (4), 305-308.

(6) Itoh, T.; McCreery, R. L. In Situ Raman Spectroelectrochemistry of Electron Transfer between Glassy Carbon and a Chemisorbed Nitroazobenzene Monolayer. J. Am. Chem. Soc. 2002, 124 (36), 10894-10902.

(7) Kaim, W.; Schwederski, B.; Dogan, A.; Fiedler, J.; Kuehl, C. J.; Stang, P. J. Metalla-Supramolecular Rectangles as Electron Reservoirs for Multielectron Reduction and Oxidation. Inorg. Chem. 2002, 41 (15), 4025-4028.

(8) Takashima, T.; Hashimoto, K.; Nakamura, R. Mechanisms of pHDependent Activity for Water Oxidation to Molecular Oxygen by $\mathrm{MnO}_{2}$ Electrocatalysts. J. Am. Chem. Soc. 2012, 134 (3), 1519-1527.

(9) Pigani, L.; Heras, A.; Colina, Á.; Seeber, R.; López-Palacios, J. Electropolymerisation of 3,4-Ethylenedioxythiophene in Aqueous Solutions. Electrochem. Commun. 2004, 6 (11), 1192-1198.

(10) Baran, D.; Balan, A.; Celebi, S.; Meana Esteban, B.; Neugebauer, H.; Sariciftci, N. S.; Toppare, L. Processable Multipurpose Conjugated Polymer for Electrochromic and Photovoltaic Applications. Chem. Mater. 2010, 22 (9), 2978-2987. 
(11) Kumar, R.; Pillai, R. G.; Pekas, N.; Wu, Y.; McCreery, R. L. Spatially Resolved Raman Spectroelectrochemistry of Solid-State Polythiophene/Viologen Memory Devices. J. Am. Chem. Soc. 2012, 134 (36), 14869-14876.

(12) Richey, F. W.; Dyatkin, B.; Gogotsi, Y.; Elabd, Y. A. Ion Dynamics in Porous Carbon Electrodes in Supercapacitors Using In Situ Infrared Spectroelectrochemistry. J. Am. Chem. Soc. 2013, 135 (34), 12818-12826.

(13) Fernandez-Blanco, C.; Heras, A.; Ruiz, V.; Colina, A. Spectroelectrochemical Synthesis of Gold Nanoparticles Using Cyclic Voltammetry in the Presence of a Protective Agent. RSC Adv. 2014, 4 (85), 45168-45173.

(14) Ibañez, D.; Romero, E. C.; Heras, A.; Colina, A. Dynamic Raman Spectroelectrochemistry of Single Walled Carbon Nanotubes Modified Electrodes Using a Langmuir-Schaefer Method. Electrochim. Acta 2014, 129, 171-176.

(15) Lee, Y. F.; Kirchhoff, J. R. Absorption and Luminescence Spectroelectrochemical Characterization of a Highly Luminescent Rhenium(II) Complex. J. Am. Chem. Soc. 1994, 116 (8), 3599-3600.

(16) Nagatani, H.; Suzuki, S.; Fermín, D. J.; Girault, H. H.; Nakatani, K. Interfacial Behavior of Sulforhodamine 101 at the Polarized Water/1,2-Dichloroethane Interface Studied by Spectroelectrochemical Techniques. Anal. Bioanal. Chem. 2006, 386 (3), 633-638.

(17) Izquierdo, D.; Martinez, A.; Heras, A.; Lopez-Palacios, J.; Ruiz, V.; Dryfe, R. A. W.; Colina, A. Spatial Scanning Spectroelectrochemistry. Study of the Electrodeposition of Pd Nanoparticles at the Liquid/Liquid Interface. Anal. Chem. 2012, 84 (13), 5723-5730.

(18) Dahlman, C. J.; Tan, Y.; Marcus, M. A.; Milliron, D. J. Spectroelectrochemical Signatures of Capacitive Charging and Ion Insertion in Doped Anatase Titania Nanocrystals. J. Am. Chem. Soc. 2015, 137 (28), 9160-9166. 
(19) González-Diéguez, N.; Colina, A.; López-Palacios, J.; Heras, A. Spectroelectrochemistry at Screen-Printed Electrodes: Determination of Dopamine. Anal. Chem. 2012, 84 (21), 9146-9153.

(20) Syed, S. N.; Schulze, H.; Macdonald, D.; Crain, J.; Mount, A. R.; Bachmann, T. T. Cyclic Denaturation and Renaturation of DoubleStranded DNA by Redox-State Switching of DNA Intercalators. J. Am. Chem. Soc. 2013, 135 (14), 5399-5407.

(21) Reybier, K.; Nguyen, T. H. Y.; Ibrahim, H.; Perio, P.; Montrose, A.; Fabre, P.-L.; Nepveu, F. Electrochemical Behavior of Indolone-NOxides: Relationship to Structure and Antiplasmodial Activity. Bioelectrochemistry 2012, 88, 57-64.

(22) Shi, Y.; Slaterbeck, A. F.; Seliskar, C. J.; Heineman, W. R. Spectroelectrochemical Sensing Based on Multimode Selectivity Simultaneously Achievable in a Single Device. 1. Demonstration of Concept with Ferricyanide. Anal. Chem. 1997, 69 (18), 3679-3686.

(23) Pinyayev, T. S.; Seliskar, C. J.; Heineman, W. R. Fluorescence Spectroelectrochemical Sensor for 1-Hydroxypyrene. Anal. Chem. 2010, 82 (23), 9743-9748.

(24) Asadpour-Zeynali, K.; Maryam Sajjadi, S.; Taherzadeh, F. Second Order Advantage Obtained by Spectroelectrochemistry along with Novel Carbon Nanotube Modified Mesh Electrode: Application for Determination of Acetaminophen in Novafen Samples. Spectrochim. Acta Part A Mol. Biomol. Spectrosc. 2016, 153, 674-680.

(25) Hansen, W. N.; Osteryoung, R. A.; Kuwana, T. Internal Reflection Spectroscopic Observation of Electrode-Solution Interface. J. Am. Chem. Soc. 1966, 88 (5), 1062-1063.

(26) Chen, W.; Liu, X.-Y.; Qian, C.; Song, X.-N.; Li, W.-W.; Yu, H.-Q. An UV-vis Spectroelectrochemical Approach for Rapid Detection of Phenazines and Exploration of Their Redox Characteristics. Biosens. Bioelectron. 2015, 64, 25-29.

(27) Shtoyko, T.; Stuart, O. D.; Gray, H. N. Spectroelectrochemical Sensing of Aqueous Iron: An Experiment for Analytical Chemistry. $J$. Chem. Educ. 2007, 84 (9), 1467-1470. 
(28) Shtoyko, T.; Maghasi, A. T.; Richardson, J. N.; Seliskar, C. J.; Heineman, W. R. Spectroelectrochemical Sensing Based on Attenuated Total Internal Reflectance Stripping Voltammetry. 1. Determination of Lead and Cadmium. Anal. Chem. 2003, 75 (17), 4585-4590.

(29) Imai, K.; Okazaki, T.; Hata, N.; Taguchi, S.; Sugawara, K.; Kuramitz, H. Simultaneous Multiselective Spectroelectrochemical Fiber-Optic Sensor: Demonstration of the Concept Using Methylene Blue and Ferrocyanide. Anal. Chem. 2015, 87 (4), 2375-2382.

(30) Garoz-Ruiz, J.; Guillen-Posteguillo, C.; Colina, A.; Heras, A. Quantitative Resolution of Complex Mixtures by Spectroelectrochemistry: The Case of Catechol and Dopamine. Anal. Chem. (Manuscript In Preparation).

(31) Garoz-Ruiz, J.; Heras, A.; Colina, A. Direct Determination of Ascorbic Acid in a Grapefruit: Paving the Way for In Vivo Spectroelectrochemistry. Anal. Chem. 2017, 89 (3), 1815-1822.

(32) Kumar, A.; Zhou, C. The Race To Replace Tin-Doped Indium Oxide: Which Material Will Win? ACS Nano 2010, 4 (1), 11-14.

(33) Dai, Y.; Swain, G. M.; Porter, M. D.; Zak, J. New Horizons in Spectroelectrochemical Measurements: Optically Transparent Carbon Electrodes. Anal. Chem. 2008, 80 (1), 14-22.

(34) Biswas, C.; Lee, Y. H. Graphene Versus Carbon Nanotubes in Electronic Devices. Adv. Funct. Mater. 2011, 21 (20), 3806-3826.

(35) Zhu, J.; Holmen, A.; Chen, D. Carbon Nanomaterials in Catalysis: Proton Affinity, Chemical and Electronic Properties, and Their Catalytic Consequences. ChemCatChem 2013, 5 (2), 378-401.

(36) Alishahi, E.; Shadlou, S.; Doagou-R, S.; Ayatollahi, M. R. Effects of Carbon Nanoreinforcements of Different Shapes on the Mechanical Properties of Epoxy-Based Nanocomposites. Macromol. Mater. Eng. 2013, 298 (6), 670-678.

(37) Trogadas, P.; Fuller, T. F.; Strasser, P. Carbon as Catalyst and Support for Electrochemical Energy Conversion. Carbon 2014, 75, $5-42$. 
(38) Dai, L.; Chang, D. W.; Baek, J.-B.; Lu, W. Carbon Nanomaterials for Advanced Energy Conversion and Storage. Small 2012, 8 (8), 11301166.

(39) Ellmer, K. Past Achievements and Future Challenges in the Development of Optically Transparent Electrodes. Nat. Photonics 2012, 6 (12), 809-817.

(40) Layani, M.; Kamyshny, A.; Magdassi, S. Transparent Conductors Composed of Nanomaterials. Nanoscale 2014, 6 (11), 5581-5591.

(41) Hecht, D. S.; Hu, L.; Irvin, G. Emerging Transparent Electrodes Based on Thin Films of Carbon Nanotubes, Graphene, and Metallic Nanostructures. Adv. Mater. 2011, 23 (13), 1482-1513.

(42) Kim, K.; Shin, K.; Han, J.-H.; Lee, K.-R.; Kim, W.-H.; Park, K.-B.; Ju, B.-K.; Pak, J. Deformable Single Wall Carbon Nanotube Electrode for Transparent Tactile Touch Screen. Electron. Lett. 2011, 47 (2), 118-120.

(43) Kavan, L.; Yum, J. H.; Grätzel, M. Optically Transparent Cathode for Dye-Sensitized Solar Cells Based on Graphene Nanoplatelets. ACS Nano 2011, 5 (1), 165-172.

(44) Pérez-López, B.; Merkoçi, A. Carbon Nanotubes and Graphene in Analytical Sciences. Microchim. Acta 2012, 179 (1), 1-16.

(45) McCreery, R. L. Advanced Carbon Electrode Materials for Molecular Electrochemistry. Chem. Rev. 2008, 108 (7), 2646-2687.

(46) Walcarius, A.; Minteer, S. D.; Wang, J.; Lin, Y.; Merkoçi, A. Nanomaterials for Bio-Functionalized Electrodes: Recent Trends. $J$. Mater. Chem. B 2013, 1 (38), 4878-4908.

(47) Scida, K.; Stege, P. W.; Haby, G.; Messina, G. A.; García, C. D. Recent Applications of Carbon-Based Nanomaterials in Analytical Chemistry: Critical Review. Anal. Chim. Acta 2011, 691 (1-2), 6-17.

(48) Hu, L.; Gruner, G.; Li, D.; Kaner, R. B.; Cech, J. Patternable Transparent Carbon Nanotube Films for Electrochromic Devices. J. Appl. Phys. 2007, 101 (1), 016102. 
(49) Malavé Osuna, R.; Hernández, V.; López Navarrete, J. T.; Kauppinen, E. I.; Ruiz, V. Ultrafast and High-Contrast Electrochromism on Bendable Transparent Carbon Nanotube Electrodes. J. Phys. Chem. Lett. 2010, 1 (9), 1367-1371.

(50) Yáñez-Sedeño, P.; Pingarrón, J. M.; Riu, J.; Rius, F. X. Electrochemical Sensing Based on Carbon Nanotubes. TrAC Trends Anal. Chem. 2010, 29 (9), 939-953.

(51) Trojanowicz, M. Analytical Applications of Carbon Nanotubes: A Review. TrAC Trends Anal. Chem. 2006, 25 (5), 480-489.

(52) Choi, D.; Choi, M.-Y.; Shin, H.-J.; Yoon, S.-M.; Seo, J.-S.; Choi, J.Y.; Lee, S. Y.; Kim, J. M.; Kim, S.-W. Nanoscale Networked SingleWalled Carbon-Nanotube Electrodes for Transparent Flexible Nanogenerators. J. Phys. Chem. C 2010, 114 (2), 1379-1384.

(53) Heras, A.; Colina, A.; López-Palacios, J.; Kaskela, A.; Nasibulin, A. G.; Ruiz, V.; Kauppinen, E. I. Flexible Optically Transparent SingleWalled Carbon Nanotube Electrodes for UV-Vis Absorption Spectroelectrochemistry. Electrochem. Commun. 2009, 11 (2), 442445.

(54) Heras, A.; Colina, A.; López-Palacios, J.; Ayala, P.; Sainio, J.; Ruiz, V.; Kauppinen, E. I. Electrochemical Purification of Carbon Nanotube Electrodes. Electrochem. Commun. 2009, 11 (7), 15351538.

(55) Gruner, G. Carbon Nanotube Films for Transparent and Plastic Electronics. J. Mater. Chem. 2006, 16 (35), 3533-3539.

(56) Hu, L.; Hecht, D. S.; Grüner, G. Carbon Nanotube Thin Films: Fabrication, Properties, and Applications. Chem. Rev. 2010, 110 (10), 5790-5844.

(57) Ge, J.; Cheng, G.; Chen, L. Transparent and Flexible Electrodes and Supercapacitors Using Polyaniline/Single-Walled Carbon Nanotube Composite Thin Films. Nanoscale 2011, 3 (8), 3084-3088.

(58) Zhang, J.; Gao, L.; Sun, J.; Liu, Y.; Wang, Y.; Wang, J.; Kajiura, H.; Li, Y.; Noda, K. Dispersion of Single-Walled Carbon Nanotubes by Nafion in Water/Ethanol for Preparing Transparent Conducting Films. J. Phys. Chem. C 2008, 112 (42), 16370-16376. 
(59) Chandra, B.; Afzali, A.; Khare, N.; El-Ashry, M. M.; Tulevski, G. S. Stable Charge-Transfer Doping of Transparent Single-Walled Carbon Nanotube Films. Chem. Mater. 2010, 22 (18), 5179-5183.

(60) Wu, Z.; Chen, Z.; Du, X.; Logan, J. M.; Sippel, J.; Nikolou, M.; Kamaras, K.; Reynolds, J. R.; Tanner, D. B.; Hebard, A. F.; Rinzler, A. G. Transparent, Conductive Carbon Nanotube Films. Science 2004, 305 (5688), 1273-1276.

(61) King, P. J.; Higgins, T. M.; De, S.; Nicoloso, N.; Coleman, J. N. Percolation Effects in Supercapacitors with Thin, Transparent Carbon Nanotube Electrodes. ACS Nano 2012, 6 (2), 1732-1741.

(62) Yim, J. H.; Kim, Y. S.; Koh, K. H.; Lee, S. Fabrication of Transparent Single Wall Carbon Nanotube Films with Low Sheet Resistance. J. Vac. Sci. Technol. B 2008, 26 (2), 851-855.

(63) Rutkowska, A.; Bawazeer, T. M.; Macpherson, J. V.; Unwin, P. R. Visualisation of Electrochemical Processes at Optically Transparent Carbon Nanotube Ultramicroelectrodes (OT-CNT-UMEs). Phys. Chem. Chem. Phys. 2011, 13 (12), 5223-5226.

(64) Valcárcel, M.; Cárdenas, S.; Simonet, B. M. Role of Carbon Nanotubes in Analytical Science. Anal. Chem. 2007, 79 (13), 47884797.

(65) Agüí, L.; Yáñez-Sedeño, P.; Pingarrón, J. M. Role of Carbon Nanotubes in Electroanalytical Chemistry: A Review. Anal. Chim. Acta 2008, 622 (1-2), 11-47.

(66) Luo, H.; Shi, Z.; Li, N.; Gu, Z.; Zhuang, Q. Investigation of the Electrochemical and Electrocatalytic Behavior of Single-Wall Carbon Nanotube Film on a Glassy Carbon Electrode. Anal. Chem. 2001, 73 (5), 915-920.

(67) Zhang, M.; Liu, K.; Xiang, L.; Lin, Y.; Su, L.; Mao, L. Carbon Nanotube-Modified Carbon Fiber Microelectrodes for In Vivo Voltammetric Measurement of Ascorbic Acid in Rat Brain. Anal. Chem. 2007, 79 (17), 6559-6565.

(68) Fu, L.; Yu, A. M. Carbon Nanotubes Based Thin Films: Fabrication, Characterization and Applications. Rev. Adv. Mater. Sci. 2014, 36 (1), 40-61. 
(69) Cao, Q.; Rogers, J. A. Ultrathin Films of Single-Walled Carbon Nanotubes for Electronics and Sensors: A Review of Fundamental and Applied Aspects. Adv. Mater. 2009, 21 (1), 29-53.

(70) Zhang, D.; Ryu, K.; Liu, X.; Polikarpov, E.; Ly, J.; Tompson, M. E.; Zhou, C. Transparent, Conductive, and Flexible Carbon Nanotube Films and Their Application in Organic Light-Emitting Diodes. Nano Lett. 2006, 6 (9), 1880-1886.

(71) Feng, C.; Liu, K.; Wu, J.-S.; Liu, L.; Cheng, J.-S.; Zhang, Y.; Sun, Y.; Li, Q.; Fan, S.; Jiang, K. Flexible, Stretchable, Transparent Conducting Films Made from Superaligned Carbon Nanotubes. Adv. Funct. Mater. 2010, 20 (6), 885-891.

(72) Wang, T.; Zhao, D.; Alvarez, N.; Shanov, V. N.; Heineman, W. R. Optically Transparent Carbon Nanotube Film Electrode for Thin Layer Spectroelectrochemistry. Anal. Chem. 2015, 87 (19), 96879695.

(73) Garoz-Ruiz, J.; Palmero, S.; Ibañez, D.; Heras, A.; Colina, A. PressTransfer Optically Transparent Electrodes Fabricated from Commercial Single-Walled Carbon Nanotubes. Electrochem. Commun. 2012, 25, 1-4.

(74) Garoz-Ruiz, J.; Ibañez, D.; Romero, E. C.; Ruiz, V.; Heras, A.; Colina, A. Optically Transparent Electrodes for Spectroelectrochemistry Fabricated with Graphene Nanoplatelets and Single-Walled Carbon Nanotubes. RSC Adv. 2016, 6 (37), 3143131439 .

(75) Garoz-Ruiz, J.; Heras, A.; Palmero, S.; Colina, A. Development of a Novel Bidimensional Spectroelectrochemistry Cell Using Transfer Single-Walled Carbon Nanotubes Films as Optically Transparent Electrodes. Anal. Chem. 2015, 87 (12), 6233-6239.

(76) Ibañez, D.; Garoz-Ruiz, J.; Heras, A.; Colina, A. Simultaneous UVVisible Absorption and Raman Spectroelectrochemistry. Anal. Chem. 2016, 88 (16), 8210-8217.

(77) Garoz-Ruiz, J.; Heras, A.; Colina, A. Following the Evolution of pH at the Electrode-Solution Interface by Spectroelectrochemistry. (Manuscript In Preparation). 
(78) López-Palacios, J.; Colina, A.; Heras, A.; Ruiz, V.; Fuente, L. Bidimensional Spectroelectrochemistry. Anal. Chem. 2001, 73 (13), 2883-2889.

(79) Colina, A.; López-Palacios, J.; Heras, A.; Ruiz, V.; Fuente, L. Digital Simulation Model for Bidimensional Spectroelectrochemistry. $J$. Electroanal. Chem. 2003, 553, 87-95.

(80) Ruiz, V.; Colina, Á.; Heras, A.; López-Palacios, J.; Seeber, R. Bidimensional Spectroelectrochemistry Applied to the Electrosynthesis and Characterization of Conducting Polymers: Study of Poly[4,4'-Bis(butylthio)-2,2'-Bithiophene]. Helv. Chim. Acta 2001, 84 (12), 3628-3642.

(81) Ruiz, V.; Colina, Á.; Heras, A.; López-Palacios, J. Study of Electrochemical Stability of Conducting Polymers by Bidimensional Spectroelectrochemistry: P- and N-Doping of Poly $\left(4,4^{\prime}-\right.$ Bis(butylthio)-2,2'-Bithiophene) Films. Polym. Degrad. Stab. 2006, 91 (12), 3117-3123.

(82) Ruiz, V.; Colina, Á.; Heras, A.; López-Palacios, J.; Seeber, R. Bidimensional Chronoabsorptometric Study of Electropolymerisation of 4,4'-bis(2-Methylbutylthio)-2,2'-Bithiophene. Electrochem.

Commun. 2002, 4 (5), 451-456.

(83) Ruiz, V.; Colina, Á.; Heras, A.; López-Palacios, J.

Electropolymerization under Potentiodynamic and Potentiostatic Conditions: Spectroelectrochemical Study on Electrosynthesis of Poly[4,4'-bis(2-Methylbutylthio)-2,2'-Bithiophene]. Electrochim. Acta 2004, 50 (1), 59-67.

(84) López-Palacios, J.; Muñoz, E.; Heras, M. A.; Colina, Á.; Ruiz, V. Study of Polyaniline Films Degradation by Thin-Layer Bidimensional Spectroelectrochemistry. Electrochim. Acta 2006, 52 (1), 234-239.

(85) Orcajo, O.; Ventosa, E.; Martínez, A.; Colina, Á.; Heras, A.; Ruiz, V.; López-Palacios, J. A New Reflection-Transmission Bidimensional Spectroelectrochemistry Cell: Electrically Controlled Release of Chemicals from a Conducting Polymer. J. Electroanal. Chem. 2006, 596 (2), 95-100. 
(86) Ventosa, E.; Colina, A.; Heras, A.; Martínez, A.; Orcajo, O.; Ruiz, V.; López-Palacios, J. Electrochemical, Spectroscopic and Electrogravimetric Detection of Oligomers Occluded in Electrochemically Synthesized Poly(3,4-Ethylenedioxythiophene) Films. Electrochim. Acta 2008, 53 (12), 4219-4227.

(87) López-Palacios, J.; Heras, A.; Colina, Á.; Ruiz, V. Bidimensional Spectroelectrochemical Study on Electrogeneration of Soluble Prussian Blue from Hexacyanoferrate(II) Solutions. Electrochim. Acta 2004, 49 (7), 1027-1033.

(88) Spectroelectrochemistry Cells from DropSens - Web Page: http://www.dropsens.com/en/spectroelectrochemical_instruments.htm 1 .

(89) Spectroelectrochemistry Cell from Pine Research Instrumentation Web Page: http://www.pineinst.com/echem/viewproduct.asp?ID=47955.

(90) Spectroelectrochemistry Cell from Gamry Instruments - Web Page: http://www.gamry.com/products/spectroelectrochemical-cellkits/spectroelectrochemical-uv-cis-cuvette-cell-kit/.

(91) Spectroelectrochemistry Cell from ALS - Web Page: http://www.alsjapan.com/1353.html.

(92) Spectroelectrochemistry Cell from LabOmak - Web Page: http://www.labomak.it/uf-sec-thin-layer-cell-full-kit/.

(93) Spectroelectrochemistry Instrument Model SPELEC - Specifications: http://www.dropsens.com/en/pdfs_productos/new_brochures/spelec_s pelec1050.pdf.

(94) Integrated Spectroelectrochemistry System from Pine Research Instrumentation - Web Page: http://www.pineinst.com/echem/viewproduct.asp?ID=49242.

(95) Spectroelectrochemistry System from Gamry Instruments - Web Page: http://www.gamry.com/products/spectroelectrochemistry/uvvis-spectroelectrochemistry/. 
(96) Heras, A.; Colina, A.; Ruiz, V.; López-Palacios, J. UV-Visible Spectroelectrochemical Detection of Side-Reactions in the Hexacyanoferrate(III)/(II) Electrode Process. Electroanalysis 2003, 15 (8), 702-708.

(97) Kaim, W.; Fiedler, J. Spectroelectrochemistry: The Best of Two Worlds. Chem. Soc. Rev. 2009, 38 (12), 3373-3382.

(98) Schroll, C. A.; Chatterjee, S.; Heineman, W. R.; Bryan, S. A. ThinLayer Spectroelectrochemistry on an Aqueous Microdrop. Electroanalysis 2012, 24 (5), 1065-1070.

(99) Flowers, P. A.; Blake, D. A. Submicroliter Electrochemistry and Spectroelectrochemistry Using Standard Electrodes and a Polymer Electrolyte Salt Bridge. Anal. Chem. 2013, 85 (6), 3059-3063.

(100) Daniel, D.; Gutz, I. G. R. Long-Optical-Path Thin-Layer Spectroelectrochemical Flow Cell with Inexpensive Gold Electrodes. Electroanalysis 2001, 13 (8-9), 681-685.

(101) Alévêque, O.; Levillain, E.; Sanguinet, L. Spectroelectrochemistry on Electroactive Self-Assembled Monolayers: Cyclic Voltammetry Coupled to Spectrophotometry. Electrochem. Commun. 2015, 51, 108-112.

(102) Moss, D.; Nabedryk, E.; Breton, J.; Mäntele, W. Redox-Linked Conformational Changes in Proteins Detected by a Combination of Infrared Spectroscopy and Protein Electrochemistry. Evaluation of the Technique with Cytochrome c. Eur. J. Biochem. 1990, 187 (3), 565-572.

(103) He, J.-B.; Wang, Y.; Deng, N.; Lin, X.-Q. Study of the Adsorption and Oxidation of Antioxidant Rutin by Cyclic VoltammetryVoltabsorptometry. Bioelectrochemistry 2007, 71 (2), 157-163.

(104) Nakamura, A.; Suzawa, T.; Kato, Y.; Watanabe, T. Species Dependence of the Redox Potential of the Primary Electron Donor P700 in Photosystem I of Oxygenic Photosynthetic Organisms Revealed by Spectroelectrochemistry. Plant Cell Physiol. 2011, 52 (5), 815-823. 
(105) D'Antonio, E. L.; Bowden, E. F.; Franzen, S. Thin-Layer Spectroelectrochemistry of the $\mathrm{Fe}(\mathrm{III}) / \mathrm{Fe}(\mathrm{II})$ Redox Reaction of Dehaloperoxidase-Hemoglobin. J. Electroanal. Chem. 2012, 668, 3743.

(106) Sokolová, R.; Nycz, J. E.; Ramešová, Š.; Fiedler, J.; Degano, I.; Szala, M.; Kolivoška, V.; Gál, M. Electrochemistry and Spectroelectrochemistry of Bioactive Hydroxyquinolines: A Mechanistic Study. J. Phys. Chem. B 2015, 119 (20), 6074-6080.

(107) Vangeneugden, D. L.; Vanderzande, D. J. M.; Salbeck, J.; van Hal, P. A.; Janssen, R. A. J.; Hummelen, J. C.; Brabec, C. J.; Shaheen, S. E.; Sariciftci, N. S. Synthesis and Characterization of a Poly(1,3Dithienylisothianaphthene) Derivative for Bulk Heterojunction Photovoltaic Cells. J. Phys. Chem. B 2001, 105 (45), 11106-11113.

(108) Yeh, S. J.; Tsai, C. Y.; Huang, C.-Y.; Liou, G.-S.; Cheng, S.-H. Electrochemical Characterization of Small Organic Hole-Transport Molecules Based on the Triphenylamine Unit. Electrochem. Commun. 2003, 5 (5), 373-377.

(109) Wang, Y.-H.; He, J.-B. Corrosion Inhibition of Copper by Sodium Phytate in $\mathrm{NaOH}$ Solution: Cyclic Voltabsorptometry for In Situ Monitoring of Soluble Corrosion Products. Electrochim. Acta 2012, $66,45-51$.

(110) Kadish, K. M.; Chen, P.; Enakieva, Y. Y.; Nefedov, S. E.; Gorbunova, Y. G.; Tsivadze, A. Y.; Bessmertnykh-Lemeune, A.; Stern, C.; Guilard, R. Electrochemical and Spectroscopic Studies of Poly(diethoxyphosphoryl)porphyrins. J. Electroanal. Chem. 2011, 656 (1-2), 61-71.

(111) Schweinfurth, D.; Büttner, N.; Hohloch, S.; Deibel, N.; Klein, J.; Sarkar, B. Heterobimetallic Cu-dppf (dppf $=1,1^{\prime}-$ Bis(diphenylphosphino)ferrocene) Complexes with "Click" Derived Ligands: A Combined Structural, Electrochemical, Spectroelectrochemical, and Theoretical Study. Organometallics 2013, 32 (20), 5834-5842.

(112) Pfaff, U.; Hildebrandt, A.; Schaarschmidt, D.; Rüffer, T.; Low, P. J.; Lang, H. Molecular Wires Using (Oligo)pyrroles as Connecting Units: An Electron Transfer Study. Organometallics 2013, 32 (20), 6106-6117. 
(113) Mandal, A.; Kundu, T.; Ehret, F.; Bubrin, M.; Mobin, S. M.; Kaim, W.; Lahiri, G. K. Varying Electronic Structural Forms of Ruthenium Complexes of Non-Innocent 9,10-Phenanthrenequinonoid Ligands. Dalt. Trans. 2014, 43 (6), 2473-2487.

(114) Paretzki, A.; Bubrin, M.; Fiedler, J.; Záliš, S.; Kaim, W. Correlated Coordination and Redox Activity of a Hemilabile Noninnocent Ligand in Nickel Complexes. Chem. - A Eur. J. 2014, 20 (18), 54145422.

(115) Tory, J.; King, L.; Maroulis, A.; Haukka, M.; Calhorda, M. J.; Hartl, F. Solvent-Dependent Formation of Os(0) Complexes by Electrochemical Reduction of $\left[\mathrm{Os}(\mathrm{CO})\left(2,2^{\prime}\right.\right.$-bipyridine $\left.)(\mathrm{L}) \mathrm{Cl} 2\right]$; $\mathrm{L}=$ $\mathrm{Cl}-$, PrCN. Inorg. Chem. 2014, 53 (3), 1382-1396.

(116) Guillén Posteguillo, C. Master Thesis.

(117) Garoz-Ruiz, J.; Guillen-Posteguillo, C.; Heras, A.; Colina, A. Simplifying the Assessment of Parameters of Electron-Transfer Reactions by Using an Easy-to-Use Thin-Layer Spectroelectrochemistry Device. Electrochem. Commun. (Manuscript In Preparation).

(118) Kuwana, T.; Strojek, J. W. Kinetic and Mechanism Studies of OTolidine Electro-Oxidation Using Optically Transparent Electrodes. Discuss. Faraday Soc. 1968, 45 (0), 134-144.

(119) Bancroft, E. E.; Sidwell, J. S.; Blount, H. N. Derivative Linear Sweep and Derivative Cyclic Voltabsorptometry. Anal. Chem. 1981, 53 (9), 1390-1394.

(120) Carbon. Periodic Table of the Royal Society of Chemistry: http://www.rsc.org/periodic-table/element/6/carbon.

(121) Wiles, P. G.; Abrahamson, J. Carbon Fibre Layers on Arc electrodes-I: Their Properties and Cool-Down Behaviour. Carbon 1978, 16 (5), 341-349.

(122) Banks, C. E.; Compton, R. G. New Electrodes for Old: From Carbon Nanotubes to Edge Plane Pyrolytic Graphite. Analyst 2006, 131 (1), $15-21$. 
(123) Iijima, S. Helical Microtubules of Graphitic Carbon. Nature 1991, 354 (6348), 56-58.

(124) Bethune, D. S.; Klang, C. H.; de Vries, M. S.; Gorman, G.; Savoy, R.; Vazquez, J.; Beyers, R. Cobalt-Catalysed Growth of Carbon Nanotubes with Single-Atomic-Layer Walls. Nature 1993, 363 (6430), 605-607.

(125) Zhou, W.; Bai, X.; Wang, E.; Xie, S. Synthesis, Structure, and Properties of Single-Walled Carbon Nanotubes. Adv. Mater. 2009, 21 (45), 4565-4583.

(126) Iijima, S.; Ichihashi, T. Single-Shell Carbon Nanotubes of 1-nm Diameter. Nature 1993, 363 (6430), 603-605.

(127) Iijima, S.; Ichihashi, T. Single-Shell Carbon Nanotubes of 1-nm Diameter (Erratum). Nature 1993, 364 (6439), 737-737.

(128) Dumitrescu, I.; Unwin, P. R.; Macpherson, J. V. Electrochemistry at Carbon Nanotubes: Perspective and Issues. Chem. Commun. 2009, No. 45, 6886-6901.

(129) Dresselhaus, M. S.; Dresselhaus, G.; Jorio, A. Unusual Properties and Structure of Carbon Nanotubes. Annu. Rev. Mater. Res. 2004, 34 , 247-278.

(130) Dresselhaus, M. S.; Jorio, A.; Hofmann, M.; Dresselhaus, G.; Saito, R. Perspectives on Carbon Nanotubes and Graphene Raman Spectroscopy. Nano Lett. 2010, 10 (3), 751-758.

(131) Unwin, P. R.; Güell, A. G.; Zhang, G. Nanoscale Electrochemistry of $\mathrm{sp}^{2}$ Carbon Materials: From Graphite and Graphene to Carbon Nanotubes. Acc. Chem. Res. 2016, 49 (9), 2041-2048.

(132) E, S. P.; Miller, T. S.; Macpherson, J. V.; Unwin, P. R. Controlled Functionalisation of Single-Walled Carbon Nanotube Network Electrodes for the Enhanced Voltammetric Detection of Dopamine. Phys. Chem. Chem. Phys. 2015, 17 (39), 26394-26402.

(133) Yang, N.; Chen, X.; Ren, T.; Zhang, P.; Yang, D. Carbon Nanotube Based Biosensors. Sensors Actuators B Chem. 2015, 207, Part A, 690-715. 
(134) Merkoçi, A.; Pumera, M.; Llopis, X.; Pérez, B.; del Valle, M.; Alegret, S. New Materials for Electrochemical Sensing VI: Carbon Nanotubes. TrAC Trends Anal. Chem. 2005, 24 (9), 826-838.

(135) Rivas, G. A.; Rubianes, M. D.; Rodríguez, M. C.; Ferreyra, N. F.; Luque, G. L.; Pedano, M. L.; Miscoria, S. A.; Parrado, C. Carbon Nanotubes for Electrochemical Biosensing. Talanta 2007, 74 (3), 291-307.

(136) Yang, C.; Denno, M. E.; Pyakurel, P.; Venton, B. J. Recent Trends in Carbon Nanomaterial-Based Electrochemical Sensors for Biomolecules: A Review. Anal. Chim. Acta 2015, 887, 17-37.

(137) Prasek, J.; Drbohlavova, J.; Chomoucka, J.; Hubalek, J.; Jasek, O.; Adam, V.; Kizek, R. Methods for Carbon Nanotubes SynthesisReview. J. Mater. Chem. 2011, 21 (40), 15872-15884.

(138) Wang, H.; Yuan, Y.; Wei, L.; Goh, K.; Yu, D.; Chen, Y. Catalysts for Chirality Selective Synthesis of Single-Walled Carbon Nanotubes. Carbon 2015, 81, 1-19.

(139) Chen, Y.; Zhang, Y.; Hu, Y.; Kang, L.; Zhang, S.; Xie, H.; Liu, D.; Zhao, Q.; Li, Q.; Zhang, J. State of the Art of Single-Walled Carbon Nanotube Synthesis on Surfaces. Adv. Mater. 2014, 26 (34), 58985922.

(140) Zou, Y.; Li, Q.; Liu, J.; Jin, Y.; Qian, Q.; Jiang, K.; Fan, S. Fabrication of All-Carbon Nanotube Electronic Devices on Flexible Substrates Through CVD and Transfer Methods. Adv. Mater. 2013, 25 (42), 6050-6056.

(141) Tseng, S. H.; Tai, N. H. Fabrication of a Transparent and Flexible Thin Film Transistor Based on Single-Walled Carbon Nanotubes Using the Direct Transfer Method. Appl. Phys. Lett. 2009, 95 (20), 204104.

(142) Cole, M.; Hiralal, P.; Ying, K.; Li, C.; Zhang, Y.; Teo, K.; Ferrari, A.; Milne, W. Dry-Transfer of Aligned Multiwalled Carbon Nanotubes for Flexible Transparent Thin Films. J. Nanomater. 2012, 2012, 272960. 
(143) Wang, T.; Carlberg, B.; Jönsson, M.; Jeong, G.-H.; Campbell, E. E. B.; Liu, J. Low Temperature Transfer and Formation of Carbon Nanotube Arrays by Imprinted Conductive Adhesive. Appl. Phys. Lett. 2007, 91 (9), 093123.

(144) Ye, Y.; Mao, Y.; Wang, F.; Lu, H.; Qu, L.; Dai, L. Solvent-Free Functionalization and Transfer of Aligned Carbon Nanotubes with Vapor-Deposited Polymer Nanocoatings. J. Mater. Chem. 2011, 21 (3), 837-842.

(145) Thanh, Q. N.; Jeong, H.; Kim, J.; Kevek, J. W.; Ahn, Y. H.; Lee, S.; Minot, E. D.; Park, J.-Y. Transfer-Printing of As-Fabricated Carbon Nanotube Devices onto Various Substrates. Adv. Mater. 2012, 24 (33), 4499-4504.

(146) Liu, H.; Takagi, D.; Chiashi, S.; Homma, Y. Transfer and Alignment of Random Single-Walled Carbon Nanotube Films by Contact Printing. ACS Nano 2010, 4 (2), 933-938.

(147) Wang, C.; Ryu, K.; De Arco, L. G.; Badmaev, A.; Zhang, J.; Lin, X.; Che, Y.; Zhou, C. Synthesis and Device Applications of HighDensity Aligned Carbon Nanotubes Using Low-Pressure Chemical Vapor Deposition and Stacked Multiple Transfer. Nano Res. 2010, 3 (12), 831-842.

(148) Tabata, H.; Shimizu, M.; Ishibashi, K. Fabrication of Single Electron Transistors Using Transfer-Printed Aligned Single Walled Carbon Nanotubes Arrays. Appl. Phys. Lett. 2009, 95 (11), 113107.

(149) Pint, C. L.; Xu, Y.-Q.; Moghazy, S.; Cherukuri, T.; Alvarez, N. T.; Haroz, E. H.; Mahzooni, S.; Doorn, S. K.; Kono, J.; Pasquali, M.; Hauge, R. H. Dry Contact Transfer Printing of Aligned Carbon Nanotube Patterns and Characterization of Their Optical Properties for Diameter Distribution and Alignment. ACS Nano 2010, 4 (2), 1131-1145.

(150) Wu, C. C.; Liu, C. H.; Zhong, Z. One-Step Direct Transfer of Pristine Single-Walled Carbon Nanotubes for Functional Nanoelectronics. Nano Lett. 2010, 10 (3), 1032-1036. 
(151) In, J. Bin; Lee, D.; Fornasiero, F.; Noy, A.; Grigoropoulos, C. P. Laser-Assisted Simultaneous Transfer and Patterning of Vertically Aligned Carbon Nanotube Arrays on Polymer Substrates for Flexible Devices. ACS Nano 2012, 6 (9), 7858-7866.

(152) Zhu, Y.; Lim, X.; Sim, M. C.; Lim, C. T.; Sow, C. H. Versatile Transfer of Aligned Carbon Nanotubes with Polydimethylsiloxane as the Intermediate. Nanotechnology 2008, 19 (32), 325304.

(153) Fu, Y.; Qin, Y.; Wang, T.; Chen, S.; Liu, J. Ultrafast Transfer of Metal-Enhanced Carbon Nanotubes at Low Temperature for LargeScale Electronics Assembly. Adv. Mater. 2010, 22 (44), 5039-5042.

(154) Abdelhalim, A.; Abdellah, A.; Scarpa, G.; Lugli, P. Fabrication of Carbon Nanotube Thin Films on Flexible Substrates by Spray Deposition and Transfer Printing. Carbon 2013, 61, 72-79.

(155) Hou, P.-X.; Yu, B.; Su, Y.; Shi, C.; Zhang, L.-L.; Liu, C.; Li, S.; Du, J.-H.; Cheng, H.-M. Double-Wall Carbon Nanotube Transparent Conductive Films with Excellent Performance. J. Mater. Chem. A 2014, 2 (4), 1159-1164.

(156) Xu, G.-H.; Huang, J.-Q.; Zhang, Q.; Zhao, M.-Q.; Wei, F. Fabrication of Double- and Multi-Walled Carbon Nanotube Transparent Conductive Films by Filtration-Transfer Process and Their Property Improvement by Acid Treatment. Appl. Phys. A 2011, 103 (2), 403-411.

(157) Lü, Q.; Cao, H.; Song, X.; Yan, H.; Gan, Z.; Liu, S. Improved Electrical Resistance-Pressure Strain Sensitivity of Carbon Nanotube Network/Polydimethylsiloxane Composite Using Filtration and Transfer Process. Chinese Sci. Bull. 2010, 55 (3), 326-330.

(158) Woo, C.-S.; Lim, C.-H.; Cho, C.-W.; Park, B.; Ju, H.; Min, D.-H.; Lee, C.-J.; Lee, S.-B. Fabrication of Flexible and Transparent SingleWall Carbon Nanotube Gas Sensors by Vacuum Filtration and Poly(dimethyl Siloxane) Mold Transfer. Microelectron. Eng. 2007, 84 (5-8), 1610-1613.

(159) Kataura, H.; Kumazawa, Y.; Maniwa, Y.; Umezu, I.; Suzuki, S.; Ohtsuka, Y.; Achiba, Y. Optical Properties of Single-Wall Carbon Nanotubes. Synth. Met. 1999, 103 (1-3), 2555-2558. 
(160) Melchionna, M.; Marchesan, S.; Prato, M.; Fornasiero, P. Carbon Nanotubes and Catalysis: The Many Facets of a Successful Marriage. Catal. Sci. Technol. 2015, 5 (8), 3859-3875.

(161) Byers, J. C.; Güell, A. G.; Unwin, P. R. Nanoscale Electrocatalysis: Visualizing Oxygen Reduction at Pristine, Kinked, and Oxidized Sites on Individual Carbon Nanotubes. J. Am. Chem. Soc. 2014, 136 (32), 11252-11255.

(162) Pumera, M. The Electrochemistry of Carbon Nanotubes: Fundamentals and Applications. Chem. - A Eur. J. 2009, 15 (20), 4970-4978.

(163) Bekyarova, E.; Itkis, M. E.; Cabrera, N.; Zhao, B.; Yu, A.; Gao, J.; Haddon, R. C. Electronic Properties of Single-Walled Carbon Nanotube Networks. J. Am. Chem. Soc. 2005, 127 (16), 5990-5995.

(164) Ebbesen, T. W.; Lezec, H. J.; Hiura, H.; Bennett, J. W.; Ghaemi, H. F.; Thio, T. Electrical Conductivity of Individual Carbon Nanotubes. Nature 1996, 382 (6586), 54-56.

(165) Tasis, D.; Tagmatarchis, N.; Bianco, A.; Prato, M. Chemistry of Carbon Nanotubes. Chem. Rev. 2006, 106 (3), 1105-1136.

(166) Sun, Y.-P.; Fu, K.; Lin, Y.; Huang, W. Functionalized Carbon Nanotubes: Properties and Applications. Acc. Chem. Res. 2002, 35 (12), 1096-1104.

(167) Zhang, H.; Wu, B.; Hu, W.; Liu, Y. Separation and/or Selective Enrichment of Single-Walled Carbon Nanotubes Based on Their Electronic Properties. Chem. Soc. Rev. 2011, 40 (3), 1324-1336.

(168) Güell, A. G.; Meadows, K. E.; Unwin, P. R.; Macpherson, J. V. Trace Voltammetric Detection of Serotonin at Carbon Electrodes: Comparison of Glassy Carbon, Boron Doped Diamond and Carbon Nanotube Network Electrodes. Phys. Chem. Chem. Phys. 2010, 12 (34), 10108-10114.

(169) Güell, A. G.; Meadows, K. E.; Dudin, P. V.; Ebejer, N.; Macpherson, J. V.; Unwin, P. R. Mapping Nanoscale Electrochemistry of Individual Single-Walled Carbon Nanotubes. Nano Lett. 2014, 14 (1), 220-224. 
(170) Nützenadel, C.; Züttel, A.; Chartouni, D.; Schlapbach, L. Electrochemical Storage of Hydrogen in Nanotube Materials. Electrochem. Solid-State Lett. 1999, 2 (1), 30-32.

(171) Baughman, R. H.; Zakhidov, A. A.; de Heer, W. A. Carbon Nanotubes-The Route Toward Applications. Science 2002, 297 (5582), 787-792.

(172) Katz, E.; Willner, I. Biomolecule-Functionalized Carbon Nanotubes: Applications in Nanobioelectronics. ChemPhysChem 2004, 5 (8), 1084-1104.

(173) Picó, F.; Rojo, J. M.; Sanjuán, M. L.; Ansón, A.; Benito, A. M.; Callejas, M. A.; Maser, W. K.; Martínez, M. T. Single-Walled Carbon Nanotubes as Electrodes in Supercapacitors. J. Electrochem. Soc. 2004, 151 (6), A831-A837.

(174) Ghosh, S.; Sood, A. K.; Kumar, N. Carbon Nanotube Flow Sensors. Science 2003, 299 (5609), 1042-1044.

(175) Star, A.; Tu, E.; Niemann, J.; Gabriel, J.-C. P.; Joiner, C. S.; Valcke, C. Label-Free Detection of DNA Hybridization Using Carbon Nanotube Network Field-Effect Transistors. Proc. Natl. Acad. Sci. U. S. A. 2006, 103 (4), 921-926.

(176) Bachtold, A.; Hadley, P.; Nakanishi, T.; Dekker, C. Logic Circuits with Carbon Nanotube Transistors. Science 2001, 294 (5545), 13171320.

(177) Tans, S. J.; Verschueren, A. R. M.; Dekker, C. Room-Temperature Transistor Based on a Single Carbon Nanotube. Nature 1998, 393 (6680), 49-52.

(178) De Volder, M. F. L.; Tawfick, S. H.; Baughman, R. H.; Hart, A. J. Carbon Nanotubes: Present and Future Commercial Applications. Science 2013, 339 (6119), 535-539.

(179) Schnorr, J. M.; Swager, T. M. Emerging Applications of Carbon Nanotubes. Chem. Mater. 2011, 23 (3), 646-657.

(180) Fabbro, A.; Bosi, S.; Ballerini, L.; Prato, M. Carbon Nanotubes: Artificial Nanomaterials to Engineer Single Neurons and Neuronal Networks. ACS Chem. Neurosci. 2012, 3 (8), 611-618. 
(181) Singhal, R.; Orynbayeva, Z.; Kalyana Sundaram, R. V.; Niu, J. J.; Bhattacharyya, S.; Vitol, E. A.; Schrlau, M. G.; Papazoglou, E. S.; Friedman, G.; Gogotsi, Y. Multifunctional Carbon-Nanotube Cellular Endoscopes. Nat. Nanotechnol. 2011, 6 (1), 57-64.

(182) Hopley, E. L.; Salmasi, S.; Kalaskar, D. M.; Seifalian, A. M. Carbon Nanotubes Leading the Way Forward in New Generation 3D Tissue Engineering. Biotechnol. Adv. 2014, 32 (5), 1000-1014.

(183) Hong, H.; Gao, T.; Cai, W. Molecular Imaging with Single-Walled Carbon Nanotubes. Nano Today 2009, 4 (3), 252-261.

(184) Kruss, S.; Hilmer, A. J.; Zhang, J.; Reuel, N. F.; Mu, B.; Strano, M. S. Carbon Nanotubes as Optical Biomedical Sensors. Adv. Drug Deliv. Rev. 2013, 65 (15), 1933-1950.

(185) Peng, G.; Tisch, U.; Haick, H. Detection of Nonpolar Molecules by Means of Carrier Scattering in Random Networks of Carbon Nanotubes: Toward Diagnosis of Diseases via Breath Samples. Nano Lett. 2009, 9 (4), 1362-1368.

(186) Serafín, V.; Martínez-García, G.; Agüí, L.; Yáñez-Sedeño, P.; Pingarrón, J. M. Multiplexed Determination of Human Growth Hormone and Prolactin at a Label Free Electrochemical Immunosensor Using Dual Carbon Nanotube-Screen Printed Electrodes Modified with Gold and PEDOT Nanoparticles. Analyst 2014, 139 (18), 4556-4563.

(187) Bianco, A.; Kostarelos, K.; Prato, M. Making Carbon Nanotubes Biocompatible and Biodegradable. Chem. Commun. 2011, 47 (37), 10182-10188.

(188) Bertoncello, P.; Edgeworth, J. P.; Macpherson, J. V.; Unwin, P. R. Trace Level Cyclic Voltammetry Facilitated by Single-Walled Carbon Nanotube Network Electrodes. J. Am. Chem. Soc. 2007, 129 (36), 10982-10983.

(189) Welch, C. M.; Compton, R. G. The Use of Nanoparticles in Electroanalysis: A Review. Anal. Bioanal. Chem. 2006, 384 (3), 601619. 
(190) Martínez-Periñán, E.; Revenga-Parra, M.; Gennari, M.; Pariente, F.; Mas-Ballesté, R.; Zamora, F.; Lorenzo, E. Insulin Sensor Based on Nanoparticle-Decorated Multiwalled Carbon Nanotubes Modified Electrodes. Sensors Actuators B Chem. 2016, 222, 331-338.

(191) Yang, W.; Thordarson, P.; Gooding, J. J.; Ringer, S. P.; Braet, F. Carbon Nanotubes for Biological and Biomedical Applications. Nanotechnology 2007, 18 (41), 412001.

(192) Garoz-Ruiz, J.; Izquierdo, D.; Colina, A.; Palmero, S.; Heras, A. Optical Fiber Spectroelectrochemical Device for Detection of Catechol at Press-Transferred Single-Walled Carbon Nanotubes Electrodes. Anal. Bioanal. Chem. 2013, 405 (11), 3593-3602.

(193) Research Group “Miniaturización y Nanotecnología Analíticas” of the Universidad de Alcalá:

http://portal.uah.es/portal/page/portal/grupos_de_investigacion/190/P resentacion/QuienesSomos.

(194) Vilela, D.; Garoz, J.; Colina, Á.; González, M. C.; Escarpa, A. Carbon Nanotubes Press-Transferred on PMMA Substrates as Exclusive Transducers for Electrochemical Microfluidic Sensing. Anal. Chem. 2012, 84 (24), 10838-10844.

(195) Vilela, D.; Martín, A.; González, M. C.; Escarpa, A. Fast and Reliable Class-Selective Isoflavone Index Determination on Carbon Nanotube Press-Transferred Electrodes Using Microfluidic Chips. Analyst 2014, 139 (10), 2342-2347.

(196) Vashist, S. K.; Zheng, D.; Al-Rubeaan, K.; Luong, J. H. T.; Sheu, F.S. Advances in Carbon Nanotube Based Electrochemical Sensors for Bioanalytical Applications. Biotechnol. Adv. 2011, 29 (2), 169-188.

(197) Mao, X.; Rutledge, G. C.; Hatton, T. A. Nanocarbon-Based Electrochemical Systems for Sensing, Electrocatalysis, and Energy Storage. Nano Today 2014, 9 (4), 405-432.

(198) The Official Web Site of the Nobel Prize: http://www.nobelprize.org/nobel_prizes/physics/laureates/2010/. 
(199) The Nobel Prize in Physics, 2010: Graphene - Nobel Prize Advanced Information:

http://www.nobelprize.org/nobel_prizes/physics/laureates/2010/advan ced-physicsprize2010.pdf.

(200) Nair, R. R.; Blake, P.; Grigorenko, A. N.; Novoselov, K. S.; Booth, T. J.; Stauber, T.; Peres, N. M. R.; Geim, A. K. Fine Structure Constant Defines Visual Transparency of Graphene. Science 2008, 320 (5881), 1308-1308.

(201) Wassei, J. K.; Kaner, R. B. Graphene, a Promising Transparent Conductor. Mater. Today 2010, 13 (3), 52-59.

(202) Pang, S.; Hernandez, Y.; Feng, X.; Müllen, K. Graphene as Transparent Electrode Material for Organic Electronics. Adv. Mater. 2011, 23 (25), 2779-2795.

(203) Kochmann, S.; Hirsch, T.; Wolfbeis, O. S. Graphenes in Chemical Sensors and Biosensors. TrAC Trends Anal. Chem. 2012, 39, 87-113.

(204) Zhang, X.; Rajaraman, B. R. S.; Liu, H.; Ramakrishna, S. Graphene's Potential in Materials Science and Engineering. RSC Adv. 2014, 4 (55), 28987-29011.

(205) Fan, Z.; Yan, J.; Zhi, L.; Zhang, Q.; Wei, T.; Feng, J.; Zhang, M.; Qian, W.; Wei, F. A Three-Dimensional Carbon Nanotube/Graphene Sandwich and Its Application as Electrode in Supercapacitors. Adv. Mater. 2010, 22 (33), 3723-3728.

(206) Peng, L.; Feng, Y.; Lv, P.; Lei, D.; Shen, Y.; Li, Y.; Feng, W. Transparent, Conductive, and Flexible Multiwalled Carbon Nanotube/Graphene Hybrid Electrodes with Two Three-Dimensional Microstructures. J. Phys. Chem. C 2012, 116 (8), 4970-4978.

(207) Xin, G.; Hwang, W.; Kim, N.; Cho, S. M.; Chae, H. A Graphene Sheet Exfoliated with Microwave Irradiation and Interlinked by Carbon Nanotubes for High-Performance Transparent Flexible Electrodes. Nanotechnology 2010, 21 (40), 405201.

(208) Wan, Q.; Cai, H.; Liu, Y.; Song, H.; Liao, H.; Liu, S.; Yang, N. Graphene Nanoplatelets: Electrochemical Properties and Applications for Oxidation of Endocrine-Disrupting Chemicals. Chem. - A Eur. J. 2013, 19 (10), 3483-3489. 
(209) Luo, X.; Zhang, F.; Ji, S.; Yang, B.; Liang, X. Graphene Nanoplatelets as a Highly Efficient Solid-Phase Extraction Sorbent for Determination of Phthalate Esters in Aqueous Solution. Talanta 2014, 120, 71-75.

(210) Lim, C. S.; Chua, C. K.; Pumera, M. Detection of Biomarkers with Graphene Nanoplatelets and Nanoribbons. Analyst 2014, 139 (5), 1072-1080.

(211) Al-Khateeb, L. A.; Almotiry, S.; Salam, M. A. Adsorption of Pharmaceutical Pollutants onto Graphene Nanoplatelets. Chem. Eng. J. 2014, 248, 191-199.

(212) Aravind, S. S. J.; Baby, T. T.; Arockiadoss, T.; Rakhi, R. B.; Ramaprabhu, S. A Cholesterol Biosensor Based on Gold Nanoparticles Decorated Functionalized Graphene Nanoplatelets. Thin Solid Films 2011, 519 (16), 5667-5672.

(213) Tian, M.; Huang, Y.; Wang, W.; Li, R.; Liu, P.; Liu, C.; Zhang, Y. Temperature-Dependent Electrical Properties of Graphene Nanoplatelets Film Dropped on Flexible Substrates. J. Mater. Res. 2014, 29 (11), 1288-1294.

(214) Yue, L.; Pircheraghi, G.; Monemian, S. A.; Manas-Zloczower, I. Epoxy Composites with Carbon Nanotubes and Graphene Nanoplatelets - Dispersion and Synergy Effects. Carbon 2014, 78, 268-278.

(215) Araby, S.; Saber, N.; Ma, X.; Kawashima, N.; Kang, H.; Shen, H.; Zhang, L.; Xu, J.; Majewski, P.; Ma, J. Implication of Multi-Walled Carbon Nanotubes on Polymer/Graphene Composites. Mater. Des. 2015, 65, 690-699.

(216) Sridhar, V.; Kim, H.-J.; Jung, J.-H.; Lee, C.; Park, S.; Oh, I.-K. Defect-Engineered Three-Dimensional Graphene-NanotubePalladium Nanostructures with Ultrahigh Capacitance. ACS Nano 2012, 6 (12), 10562-10570.

(217) Park, S.; An, J.; Suk, J. W.; Ruoff, R. S. Graphene-Based Actuators. Small 2010, 6 (2), 210-212. 
(218) Janczak, D.; Słoma, M.; Wróblewski, G.; Młożniak, A.; Jakubowska, M. Screen-Printed Resistive Pressure Sensors Containing Graphene Nanoplatelets and Carbon Nanotubes. Sensors 2014, 14 (9), 1730417312.

(219) Hu, Y.; Li, X.; Wang, J.; Li, R.; Sun, X. Free-Standing GrapheneCarbon Nanotube Hybrid Papers Used as Current Collector and Binder Free Anodes for Lithium Ion Batteries. J. Power Sources 2013, 237, 41-46.

(220) Hwang, S.-H.; Park, H. W.; Park, Y.-B. Piezoresistive Behavior and Multi-Directional Strain Sensing Ability of Carbon NanotubeGraphene Nanoplatelet Hybrid Sheets. Smart Mater. Struct. 2013, 22 (1), 015013.

(221) Borges, R. S.; Ribeiro, H.; Lavall, R. L.; Silva, G. G. Temperature Stable Supercapacitors Based on Ionic Liquid and Mixed Functionalized Carbon Nanomaterials. J. Solid State Electrochem. 2012, 16 (11), 3573-3580.

(222) Kaniyoor, A.; Ramaprabhu, S. Hybrid Carbon Nanostructured Ensembles as Chemiresistive Hydrogen Gas Sensors. Carbon 2011, 49 (1), 227-236.

(223) Muñoz, E.; Colina, Á.; Heras, A.; Ruiz, V.; Palmero, S.; LópezPalacios, J. Electropolymerization and Characterization of Polyaniline Films Using a Spectroelectrochemical Flow Cell. Anal. Chim. Acta 2006, 573-574, 20-25.

(224) Muñoz, E.; Heras, M. A.; Colina, Á.; Ruiz, V.; López-Palacios, J. Electropolymerization of Aniline on Polyaniline-Modified Electrodes under Hydrodynamic Conditions. Electrochim. Acta 2007, 52 (14), 4778-4783.

(225) Zanardi, C.; Terzi, F.; Pigani, L.; Heras, A.; Colina, A.; LopezPalacios, J.; Seeber, R. Development and Characterisation of a Novel Composite Electrode Material Consisting of Poly(3,4Ethylenedioxythiophene) Including Au Nanoparticles. Electrochim. Acta 2008, 53 (11), 3916-3923. 
(226) Palmero, S.; Colina, A.; Muñoz, E.; Heras, A.; Ruiz, V.; LópezPalacios, J. Layer-by-Layer Electrosynthesis of Pt-Polyaniline Nanocomposites for the Catalytic Oxidation of Methanol. Electrochem. Commun. 2009, 11 (1), 122-125.

(227) Zanfrognini, B.; Colina, A.; Heras, A.; Zanardi, C.; Seeber, R.; López-Palacios, J. A UV-Visible/Raman Spectroelectrochemical Study of the Stability of Poly(3,4-Ethylendioxythiophene) Films. Polym. Degrad. Stab. 2011, 96 (12), 2112-2119.

(228) Patten, H. V.; Ventosa, E.; Colina, A.; Ruiz, V.; López-Palacios, J.; Wain, A. J.; Lai, S. C. S.; Macpherson, J. V.; Unwin, P. R. Influence of Ultrathin Poly-(3,4-Ethylenedioxythiophene) (PEDOT) Film Supports on the Electrodeposition and Electrocatalytic Activity of Discrete Platinum Nanoparticles. J. Solid State Electrochem. 2011, 15 (11), 2331-2339.

(229) Ventosa, E.; Colina, A.; Heras, A.; Ruiz, V.; Garoz, J.; LópezPalacios, J. One-Pot Synthesis of Gold/Poly(3,4Ethylendioxythiophene) Nanocomposite. J. Nanoparticle Res. 2012, $14(1), 661$.

(230) Fernandez-Blanco, C.; Ibañez, D.; Colina, A.; Ruiz, V.; Heras, A. Spectroelectrochemical Study of the Electrosynthesis of Pt Nanoparticles/Poly(3,4-(ethylenedioxythiophene) Composite. Electrochim. Acta 2014, 145, 139-147.

(231) Research Group "Warwick Electrochemistry \& Interfaces" of the University of Warwick (United Kingdom): http://www2.warwick.ac.uk/fac/sci/chemistry/research/unwin/electroc hemistry/home/.

(232) Aaronson, B. D. B.; Garoz-Ruiz, J.; Byers, J. C.; Colina, A.; Unwin, P. R. Electrodeposition and Screening of Photoelectrochemical Activity in Conjugated Polymers Using Scanning Electrochemical Cell Microscopy. Langmuir 2015, 31 (46), 12814-12822.

(233) Nordén, B.; Krutmeijer, E. The Nobel Prize in Chemistry, 2000: Conductive Polymers - Nobel Prize Advanced Information: http://www.nobelprize.org/nobel_prizes/chemistry/laureates/2000/adv anced-chemistryprize2000.pdf. 
(234) Letheby, H. XXIX.- On the Production of a Blue Substance by the Electrolysis of Sulphate of Aniline. J. Chem. Soc. 1862, 15 (0), 161163.

(235) Ito, T.; Shirakawa, H.; Ikeda, S. Simultaneous Polymerization and Formation of Polyacetylene Film on the Surface of Concentrated Soluble Ziegler-Type Catalyst Solution. J. Polym. Sci. Polym. Chem. Ed. 1974, 12 (1), 11-20.

(236) Shirakawa, H.; Louis, E. J.; MacDiarmid, A. G.; Chiang, C. K.; Heeger, A. J. Synthesis of Electrically Conducting Organic Polymers: Halogen Derivatives of Polyacetylene, $(\mathrm{CH})_{\mathrm{x}}$.J. Chem. Soc. Chem. Commun. 1977, No. 16, 578-580.

(237) Chiang, C. K.; Fincher, C. R.; Park, Y. W.; Heeger, A. J.; Shirakawa, H.; Louis, E. J.; Gau, S. C.; MacDiarmid, A. G. Electrical Conductivity in Doped Polyacetylene. Phys. Rev. Lett. 1977, 39 (17), 1098-1101.

(238) Kanatzidis, M. G. SPECIAL REPORT: Conductive Polymers. Chem. Eng. News Arch. 1990, 68 (49), 36-54.

(239) Feast, W. J.; Tsibouklis, J.; Pouwer, K. L.; Groenendaal, L.; Meijer, E. W. Synthesis, Processing and Material Properties of Conjugated Polymers. Polymer 1996, 37 (22), 5017-5047.

(240) The Official Web Site of the Nobel Prize: http://www.nobelprize.org/nobel_prizes/chemistry/laureates/2000/.

(241) Gettinger, C. L.; Heeger, A. J.; Drake, J. M.; Pine, D. J. A Photoluminescence Study of Poly(phenylene Vinylene) Derivatives: The Effect of Intrinsic Persistence Length. J. Chem. Phys. 1994, 101 (2), 1673-1678.

(242) Patil, A. O.; Heeger, A. J.; Wudl, F. Optical Properties of Conducting Polymers. Chem. Rev. 1988, 88 (1), 183-200.

(243) Stubb, H.; Punkka, E.; Paloheimo, J. Electronic and Optical Properties of Conducting Polymer Thin Films. Mater. Sci. Reports 1993, 10 (3), 85-140.

(244) Gerard, M.; Chaubey, A.; Malhotra, B. D. Application of Conducting Polymers to Biosensors. Biosens. Bioelectron. 2002, 17 (5), 345-359. 
(245) Janata, J.; Josowicz, M. Conducting Polymers in Electronic Chemical Sensors. Nat. Mater. 2003, 2 (1), 19-24.

(246) Tuncagil, S.; Odaci, D.; Yildiz, E.; Timur, S.; Toppare, L. Design of a Microbial Sensor Using Conducting Polymer of 4-(2,5-Di(thiophen2-Y1)-1H-Pyrrole-1-L) Benzenamine. Sensors Actuators B Chem. 2009, 137 (1), 42-47.

(247) Ates, M. A Review Study of (Bio)Sensor Systems Based on Conducting Polymers. Mater. Sci. Eng. C 2013, 33 (4), 1853-1859.

(248) Guimard, N. K.; Gomez, N.; Schmidt, C. E. Conducting Polymers in Biomedical Engineering. Prog. Polym. Sci. 2007, 32 (8-9), 876-921.

(249) Kaur, G.; Adhikari, R.; Cass, P.; Bown, M.; Gunatillake, P. Electrically Conductive Polymers and Composites for Biomedical Applications. RSC Adv. 2015, 5 (47), 37553-37567.

(250) Green, R. A.; Lovell, N. H.; Wallace, G. G.; Poole-Warren, L. A. Conducting Polymers for Neural Interfaces: Challenges in Developing an Effective Long-Term Implant. Biomaterials 2008, 29 (24-25), 3393-3399.

(251) Snook, G. A.; Kao, P.; Best, A. S. Conducting-Polymer-Based Supercapacitor Devices and Electrodes. J. Power Sources 2011, 196 (1), 1-12.

(252) Ramya, R.; Sivasubramanian, R.; Sangaranarayanan, M. V. Conducting Polymers-Based Electrochemical SupercapacitorsProgress and Prospects. Electrochim. Acta 2013, 101, 109-129.

(253) Fernández Otero, T.; Cortés, M. T. Artificial Muscles with Tactile Sensitivity. Adv. Mater. 2003, 15 (4), 279-282.

(254) Ghosh, S.; Kouamé, N. A.; Ramos, L.; Remita, S.; Dazzi, A.; Deniset-Besseau, A.; Beaunier, P.; Goubard, F.; Aubert, P.-H.; Remita, H. Conducting Polymer Nanostructures for Photocatalysis under Visible Light. Nat. Mater. 2015, 14 (5), 505-511.

(255) Gustafsson, G.; Cao, Y.; Treacy, G. M.; Klavetter, F.; Colaneri, N.; Heeger, A. J. Flexible Light-Emitting Diodes Made from Soluble Conducting Polymers. Nature 1992, 357 (6378), 477-479. 
(256) Lee, J.; Lee, P.; Lee, H. B.; Hong, S.; Lee, I.; Yeo, J.; Lee, S. S.; Kim, T.-S.; Lee, D.; Ko, S. H. Room-Temperature Nanosoldering of a Very Long Metal Nanowire Network by Conducting-PolymerAssisted Joining for a Flexible Touch-Panel Application. Adv. Funct. Mater. 2013, 23 (34), 4171-4176.

(257) Gangopadhyay, R.; De, A. Conducting Polymer Nanocomposites: A Brief Overview. Chem. Mater. 2000, 12 (3), 608-622.

(258) Lin, H.; Li, L.; Ren, J.; Cai, Z.; Qiu, L.; Yang, Z.; Peng, H. Conducting Polymer Composite Film Incorporated with Aligned Carbon Nanotubes for Transparent, Flexible and Efficient Supercapacitor. Sci. Rep. 2013, 3, 1353.

(259) Chen, J.; Liu, Y.; Minett, A. I.; Lynam, C.; Wang, J.; Wallace, G. G. Flexible, Aligned Carbon Nanotube/Conducting Polymer Electrodes for a Lithium-Ion Battery. Chem. Mater. 2007, 19 (15), 3595-3597.

(260) Li, Z.; Ye, B.; Hu, X.; Ma, X.; Zhang, X.; Deng, Y. Facile Electropolymerized-PANI as Counter Electrode for Low Cost DyeSensitized Solar Cell. Electrochem. Commun. 2009, 11 (9), 17681771.

(261) Tang, Q.; Cai, H.; Yuan, S.; Wang, X. Counter Electrodes from Double-Layered Polyaniline Nanostructures for Dye-Sensitized Solar Cell Applications. J. Mater. Chem. A 2013, 1 (2), 317-323.

(262) Teli, S. B.; Molina, S.; Calvo, E. G.; Lozano, A. E.; de Abajo, J. Preparation, Characterization and Antifouling Property of Polyethersulfone-PANI/PMA Ultrafiltration Membranes. Desalination 2012, 299, 113-122.

(263) Salinas-Torres, D.; Sieben, J. M.; Lozano-Castelló, D.; CazorlaAmorós, D.; Morallón, E. Asymmetric Hybrid Capacitors Based on Activated Carbon and Activated Carbon Fibre-PANI Electrodes. Electrochim. Acta 2013, 89, 326-333.

(264) Kobayashi, T.; Yoneyama, H.; Tamura, H. Polyaniline Film-Coated Electrodes as Electrochromic Display Devices. J. Electroanal. Chem. Interfacial Electrochem. 1984, 161 (2), 419-423. 
(265) Wei, H.; Zhu, J.; Wu, S.; Wei, S.; Guo, Z. Electrochromic Polyaniline/Graphite Oxide Nanocomposites with Endured Electrochemical Energy Storage. Polymer 2013, 54 (7), 1820-1831.

(266) Qazi, T. H.; Rai, R.; Dippold, D.; Roether, J. E.; Schubert, D. W.; Rosellini, E.; Barbani, N.; Boccaccini, A. R. Development and Characterization of Novel Electrically Conductive PANI-PGS Composites for Cardiac Tissue Engineering Applications. Acta Biomater. 2014, 10 (6), 2434-2445.

(267) Armelin, E.; Pla, R.; Liesa, F.; Ramis, X.; Iribarren, J. I.; Alemán, C. Corrosion Protection with Polyaniline and Polypyrrole as Anticorrosive Additives for Epoxy Paint. Corros. Sci. 2008, 50 (3), 721-728.

(268) Shao, D.; Hou, G.; Li, J.; Wen, T.; Ren, X.; Wang, X. PANI/GO as a Super Adsorbent for the Selective Adsorption of Uranium(VI). Chem. Eng. J. 2014, 255, 604-612.

(269) Zhou, W.; Yu, Y.; Chen, H.; DiSalvo, F. J.; Abruña, H. D. YolkShell Structure of Polyaniline-Coated Sulfur for Lithium-Sulfur Batteries. J. Am. Chem. Soc. 2013, 135 (44), 16736-16743.

(270) Xu, W.; Zhao, K.; Niu, C.; Zhang, L.; Cai, Z.; Han, C.; He, L.; Shen, T.; Yan, M.; Qu, L.; Mai, L. Heterogeneous Branched Core-Shell $\mathrm{SnO}_{2}-\mathrm{PANI}$ Nanorod Arrays with Mechanical Integrity and Three Dimentional Electron Transport for Lithium Batteries. Nano Energy 2014, 8, 196-204.

(271) Hou, J.; Liu, Z.; Zhang, P. A New Method for Fabrication of Graphene/Polyaniline Nanocomplex Modified Microbial Fuel Cell Anodes. J. Power Sources 2013, 224, 139-144.

(272) Porcel-Valenzuela, M.; Ballesta-Claver, J.; de Orbe-Payá, I.; Montilla, F.; Capitan-Vallvey, L. F. Disposable Electrochromic Polyaniline Sensor Based on a Redox Response Using a Conventional Camera: A First Approach to Handheld Analysis. J. Electroanal. Chem. 2015, 738, 162-169.

(273) Zhai, D.; Liu, B.; Shi, Y.; Pan, L.; Wang, Y.; Li, W.; Zhang, R.; Yu, G. Highly Sensitive Glucose Sensor Based on Pt Nanoparticle/Polyaniline Hydrogel Heterostructures. ACS Nano 2013, 7 (4), 3540-3546. 
(274) Virji, S.; Huang, J.; Kaner, R. B.; Weiller, B. H. Polyaniline Nanofiber Gas Sensors: Examination of Response Mechanisms. Nano Lett. 2004, 4 (3), 491-496.

(275) Ruecha, N.; Rangkupan, R.; Rodthongkum, N.; Chailapakul, O. Novel Paper-Based Cholesterol Biosensor Using Graphene/Polyvinylpyrrolidone/Polyaniline Nanocomposite. Biosens. Bioelectron. 2014, 52, 13-19.

(276) Hu, X.-W.; Mao, C.-J.; Song, J.-M.; Niu, H.-L.; Zhang, S.-Y.; Huang, H. Fabrication of GO/PANi/CdSe Nanocomposites for Sensitive Electrochemiluminescence Biosensor. Biosens. Bioelectron. 2013, 41, 372-378.

(277) PANI Chemical Structure - Web Page:

http://www.sigmaaldrich.com/catalog/substance/polyanilineemeraldin ebase123452523330111?lang=es\&region=ES.

(278) Gupta, V.; Miura, N. Polyaniline/Single-Wall Carbon Nanotube (PANI/SWCNT) Composites for High Performance Supercapacitors. Electrochim. Acta 2006, 52 (4), 1721-1726.

(279) Li, M.; Jing, L. Electrochemical Behavior of Acetaminophen and Its Detection on the PANI-MWCNTs Composite Modified Electrode. Electrochim. Acta 2007, 52 (9), 3250-3257.

(280) Groenendaal, L.; Zotti, G.; Aubert, P.-H.; Waybright, S. M.; Reynolds, J. R. Electrochemistry of Poly(3,4Alkylenedioxythiophene) Derivatives. Adv. Mater. 2003, 15 (11), 855-879.

(281) Feng, W.; Li, Y.; Wu, J.; Noda, H.; Fujii, A.; Ozaki, M.; Yoshino, K. Improved Electrical and Optical Properties of Poly $(3,4-$ Ethylenedioxythiophene) via Ordered Microstructure. J. Phys. Condens. Matter 2007, 19 (18), 186220.

(282) Lefebvre, M.; Qi, Z.; Rana, D.; Pickup, P. G. Chemical Synthesis, Characterization, and Electrochemical Studies of Poly(3,4ethylenedioxythiophene)/Poly(styrene-4-Sulfonate) Composites. Chem. Mater. 1999, 11 (2), 262-268. 
(283) Park, T.; Park, C.; Kim, B.; Shin, H.; Kim, E. Flexible PEDOT Electrodes with Large Thermoelectric Power Factors to Generate Electricity by the Touch of Fingertips. Energy Environ. Sci. 2013, 6 (3), 788-792.

(284) Aradilla, D.; Estrany, F.; Armelin, E.; Alemán, C. Ultraporous Poly(3,4-Ethylenedioxythiophene) for Nanometric Electrochemical Supercapacitor. Thin Solid Films 2012, 520 (13), 4402-4409.

(285) Kim, Y. H.; Sachse, C.; Machala, M. L.; May, C.; Müller-Meskamp, L.; Leo, K. Highly Conductive PEDOT:PSS Electrode with Optimized Solvent and Thermal Post-Treatment for ITO-Free Organic Solar Cells. Adv. Funct. Mater. 2011, 21 (6), 1076-1081.

(286) Ouyang, J.; Chu, C.-W.; Chen, F.-C.; Xu, Q.; Yang, Y. HighConductivity Poly(3,4-Ethylenedioxythiophene):Poly(styrene Sulfonate) Film and Its Application in Polymer Optoelectronic Devices. Adv. Funct. Mater. 2005, 15 (2), 203-208.

(287) Jiang, F.; Yue, R.; Du, Y.; Xu, J.; Yang, P. A One-Pot "Green" Synthesis of Pd-Decorated PEDOT Nanospheres for Nonenzymatic Hydrogen Peroxide Sensing. Biosens. Bioelectron. 2013, 44, $127-$ 131.

(288) Nie, T.; Xu, J.-K.; Lu, L.-M.; Zhang, K.-X.; Bai, L.; Wen, Y.-P. Electroactive Species-Doped Poly(3,4-Ethylenedioxythiophene) Films: Enhanced Sensitivity for Electrochemical Simultaneous Determination of Vitamins B2, B6 and C. Biosens. Bioelectron. 2013, 50, 244-250.

(289) Groenendaal, L.; Jonas, F.; Freitag, D.; Pielartzik, H.; Reynolds, J. R. Poly(3,4-Ethylenedioxythiophene) and Its Derivatives: Past, Present, and Future. Adv. Mater. 2000, 12 (7), 481-494.

(290) Kirchmeyer, S.; Reuter, K. Scientific Importance, Properties and Growing Applications of Poly(3,4-Ethylenedioxythiophene). J. Mater. Chem. 2005, 15 (21), 2077-2088.

(291) PEDOT Chemical Structure - Web Page: http://www.sigmaaldrich.com/catalog/product/aldrich/675288?lang=e s\&region=ES. 
(292) Xu, G.; Li, B.; Luo, X. Carbon Nanotube Doped Poly(3,4Ethylenedioxythiophene) for the Electrocatalytic Oxidation and Detection of Hydroquinone. Sensors Actuators B Chem. 2013, 176, 69-74.

(293) Zhou, H.; Cheng, X.; Rao, L.; Li, T.; Duan, Y. Y. Poly(3,4Ethylenedioxythiophene)/Multiwall Carbon Nanotube Composite Coatings for Improving the Stability of Microelectrodes in Neural Prostheses Applications. Acta Biomater. 2013, 9 (5), 6439-6449.

(294) Ebejer, N.; Güell, A. G.; Lai, S. C. S.; McKelvey, K.; Snowden, M. E.; Unwin, P. R. Scanning Electrochemical Cell Microscopy: A Versatile Technique for Nanoscale Electrochemistry and Functional Imaging. Annu. Rev. Anal. Chem. 2013, 6 (1), 329-351.

(295) Ebejer, N.; Schnippering, M.; Colburn, A. W.; Edwards, M. A.; Unwin, P. R. Localized High Resolution Electrochemistry and Multifunctional Imaging: Scanning Electrochemical Cell Microscopy. Anal. Chem. 2010, 82 (22), 9141-9145.

(296) P3HT Chemical Structure - Web Page: http://www.sigmaaldrich.com/catalog/substance/poly3hexylthiophene 25diyl1234515607498511?lang=es\&region=ES.

(297) Catechol Chemical Structure - Web Page: http://www.sigmaaldrich.com/catalog/substance/pyrocatechol110111 2080911?lang=es\&region=ES.

(298) Sedó, J.; Saiz-Poseu, J.; Busqué, F.; Ruiz-Molina, D. Catechol-Based Biomimetic Functional Materials. Adv. Mater. 2013, 25 (5), 653-701.

(299) Waite, J. H.; Tanzer, M. L. Polyphenolic Substance of Mytilus Edulis: Novel Adhesive Containing L-Dopa and Hydroxyproline. Science 1981, 212 (4498), 1038-1040.

(300) Yang, J.; Cohen Stuart, M. A.; Kamperman, M. Jack of All Trades: Versatile Catechol Crosslinking Mechanisms. Chem. Soc. Rev. 2014, 43 (24), 8271-8298.

(301) Xie, T.; Liu, Q.; Shi, Y.; Liu, Q. Simultaneous Determination of Positional Isomers of Benzenediols by Capillary Zone Electrophoresis with Square Wave Amperometric Detection. $J$. Chromatogr. A 2006, 1109 (2), 317-321. 
(302) Yin, H.; Zhang, Q.; Zhou, Y.; Ma, Q.; Liu, T.; Zhu, L.; Ai, S. Electrochemical Behavior of Catechol, Resorcinol and Hydroquinone at Graphene-Chitosan Composite Film Modified Glassy Carbon Electrode and Their Simultaneous Determination in Water Samples. Electrochim. Acta 2011, 56 (6), 2748-2753.

(303) Du, H.; Ye, J.; Zhang, J.; Huang, X.; Yu, C. A Voltammetric Sensor Based on Graphene-Modified Electrode for Simultaneous Determination of Catechol and Hydroquinone. J. Electroanal. Chem. 2011, 650 (2), 209-213.

(304) Zhang, Y.; Sun, R.; Luo, B.; Wang, L. Boron-Doped Graphene as High-Performance Electrocatalyst for the Simultaneously Electrochemical Determination of Hydroquinone and Catechol. Electrochim. Acta 2015, 156, 228-234.

(305) Zhao, D.-M.; Zhang, X.-H.; Feng, L.-J.; Jia, L.; Wang, S.-F. Simultaneous Determination of Hydroquinone and Catechol at PASA/MWNTs Composite Film Modified Glassy Carbon Electrode. Colloids Surfaces B Biointerfaces 2009, 74 (1), 317-321.

(306) Yue, X.; Pang, S.; Han, P.; Zhang, C.; Wang, J.; Zhang, L. Carbon Nanotubes/Carbon Paper Composite Electrode for Sensitive Detection of Catechol in the Presence of Hydroquinone. Electrochem. Commun. 2013, 34, 356-359.

(307) Guo, Q.; Huang, J.; Chen, P.; Liu, Y.; Hou, H.; You, T. Simultaneous Determination of Catechol and Hydroquinone Using Electrospun Carbon Nanofibers Modified Electrode. Sensors Actuators B Chem. 2012, 163 (1), 179-185.

(308) Song, Y.; Yang, T.; Zhou, X.; Zheng, H.; Suye, S. A Microsensor for Hydroquinone and Catechol Based on a Poly $(3,4-$ Ethylenedioxythiophene) Modified Carbon Fiber Electrode. Anal. Methods 2016, 8 (4), 886-892.

(309) Lakshmi, D.; Bossi, A.; Whitcombe, M. J.; Chianella, I.; Fowler, S. A.; Subrahmanyam, S.; Piletska, E. V.; Piletsky, S. A. Electrochemical Sensor for Catechol and Dopamine Based on a Catalytic Molecularly Imprinted Polymer-Conducting Polymer Hybrid Recognition Element. Anal. Chem. 2009, 81 (9), 3576-3584. 
(310) Unnikrishnan, B.; Ru, P.-L.; Chen, S.-M. Electrochemically Synthesized Pt- $\mathrm{MnO}_{2}$ Composite Particles for Simultaneous Determination of Catechol and Hydroquinone. Sensors Actuators $B$ Chem. 2012, 169, 235-242.

(311) Zhou, Y.; Tang, L.; Zeng, G.; Chen, J.; Cai, Y.; Zhang, Y.; Yang, G.; Liu, Y.; Zhang, C.; Tang, W. Mesoporous Carbon Nitride Based Biosensor for Highly Sensitive and Selective Analysis of Phenol and Catechol in Compost Bioremediation. Biosens. Bioelectron. 2014, 61, 519-525.

(312) Biegunski, A. T.; Michota, A.; Bukowska, J.; Jackowska, K. Immobilization of Tyrosinase on Poly(indole-5-Carboxylic Acid) Evidenced by Electrochemical and Spectroscopic Methods. Bioelectrochemistry 2006, 69 (1), 41-48.

(313) Nematollahi, D.; Hesari, M. Electrochemical Synthesis of AminoSubstituted 1,2-Benzoquinone Derivatives. J. Electroanal. Chem. 2005, 577 (2), 197-203.

(314) Rein, F. N.; Rocha, R. C.; Toma, H. E. Changing the Electrochemical Behavior of Catechols by Means of Their Conversion into the Corresponding Ruthenium(III)-dioxolene Complexes. J. Electroanal. Chem. 2000, 494 (1), 21-29.

(315) Chandra, S.; Lang, H.; Bahadur, D. Polyaniline-Iron Oxide Nanohybrid Film as Multi-Functional Label-Free Electrochemical and Biomagnetic Sensor for Catechol. Anal. Chim. Acta 2013, 795, 8-14.

(316) Sarkar, C.; Basu, B.; Chakroborty, D.; Dasgupta, P. S.; Basu, S. The Immunoregulatory Role of Dopamine: An Update. Brain. Behav. Immun. 2010, 24 (4), 525-528.

(317) Nieoullon, A. Dopamine and the Regulation of Cognition and Attention. Prog. Neurobiol. 2002, 67 (1), 53-83.

(318) Dopamine Chemical Structure - Web Page: http://www.sigmaaldrich.com/catalog/substance/dopaminehydrochlor ide189646231711?lang=es\&region=ES. 
(319) Bromberg-Martin, E. S.; Matsumoto, M.; Hikosaka, O. Dopamine in Motivational Control: Rewarding, Aversive, and Alerting. Neuron 2010, 68 (5), 815-834.

(320) Venton, B. J.; Wightman, R. M. Psychoanalytical Electrochemistry: Dopamine and Behavior. Anal. Chem. 2003, 75 (19), 414 A - 421 A.

(321) Perez-Costas, E.; Melendez-Ferro, M.; Roberts, R. C. Basal Ganglia Pathology in Schizophrenia: Dopamine Connections and Anomalies. J. Neurochem. 2010, 113 (2), 287-302.

(322) Lotharius, J.; Brundin, P. Pathogenesis of Parkinson's Disease: Dopamine, Vesicles and $\alpha$-Synuclein. Nat. Rev. Neurosci. 2002, 3 (12), 932-942.

(323) Schizophrenia. World Health Organization - Web Page: http://www.who.int/mediacentre/factsheets/fs397/en/.

(324) Grace, A. A. Dysregulation of the Dopamine System in the Pathophysiology of Schizophrenia and Depression. Nat. Rev. Neurosci. 2016, 17 (8), 524-532.

(325) Howes, O. D.; Kapur, S. The Dopamine Hypothesis of Schizophrenia: Version III-The Final Common Pathway. Schizophr. Bull. 2009, 35 (3), 549-562.

(326) Trinh, J.; Farrer, M. Advances in the Genetics of Parkinson Disease. Nat. Rev. Neurol. 2013, 9 (8), 445-454.

(327) Damier, P.; Hirsch, E. C.; Agid, Y.; Graybiel, A. M. The Substantia Nigra of the Human Brain: II. Patterns of Loss of DopamineContaining Neurons in Parkinson's Disease. Brain 1999, 122 (8), 1437-1448.

(328) Jackowska, K.; Krysinski, P. New Trends in the Electrochemical Sensing of Dopamine. Anal. Bioanal. Chem. 2013, 405 (11), 37533771.

(329) Pandikumar, A.; Soon How, G. T.; See, T. P.; Omar, F. S.; Jayabal, S.; Kamali, K. Z.; Yusoff, N.; Jamil, A.; Ramaraj, R.; John, S. A.; Lim, H. N.; Huang, N. M. Graphene and Its Nanocomposite Material Based Electrochemical Sensor Platform for Dopamine. RSC Adv. 2014, 4 (108), 63296-63323. 
(330) Canevari, T. C.; Nakamura, M.; Cincotto, F. H.; de Melo, F. M.; Toma, H. E. High Performance Electrochemical Sensors for Dopamine and Epinephrine Using Nanocrystalline Carbon Quantum Dots Obtained under Controlled Chronoamperometric Conditions. Electrochim. Acta 2016, 209, 464-470.

(331) Zhang, P.; Wu, F.-H.; Zhao, G.-C.; Wei, X.-W. Selective Response of Dopamine in the Presence of Ascorbic Acid at Multi-Walled Carbon Nanotube Modified Gold Electrode. Bioelectrochemistry 2005, 67 (1), 109-114.

(332) Oh, J.-W.; Yoon, Y. W.; Heo, J.; Yu, J.; Kim, H.; Kim, T. H. Electrochemical Detection of Nanomolar Dopamine in the Presence of Neurophysiological Concentration of Ascorbic Acid and Uric Acid Using Charge-Coated Carbon Nanotubes via Facile and Green Preparation. Talanta 2016, 147, 453-459.

(333) Wang, X.; Wu, M.; Tang, W.; Zhu, Y.; Wang, L.; Wang, Q.; He, P.; Fang, Y. Simultaneous Electrochemical Determination of Ascorbic Acid, Dopamine and Uric Acid Using a Palladium Nanoparticle/Graphene/Chitosan Modified Electrode. J. Electroanal. Chem. 2013, 695, 10-16.

(334) Sajid, M.; Nazal, M. K.; Mansha, M.; Alsharaa, A.; Jillani, S. M. S.; Basheer, C. Chemically Modified Electrodes for Electrochemical Detection of Dopamine in the Presence of Uric Acid and Ascorbic Acid: A Review. TrAC Trends Anal. Chem. 2016, 76, 15-29.

(335) Rein, F. N.; Rocha, R. C.; Toma, H. E. Catecholamine Complexes of Ruthenium-edta and Their Redox Chemistry. J. Inorg. Biochem. 2001, 85 (2-3), 155-166.

(336) Chen, S.-M.; Peng, K.-T. The Electrochemical Properties of Dopamine, Epinephrine, Norepinephrine, and Their Electrocatalytic Reactions on Cobalt(II) Hexacyanoferrate Films. J. Electroanal. Chem. 2003, 547 (2), 179-189.

(337) Mayausky, J. S.; McCreery, R. L. Spectroelectrochemical Examination of Charge Transfer between Chlorpromazine Cation Radical and Catecholamines. Anal. Chem. 1983, 55 (2), 308-312. 
(338) Davey, M. W.; Montagu, M. Van; Inzé, D.; Sanmartin, M.; Kanellis, A.; Smirnoff, N.; Benzie, I. J. J.; Strain, J. J.; Favell, D.; Fletcher, J. Plant L-Ascorbic Acid: Chemistry, Function, Metabolism, Bioavailability and Effects of Processing. J. Sci. Food Agric. 2000, 80 (7), 825-860.

(339) Ascorbic Acid Chemical Structure - Web Page:

http://www.sigmaaldrich.com/catalog/substance/lascorbicacid176125 081711 ?lang=es\&region=ES.

(340) Weinstein, M.; Babyn, P.; Zlotkin, S. An Orange a Day Keeps the Doctor Away: Scurvy in the Year 2000. Pediatrics 2001, 108 (3), e55.

(341) Magiorkinis, E.; Beloukas, A.; Diamantis, A. Scurvy: Past, Present and Future. Eur. J. Intern. Med. 2011, 22 (2), 147-152.

(342) Levavasseur, M.; Becquart, C.; Pape, E.; Pigeyre, M.; Rousseaux, J.; Staumont-Sallé, D.; Delaporte, E. Severe Scurvy: An Underestimated Disease. Eur. J. Clin. Nutr. 2015, 69 (9), 1076-1077.

(343) Hirschmann, J. V.; Raugi, G. J. Adult Scurvy. J. Am. Acad. Dermatol. 1999, 41 (6), 895-910.

(344) Pisoschi, A. M.; Pop, A.; Serban, A. I.; Fafaneata, C. Electrochemical Methods for Ascorbic Acid Determination. Electrochim. Acta 2014, 121, 443-460.

(345) Van Dyke, D. A.; Cheng, H.-Y. Fabrication and Characterization of a Fiber-Optic-Based Spectroelectrochemical Probe. Anal. Chem. 1988, 60 (13), 1256-1260.

(346) Kobayashi, H.; Akamine, H.; Okawa, Y.; Ohno, T.; Mizusawa, S. Electrochemical Production of the Ascorbic Acid Radical and Its In Situ Detection Using UV Spectroelectrochemical Method. Electrochim. Acta 1991, 36 (10), 1649-1651.

(347) Takahashi, F.; Hattori, K.; Matsuoka, M.; Jin, J. Electrochemiluminescence of Tris(2,2'-bipyridyl)ruthenium(II) with Ascorbic Acid and Dehydroascorbic Acid in Aqueous and NonAqueous Solutions. Anal. Sci. 2016, 32 (4), 443-447. 
(348) Ye, B.-X.; Lin, L.; Wang, C.-H.; Jin, B.-H.; Liu, L.-F. A New Redox Reaction of Ascorbic Acid at Platinum Electrodes. J. Chinese Chem. Soc. 2002, 49 (3), 415-419.

(349) DiVirgilio-Thomas, J. M.; Heineman, W. R.; Seliskar, C. J. Spectroelectrochemical Sensing Based on Multimode Selectivity Simultaneously Achievable in a Single Device. 6. Sensing with a Mediator. Anal. Chem. 2000, 72 (15), 3461-3467.

(350) Potentiostat/Galvanostat Model PGSTAT302N - Web Page: http://www.metrohmautolab.com/Products/Echem/NSeriesFolder/PGSTAT302N.

(351) Metrohm Autolab - Website: http://www.metrohm-autolab.com/.

(352) Light Source Model AvaLight-DH-S-BAL - Web Page: http://www.avantes.com/products/light-sources/item/238-avalight-dhs-bal-balanced-deuterium-halogen-light-source.

(353) Avantes - Website: http://www.avantes.com/.

(354) Fibers and Probes from Ocean Optics - Web Page: http://oceanoptics.com/product-category/fibers-and-probes/.

(355) Ocean Optics - Website: http://oceanoptics.com/.

(356) Fiber-Optics from Avantes - Web Page: http://avantes.com/products/fiber-optics.

(357) Spectrometer Model QE65000 - Installation and Operation Manual: http://oceanoptics.com/wp-content/uploads/QE65000.pdf.

(358) Spectrometer Model QE65000 - Data Sheet: http://oceanoptics.com/wp-content/uploads/OEM-Data-SheetQE65000.pdf.

(359) DropSens - Website: http://www.dropsens.com/.

(360) Spectroelectrochemistry Instrument Model SPELEC - Web Page: http://www.dropsens.com/en/spectroelectrochemical_instruments.htm 1. 
(361) Navarro Hernández, C.; González García, M. B.; Hernández Santos, D.; Heras, M. A.; Colina, A.; Fanjul-Bolado, P. Aqueous UV-VIS Spectroelectrochemical Study of the Voltammetric Reduction of Graphene Oxide on Screen-Printed Carbon Electrodes. Electrochem. Commun. 2016, 64, 65-68.

(362) MATLAB - Web Page: http://www.mathworks.com/products/matlab.html.

(363) MATLAB - Wikipedia: http://en.wikipedia.org/wiki/MATLAB.

(364) Colina Santamaría, Á. Doctoral Thesis.

(365) Heras Vidaurre, A. Doctoral Thesis.

(366) R Project - Website: http://www.r-project.org/.

(367) Ruiz, V.; Colina, Á.; Heras, M. A.; López-Palacios, J. Nernstian Performance of the Optical Response of Monolayer-Protected Gold Cluster Films. Electrochem. Commun. 2006, 8 (5), 863-868.

(368) Ferrari, A. C.; Meyer, J. C.; Scardaci, V.; Casiraghi, C.; Lazzeri, M.; Mauri, F.; Piscanec, S.; Jiang, D.; Novoselov, K. S.; Roth, S.; Geim, A. K. Raman Spectrum of Graphene and Graphene Layers. Phys. Rev. Lett. 2006, 97 (18), 187401.

(369) Kavan, L.; Dunsch, L. Spectroelectrochemistry of Carbon Nanostructures. ChemPhysChem 2007, 8 (7), 974-998.

(370) Campos Hernández, T.; Fernández Blanco, A. C.; Williams, A. T.; Velický, M.; Patten, H. V.; Colina, A.; Dryfe, R. A. W. Electrochemical and Spectroelectrochemical Characterization of Graphene Electrodes Derived from Solution-Based Exfoliation. Electroanalysis 2015, 27 (4), 1026-1034.

(371) Kim, K.-S.; Rhee, K.-Y.; Park, S.-J. Influence of Multi-Walled Carbon Nanotubes on Electrochemical Performance of Transparent Graphene Electrodes. Mater. Res. Bull. 2011, 46 (8), 1301-1306.

(372) Liljeroth, P.; Johans, C.; Slevin, C. J.; Quinn, B. M.; Kontturi, K. Micro Ring-Disk Electrode Probes for Scanning Electrochemical Microscopy. Electrochem. Commun. 2002, 4 (1), 67-71. 
(373) Brewster, J. D.; Anderson, J. L. Fiber Optic Thin-Layer Spectroelectrochemistry with Long Optical Path. Anal. Chem. 1982, 54 (14), 2560-2566.

(374) Deiss, F.; Sojic, N.; White, D. J.; Stoddart, P. R. Nanostructured Optical Fibre Arrays for High-Density Biochemical Sensing and Remote Imaging. Anal. Bioanal. Chem. 2010, 396 (1), 53-71.

(375) Allhusen, J. S.; Conboy, J. C. Preparation and Characterization of Conductive and Transparent Ruthenium Dioxide Sol-Gel Films. ACS Appl. Mater. Interfaces 2013, 5 (22), 11683-11691.

(376) Weber, C. M.; Eisele, D. M.; Rabe, J. P.; Liang, Y.; Feng, X.; Zhi, L.; Müllen, K.; Lyon, J. L.; Williams, R.; Vanden Bout, D. A.; Stevenson, K. J. Graphene-Based Optically Transparent Electrodes for Spectroelectrochemistry in the UV-Vis Region. Small 2010, 6 (2), 184-189.

(377) Flavel, B. S.; Yu, J.; Shapter, J. G.; Quinton, J. S. Patterned Ferrocenemethanol Modified Carbon Nanotube Electrodes on Silane Modified Silicon. J. Mater. Chem. 2007, 17 (45), 4757-4761.

(378) Zhu, Z.; Wang, M.; Gautam, A.; Nazor, J.; Momeu, C.; Prodanovic, R.; Schwaneberg, U. Directed Evolution of Glucose Oxidase from Aspergillus Niger for Ferrocenemethanol-Mediated Electron Transfer. Biotechnol. J. 2007, 2 (2), 241-248.

(379) Shan, D.; Yao, W.; Xue, H. Electrochemical Study of Ferrocenemethanol-Modified Layered Double Hydroxides Composite Matrix: Application to Glucose Amperometric Biosensor. Biosens. Bioelectron. 2007, 23 (3), 432-437.

(380) Lertanantawong, B.; O’Mullane, A. P.; Zhang, J.; Surareungchai, W.; Somasundrum, M.; Bond, A. M. Investigation of Mediated Oxidation of Ascorbic Acid by Ferrocenemethanol Using LargeAmplitude Fourier Transformed AC Voltammetry under QuasiReversible Electron-Transfer Conditions at an Indium Tin Oxide Electrode. Anal. Chem. 2008, 80 (17), 6515-6525.

(381) Vasilescu, I.; Eremia, S. A. V.; Radoi, A.; Radu, G.-L.; Litescu, S.C. Lipid Hydroxide Determination on a Ferrocenemethanol Modified Electrode. Anal. Methods 2013, 5 (8), 2013-2019. 
(382) Zhan, D.; Li, X.; Nepomnyashchii, A. B.; Alpuche-Aviles, M. A.; Fan, F.-R. F.; Bard, A. J. Characterization of $\mathrm{Ag}^{+}$Toxicity on Living Fibroblast Cells by the Ferrocenemethanol and Oxygen Response with the Scanning Electrochemical Microscope. J. Electroanal. Chem. 2013, 688, 61-68.

(383) Pruiksma, R.; McCreery, R. L. Observation of Electrochemical Concentration Profiles by Absorption Spectroelectrochemistry. Anal. Chem. 1979, 51 (13), 2253-2257.

(384) Ibañez, D.; Fernandez-Blanco, C.; Heras, A.; Colina, A. TimeResolved Study of the Surface-Enhanced Raman Scattering Effect of Silver Nanoparticles Generated in Voltammetry Experiments. $J$. Phys. Chem. C 2014, 118 (40), 23426-23433.

(385) Shi, C.; Zhang, W.; Birke, R. L.; Lombardi, J. R. Detection of ShortLived Intermediates in Electrochemical Reactions Using TimeResolved Surface-Enhanced Raman Spectroscopy. J. Phys. Chem. 1990, 94 (12), 4766-4769.

(386) Gao, P.; Gosztola, D.; Weaver, M. J. Surface-Enhanced Raman Spectroscopy as a Probe of Electroorganic Reaction Pathways. 1. Processes Involving Adsorbed Nitrobenzene, Azobenzene, and Related Species. J. Phys. Chem. 1988, 92 (25), 7122-7130.

(387) Zong, C.; Chen, C.-J.; Zhang, M.; Wu, D.-Y.; Ren, B. Transient Electrochemical Surface-Enhanced Raman Spectroscopy: A Millisecond Time-Resolved Study of an Electrochemical Redox Process. J. Am. Chem. Soc. 2015, 137 (36), 11768-11774.

(388) Ibañez, D.; Plana, D.; Heras, A.; Fermín, D. J.; Colina, A. Monitoring Charge Transfer at Polarisable Liquid/Liquid Interfaces Employing Time-Resolved Raman Spectroelectrochemistry. Electrochem. Commun. 2015, 54, 14-17.

(389) Ren, B.; Li, X. Q.; She, C. X.; Wu, D. Y.; Tian, Z. Q. Surface Raman Spectroscopy as a Versatile Technique to Study Methanol Oxidation on Rough Pt Electrodes. Electrochim. Acta 2000, 46 (2-3), 193-205.

(390) Hu, Q.; Hinman, A. S. A Bulk Electrolysis Raman Spectroelectrochemical Cell Using a Rotating Electrode. Anal. Chem. 2000, 72 (14), 3233-3235. 
(391) Kavan, L.; Janda, P.; Krause, M.; Ziegs, F.; Dunsch, L. Rotating Cell for In Situ Raman Spectroelectrochemical Studies of Photosensitive Redox Systems. Anal. Chem. 2009, 81 (5), 2017-2021.

(392) Gómez, R.; Pérez, J. M.; Solla-Gullón, J.; Montiel, V.; Aldaz, A. In Situ Surface Enhanced Raman Spectroscopy on Electrodes with Platinum and Palladium Nanoparticle Ensembles. J. Phys. Chem. B 2004, 108 (28), 9943-9949.

(393) Bonifacio, A.; Millo, D.; Gooijer, C.; Boegschoten, R.; van der Zwan, G. Linearly Moving Low-Volume Spectroelectrochemical Cell for Microliter-Scale Surface-Enhanced Resonance Raman Spectroscopy of Heme Proteins. Anal. Chem. 2004, 76 (5), 15291531.

(394) Yuan, T.; Le Thi Ngoc, L.; van Nieuwkasteele, J.; Odijk, M.; van den Berg, A.; Permentier, H.; Bischoff, R.; Carlen, E. T. In Situ Surface-Enhanced Raman Spectroelectrochemical Analysis System with a Hemin Modified Nanostructured Gold Surface. Anal. Chem. 2015, 87 (5), 2588-2592.

(395) Yu, J.-S.; Yang, C.; Fang, H.-Q. Variable Thickness Thin-Layer Cell for Electrochemistry and In Situ UV-VIS Absorption, Luminescence and Surface-Enhanced Raman Spectroelectrochemistry. Anal. Chim. Acta 2000, 420 (1), 45-55.

(396) Gaillard, F.; Levillain, E.; Dhamelincourt, M.-C.; Dhamelincourt, P.; Lelieur, J. P. Polysulphides in Dimethylformamide: A Micro-Raman Spectroelectrochemical Study. J. Raman Spectrosc. 1997, 28 (7), 511-517.

(397) Bellec, V.; De Backer, M. G.; Levillain, E.; Sauvage, F. X.; Sombret, B.; Wartelle, C. In Situ Time-Resolved FTIR Spectroelectrochemistry: Study of the Reduction of TCNQ. Electrochem. Commun. 2001, 3 (9), 483-488.

(398) Dias, M.; Hudhomme, P.; Levillain, E.; Perrin, L.; Sahin, Y.; Sauvage, F.-X.; Wartelle, C. Electrochemistry Coupled to Fluorescence Spectroscopy: A New Versatile Approach. Electrochem. Commun. 2004, 6 (3), 325-330. 
(399) Schroll, C. A.; Chatterjee, S.; Heineman, W. R.; Bryan, S. A. SemiInfinite Linear Diffusion Spectroelectrochemistry on an Aqueous Micro-Drop. Anal. Chem. 2011, 83 (11), 4214-4219.

(400) Hawley, M. D.; Tatawawadi, S. V.; Piekarski, S.; Adams, R. N. Electrochemical Studies of the Oxidation Pathways of Catecholamines. J. Am. Chem. Soc. 1967, 89 (2), 447-450.

(401) Dresselhaus, M. S.; Dresselhaus, G.; Saito, R.; Jorio, A. Raman Spectroscopy of Carbon Nanotubes. Phys. Rep. 2005, 409 (2), 47-99.

(402) Rozlosnik, N. New Directions in Medical Biosensors Employing Poly(3,4-Ethylenedioxy Thiophene) Derivative-Based Electrodes. Anal. Bioanal. Chem. 2009, 395 (3), 637-645.

(403) Hohnholz, D.; Okuzaki, H.; MacDiarmid, A. G. Plastic Electronic Devices Through Line Patterning of Conducting Polymers. Adv. Funct. Mater. 2005, 15 (1), 51-56.

(404) Laforgue, A. All-Textile Flexible Supercapacitors Using Electrospun Poly(3,4-Ethylenedioxythiophene) Nanofibers. J. Power Sources 2011, 196 (1), 559-564.

(405) Liu, R.; Duay, J.; Lee, S. B. Redox Exchange Induced $\mathrm{MnO}_{2}$ Nanoparticle Enrichment in Poly(3,4-Ethylenedioxythiophene) Nanowires for Electrochemical Energy Storage. ACS Nano 2010, 4 (7), 4299-4307.

(406) Tintula, K. K.; Sahu, A. K.; Shahid, A.; Pitchumani, S.; Sridhar, P.; Shukla, A. K. Mesoporous Carbon and Poly(3,4Ethylenedioxythiophene) Composite as Catalyst Support for Polymer Electrolyte Fuel Cells. J. Electrochem. Soc. 2010, 157 (11), B1679B1685.

(407) Vasantha, V. S.; Phani, K. L. N. Effect of Hydroxypropyl- $\beta$ Cyclodextrin on the Electrochemical Oxidation and Polymerization of 3,4-Ethylenedioxythiophene. J. Electroanal. Chem. 2002, 520 (1-2), 79-88.

(408) Coletta, C.; Cui, Z.; Archirel, P.; Pernot, P.; Marignier, J.-L.; Remita, S. Electron-Induced Growth Mechanism of Conducting Polymers: A Coupled Experimental and Computational Investigation. J. Phys. Chem. B 2015, 119 (16), 5282-5298. 
(409) Harshman, R. A.; Lundy, M. E. PARAFAC: Parallel Factor Analysis. Comput. Stat. Data Anal. 1994, 18 (1), 39-72.

(410) Bro, R. PARAFAC. Tutorial and Applications. Chemom. Intell. Lab. Syst. 1997, 38 (2), 149-171.

(411) Li, X.; Pan, J.; Yang, F.; Feng, J.; Mo, J.; Chen, Z. Simple Amperometric Detector for Microchip Capillary Electrophoresis, and Its Application to the Analysis of Dopamine and Catechol. Microchim. Acta 2011, 174 (1), 123-130.

(412) Lin, K.-W.; Huang, Y.-K.; Su, H.-L.; Hsieh, Y.-Z. In-Channel Simplified Decoupler with Renewable Electrochemical Detection for Microchip Capillary Electrophoresis. Anal. Chim. Acta 2008, 619 (1), 115-121.

(413) Schöning, M. J.; Jacobs, M.; Muck, A.; Knobbe, D.-T.; Wang, J.; Chatrathi, M.; Spillmann, S. Amperometric PDMS/Glass Capillary Electrophoresis-Based Biosensor Microchip for Catechol and Dopamine Detection. Sensors Actuators B Chem. 2005, 108 (1-2), 688-694.

(414) Berg, R. W. Investigation of L(+)-Ascorbic Acid with Raman Spectroscopy in Visible and UV Light. Appl. Spectrosc. Rev. 2015, 50 (3), 193-239.

(415) Bielski, B. H. J.; Comstock, D. A.; Bowen, R. A. Ascorbic Acid Free Radicals. I. Pulse Radiolysis Study of Optical Absorption and Kinetic Properties. J. Am. Chem. Soc. 1971, 93 (22), 5624-5629.

(416) Shukla, M. K.; Mishra, P. C. Electronic Structures and Spectra of Two Antioxidants: Uric Acid and Ascorbic Acid. J. Mol. Struct. 1996, 377 (3), 247-259.

(417) Rueda, M.; Aldaz, A.; Sanchez-Burgos, F. Oxidation of L-Ascorbic Acid on a Gold Electrode. Electrochim. Acta 1978, 23 (5), 419-424.

(418) Eggersdorfer, M.; Laudert, D.; Létinois, U.; McClymont, T.; Medlock, J.; Netscher, T.; Bonrath, W. One Hundred Years of Vitamins - A Success Story of the Natural Sciences. Angew. Chemie Int. Ed. 2012, 51 (52), 12960-12990. 
(419) Swamy, B. E. K.; Venton, B. J. Carbon Nanotube-Modified Microelectrodes for Simultaneous Detection of Dopamine and Serotonin In Vivo. Analyst 2007, 132 (9), 876-884.

(420) Cheng, H.; Wang, X.; Wei, H. Ratiometric Electrochemical Sensor for Effective and Reliable Detection of Ascorbic Acid in Living Brains. Anal. Chem. 2015, 87 (17), 8889-8895.

(421) Liju, Y.; Yang, C. F.; Tuzhi, P.; Hangsheng, Y.; Cong, G.; Guoqing, L. Electrochemical Behavior and In Vivo Determination of the Neurotransmitter Dopamine Using Sodium Montmorillonite Modified Electrodes. Electroanalysis 1999, 11 (6), 438-442.

(422) Cahill, P. S.; Walker, Q. D.; Finnegan, J. M.; Mickelson, G. E.; Travis, E. R.; Wightman, R. M. Microelectrodes for the Measurement of Catecholamines in Biological Systems. Anal. Chem. 1996, 68 (18), 3180-3186.

(423) Ariansen, J. L.; Heien, M. L. A. V.; Hermans, A.; Phillips, P. E. M.; Hernadi, I.; Bermudez, M. A.; Schultz, W.; Wightman, R. M. Monitoring Extracellular $\mathrm{pH}$, Oxygen, and Dopamine during Reward Delivery in the Striatum of Primates. Front. Behav. Neurosci. 2012, 6 (36), 1-10.

(424) Liu, Y.; Kim, H.; Franklin, R. R.; Bond, D. R. Linking Spectral and Electrochemical Analysis to Monitor c-Type Cytochrome Redox Status in Living Geobacter Sulfurreducens Biofilms. ChemPhysChem 2011, 12 (12), 2235-2241.

(425) Millo, D.; Harnisch, F.; Patil, S. A.; Ly, H. K.; Schröder, U.; Hildebrandt, P. In Situ Spectroelectrochemical Investigation of Electrocatalytic Microbial Biofilms by Surface-Enhanced Resonance Raman Spectroscopy. Angew. Chemie Int. Ed. 2011, 50 (11), 26252627.

(426) El-Said, W. A.; Kim, T.-H.; Chung, Y.-H.; Choi, J.-W. Fabrication of New Single Cell Chip to Monitor Intracellular and Extracellular Redox State Based on Spectroelectrochemical Method. Biomaterials 2015, 40, 80-87. 
(427) Maizels, M.; Stegemiller, M.; Ross, S.; Slaterbeck, A.; Shi, Y.; Ridgway, T. H.; Heineman, W. R.; Seliskar, C. J.; Bryan, S. A. Novel Spectroelectrochemical Sensor for Ferrocyanide in Hanford Waste Simulant. In Nuclear Site Remediation; Eller, P. G., Heineman, W. R., Eds.; American Chemical Society: Washington, DC, 2000; pp 364-378.

(428) Stegemiller, M. L.; Heineman, W. R.; Seliskar, C. J.; Ridgway, T. H.; Bryan, S. A.; Hubler, T.; Sell, R. L. Spectroelectrochemical Sensing Based on Multimode Selectivity Simultaneously Achievable in a Single Device. 11. Design and Evaluation of a Small Portable Sensor for the Determination of Ferrocyanide in Hanford Waste Samples. Environ. Sci. Technol. 2003, 37 (1), 123-130.

(429) AOAC Official Method 967.21 - Ascorbic Acid in Vitamin Preparations and Juices - 2,6-Dichloroindophenol Titrimetric Method. In Official Methods of Analysis of AOAC International; Cunniff, P., Ed.; AOAC International: Gaithersburg, 1997; pp 16-17. 
Note and Abbreviations 

Note for the figures: For figures containing several panels, panels (a), (b),

(c), and (d) are ordered in the following way:

- 1. From left to right.

- 2. From top to bottom.

Abbreviations:

AFM Atomic Force Microscopy

BSEC Bidimensional Spectroelectrochemistry

CCD Charge-Coupled Device

CE Counter Electrode

CVD Chemical Vapor Deposition

DCE 1,2-Dichloroethane

DCIP 2,6-Dichloroindophenol Sodium Salt Hydrate

DNA Deoxyribonucleic Acid

EDOT 3,4-Ethylenedioxythiophene

FcMeOH Ferrocenemethanol

FE-SEM Field Emission Scanning Electron Microscopy

GC Glassy Carbon

GNPs Graphene Nanoplatelets 
HOPG Highly Ordered Pyrolytic Graphite

IR Infrared

ITO Tin-Doped Indium Oxide

LMS Least Median of Squares

LTE Long Term Evolution

MWCNTs Multi-Walled Carbon Nanotubes

NIR Near Infrared

OLS Ordinary Least Squares

OTEs Optically Transparent Electrodes

P3HT Poly(3-hexylthiophene)

PANI Polyaniline

PARAFAC Parallel Factor Analysis

PEDOT Poly(3,4-ethylenedioxythiophene)

PET Polyethylene Terephthalate

PLS Partial Least Squares

PMMA Poly(methyl methacrylate)

PSS Poly(styrenesulfonate)

PTFE Polytetrafluoroethylene

RE Reference Electrode 
RSD Relative Standard Deviation

SECCM Scanning Electrochemical Cell Microscopy

SWCNTs Single-Walled Carbon Nanotubes

UV Ultraviolet

$\mathrm{UV}-\mathrm{Vis} \quad$ Ultraviolet-Visible

WE Working Electrode 